Alex Ricardo Arquiñego Paz

\title{
Aplicação do Método GMRES na Solução de Problemas de Estabilidade em Sistemas de Energia Elétrica
}

\section{Tese de Doutorado}

Tese apresentada ao programa de Pós-Graduação em Engenharia Elétrica do Departamento de Engenharia Elétrica da PUC-Rio como parte dos requisitos parciais para obtenção do título de Doutor em Engenharia Elétrica.

Orientador : Prof. Ricardo Bernardo Prada

Co-orientador : Prof. José Eduardo Onoda Pessanha 


\section{Alex Ricardo Arquiñego Paz \\ Aplicação do Método GMRES na Solução de Problemas de Estabilidade em Sistemas de Energia \\ Elétrica}

Tese apresentada como requisito parcial para obtenção do grau de Doutor pelo Programa de Pós-Graduação em Engenharia Elétrica do Departamento de Engenharia Elétrica do Centro Técnico Científico da PUC-Rio. Aprovada pela Comissão Examinadora abaixo assinada.

Prof. Ricardo Bernardo Prada Orientador

Departamento de Engenharia Elétrica - PUC-Rio

Prof. José Eduardo Onoda Pessanha Co-Orientador UFMA

Prof. Julio Cesar Stacchini de Souza UFF

Prof. Flávio Rodrigo de Miranda Alves Cepel

Prof. Eduardo Nobuhiro Asada USP- São Carlos

Prof. Delberis Araujo Lima Departamento de Engenharia Elétrica - PUC-Rio

Prof. José Eugenio Leal Coordenador Setorial do Centro

Técnico Científico

Rio de Janeiro, 08 de Novembro de 2012 
Todos os direitos reservados. É proibida a reprodução total ou parcial do trabalho sem autorização da universidade, do autor e do orientador.

\section{Alex Ricardo Arquiñego Paz}

Graduou-se em Engenharia Mecânica e Elétrica na Universidade Nacional San Luis Gonzaga de Ica (UNICA, Perú) em 1999. Mestre em Engenharia Elétrica pela Universidade Federal de Maranhão (UFMA, Brasil) em 2004.

Ficha Catalográfica

Paz, Alex Ricardo Arquiñego

Aplicação do Método GMRES na Solução de Problemas de Estabilidade em Sistemas de Energia Elétrica/ Alex Ricardo Arquiñego Paz; orientador: Ricardo B. Prada ; co-orientador: José Eduardo Onoda Pessanha. - 2012.

192 f. : il. (color.) ; $30 \mathrm{~cm}$

Tese (doutorado) - Pontifícia Universidade Católica do Rio de Janeiro, Departamento de Engenharia Elétrica, 2012.

Inclui bibliografia

1. Engenharia elétrica - Teses. 2. Estabilidade em sistemas elétricos de potência. 3. Sistemas lineares. 4. GMRES. 5. Pré-condicionador. 6. Filtros-digitais. I. Prada, Ricardo B. II. Pessanha, José Eduardo Onoda. III. Pontifícia Universidade Católica do Rio de Janeiro. Departamento de Engenharia Elétrica. IV. Título. 
Dedico este trabalho:

a meu querido filho: José Guilherme (Guille) por seu imenso amor, ternura e força que me deram a energia e a esperança nesta etapa final do trabalho 


\section{Agradecimentos}

A Deus, que me guia e acompanha no dia-a-dia, me ajudando na obtenção de meus objetivos e metas traçadas. A meu amigo inseparável que sempre me sabe dar tranquilidade e forças nos momentos mais difíceis.

Ao professor José E. Onoda Pessanha, pela incondicional amizade mostrada dentro e fora da sala de aula, pela perene motivação e acertada orientação no longo caminhar deste trabalho.

Ao professor Ricardo B. Prada, pelo seu continuo e imprescindível apoio que tornaram real a culminação do trabalho. A sua formidável orientação a través de muitas sugestões e/ou recomendações que enriquecerem a contribuição da pesquisa.

Aos professores membros da banca examinadora pelas pertinentes recomendações, sugestões e críticas construtivas que me permitiram afinar a elaboração do documento final da pesquisa.

A minha mãe Dona Dorihs e meu pai Don Gregorio, pelo inesgotável incentivo, amor incondicional, e pelo esforço dedicado a meu crescimento professional e pessoal.

A meus irmãos Rony e Juan, pelo continuo apoio e confiança que sempre me oferecem dia-a-dia.

A minha companheira e esposa Dayanne, pelo apoio, amor e compreensão que me motivaram na etapa final da pesquisa.

A meus incondicionais amigos do grupo de Sistema de Energia Elétrica (SEE) da PUC-RJ e do Grupo de Sistemas de Potência (GSP) da UFMA, pela verdadeira amizade.

Ao Conselho Nacional de Pesquisa e Desenvolvimento (CNPQ) e á Pontifícia Universidade Católica do Rio de Janeiro (PUC-RJ) pelo suporte financeiro suprido durante esses anos de pesquisa. 


\section{Resumo}

Arquiñego Paz, Alex; Prada, Ricardo Bernardo (Orientador); Pessanha, José Eduardo Onoda (Co-orientador). Aplicação do Método GMRES na Solução de Problemas de Estabilidade em Sistemas de Energia Elétrica. Rio de Janeiro, 2012. 192p. Tese de Doutorado Departamento de Engenharia Elétrica, Pontifícia Universidade Católica do Rio de Janeiro.

O desenvolvimento e/ou a adaptação de métodos numéricos para aplicação em análises computacionais de estabilidade de sistemas elétricos no domínio do tempo costumam despertar interesse em função das dificuldades de solução das equações diferenciais e algébricas (EDAs) que representam a rede e seus componentes. Condições de operações muito carregadas e compensadas dificultam a solução, devido, p.ex., ao mau condicionamento da matriz Jacobiana, instabilidade numérica e singularidade. Uma dessas dificuldades pode surgir durante a solução de equações não lineares, especificamente no problema linear do tipo $\mathrm{Ax}=\mathrm{b}$. Para contornar estas e outras dificuldades, a presente tese procurou contribuir no aspecto numérico do problema destacando a aplicação do método iterativo Resíduo Mínimo Generalizado - GMRES na solução do problema. Optou-se por trabalhar na qualidade do pré-condicionador construído com base na matriz Jacobiana calculada no início do processo de solução. Verificou-se que, se esta matriz estiver bem condicionada, a qualidade do pré-condicionador resultante dela é boa para o GMRES atingir a convergência em poucas iterações. Comprovou-se através de experimentos numéricos com diferentes sistemas-teste e diferentes condições de operação, que o condicionamento da matriz Jacobiana é melhorado se escalonada, normalizada e reordenada antes da construção do pré-condicionador, resultando, de fato, num pré-condicionador de boa qualidade, agindo positivamente no desempenho do GMRES e consequentemente no processo global de solução.

\section{Palavras-chave}

Estabilidade em sistemas elétricos de potência; sistemas lineares; GMRES; pré-condicionador; filtros-digitais. 


\section{Abstract}

Arquiñego Paz, Alex; Prada, Ricardo Bernardo (Advisor); Pessanha, José Eduardo Onoda (Co-advisor); Application of GMRES Method in the Solution of Stability Problems in Electrical Energy System. Rio de Janeiro, 2012. 192p. D.Sc. Thesis - Departamento de Engenharia Elétrica, Pontifícia Universidade Católica do Rio de Janeiro.

The development and/or adaptation of numerical methods when applied to power systems stability computer simulations in time domain are of interest due to the difficulties related to the solution of the algebraic differential equations (ADEs) which represent the network and its components. The solution of networks operating under heavy load conditions and extremely compensated is difficult due to the ill-conditioning of the Jacobian matrix, numerical instability and singularity. It can happen, for instance, when solving linear problems of type $A x=b$. In order to overcome this and other difficulties, this thesis aims to contribute in the numerical aspect of the problem applying the Generalized Minimal Residual method - GMRES to solve the problem. The idea is to work over the preconditioner quality constructed based on the Jacobian matrix. It is shown that, if this matrix is well conditioned, the quality of the resulting preconditioner is good enough to the GMRES reaches convergence in few iterations. It is seen through numerical experiments using different test-systems and different operating conditions as well, that the Jacobian matrix conditioning is improved if scaled, normalized and reordered before the preconditioner construction, resulting, in fact, in a high quality preconditioner, improving the GMRES performance.

\section{Keywords}

Power systems stability; linear systems; GMRES; preconditioner; digital-filters. 


\section{Sumário}

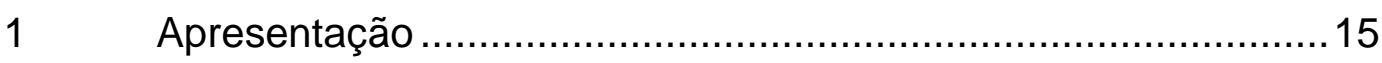

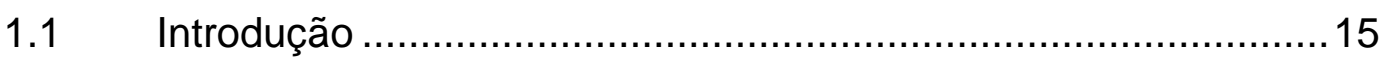

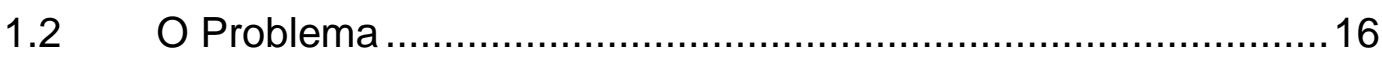

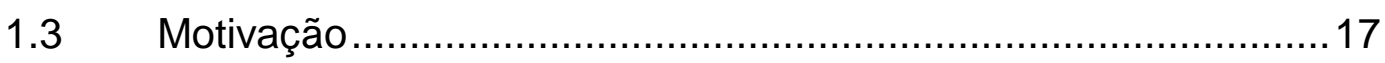

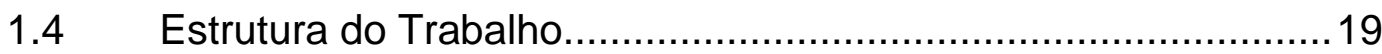

2 Conceitos Fundamentais de Técnicas de Solução de Equações Algébricas Lineares e Diferenciais ..............................................20

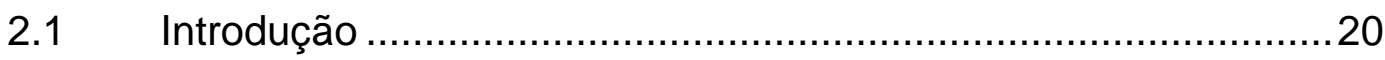

2.2 Solução de Sistemas de Equações Algébricas Lineares ............21

2.2.1 Identificação do Problema..........................................................21

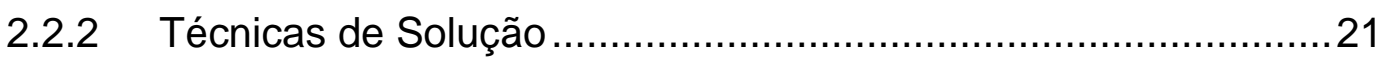

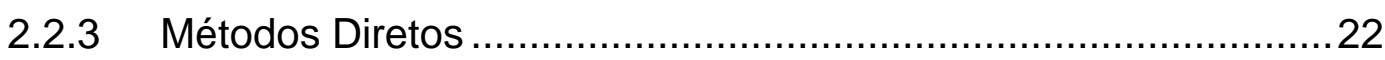

2.2.4 Conceitos Associados aos Métodos Iterativos ............................24

2.2.5 Técnicas de Projeção e Estratégias de Pré-Condicionamento ...33

2.2.6 Desempenho dos Métodos Iterativos ..........................................35

2.3 Conceitos Associados ás Técnicas de Solução das EDAs ..........38

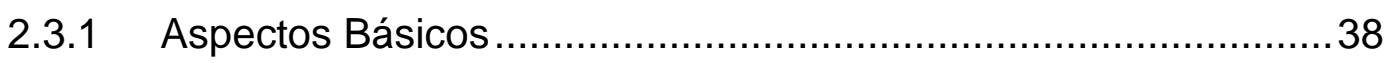

2.3.2 O Método Backward Differentiation Formulae - BDF.................. 39

2.3.3 Estratégias de Seleção de Ordem e Passo de Integração............41

2.3.4 Controle do Passo de Integração Através de Filtro Digital .......... 43

3 Métodos Iterativos e Suas Estratégias .......................................45

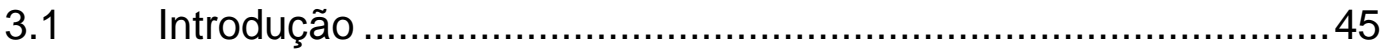

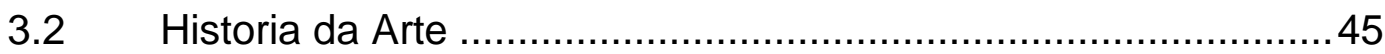

3.2.1 Métodos e Estratégias no Subespaço Krylov

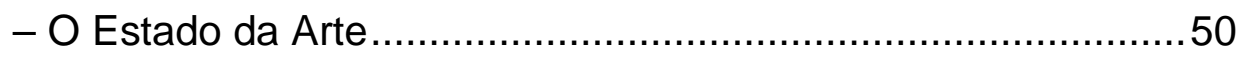

3.3 Conceitos Associados ao Subespaço Krylov ..............................55

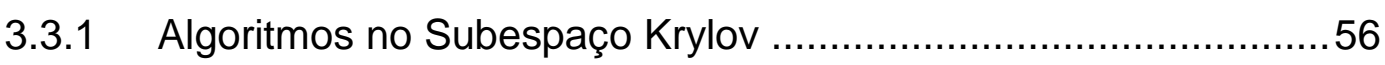

3.4 O Método Resíduo Mínimo Generalizado (GMRES) ....................57

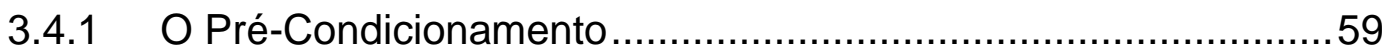


3.4.2 Reordenamento e Diferenças de Quocientes 61

3.4.3 Estratégias de Pré-condicionamento Baseadas em Fatoração

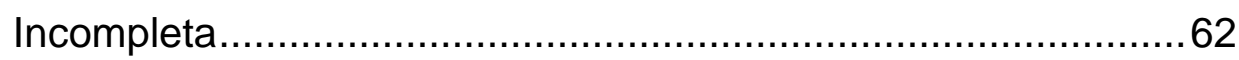

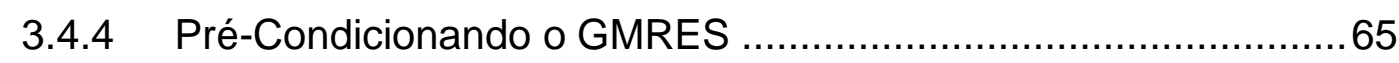

3.4.5 Experimentos Numéricos ........................................................... 71

3.4.6 Sistema-Teste de 30 barras (IEEE30).................................... 72

3.4.7 Sistema-Teste de 118 barras (IEEE118).................................. 76

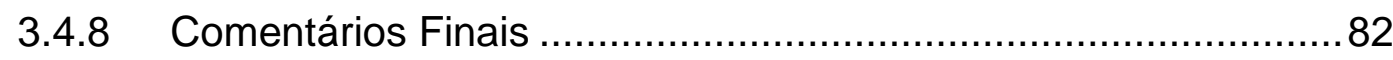

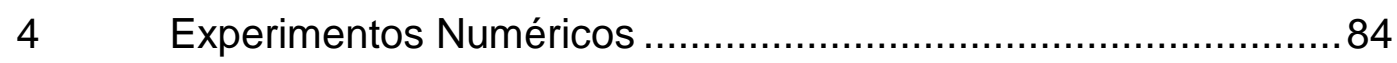

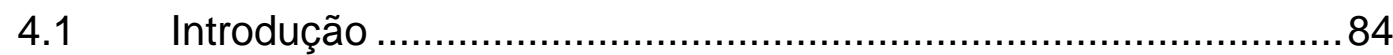

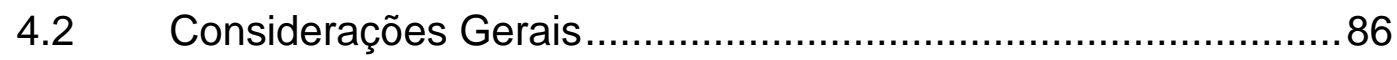

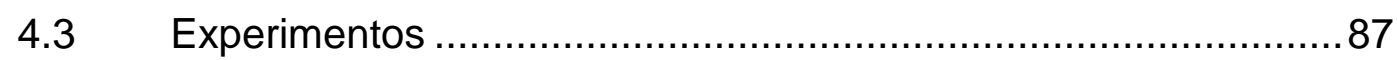

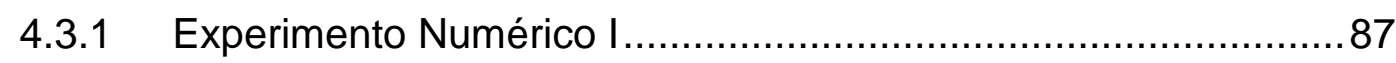

4.3.2 Experimento Numérico II.......................................................... 91

4.3.3 Experimento Numérico III........................................................96

4.3.4 Comentários Gerais sobre os Experimentos I, II e III................ 101

4.3.5 Experimento Numérico IV .......................................................103

4.3.6 Experimento Numérico V ..................................................... 104

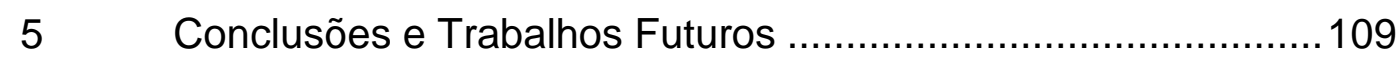

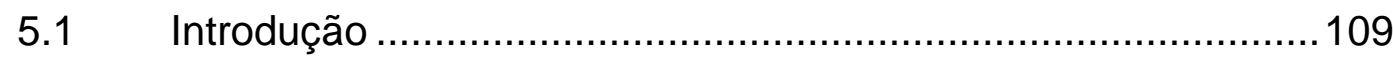

5.2 A Proposta e as Contribuições ...............................................112

5.3 Trabalhos Publicados .............................................................113

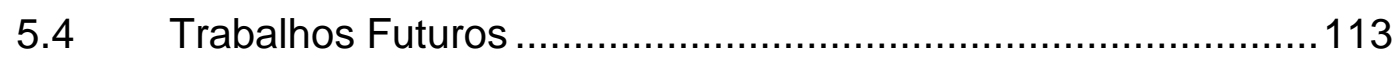

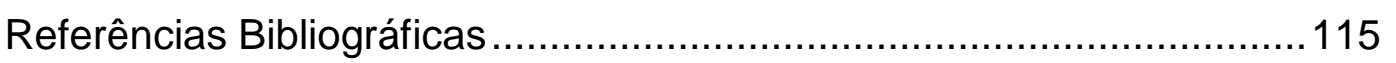

Apêndice A - Fórmulas de Diferenciação Regressiva (BDF) …..............130

Apêndice B - Diagramas de Blocos dos Principais Controles Dinâmicos Implementados no Programa Computacional ...........................132

B.1 Modelos implementados no programa computacional ..............132

B.2 Máquina síncrona de polos salientes - MS..............................134 
B.3 Regulador automático de tensão - RAT .................................136

B.4 Estabilizadores de potencia - PSS ...................................... 144

B.5 Reguladores de velocidade - RV ............................................ 145

B.6 Regulador automático de tensão - TYPE G (Kundur, 1994).....148

B.7 Limitador de sobre-excitação - OXL (Kundur, 1994) ................ 148

B.8 Transformador de potência com tape variável - ULTC..............149

Apêndice C Dados de Simulação Associados aos Métodos Numéricos 150

C.1 Parâmetros do experimento I ................................................150

C.2 Parâmetros do experimento II .............................................. 150

C.3 Parâmetros do experimento III .................................................151

Apêndice D Dados de Simulação Associados aos Sistemas -Testes ....152

D.1 Sistema-Teste Kundur - 10 barras ......................................... 152

D.2 Sistema-Teste IEEE118 - 118 barras ................................... 154

D.3 Sistema Interligado Norte-Nordeste Brasileiro - 564 barras ..... 163 


\section{Lista de Tabelas}

Tabela 2.1 - Desempenho dos métodos iterativos PCG, GMRES e MINRES.......36

Tabela 3.1 - Descrição dos experimentos numéricos do GMRES e suas

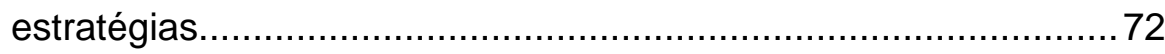

Tabela 3.2 - Definição de parâmetros para o algoritmo GMRES - IEEE30 .........73

Tabela 3.3 - Resultados das simulações - Sistema IEEE30 ............................. 74

Tabela 3.4 - Definição de parâmetros para o algoritmo GMRES - IEEE118 …...77

Tabela 3.5 - Resultados das simulações - Sistema IEEE118 ….........................79

Tabela 4.1 - Dados sobre as simulações do Experimento I ................................88

Tabela 4.2 - Dados sobre as equações diferenciais ordinárias (EDO) e algébricas (EA) do Experimento I ............................................... 88

Tabela 4.3 - Lista de contingências do Experimento I .....................................88

Tabela 4.4 - Dados associados aos resultados do Experimento I.......................89

Tabela 4.5 - Número de condicionamento e autovalores da matriz Jacobiana

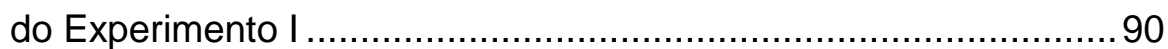

Tabela 4.6 - Dados sobre as simulações do Experimento II ...............................92

Tabela 4.7 - Lista de contingências do Experimento II .....................................92

Tabela 4.8 - Dados associados aos resultados do Experimento II.......................99

Tabela 4.9 - Dados sobre as equações diferenciais ordinárias (EDO) e algébricas (EA) do Experimento II .............................................99

Tabela 4.10 - Número de condicionamento e autovalores da matriz Jacobiana do Experimento II ....................................................95

Tabela 4.11 - Sequência de eventos do Experimento III.....................................96

Tabela 4.12 - Informações das máquinas síncronas do sistema N-NE Brasileiro 98

Tabela 4.13 - Dados sobre as equações diferenciais ordinárias (EDO) e algébricas (EA)

Tabela 4.14 - Número de condicionamento e autovalores da matriz Jacobiana do Experimento III ....................................................98

Tabela 4.15 - Número de condicionamento das matrizes Jacobianas ................ 102

Tabela 4.16 - Tempo CPU..................................................................... 102

Tabela 4.17 - Resultados para valor sugerido de $\tau$........................................ 104

Tabela 4.18 - Descrição dos filtros considerados ............................................ 104

Tabela 4.19 - Simulações envolvendo o Filtro H211B4 .................................... 105

Tabela 4.20 - Simulações envolvendo o Filtro PI42 .......................................... 106 


\section{Lista de Figuras}

Figura 2.1 - Conceito básico dos métodos BDFs de ordem/passo variável .........40 40

Figura 3.1 - O Algoritmo Básico do GMRES ..................................................59

Figura 3.2 - Algoritmo básico do ILUT ...................................................... 65

Figura 3.3 - Algoritmo do GMRES Pré-condicionado a esquerda .......................68

Figura 3.4 - Diagrama unifilar do sistema-teste IEEE30 (Power, 2007) ...............73

Figura 3.5 - Melhores desempenhos em termos de número de iterações -

IEEE30 ................................................................................. 76

Figura 3.6 - Melhores tempos de CPU - .............................................. 76

Figura 3.7 - Diagrama unifilar do sistema-teste IEEE118 (Power, 2007) .............78

Figura 3.8 - Melhores desempenhos em termos de número de iterações -

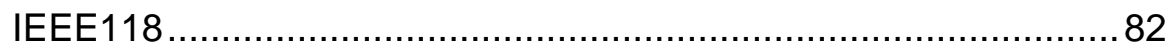

Figura 3.9 - Melhores tempos de CPU - IEEE118.................................... 82

Figura 4.1 - Fluxograma do Gerenciador do protótipo computacional...................85

Figura 4.2 - Sistema-teste do Experimento I (Kundur, 1994) ..............................87

Figura 4.3 - Estrutura da Matriz Jacobiana - Sistema-teste de 10 Barras ............88

Figura 4.4 - Distribuição espectral da matriz Jacobiana para os Casos (a) -

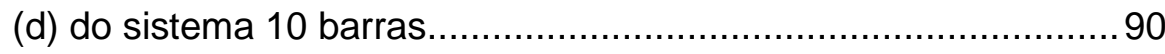

Figura 4.5 - Curvas obtidas pelo ILUT-GMRES e pelo programa ANATEM -

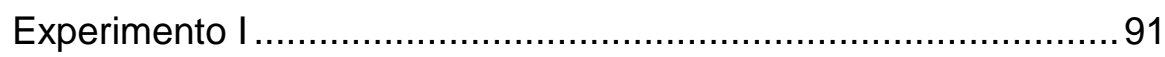

Figura 4.6 - Estrutura da Matriz Jacobiana IEEE118 - 118 Barras .....................93

Figura 4.7 - Distribuição espectral da matriz Jacobiana para os Casos (a) -

(d)

Figura 4.8 - Curvas obtidas pelo BDF-GMRES e pelo programa ANATEM -

Experimento II ...................................................................... 95

Figura 4.9 - Diagrama unifilar do sistema Norte-Nordeste Brasileiro ...................97

Figura 4.10 - Estrutura da matriz Jacobiana do sistema N/NE - 564 Barras .......99

Figura 4.11 - Distribuição espectral da matriz Jacobiana do sistema N/NE .......100

Figura 4.12 - Tempo de CPU para diferentes métodos .................................. 100

Figura 4.13 - Curvas obtidas pelo BDF-GMRES e pelo programa ANATEM -

Experimento III ...................................................................... 101

Figura 4.14 - Efeitos do filtro H211B4(6) .................................................... 107

Figura 4.15 - Efeitos do filtro PI42(4) ...................................................... 108 


\section{Lista de Abreviaturas e Notações}

\section{$\underline{\text { Abreviaturas }}$}

ANATEM Programa de Análise de Transitórios Eletromecânicos de CEPEL.

ANAREDE Programa de Análise de Redes de CEPEL.

AVR Regulador Automático de Tensão (Automatic Voltage Regulator).

BCG Método Gradiente Bi-conjugado

BiCGSTAB Método Gradiente Bi-conjugado Estabilizado

BDF Formula de Diferenciação Regressiva (Backward Differentiation Formulae)

CDU Controlador Definido pelo Usuário do programa ANATEM

CEPEL Centro de Pesquisas de Energia Elétrica de Brasil

CIGRE Conseil International des Grands Réseaux Electriques

GC Método Gradiente Conjugado

CPU Unidade Central de Processamento

DASPK Differential Algebraic Solver with a Precondicioned Krylov Iterative Method

EDAs Sistema de Equações Diferenciais e Algébricas

EDOs Sistema de Equações Diferenciais Ordinárias

ERAC Esquema Regional de Alívio de Carga

FOM Método de Ortogonalização Completa

CGS Gradiente Conjugado Quadrado (Conjugate Gradient Squared)

GMRES Método de Resíduo Mínimo Generalizado (Generalized Minimal Residual)

IEEE Institute of Electrical and Electronics Engineers

ILU(k) Pré-condicionador de fatoração incompleta baseado no nível de preenchimento $(k)$

ILU(६) Pré-condicionador de fatoração incompleta com regra de preenchimento baseada no erro $(\varepsilon)$

$\operatorname{ILUT}(\tau) \quad$ Pré-condicionador de fatoração incompleta com parâmetro limitante

$\operatorname{ILUT}(\rho, \tau) \quad$ Pré-condicionador de fatoração incompleta com duplo parâmetro limitante

J Matriz Jacobiana resultante da simulação dinâmica

LINPACK LINear equations software PACKage

Matlab MATrix LABoratory

MMD Reordenamento Mínimo Grau (Multiple Minimum Degree) 


$\begin{array}{ll}\text { MINRES } & \text { Método de Resíduo Mínimo } \\ \text { ONS } & \text { Operador Nacional do Sistema Elétrico Brasileiro } \\ \text { OXL } & \text { Limitador de SobreExcitação (Over eXcitation Limiter) } \\ \text { PSS } & \text { Sinal Estabilizante (Power System Stabilizer) } \\ \text { QMR } & \text { Método Iterativo do Resíduo Quase-Mínimo } \\ \text { RCM } & \text { Reordenamento Cuthill-McKee invertido } \\ \text { SIN } & \text { Sistema Interligado Nacional Brasileiro } \\ \text { SOR } & \text { Sucessive Overrelaxation } \\ \text { SSOR } & \text { Symmetric Sucessive Overrelaxation } \\ \text { SYMMLQ } & \text { Método Iterativo Symmetric LQ } \\ \text { ULTC } & \text { Transformador de Tape Variável (Under Load Tap Changing) }\end{array}$

\section{Notacões e Símbolos}

$\lambda(\mathrm{A}) \quad$ Autovalores da matriz A.

$\lambda \max (\mathrm{A}) \quad$ Autovalor máximo da matriz $\mathrm{A}$.

$\lambda \min (\mathrm{A}) \quad$ Autovalor mínimo da matriz A.

$\Re \quad$ Conjunto de números reales.

$\mathrm{A}^{-1} \quad$ Inversa da matriz A.

$\mathrm{A}^{\mathrm{T}} \quad$ Matriz transposta de A.

$\rho(\mathrm{A}) \quad$ Raio espectral da matriz A.

$\|\mathrm{A}\|_{2} \quad$ Norma Euclidiana da matriz A.

$\|\mathrm{x}\|_{2} \quad$ Norma Euclidiana do vetor $\mathrm{x}$.

$\mathrm{J}(\mathrm{x}) \quad$ Matriz Jacobiana da matriz A.

[M] Matriz de transformação no processo de Pré-condicionamento da matriz A.

$[\mathrm{M}]^{-1} \quad$ Inversa da matriz de transformação M.

S Conjunto de posições i, j da matriz A.

$\tau \quad$ Tolerância utilizada na fatoração incompleta ILUT.

$\rho \quad$ Número de elementos não-nulos permitidos na fatoração incompleta ILUT.

K(A) Número condição da matriz A.

$(\mathrm{x}, \mathrm{y}) \quad$ Produto interno do vetor $\mathrm{x}$ e $\mathrm{y}, \mathrm{n}$-dimensional.

Пn Conjunto de polinômios de grau n o menor.

$\mathrm{p}_{\mathrm{n}-1}(\mathrm{~A}) \quad$ Polinômio de grau $\mathrm{n}-1$

$\perp \quad$ Perpendicular entre matrizes e vetores. 


\section{Apresentação}

\subsection{Introdução}

Devido à competitividade nos mercados de energia elétrica, sistemas elétricos de potência cresceram, e continuam crescendo em dimensão e complexidade, sem deixar de observar certas restrições (principalmente as econômicas e ambientais), a fim de suprir e atender consumidores cada vez mais exigentes. Ainda, tendo que acompanhar o crescimento dos níveis de carga, com um serviço contínuo e confiável, preservando a qualidade da energia fornecida. Nesse cenário de crescimento, destacam-se, além dos níveis e da complexidade das cargas, a quantidade e a complexidade dos dispositivos de controle atuais, principalmente os de tensão, tanto ao nível de geração quanto de transmissão. Vários equipamentos e estratégias fazem parte do dia a dia da operação e das fases de planejamento para assegurar a boa qualidade do produto final (energia elétrica firme e de qualidade na sua forma de consumo) de acordo com metas pré-estabelecidas (níveis de tensão e frequência, por exemplo). Para uma monitoração e avaliação de seus serviços, as concessionárias de energia elétrica fazem uso de diversas estratégias e ferramentas, destacando-se aqui os programas computacionais, principalmente para investigar causas e consequências de distúrbios nos sistemas elétricos através de reproduções fiéis, podendo incluir testes de medidas preventivas/corretivas. Esta tese quando se refere a programas computacionais, está na verdade enfatizando os modelos matemáticos e as técnicas numéricas neles disponíveis.

Como resultado das necessidades acima, simulações computacionais passaram a envolver sistemas elétricos extremamente complexos em termos de configuração, dispositivos de controle, características e níveis de cargas. A combinação desses fatores, junto com particularidades do(s) fenômeno(s) investigado(s), forma fatores complicadores quando se trata de solucionar os sistemas matemáticos resultantes, sejam os puramente algébricos, os compostos por Equações Diferencias e Algébricas (EDAs), ou os compostos apenas por Equações Diferencias Ordinárias (EDOs), mesmo nos melhores ambientes computacionais, principalmente se os modelos e os métodos numéricos usados forem limitados em alguns aspectos importantes. Os métodos matemáticos podem simplesmente falhar durante o processo de solução ou não serem econômicos em termos de tempo de CPU e espaço de memória. 
Portanto, programas computacionais associados à solução de diferentes classes de problemas envolvendo sistemas elétricos tornaram-se uma questão de preocupação demandando não apenas por tecnologias computacionais eficientes, mas também por modelos matemáticos adequados e técnicas numéricas bem organizadas em termos de eficiência computacional e robustez (solução de sistemas lineares malcondicionados, por exemplo).

\subsection{O Problema}

Simulação no domínio do tempo é uma forma de análise útil para as concessionárias de energia elétrica desenvolverem estudos computacionais associados a fenômenos de estabilidade em sistemas de energia elétrica, pois através dela é possível:

- Determinar o tempo de coordenação dos equipamentos; p.ex., controle da excitação dos geradores, chaveamento de bancos de capacitores, compensadores estáticos e dispositivos para corte de carga devido à subtensão (ERAC).

- Esclarecer o fenômeno investigado e ajuda na prevenção contra o dimensionamento excessivo na fase de projeto. Simulação no domínio do tempo força uma análise mais cuidadosa e a utilização (desenvolvimento) de modelos mais aprimorados.

- Simular dinâmicas rápidas associadas com as fases finais do distúrbio.

- Demonstrar e apresentar o desempenho dinâmico do sistema através de gráficos onde se visualiza a evolução no tempo do fenômeno simulado.

- Visualizar como o desempenho do sistema é afetado tanto pela dinâmica rápida, comum nos estudos convencionais de estabilidade transitória, como pelas dinâmicas lentas, associadas com os transformadores de tape variável e com os limitadores de corrente de campo dos geradores, por exemplo.

O desenvolvimento e/ou a adaptação de métodos numéricos para aplicação em análises computacionais de estabilidade de sistemas elétricos no domínio do tempo costumam despertar interesse em função das dificuldades de solução das equações diferenciais e algébricas (EDAs) que representam a rede e seus componentes. Condições de operações muito carregadas e compensadas dificultam a solução, devido, p.ex., ao mau condicionamento da matriz Jacobiana, instabilidade numérica e 
singularidade. Uma dessas dificuldades pode surgir durante a solução de equações não-lineares através do método Newton-Raphson, especificamente no subproblema linear do tipo (1.1).

$$
A \cdot x=b
$$

É mostrado ao longo da tese que, o problema que pode dificultar a solução está associado ao número de condicionamento de matrizes de coeficiente (neste caso, a matriz Jacobiana que representa o sistema elétrico incluindo dispositivos dinâmicos) próximas da singularidade e com autovalores muito espalhados na distribuição espectral, alguns com magnitudes muito elevadas.

\subsection{Motivação}

Para contornar as dificuldades apresentadas acima, e outras mais, a presente tese procurou contribuir no aspecto numérico do problema integrando e aproveitando adequadamente os avanços na solução das EDAs, destacando a aplicação do método iterativo Resíduo Mínimo Generalizado - GMRES (Saad et al., 1986) no subproblema linear (1.1). A opção pelo GMRES está baseada nas suas características adequadas para solucionar o problema, já que a matriz Jacobiana do sistema elétrico incluindo dispositivos dinâmicos além de mal-condicionada, é bloco-diagonal dominante, altamente esparsa e não-simétrica (Pai et al., 1995). Portanto, ao invés de se usar um método direto tradicional, cuja característica é fornecer uma solução para o sistema linear em um número fixo de passos sujeitos apenas a erros de arredondamento, optou-se pelo método iterativo GMRES pré-condicionado que gera uma sequência de vetores solução após se estabelecer o vetor inicial x(0) (Chen, 2005).

Durante o desenvolvimento desta tese, notou-se que a maior parte das referências consultadas (citadas ao longo do texto) estava associada à aplicação de métodos iterativos baseados no subespaço Krylov em estudos envolvendo sistemas de energia elétrica para a solução do problema linear do fluxo de carga. Pouco se encontrou com relação às análises no domínio do tempo. Ainda, a maioria dessas referências também estava associada à aplicação de métodos iterativos do subespaço Krylov em análises de estabilidade transitória angular fazendo uso do método trapezoidal implícito com solução simultânea (ou alternada). 
Portanto, outra proposta é estender a faixa de fenômenos e incluir os de longa duração, como os de estabilidade de tensão, e para tal, é desejável um método de integração estável em termos de variação do comprimento do passo, já que em simulações envolvendo fenômenos de longa duração o método de integração deve variar o comprimento do passo sempre que possível, visando desta forma melhorar a eficiência computacional do processo de solução. Optou-se, portanto, pelo método Backward Differentiation Formulae - BDF (Capítulo 2) com mecanismo de passo variável (Brenan et al., 1996) por apresentar tais características. A presente tese surge então com uma contribuição para a solução das EDAs associadas à análise de estabilidade no domínio do tempo: o BDF-GMRES.

Uma vez estipulada à proposta, a eficiência computacional passou a ser um fator preocupante. Já que o método BDF é bem consolidado para este tipo de aplicação, foram investigadas formas para melhorar a eficiência de todo o processo de solução, estando dividida em duas etapas. Uma, aplica filtros digitais para o controle do erro resultante das heurísticas consideradas pelo método quando se calcula um novo passo de integração. A outra é através do GMRES e entre as encontradas optou-se por trabalhar na qualidade do pré-condicionador construído com base na matriz Jacobiana J(x) calculada no início do processo de solução. Verificou-se que, se esta matriz estiver bem condicionada, a qualidade do pré-condicionador resultante dela é boa para o GMRES atingir a convergência em poucas iterações. Como informado anteriormente, matrizes Jacobianas que representam sistemas elétricos reais geralmente são mal condicionadas, sendo necessárias, portanto, estratégias numéricas para torna-las bem condicionadas, ou, pelo menos, melhorar suas características (menor número de condicionamento e autovalores agregados próximos da origem da distribuição espectral).

Por fim, comprova-se através de experimentos numéricos com diferentes sistemasteste e diferentes condições de operação, que o condicionamento da matriz Jacobiana é melhorado se escalonada, normalizada e reordenada antes da construção do précondicionador, resultando, de fato, num pré-condicionador de boa qualidade, agindo positivamente no desempenho do GMRES e consequentemente no processo global de solução. Destaca-se também o desempenho de filtros digitais para controle do erro associado ao método BDF de passo variável. O BDF-GMRES solucionou todos os cenários sem nenhum tipo de interrupção, mesmo os mais adversos. 


\subsection{Estrutura do Trabalho}

O presente documento está organizado da seguinte forma, com exceção do atual Capítulo:

- Capítulo 2 - Conceitos Fundamentais de Técnicas de Solução de Equações Algébricas Lineares e Diferenciais, Solução de Sistemas de Equações Algébricas Lineares, Conceitos Associados às Técnicas de Solução das EDAs.

- Capítulo 3 - Métodos Iterativos e Suas Estratégias: Origens e Perspectivas, A História da Arte, Conceitos Associados ao Subespaço Krylov, O Método Resíduo Mínimo Generalizado (GMRES), Pré-Condicionando o GMRES, Testes Computacionais.

- Capítulo 4 - Apresenta experimentos numéricos a fim de verificar a eficiência e a robustez do BDF-GMRES em estudos de estabilidade de sistemas de energia elétrica, utilizando-se sistemas-teste hipotéticos e o sistema elétrico NorteNordeste Brasileiro.

- $\quad$ Capítulo 5 - Conclusões e Recomendações.

- Apêndices. 


\section{Conceitos Fundamentais de Técnicas de Solução de Equações Algébricas Lineares e Diferenciais}

\subsection{Introdução}

Sistemas de equações algébricas lineares se destacam pela importância e pela assiduidade com que são encontrados em diversas aplicações científicas e industriais. No caso de estudos envolvendo sistemas de energia elétrica, dependendo do cenário e da dimensão do sistema elétrico de interesse, o sistema linear resultante pode ser de grande porte, requisitando uma técnica eficiente de solução, a fim de evitar problemas de memória (demanda por muito espaço de armazenamento) e excessivo tempo de CPU. Geralmente, em sistemas de energia elétrica, tanto em análises em regime-permanente como no domínio do tempo, os esforços associados à solução de sistemas algébricos lineares são responsáveis pelas maiores parcelas inerentes ao tempo de CPU total gasto, bem como espaço de memória.

Este Capítulo apresenta conceitos fundamentais sobre Técnicas de Solução de Sistemas de Equações Algébricas Lineares e de Equações Diferenciais e Algébricas, conceitos esses essenciais para um bom entendimento dos aspectos matemáticos inerentes aos métodos de solução dessas duas formas de sistemas de equações. Como informado no Capítulo 1, os métodos iterativos se destacam como uma das mais importantes frentes de investigação deste trabalho, devido as suas tendências promissoras em solucionar eficientemente sistemas lineares de grande porte, com reduzida capacidade de armazenagem e baixo tempo de CPU, muitas vezes superando os tradicionais métodos diretos. Basicamente, as técnicas iterativas são compostas por dois grupos de métodos; os estacionários e os não-estacionários.

Como mostrado ao longo neste capítulo através de exemplos ilustrativos, os métodos não-estacionários mostram-se mais eficientes para aplicações envolvendo sistemas elétricos de potência de grande-porte, eficiência esta que pode e deve ser melhorada através de técnicas de pré-condicionamento e estratégias numéricas bem elaboradas.

Já a solução dos sistemas de equações diferenciais e algébricas correspondem ao tradicional método de diferenciação regressiva, ou simplesmente BDF (em inglês: Backward Differentiation Formulae). 


\subsection{Solução de Sistemas de Equações Algébricas Lineares}

\subsubsection{Identificação do Problema}

Muitos componentes dos sistemas de energia elétrica, dependendo do fenômeno investigado, são matematicamente modelados por sistemas de equações algébricas e diferenciais (dinâmicas rápidas e lentas associadas à estabilidade de tensão, angular e de frequência), equações diferenciais ordinárias (transitórios eletromagnéticos), ou sistemas puramente algébricos lineares (regime-permanente). Essencialmente, quando se investiga um sistema de energia elétrica real de grandes dimensões, temse associado a primeira e a terceira categoria, sistemas algébricos lineares também de grande porte, e em geral, a matriz de coeficientes resultante é esparsa com uma estrutura apropriada de elementos não nulos (zeros), e a solução pode ser obtida por um método direto. Entretanto, métodos diretos podem ser bem dispendiosos em termos de espaço de memória e tempo de CPU, visto que durante o processo de solução podem aparecer elementos não nulos, em posições anteriormente ocupadas por elementos nulos, mesmo com estratégias de reordenamento para reduzir estas entradas. Nestes casos, métodos iterativos são mais atrativos em comparação aos métodos diretos, mesmo se a matriz for densa; seus requisitos de espaço de memória e tempo de CPU são geralmente menores da ordem de magnitudes (Van der Vorst, 2003). Ao invés de solucionar o sistema original do tipo (1.1), métodos iterativos solucionam um sistema equivalente menos complexo, ou seja, o sistema original é substituído por outro cuja solução é mais fácil de obter. Além disso, métodos iterativos não requerem o armazenamento de matrizes, apenas a habilidade de realizar multiplicações matriz-vetor.

\subsubsection{Técnicas de Solução}

Como já mencionado, existem duas classes bem consolidadas de métodos numéricos para a solução de sistemas de equações lineares esparsas e de grande porte: os diretos e os iterativos. Os métodos diretos fornecem uma solução para o sistema representado pela Equação (2.1) em um número fixo de passos, sujeitos apenas a erros de arredondamento. Já as técnicas iterativas começam o processo de solução com uma aproximação inicial $\mathrm{x}^{(0)}$ para a solução $\mathrm{x}$, gerando a partir deste ponto uma sequência de vetores $\{x(k)\}_{k=0}^{\infty}$ que converge para $x$. Ambos os métodos são abordados nas próximas seções, destacando-se alguns métodos mais mencionados e 
usados na literatura, evitando-se por enquanto as complexidades matemáticas inerentes às respectivas classes de solução:

$$
A \cdot x=b
$$

\subsubsection{Métodos Diretos}

O método de eliminação de Gauss-Jordan pode ser aplicado para resolver sistemas de equações lineares da forma (2.1), para um ou mais vetores $\vec{b}$, como também para determinar a inversa da matriz $A$ se necessário. Para atividades especificas de inversão da matriz de coeficientes, o método Gauss-Jordan apresenta uma aceitável eficiência quando comparado a outros métodos. Entretanto, existem desvantagens associadas a esse método, sendo estas (Mayer, 2004; Golub \& Van Loab, 1996; Stoer, 1993; Halmos, 1987):

Armazenamento e manipulação simultânea de todos os vetores à esquerda.

$>$ Caso o cálculo da inversa da matriz $A$ não seja necessário, o tempo computacional do método é reduzido em pelo menos três vezes se comparado aos similares quando aplicados para o mesmo fim.

> Quando a matriz inversa é determinada explicitamente, aplica-se um novo vetor $\vec{b}$, resultando em uma solução diferente da encontrada no processo inicial. A razão está no erro de arredondamento associado à aritmética computacional.

Uma vantagem interessante e importante é a confiabilidade do método baseada na estabilidade apresentada quando comparado a outros métodos diretos, aumentando sua robustez se uma estratégia de pivotamento completo for aplicada. A sequência de operações executadas na eliminação Gauss-Jordan constitui-se como uma base de novas alternativas, como é o caso dos métodos de eliminação Gaussiana e decomposição triangular.

\section{A. Estratégias de Pivotamento}

A troca de linhas é necessária quando um elemento pivô $\mathrm{a}_{\mathrm{kk}}^{(\mathrm{k})}$ é zero. Esta troca de linhas tem a forma $\left(\mathrm{E}_{\mathrm{i}}\right) \leftrightarrow\left(\mathrm{E}_{\mathrm{p}}\right)$ onde $p$ é o menor inteiro maior que $k$ com $\mathrm{a}_{\mathrm{pk}}^{(\mathrm{k})}=0$. De fato, é geralmente necessário realizar trocas de linhas mesmo quando os elementos pivô não forem zero, a fim de se reduzir os erros de arredondamento associados a 
aritmética de dígitos finitos. Para se evitar este problema, o processo de pivotamento é realizado selecionando-se um elemento grande $\mathrm{a}_{\mathrm{pk}}^{(\mathrm{k})}$ para pivô e trocar as $k$-ésimas e $p$-ésimas linhas, seguido das trocas das $k$-ésimas e $p$-ésimas colunas, se necessário. A estratégia mais simples é selecionar o elemento na mesma coluna que esteja abaixo da diagonal e que possua o maior valor absoluto. Um exemplo ilustrativo que segue pode ser útil para se entender este procedimento.

\section{B. Fatoração Triangular LU}

Considere a hipótese de se representar a matriz $A$ como um produto de duas matrizes:

$$
\mathrm{LU}=\mathrm{A}
$$

Onde L é uma matriz triangular inferior, e U uma matriz triangular superior. O sistema linear de interesse pode ser representado na seguinte forma matricial:

$$
\left[\begin{array}{cccc}
\alpha_{11} & 0 & 0 & 0 \\
\alpha_{21} & \alpha_{22} & 0 & 0 \\
\alpha_{31} & \alpha_{32} & \alpha_{33} & 0 \\
\alpha_{41} & \alpha_{42} & \alpha_{43} & \alpha_{44}
\end{array}\right]\left[\begin{array}{cccc}
\beta_{11} & \beta_{12} & \beta_{13} & \beta_{14} \\
0 & \beta_{22} & \beta_{23} & \beta_{24} \\
0 & 0 & \beta_{33} & \beta_{34} \\
0 & 0 & 0 & \beta_{44}
\end{array}\right]=\left[\begin{array}{llll}
a_{11} & a_{12} & a_{13} & a_{14} \\
a_{21} & a_{22} & a_{23} & a_{24} \\
a_{31} & a_{32} & a_{33} & a_{34} \\
a_{41} & a_{42} & a_{43} & a_{44}
\end{array}\right]
$$

Considerando-se a decomposição (Equação (2.2)) para resolver o conjunto linear:

$$
A x=(L U) x=L(U x)=b
$$

Pode-se observar por inspeção a possibilidade de dividir o sistema linear em dois sistemas triangulares lineares, resultando na seguinte simplificação:

$$
L y=b
$$

E depois resolver:

$$
\mathrm{Ux}=\mathrm{y}
$$

A vantagem está na facilidade em se resolver um sistema de equações triangulares, simplificando o processo de solução. Assim, a Equação (2.5) pode ser resolvida através do processo substituição progressiva, representada pelas Equações (2.7) e 
(2.8). Já o sistema representado pela Equação (2.6) pode ser resolvido pelo processo de substituição regressiva, representada pelas Equações (2.9) e (2.10). É interessante notar que, uma vez que determinada a decomposição LU de $A$ é possível resolver mais rapidamente o sistema algébrico ao variar o vetor à esquerda, sendo esta uma vantagem relevante sobre outros métodos (Mayer, 2004; Golub, 1996; Stoer, 1993; Halmos, 1987).

$$
\begin{gathered}
y_{i}=b_{1} / a_{11} \\
y_{i}=1 / a_{i, i}\left[b_{i}-\sum_{j=1}^{i-1} a_{i, j} y_{i}\right] \quad i=2,3, . . n \\
x_{n}=y_{n} / b_{n, n} \\
x_{i}=1 / b_{i, i}\left[y_{i}-\sum_{j=i+1}^{n} b_{i, j} y_{j}\right] \quad i=n-1, n-2, \ldots, 1 .
\end{gathered}
$$

Para matrizes altamente esparsas e de grande porte, o processo de solução não é, a principio, diferente do método geral da fatoração triangular LU; o problema está no preenchimento de elementos não zero e grandes durante o processo de solução. Estes esquemas de decomposição (ou de eliminação) devem minimizar o número de elementos indesejados não zero. Estes novos elementos, inicialmente zeros, tornamse valores representativos durante o processo de solução, e, como consequência, o espaço de armazenagem requerido é bem maior.

As $n$ entradas conhecidas da matriz $A_{(n \times n)}$ podem ser usadas para determinar parcialmente as m incógnitas de L e o mesmo número em U. Se uma única solução é desejada, entretanto, certo número de condições adicionais nas entradas de L e U se fazem necessárias. Vários métodos podem ser usados para estabelecer essas condições, como o Doolittle's (Burden, 1989).

\subsubsection{Conceitos Associados aos Métodos Iterativos}

Quando um sistema linear é suficientemente pequeno permitindo um uso adequado e limitado de espaço de memória, é preferível usar uma técnica direta eficiente que minimize os erros de arredondamento. O método de Eliminação Gaussiana com Pivotamento Parcial é uma escolha apropriada neste caso (Burden, 1989). Entretanto, sistemas lineares de grande porte com elevada porcentagem de elementos nulos (zeros) obedecendo a certo padrão pode ser resolvido de forma eficiente usando um 
método iterativo, onde a principal ideia é converter o sistema original (Equação (2.1)) por um sistema equivalente cuja solução seja mais simples. Após selecionar o vetor inicial $\mathrm{x}^{(0)}$, uma sequência de vetores solução é gerada (para $\mathrm{k}=1,2,3, \ldots$ ) computando:

$$
x^{(k)}=T x^{(k-1)}+C
$$

Onde $\mathrm{T}$ é uma matriz $\mathrm{n} x \mathrm{n}$ e $\vec{c}$ é um vetor. Um possível critério de parada para a Equação (2.11) seria continuar o processo iterativo até que o resultado obtido pela Equação (2.12) seja menor que uma dada tolerância $(\varepsilon)$. Normalmente para este propósito, normas adequadas são usadas. Portanto, o termo "método iterativo" se refere a uma ampla faixa de técnicas que usam aproximações sucessivas para obter soluções mais precisas para um sistema linear.

$$
\frac{\left\|x^{(k)}-x^{(k-1)}\right\|}{\left\|x^{(k)}\right\|} \leq \varepsilon, \text { para } \varepsilon>0
$$

Se $\tilde{x}$ for uma aproximação para a solução do sistema linear, existe um vetor residual para x̃ com relação a este sistema definido pela Equação (2.13). O objetivo é gerar uma sequência de aproximações que irão levar os vetores residuais associados a convergir rapidamente à zero. Entretanto, se x̃ for uma aproximação para a solução x e o vetor residual possuir uma propriedade a qual a norma ||r|| seja pequena, então $\|x-\tilde{x}\|$ também seria pequeno. Isto ocorre com frequência, mas sistemas com certas características, não muito observadas na prática, falham em relação a esta propriedade. Um Exemplo ilustrativo descreve melhor esta situação.

$$
r=b-A \tilde{x}
$$

Exemplo. Considere o sistema linear $\mathrm{Ax}=\mathrm{b}$ dado por:

$$
\left[\begin{array}{cr}
1 & 2 \\
1,0001 & 2
\end{array}\right]\left[\begin{array}{l}
x_{1} \\
x_{2}
\end{array}\right]=\left[\begin{array}{c}
3 \\
3,0001
\end{array}\right]
$$

Possui única solução $\mathrm{x}=(1,1)^{\mathrm{T}}$. Uma aproximação não adequada $\tilde{\mathrm{x}}=(3,0)^{\mathrm{T}}$ possui 0 vetor residual:

$$
r=b-A \tilde{x}=\left[\begin{array}{c}
3 \\
3,0001
\end{array}\right]-\left[\begin{array}{cc}
1 & 2 \\
1,0001 & 2
\end{array}\right]\left[\begin{array}{l}
3 \\
0
\end{array}\right]=\left[\begin{array}{c}
0 \\
0,0002
\end{array}\right]
$$


Então $\|r\|_{\infty}=0,0002^{1}$. Embora a norma do vetor residual seja pequena, a aproximação $\tilde{\mathrm{x}}=(3,0)^{\mathrm{T}}$ é obviamente inadequada, de fato $\|\mathrm{x}-\tilde{\mathrm{x}}\|_{\infty}=2$. Este exemplo é um alerta caso o método iterativo se baseie apenas na norma residual para interromper 0 processo, na esperança de que uma solução precisa tenha sido obtida. Informações sobre a possibilidade de ocorrer situação deste tipo podem ser obtidas considerandose as normas da matriz A e de sua inversa. Neste caso, se $\tilde{x}$ for uma aproximação para a solução do sistema linear e A for uma matriz não singular, então para qualquer norma natural (Burden, 1989):

$$
\|x-\tilde{x}\| \leq\|r\| A^{-1} \|
$$

e

$$
\frac{\|x-\tilde{x}\|}{\|x\|} \leq\|A\|\left\|A^{-1}\right\| \frac{\|r\|}{\|b\|} \operatorname{parax} \neq 0 \text { e } b \neq 0
$$

O número condição $\mathrm{K}(\mathrm{A})$ da matriz não singular $\mathrm{A}$ relativo à norma natural $\|*\|$ é dado por:

$$
K(A)=\|A\|\left\|A^{-1}\right\|
$$

A matriz A é bem comportada (bem condicionada) se $K(A)$ é próximo de 1 , e não é bem comportada (mal condicionada) quando $\mathrm{K}(\mathrm{A})$ é significativamente maior/menor que 1. Comportamento neste caso se refere à relativa segurança que um pequeno vetor residual implica numa solução aproximada. Uma estimativa inicial apropriada para o processo iterativo pode levar o vetor da solução aproximada a convergir rapidamente uma vez satisfeito o critério de parada. Se este não for o caso, então b é o único vetor associado com o problema e assumindo algum múltiplo de b como uma primeira aproximação parece um procedimento adequado. As próximas aproximações estão baseadas em alguma combinação linear de b e Ab e o processo continua até que o critério de parada seja satisfeito; isto é, a precisão da solução aproximada é boa o bastante para interromper o processo. O espaço que representa esta combinação linear é conhecido com subespaço Krylov (K) da matriz A e vetor inicial b, como mostra o lado direito da Equação (2.17) (Greenbaum, 1997).

$$
x_{k} \in \operatorname{span}\left\{b, A b, \ldots, A^{k-1} b\right\}, \quad k=1,2, \ldots
$$

\footnotetext{
${ }^{1}$ Norma $\|r\|_{\infty}=\max \left\{x_{i}\right\}$ para $1 \leq \mathrm{i} \leq \mathrm{n}$
} 
Assumindo que um método iterativo baseado no subespaço Krylov não contenha uma boa aproximação para a solução em um número razoável (k) de iterações, ou que uma solução aproximada não possa ser computada facilmente, o método falha em fornecer soluções aproximadas aceitáveis com um razoável esforço computacional, se comparado a outros métodos de solução. Existem restrições associadas e efeitos indesejáveis, tais como estagnação e parada forçada, particularmente para certas classes de problemas. Os problemas de convergência estão associados à propriedades espectrais (distribuição de autovalores, valores de campo, condição dos autovetores), e tais informações não estão disponíveis em circunstâncias práticas (Van der Vorst, 2003).

A fim de fazer uso dos métodos iterativos numa forma racional, as desvantagens apresentadas devem ser mitigadas. Isto pode ser feito encontrando-se algum operador $\mathrm{M}$ tal que $\mathrm{M}^{-1} \mathrm{~A}$ possua melhores (mas ainda não identificáveis) propriedades espectrais. $O$ mais próximo que $M$ estiver de $A$ (idealmente $M=A$ ), menor será 0 número de iterações para se alcançar uma solução aproximada confiável. O operador M associado a este processo é chamado de pré-condicionador (também chamado de matriz de transformação) da matriz A. O fator chave é modificar o problema original para se obter um melhor subespaço Krylov usando um pré-condicionador $\mathrm{M}$ (geralmente M apresenta a mesma dimensão da matriz original) e resolver eficientemente o problema modificado, onde uma melhor solução aproximada $x_{k+1}$ pode ser obtida, como segue (Greenbaum, 1997; Van der Vorst, 2003):

$$
x_{k+1}=x_{k}+M^{-1}\left(b-A x_{k}\right)
$$

A combinação do pré-condicionador com o subespaço Krylov resulta em procedimentos eficientes e não complexos que podem competir com métodos diretos (Saad, 2003). Entretanto, encontrar um pré-condicionador para acelerar a convergência do processo iterativo não é uma tarefa fácil, uma vez que (Van der Vorst, 2003):

M deve ser uma boa aproximação para A.

O custo para construir M não pode ser abusivo.

$>\quad$ O sistema resultante equivalente deve ser mais fácil de resolver em comparação ao original. 
Uma vez que a taxa de convergência do método iterativo depende fortemente do espectro da matriz A, um bom pré-condicionador irá melhorar esta taxa o bastante para superar o custo adicional associado a sua construção e aplicação. Se um précondicionador não for considerado, o método iterativo poderá falhar e não convergir para uma solução aproximada de qualidade num razoável esforço computacional.

Os métodos iterativos são divididos basicamente em duas categorias; os estacionários e os não-estacionários. Os estacionários são os precursores dos métodos iterativos, são mais simples de se entender e implementar, mas são menos eficientes. Já os métodos não-estacionários são relativamente mais recentes, suas análises são mais complexas, entretanto são mais eficientes. Os métodos não-estacionários diferem dos estacionários não apenas nesses aspectos, mas também no fato do processo iterativo envolver informações que variam a cada iteração, justificando a sua característica nãoestacionária. Informações fundamentais sobre os principais métodos de cada uma dessas classes são apresentadas a seguir.

\section{a) Métodos Iterativos Estacionários}

Tanto os métodos iterativos estacionários quanto os não-estacionários podem ser expressos na forma simplificada e geral da Equação (2.11). Os estacionários são classificados com tal pelo fato de tanto a matriz $\mathrm{T}$ como o vetor $\overrightarrow{\mathrm{c}}$ não dependerem de k. Nesta categoria os mais mencionados na literatura (Barrett et al., 2006) são o Jacobi, Gauss-Seidel, SOR (Sucessive Overrelaxation) e o SSOR (Symmetric Sucessive Overrelaxation).

Método Jacobi - é simples de ser entendido e implementado, porém seu processo de convergência é lento. Este método examina cada uma das $n$ equações do sistema linear de forma isolada. Se na $i$-ésima equação:

$$
\sum_{j=1}^{n} a_{i, j}, x_{j}=b_{i}
$$

a solução for encontrada para o valor de $x_{i}$ fixando as outras entradas de $x$, tem-se:

$$
x_{i}=\left(b_{i}-\sum_{j \neq 1} a_{i, j} x_{j}\right) / a_{i, i}
$$


A Equação (2.20) sugere um método iterativo, conhecido como Método Jacobi, definido por:

$$
x_{i}^{(k)}=\left(b_{i}-\sum_{j \neq 1} a_{i, j} x_{j}^{(k-1)}\right) / a_{i, i}
$$

Na forma matricial, o método Jacobi pode ser expresso como:

$$
x^{(k)}=D^{-1}(L+U) x^{(k-1)}+D^{-1} b
$$

Onde as matrizes $\mathrm{D}, \mathrm{L}$ e $\mathrm{U}$ representam a diagonal, estritamente triangular inferior, e estritamente triangular superior, ambas as partes da matriz A, respectivamente.

Método Gauss-Seidel - está baseado no método Jacobi, sendo que se assume agora que as equações são examinadas uma de cada vez, mas em sequência, e os resultados previamente computados são usados, resultando em:

$$
m m x_{i}^{(k)}=\left(b_{i}-\sum_{j<i} a_{i, j} x_{j}^{(k)}-\sum_{j>1} a_{i, j} x_{j}^{(k-1)}\right) / a_{i, i}
$$

Duas observações importantes com relação a este método devem ser mencionadas. Primeiro, a Equação (2.23) sugere um processo serial uma vez que cada componente da nova iteração depende dos componentes computados previamente, e, portanto as atualizações não podem ser feitas simultaneamente como no método Jacobi. Segundo, a nova iteração $\mathrm{x}^{(\mathrm{k})}$ depende da ordem a qual as equações são examinadas.

Estes dois pontos são importantes porque se A for esparsa, a dependência de cada componente da nova iteração com os componentes prévios não é absoluta. A presença de zeros na matriz pode remover a influência de alguns dos componentes prévios. Usando um ordenamento adequado das equações, pode ser possível reduzir tal dependência, recuperando a habilidade de fazer atualizações de grupos de componentes em paralelo. Entretanto, o reordenamento das equações pode afetar a taxa de convergência do método. Uma escolha inadequada de ordenamento pode 
degradar a taxa de convergência; uma boa escolha pode melhorá-la (Barrett et al., 2006).

Em termos de representação matricial, este método pode ser representado como:

$$
x^{(k)}=(D-L)^{-1}\left(U x^{(k-1)}+b\right)
$$

Da mesma forma que o Jacobi, as matrizes D, L e U representam a diagonal, estritamente triangular inferior, e estritamente triangular superior, ambas as partes da matriz A, respectivamente.

Método SOR (Successive Overrelaxation) - deriva da aplicação de um processo de extrapolação sobre o método Gauss-Seidel. Esta extrapolação assume a forma de um peso médio entre a iteração prévia e a iteração computada com sucesso pelo GaussSeidel, para cada componente:

$$
x_{i}^{(k)}=\omega \bar{x}_{i}^{(k)}+(1-\omega) x_{i}^{(k-1)}
$$

Onde $\overline{\mathrm{x}}_{1}^{(\mathrm{k})}$ representa a iteração Gauss-Seidel e $\omega$ o fator de extrapolação. A ideia é escolher um valor para este fator para acelerar o processo de convergência. Em termos de representação matricial, este método apresenta a seguinte forma:

$$
x^{(k)}=(D-w L)^{-1}(w U+(1-w) D) x^{(k-1)}+w(D-w L)^{-1} b
$$

Em geral, não é possível computar previamente o valor ótimo de $\omega$ com relação à taxa de convergência. Mesmo quando for possível calcular este valor ótimo, o esytforço computacional gasto é geralmente proibitivo. Frequentemente, uma estimativa heurística é usada (Barrett et al., 2006).

Se a matriz de coeficiente A for simétrica e definida positiva, o processo iterativo SOR converge para qualquer valor de $\omega$ entre 0 e 2 . Algoritmos SOR sofisticados aplicam esquemas de estimação adaptativa de parâmetros para tentar obter um valor apropriado de $\omega$ estimando a taxa a qual a iteração está convergindo. 
Método SSOR (Symmetric Sucessive Overrelaxation) - assumindo a matriz A como simétrica, então o SSOR combina simultaneamente duas varreduras do SOR de forma que a matriz resultante da iteração seja similar a uma matriz simétrica. A similaridade da matriz iteração SSOR com uma matriz simétrica permite a aplicação deste método como um pré-condicionador para outros esquemas iterativos para matrizes simétricas. De fato, esta é a motivação principal para se usar o SSOR uma vez que sua taxa de convergência, com um valor ótimo para $\omega$, geralmente, é mais lenta que a do SOR com um valor ótimo de $\omega$.

Em termos matriciais, o método SSOR é expresso na seguinte forma:

$$
\begin{aligned}
x^{(k)} & =B_{1} B_{2} x^{(k-1)}+\omega(2-\omega)(D-\omega U)^{-1} D(D-\omega L)^{-1} b \\
B_{1} & =(D-\omega U)^{-1}(\omega L+(1-\omega) D) \\
B_{2} & =(D-\omega L)^{-1}(\omega U+(1-\omega) D)
\end{aligned}
$$

A matriz $B_{2}$ é simplesmente a matriz iteração para SOR (Equação (2.27)), idem $B_{1}$, mas com L e U invertidas.

\section{b) Métodos Iterativos Não-Estacionários}

Como já mencionado os métodos não-estacionários diferem dos estacionários no fato do processo envolver informações que variam a cada iteração. Normalmente, são computadas constantes calculando os produtos internos dos resíduos (Equação (2.13)) ou outros vetores associados ao respectivo método iterativo. Nem todos os métodos disponíveis na literatura são abordados aqui, apenas aqueles que direta, ou indiretamente, são relevantes para o trabalho, sendo estes o Gradiente Conjugado (GC), Resíduo Mínimo (MINRES) e Resíduo Mínimo Generalizado (GMRES).

Método Gradiente Conjugado (GC) - é eficiente para matrizes simétricas definidas positivas sendo um dos mais antigos e mais conhecidos métodos não-estacionários. $O$ método gera uma sequência de vetores das iterações (sucessivas aproximações para a solução), resíduos correspondentes às iterações, e direção de busca para atualizar as iterações e os resíduos. Embora o comprimento dessas sequências possa se tornar extenso, apenas um pequeno número de vetores precisa ser armazenado na memória. Em cada iteração, dois produtos internos são efetuados a fim de computar escalares atualizados que são definidos para fazer com que as sequências satisfaçam certas 
condições de ortogonalidade. Em sistemas lineares definidos positivos isso implica que a distância para a solução verdadeira é minimizada em alguma norma (Barrett et al., 2006).

O método gradiente conjugado não pré-condicionado constrói a i-ésima iteração $\mathrm{x}^{(\mathrm{i})}$ como um elemento $\mathrm{x}^{(0)}+\operatorname{span}\left\{\mathrm{r}^{(0)}, \ldots, \mathrm{A}^{\mathrm{i}-1} \mathrm{r}^{(0)}\right\}$ de forma que $\left(\mathrm{x}^{(\mathrm{i})}-\hat{\mathrm{x}}\right)^{\mathrm{T}} \mathrm{A}\left(\mathrm{x}^{(\mathrm{i})}-\hat{\mathrm{x}}\right)$ seja minimizada, onde $\hat{x}$ é a solução exata de $A x=b$. Em geral, a existência deste mínimo é garantida apenas se A for simétrica definida positiva. A versão pré-condicionada do método usa um subespaço diferente para construir as iterações, mas satisfaz a mesma propriedade de minimização; embora sobre um subespaço diferente. Isto requer ainda que o pré-condicionador $\mathrm{M}$ (matriz) seja simétrica e definida positiva. $\mathrm{A}$ minimização dos erros é equivalente aos resíduos $\mathrm{r}^{(\mathrm{i})}=\mathrm{b}-\mathrm{Ax}^{(\mathrm{i})}$ sendo $\mathrm{M}^{-1}$ ortogonal.

O método Gradiente Conjugado utiliza dois termos de recorrência acoplados; um que atualiza os resíduos usando um vetor de direção de busca, e um que atualiza a direção de busca com um novo resíduo computado. Esta característica torna este método extremamente atraente computacionalmente (Barrett et al., 2006).

Método Resíduo Mínimo (MINRES) - O método GC pode ser visto como uma variante especial do método Lanczos para sistemas simétricos definidos positivos. $O$ método MINRES é uma variante que poder ser aplicado em sistemas simétricos indefinidos.

A sequência de vetores do método GC corresponde à fatoração de uma matriz tridiagonal similar a matriz de coeficientes. Portanto, uma interrupção no processo pode ocorrer correspondendo a um elemento pivô nulo (zero) se a matriz for indefinida. Além do mais, para matrizes indefinidas a propriedade de minimização do método GC não é mais bem-definida. O MINRES é uma variante do GC com a propriedade da fatoração LU não estar sujeita a esse problema, minimizando o resíduo na norma-2.

Resíduo Mínimo Generalizado (GMRES) - é um método de projeção (Saad, 1986) possuindo a propriedade de minimizar a cada passo a norma do vetor residual (Equação (2.13)) sobre o m-ésimo subespaço Krylov $(\zeta=\mathrm{AK}$ m). 
Aplicado com sucesso em sistemas simétricos, este método é uma extensão do método de Resíduo Mínimo (MINRES). A maior desvantagem associada ao GMRES é que o esforço e a armazenagem por iteração crescem linearmente com processo iterativo e o custo associado se torna rapidamente excessivo. A forma usual de superar esta condição indesejada é reiniciando a iteração. Após selecionar um número $\mathrm{m}$ de iterações, as informações acumuladas são eliminadas e os resultados mais imediatos são usados como dados iniciais para as próximas m iterações. Este procedimento é repetido até que a convergência seja obtida. Entretanto, a escolha de um valor apropriado para m não é uma tarefa fácil porque se o valor for muito pequeno, o processo associado ao $\operatorname{GMRES}(\mathrm{m})$ pode ser lento para convergir, ou falhar completamente e não convergir. Por outro lado se o valor de $\mathrm{m}$ for grande, acima do necessário, um considerável espaço de memória será usado. Não existem regras específicas para a escolha de $\mathrm{m}$, portanto a escolha apropriada do instante de reinicialização é uma questão de prática. Portanto, o fator chave para se aplicar com sucesso o GMRES $(m)$ recai sobre a decisão de quando reinicializar. Se estratégias de reinicialização não forem consideradas, o GMRES irá convergir em não mais do que $n$ passos e isto não é prático para elevados n; além do mais os requisitos de memória e tempo de CPU na ausência estratégias de reinicialização são excessivos. Existem casos onde o método declina e a convergência é atingida apenas na n-ésima iteração, e qualquer escolha para m inferior a $n$ resultará em falha de convergência (Barrett et al., 2006).

\subsubsection{Técnicas de Projeção e Estratégias de Pré-Condicionamento}

É importante trazer neste ponto o conceito de técnicas de projeção cujo principal objetivo é obter uma solução aproximada para o sistema linear a partir do subespaço $\mathfrak{R}^{n}$. Para um espaço m-dimensional, é apropriado considerar, em geral, m condições de ortogonalidade (restrições) para se obter tal aproximação. Especificamente, o vetor residual dado pela Equação (2.13) é forçado a ser ortogonal a m vetores linearmente independentes. Isto define outro subespaço m-dimensional $\zeta$, identificado como um subespaço de restrições (ou espaço esquerdo). Portanto, uma técnica de projeção sobre o subespaço $\mathrm{K}$ e ortogonal a $\zeta$ encontra uma solução aproximada $\tilde{\mathrm{x}}$ impondo condições para que $\tilde{x}$ pertença a $K$ e que o novo vetor residual seja ortogonal a $\zeta$ (encontrar $\tilde{\mathrm{x}} \in \mathrm{K}$ impondo a condição de Petrov-Galerkin $\mathrm{b}-\mathrm{A} \tilde{\mathrm{x}} \perp \zeta$ ). Para tirar vantagem do conhecimento de uma estimativa inicial $\left(\mathrm{x}_{0}\right)$ para a solução, esta deve ser procurada em um espaço $\mathrm{x}_{0}+\mathrm{K}$ ao invés do vetor espaço uniforme (encontrar 
$\tilde{\mathrm{x}} \in \mathrm{x}_{0}+\mathrm{K}$ impondo a condição de Petrov-Galerkin $\left.\mathrm{b}-\mathrm{A} \tilde{\mathrm{x}} \perp \zeta\right)$. Note que se $\tilde{\mathrm{x}}$ for escrito na forma $\tilde{x}=x_{0}+\delta$, e o vetor residual inicial $r_{0}$ como:

$$
r_{0}=b-A x_{0}
$$

Então, a condição Petrov-Galerkin se torna:

$$
\text { b- } A\left(x_{0}+\delta\right) \perp \zeta ; \text { ou } r_{0}-A \delta \perp \zeta
$$

E a solução aproximada pode ser definida como:

$$
\begin{gathered}
\tilde{\mathrm{x}}=\mathrm{x}_{0}+\delta, \delta \in \mathrm{K} \\
\left(\mathrm{r}_{0}-\mathrm{A} \delta, \omega\right)=0, \forall \omega \in \zeta
\end{gathered}
$$

As Equações (2.30) e (2.31) representam a forma genérica de um método de projeção. Em geral, um novo passo de projeção usa um novo par de subespaços $\mathrm{K}$ e $\zeta$ e assume $\mathrm{x}_{0}$ como uma estimativa inicial igual à última aproximação obtida do passo de projeção imediatamente anterior.

\section{Estratégias de Pré-condicionamento}

Uma vez que a taxa de convergência dos métodos iterativos depende das propriedades espectrais da matriz de coeficientes, parece adequado trabalhar sobre essas propriedades a fim de melhorá-las e consequentemente também a taxa de convergência. Como mencionado numa seção anterior, isto pode ser alcançado convertendo-se o sistema linear original em um equivalente apresentando condições espectrais mais favoráveis, observando-se que o sistema convertido deve apresentar a mesma solução do sistema original. O pré-condicionador é a matriz responsável por tal transformação, o custo extra, associado a sua construção e pela sua aplicação por iteração, pode ser compensado pelo ganho resultante observado na velocidade de convergência.

Quando se formula um pré-condicionador, existe opção de escolher entre encontrar uma matriz $\mathrm{M}$ que aproxima $\mathrm{A}$, e para qual a solução do sistema equivalente é mais fácil do que do sistema original; ou encontrar uma matriz $M$ que aproxima $A^{-1}$, de 
forma que apenas multiplicação por M é necessária. Aproximadamente todos os précondicionadores estão na primeira opção de escolha e gastam nas suas aplicações um esforço proporcional a quantidade de variáveis existentes. Inversamente, o número de iterações, função da dimensão da matriz, é geralmente apenas melhorado por uma constante. Alguns pré-condicionadores são capazes de melhorar esta condição, destacando-se a Fatoração Incompleta LU (ILU), e pré-condicionadores baseados em técnicas multigrid (Barrett et al., 2006).

\subsubsection{Desempenho dos Métodos Iterativos}

Este item apresenta exemplos computacionais simples, ainda não envolvendo sistemas de energia elétrica, realizados com métodos não-estacionários descritos no item anterior, usando para tal fim a plataforma computacional MATLAB. A principal diferença entre os testes está nas características das matrizes como dimensão, arranjo e amplitude dos seus elementos. Os métodos usados aqui são GradienteConjugado, Resíduo Mínimo Generalizado (GMRES) e Resíduo Mínimo (MINRES). O objetivo é de apenas fornecer informações ilustrativas sobre certas características desses métodos e de suas variantes, como por exemplo, número de iterações, resíduo, tempo de CPU e a relação dessas grandezas com estratégias de précondicionamento e com a estratégia de reinicialização. As matrizes usadas nos testes fazem parte de uma biblioteca de matrizes disponíveis no MATLAB apresentando características não "amigáveis". Ao fim, agregando o desempenho individual de cada método, é possível destacar aquele que apresenta as melhores características. A Tabela 2.1 mostra o desempenho desses métodos através de gráficos de barras, ilustrando também as matrizes $\mathrm{A}$, os vetores $\mathrm{b}$, e o número de condicionamento $\mathrm{K}(\mathrm{A})$ da matriz associado a cada teste. Lembrando que a matriz é bem condicionada se este número for próximo de um (1), e mal condicionada quanto mais distante. Nota-se pelos valores correspondentes de $\mathrm{K}(\mathrm{A})$ que as matrizes são mal condicionadas. A sigla RET corresponde a situações onde o método só convergiu após implementação de estratégia de reinicialização. Também:

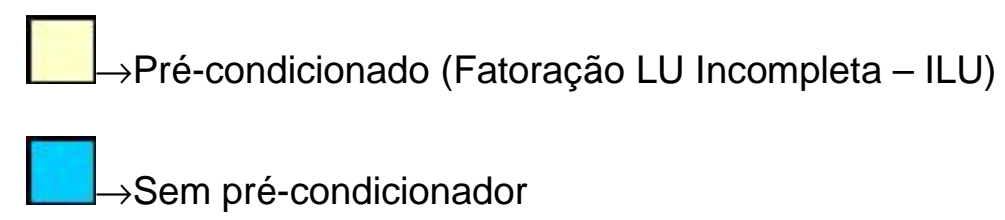


Tabela 2.1 - Desempenho dos métodos iterativos PCG, GMRES e MINRES

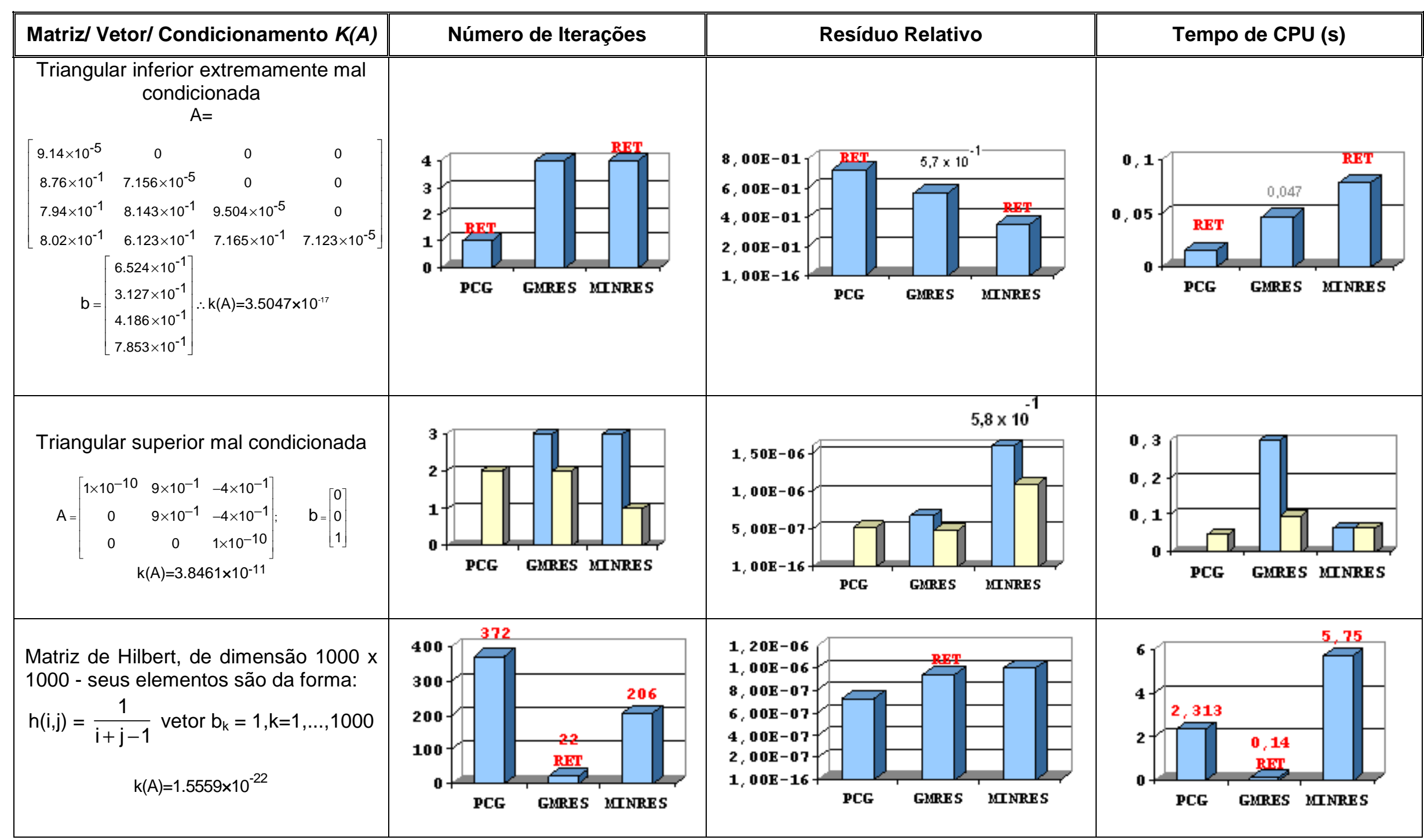




\section{Comentários Gerais}

Os resultados das simulações indicam alguns aspectos interessantes, embora ainda não envolvam sistemas de energia elétrica, destacando:

\section{- Matriz triangular inferior extremamente mal condicionada}

> Não se conseguiu gerar a matriz de transformação $M$ para o précondicionamento com relação aos três métodos, ou seja, a solução foi obtida sem essa estratégia.

> Tanto o PGC (Gradiente Conjugado) quanto o MINRES só resolveram o sistema com estratégia de reinicialização.

$>$ Os resíduos relativos são elevados se comparado aos demais testes, comprometendo a precisão da solução.

$>$ Se for considerado o fato da matriz ser de dimensão $4 \times 4$, ou seja, de pequeno porte, o tempo de CPU gasto para solucionar o problema pode ser considerado elevado.

- Matriz triangular superior mal condicionada

> O Gradiente Conjugado só obteve sucesso pré-condicionado. Já o GMRES e MINRES solucionaram o problema sem e com pré-condicionamento, sendo possível verificar a melhoria de desempenho.

> O resíduo relativo do MINRES sem pré-condicionamento é muito elevado, comprometendo a precisão dos resultados.

> O tempo de CPU do GMRES sem pré-condicionamento é o maior dentre todos, sendo reduzido com o pré-condicionador, porém, ainda superior aos demais.

\section{- $\quad$ Matriz de Hilbert}

$>\quad$ Também não se conseguiu gerar a matriz de transformação $\mathrm{M}$ para o précondicionamento com relação aos três métodos. A solução foi obtida sem essa estratégia.

> É notável a superioridade do GMRES em relação aos demais métodos, principalmente nos aspectos número de iterações e tempo de CPU.

$>\quad$ O resíduo relativo do GMRES apesar de superior ao do GC é muito pequeno, não comprometendo a precisão dos resultados. 
Este último teste comprova a eficiência do GMRES para sistemas de grande porte, mesmo não estando pré-condicionado. Devido a sua importância para esta pesquisa, este método volta a ser abordado no Capítulo 3.

\subsection{Conceitos Associados ás Técnicas de Solução das EDAs}

\subsubsection{Aspectos Básicos}

Os modelos de equipamentos e dispositivos de controle necessários para simulação computacional de fenômenos de estabilidade podem ser representados por um sistema de equações diferenciais e algébricas, cuja formulação geral é descrita por:

$$
F\left(t, y, y^{\prime}\right)=0 \quad y\left(t_{0}\right)=y_{0} \quad y^{\prime}\left(t_{0}\right)=y_{0}^{\prime}
$$

F, y e y' são vetores n-dimensionais, com y representando as variáveis de estado associadas às máquinas síncronas, controles e outros dispositivos dinâmicos da rede; variáveis algébricas do estator da máquina e da rede. Já o vetor y’ representa as derivadas dessas variáveis, sendo $t$ (tempo) a variável independente. Sujeito às condições iniciais $\mathrm{y}_{0}$ e $\mathrm{y}^{\prime}{ }_{0}$ no instante de tempo igual $\mathrm{t}_{0}$.

O processo de solução aproxima a derivada de (2.32) a cada iteração k por diferenças e o sistema algébrico não-lineal resultante (2.33) é solucionado por um método de Newton a cada intervalo de tempo para encontrar $y_{n}$ de acordo com (2.34) (Brown et al., 1994).

$$
\begin{gathered}
F\left(t_{n}, y_{n}, \frac{y_{n}-y_{n-1}}{h_{n}}\right)=0 ; h_{n}=t_{n}-t_{n-1} \\
\underbrace{y_{n}^{k+1}-y_{n}^{k}}_{x}=-\underbrace{(\frac{1}{\left.h_{n} \frac{\partial F}{\partial y^{\prime}}+\frac{\partial F}{\partial y}\right)^{-1}} \cdot \underbrace{F\left(t_{n}, y_{n}^{k}, \frac{y_{n}^{k}-y_{n-1}}{h_{n}}\right)}_{b}}_{A}
\end{gathered}
$$

O processo de aproximação de (2.32) é feito através do método BDF com um mecanismo de variação e seleção do tamanho do passo de integração $h_{n}$ e da ordem $\mathrm{k}$ ( 1 a 5 ) do método através de uma estratégia conhecida como coeficiente-fixo direcionado. Esta seleção se baseia no cálculo dos erros de truncamento e 
interpolação polinomial, fixando-se o comprimento do passo de integração e da ordem dos últimos intervalos, até satisfazer a condição de convergência para iniciar outro processo de seleção (Brenan et. al., 1996).

Se a simulação envolver um sistema de energia elétrica de grande porte com centenas de máquinas e dispositivos de controle, os custos para computar e fatorar a matriz $\mathrm{A}$ de (2.34) dominam o custo da integração. Na presente tese este subproblema linear, representado por (2.35), é solucionado a cada iteração Newton através do método iterativo GMRES, onde A é a matriz Jacobiana do sistema (também conhecida como matriz de iteração) de ordem $\mathrm{n} \times \mathrm{n}$; $\mathrm{x}$ e b são vetores $\mathrm{n}$-dimensionais. $\mathrm{O}$ parâmetro $\alpha$ está associado ao passo ou a ordem do método (Apêndice $A$ ); e $\beta$ é um vetor que depende da solução de intervalos anteriores.

$$
\begin{aligned}
& \text { A. } x=b \\
& x=y^{k+1}-y^{k} \\
& b=-F\left(t, y^{k}, \alpha y^{k}+\beta\right)
\end{aligned}
$$

\subsubsection{O Método Backward Differentiation Formulae - BDF}

Uma característica comumente encontrada na maioria dos métodos numéricos desenvolvidos para problemas de valor inicial de índice menor que dois, é a implementação de métodos BDF da classe multi-passo. O método considerado aqui aproxima a derivada na Equação (2.32) usando um método BDF de ordem $\mathrm{k}$ ( $1 \leq \mathrm{k} \leq$ 5), mas está em análise à possibilidade de limitar esta faixa entre $1 \leq \mathrm{k} \leq 2$ (Jardim 1999). A escolha da ordem do método e do passo de integração em cada intervalo de tempo depende do comportamento da solução, determinado pela avaliação de dois tipos de erros. O primeiro é conhecido como erro de truncamento local do método, que mede quanto o operador diferença se aproxima do operador diferencial. O outro tipo de erro está associado com o processo de interpolação polinomial (Brenan, 1996).

O método BDF considerado aplica o coeficiente-fixo direcionado, já mencionado anteriormente, para melhorar a eficiência do processo de variação da ordem do método e do tamanho do passo de integração (Jackson, 1980). Normalmente, os métodos multi-passo da família BDF de k-passos (passo de integração fixo) assume conhecidos os valores passados $\left(y_{n-j}, f_{n-j}\right), j=1, \ldots, k$ numa sequência de pontos igualmente espaçados pelo comprimento de passo $(h)$. Supondo que em $t_{n-1}$ tem-se 
um passo de comprimento $h_{n}$, tal que $h_{n} \neq h$, sendo $h$ comprimento de passo correspondente aos intervalos de integração imediatamente anteriores ao ponto n, é necessário atualizar as soluções nos intervalos passados $t_{n-1}-j h_{n}$, onde $1 \leq \mathrm{j} \leq \mathrm{k}-1$.

A Figura 2.1 ilustra a aplicação e o desenvolvimento do método BDF realçando o mecanismo de correção e predição com coeficiente-fixo direcionado, sendo uma forma genérica do método de Gear (Gear, 1971) incluindo a capacidade de flexibilizar a ordem e o passo de integração (Jackson, 1980).

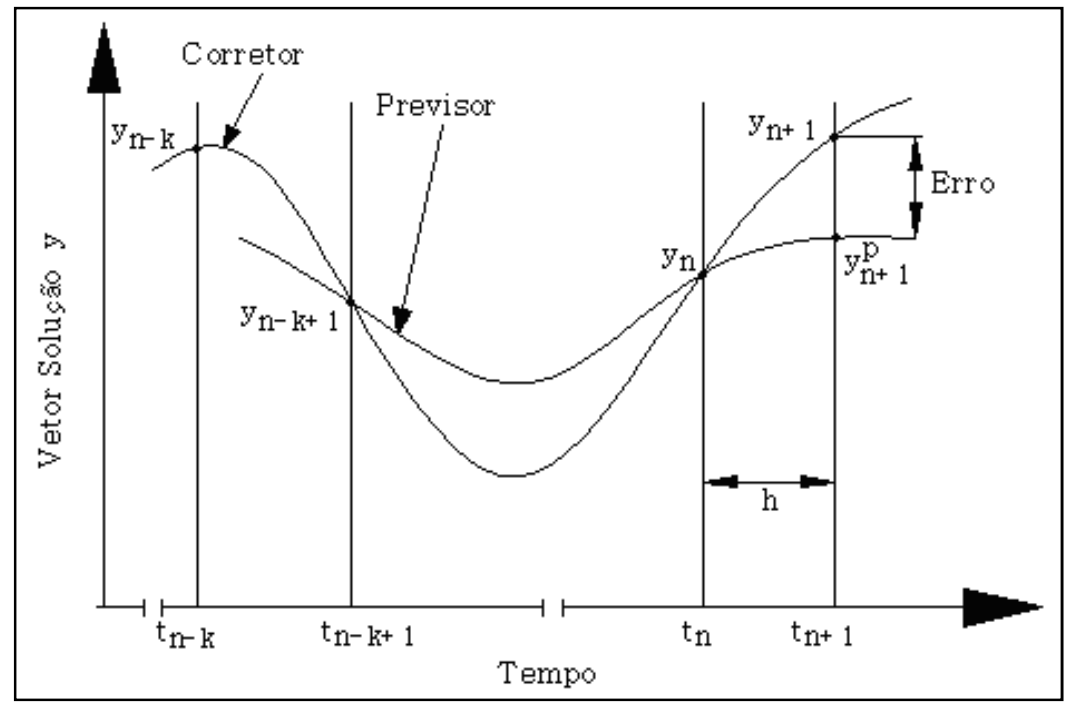

Figura 2.1 - Conceito básico dos métodos BDFs de ordem/passo variável

A equação previsor (ou polinômio previsor) é uma fórmula de extrapolação explícita que interpola $y_{n-i}$ nos últimos $i=1, \ldots, k+1$ ( $\mathrm{k}$ é a ordem das fórmulas BDF Apêndice $A$ ), fornecendo os valores iniciais do vetor aproximado da solução no intervalo de tempo a integrar $t_{n+1}$ para serem usados nas iterações da equação corretor (procedimento de integração implícita), com o sistema não-linear resultante. 0 previsor é responsável pela primeira aproximação $\mathrm{y}_{(\mathrm{n}+1)}^{\mathrm{P}}$ ao vetor solução $\mathrm{y}_{(\mathrm{n}+1)}$ no intervalo de tempo $t_{n+1}$ através de uma formulação polinomial composta de diferenças divididas, dada por:

$$
\begin{aligned}
y_{n+1}^{P}= & y_{n}+\left(t-t_{n}\right)\left[y_{n}, y_{n-1}\right]+\left(t-t_{n}\right)\left(t-t_{n-1}\right)\left[y_{n}, y_{n-1}, y_{n-2}\right. \\
& +\ldots+\left(t-t_{n}\right)\left(t-t_{n-1}\right) \cdots\left(t-t_{n-k+1}\right)\left[y_{n}, y_{n-1}, \cdots, y_{n-k}\right]
\end{aligned}
$$

$A$ avaliação em $t_{n+1}$ determina a primeira aproximação de valores $y_{n+1}^{0}$, que serão usados na iteração-corretor para a determinação explícita da aproximação final no 
intervalo $t_{n+1}$. Da mesma forma, o vetor $y_{n+1}^{\prime 0}$ é obtido diferenciando-se o polinômio previsor (Equação (2.36)) no instante $t_{n+1}$.

$\mathrm{Na}$ etapa de correção, algumas hipóteses apresentadas por (Byrne, 1975; Jackson, 1980) permitem o conhecimento implícito do vetor solução $y_{n+1}$ no instante $t_{n+1}$ através da relação com os valores aproximados na etapa de previsão. O polinômio corretor interpolará o polinômio previsor em k pontos igualmente espaçados anteriores a $t_{n+1}$, resultando na seguinte equação:

$$
y_{n+1}^{C}(t)=y_{n+1}^{P}(t)+b(t)\left(y_{n+1}^{C}-y_{n+1}^{(0)}\right)
$$

onde a constante numérica b é dada por:

$$
\begin{aligned}
& b\left(t_{n+1}-i h_{n+1}\right)=0, \forall i=1, . ., k \\
& b\left(t_{n+1}\right)=1
\end{aligned}
$$

Diferenciando-se a Equação (2.37) e fazendo uma avaliação em $t_{n+1}$, tem-se:

$$
\alpha_{s}\left(y_{n+1}+y_{n+1}^{(0)}\right)+h_{n+1}\left(y_{n+1}^{\prime}-y_{n+1}^{\prime(0)}\right)=0 \quad \alpha_{s}=-\sum_{j=1}^{k} \frac{1}{j}
$$

Resolvendo a Equação (2.38) para y $_{n+1}$, a iteração correção deve resolver:

$$
F\left(t_{n+1}, y_{n+1}, y_{n+1}^{\prime(0)}-\frac{a_{s}}{h_{n+1}}\left(y_{n+1}-y_{n+1}^{(0)}\right)\right)=0
$$

\subsubsection{Estratégias de Seleção de Ordem e Passo de Integração}

Os métodos BDF com coeficiente-fixo direcionado permitem escolher a ordem do método e o tamanho do passo para a aproximação do próximo intervalo. Este processo é feito através de estratégias de seleção baseadas no cálculo dos erros, fixando-se o tamanho dos passos de integração dos últimos intervalos $t_{n}$ e ordens $\mathrm{k}_{\mathrm{n}-2}, \mathrm{k}_{\mathrm{n}-1}, \mathrm{k}_{\mathrm{n}+1}$. Após atender à condição de convergência, inicia-se outro processo de avaliação correspondente à aceitação do passo $t_{n+1}-t_{n}$ através de uma estratégia de cálculos de erro. Esta etapa corresponde a um dos aspectos mais relevantes do 
processo de solução, ou seja, a confiabilidade em resolver de forma eficiente o sistema de EDAs.

Os dois tipos de erros envolvidos no processo de aceitação ou rejeição do passo estão relacionados ao erro de truncamento local do método e ao processo de interpolação polinomial, sendo este último composto de duas partes (Brenan et al., 1996). Considerando-se estes erros, é elaborada a seguinte condição de decisão:

$$
\max \left(\alpha_{k+1}(n+1),\left|\alpha_{k+1}(n+1)+\alpha_{s}-\alpha^{0}(n+1)\right|\right) \times\left\|y_{n+1}-y_{n+1}^{(0)}\right\| \leq 1.0
$$

onde

$$
\begin{aligned}
& \alpha_{s}=-\sum_{j=1}^{k} \frac{1}{j} \\
& \alpha^{0}=-\sum_{j=1}^{k} \alpha_{i}(n+1)
\end{aligned}
$$

O passo é rejeitado se a condição acima não for satisfeita e o cálculo da ordem do método independe da aceitação do passo de integração.

Após o teste de verificação do tamanho do passo e do cálculo da ordem do método, é feita nova tentativa, se rejeitado, para encontrar um tamanho de passo que satisfaça as condições estabelecidas, ou seguirá em frente calculando novos passos (Shampine \& Gordon, 1975). O erro na nova ordem $\mathrm{k}$ é estimado como se os últimos $\mathrm{k}+1$ intervalos fossem calculados com um novo passo, e este passo é escolhido de forma que o erro estimado satisfaça a (2.40). O novo passo de integração $h_{n+1}$ é escolhido de forma conservadora (2.41) para que o erro seja a metade do valor da tolerância do erro de integração desejado.

$$
\begin{aligned}
& h_{n+1}=r h_{n} \\
& r=(2 E S T)^{-\frac{1}{(k+1)}}
\end{aligned}
$$

O parâmetro "EST" representa o erro estimado para o método de ordem k selecionado para o passo seguinte $h_{n+1}$. Quando se tem uma condição na qual o passo foi aceito, o seu tamanho aumenta apenas se for possível dobrá-lo. Se for necessária uma redução, o tamanho do passo é reduzido de pelo menos um fator $r=0.9$, e no máximo de $r=0.5$. 
Por outro lado, quando se encontra numa condição na qual o passo foi rejeitado, sendo a primeira tentativa desde a última aceitação, o fator $r$ é dado por (2.41) e multiplicado por 0.9. O passo de integração é reduzido no mínimo pelo fator 0.9 e no máximo por 0.25 . Após a segunda tentativa sem êxito, o passo de integração é reduzido por um fator de 0.25 . Depois de três tentativas sem sucesso, a ordem é reduzida para 1 (um) e o tamanho do passo é reduzido por um fator de 0.25 sempre que o teste falhar. Atingindo-se um tamanho de passo tal que $t_{n} \approx t_{n+h}$, gera-se uma mensagem de erro e o processo é interrompido. Este tamanho de passo $\mathrm{h}_{\min }$, representando o cumprimento da condição de $t_{n} \approx t_{n+h}$, é calculado através seguinte equação:

$$
\mathrm{h}_{\min }=4 \times \bar{\varepsilon} \times \max \left(\left|\mathrm{t}_{\mathrm{n}}\right|,\left|\mathrm{T}_{\text {Fin }}\right|\right)
$$

onde $\tilde{\varepsilon}$ representa o erro da unidade de arredondamento e $\mathrm{T}_{\mathrm{Fin}}$ é o instante de tempo final da simulação estabelecido pelo usuário.

\subsubsection{Controle do Passo de Integração Através de Filtro Digital}

O item anterior apresentou as principais etapas associadas ao controle do erro e, consequentemente, do comprimento do passo de integração a ser aceito, ou não, durante o processo de solução das equações diferenciais ordinárias. As estratégias adaptativas associadas ao processo de solução estão baseadas em heurísticas com muitas lógicas e constantes tomadas de decisão. Por causa destes fatores, a capacidade em termos de solucionar eficientemente o problema pode ser bastante degradada. Portanto, é necessário desenvolver estratégias para amenizar as consequências indesejáveis resultantes e obter um comportamento bem suave da solução.

A referência (Soderlind \& Wang, 2003) enfoca as deficiências associadas às estratégias de variação do passo apresentadas anteriormente e sugere formas de amenizá-las através de um controle adaptativo do comprimento do passo (2.43), incluindo filtros digitais. O algoritmo está baseado na teoria de controle e tem como objetivo manter o erro estimado igual à tolerância, e para consegui-lo é necessário computar a diferença entre o erro e a tolerância desejada e usar esta diferença em um laço de controle retroalimentado para ajustar o comprimento do passo de forma contínua. 


$$
h_{n+1}=\left(\frac{\varepsilon}{\hat{r}_{n}}\right)^{k \beta_{1}}\left(\frac{\varepsilon}{\hat{r}_{n-1}}\right)^{k \beta_{2}}\left(\frac{h_{n}}{h_{n-1}}\right)^{-\alpha_{2}} h_{n}
$$

O parâmetro $\varepsilon$ corresponde a uma parcela de uma determinada tolerância do erro local e k é p ou p + 1 (dependendo do objetivo do controle), onde p é a ordem do estimador do erro local $\widehat{r_{\mathrm{n}}}$. Os parâmetros $\beta_{1}, \beta_{2}$ e, $\alpha_{2}$ são selecionados de acordo com ordem das condições para adaptação e filtro passa-baixa (Soderlind, 2003).

De acordo com (Valli et al., 2004) técnicas adaptativas para seleção automática do passo de integração são provavelmente os meios mais importantes para melhorar a eficiência de certo método de integração. Os autores aplicaram duas técnicas em problemas envolvendo elementos finitos obtendo-se bons resultados. Nesta tese, um controlador é disponibilizado para determinar o comprimento do passo de integração na simulação de cenários de estabilidade de curta e de longa-duração, sendo possivelmente uma contribuição já que nada relacionado foi encontrado na literatura consultada. 


\section{Métodos Iterativos e Suas Estratégias}

\subsection{Introdução}

O Capítulo anterior apresentou conceitos fundamentais sobre técnicas numéricas, destacando alguns métodos (diretos e os iterativos) na solução de sistemas algébricos lineares, e o BDF para a solução de Equações Diferenciais e Algébricas (EDAs). O presente Capítulo aborda com mais detalhes os métodos iterativos, précondicionadores e estratégias numéricas, oferecendo também uma abordagem da história da arte (evolução) desses métodos, enfocando os que mais se destacam entre os especialistas, bem como suas principais características, vantagens e desvantagens associadas.

Destaca-se neste Capítulo a abordagem do método numérico iterativo de interesse, o GMRES, e as estratégias numéricas adotadas, incluindo a técnica de précondicionamento. Essas combinações são: GMRES Sem Pré-Condicionamento e com Estratégias de Reinicialização; GMRES Sem Pré-Condicionamento e com Estratégias de Reinicialização e Diferenças de Quocientes; GMRES com Pré-Condicionamento ILUT com Estratégias de Reinicialização. Em conjunto com a exposição da teoria, simulações computacionais envolvendo sistemas de energia elétrica também são apresentadas, apesar do Capítulo 4 ser dedicado exclusivamente aos experimentos numéricos. Como no Capítulo 2, o objetivo de mostrar simulações já neste Capítulo é simplesmente didático, mas desta vez envolvendo sistemas elétricos.

Será notado que algumas informações presentes já foram vistas anteriormente, mas aqui são abordadas com mais detalhes, e também porque dependendo da importância do assunto é imperativo trazê-las de volta.

\subsection{Historia da Arte}

Métodos de projeção surgiram na primeira metade do século passado, e tentavam solucionar um conjunto de equações resolvendo cada equação separadamente baseado numa pequena correção sobre certa norma. Esses métodos poderiam ser aplicados em sistema lineares sobre determinados (mais equações que funções incógnitas) ou subdeterminados (menos equações que funções incógnitas). Surgiram 
em seguida os métodos de Cimmino (Cimmino, 1939) e Kaczmarz (Kaczmarz, 1939), que foram mais tarde identificados como variantes do Gauss-Jacobi e/ou Gauss-Seidel para sistemas $\mathrm{A}^{\mathrm{T}} \mathrm{A}$ ou $\mathrm{AA^{ \textrm {T } }}$. Já a segunda metade do século passado foi marcada pelo desenvolvimento do método Gradiente Conjugado (1952) por Hestenes e Stiefel (Hestenes et al., 1952) e do algoritmo de Lanczos para sistemas lineares (Lanczos, 1950), iniciando a partir daí a era dos métodos iterativos no subespaço Krylov. Estes não foram tratados inicialmente como técnicas iterativas, mas como algoritmos de solução direta uma vez que encontravam a solução em menos que n passos, sendo $n$ a ordem da matriz. Após algum tempo, Lanczos (Lanczos, 1950) e Arnoldi (Arnoldi, 1951) levantaram a hipótese de transformar a matriz para uma forma mais simples com o propósito de facilitar a diagonalização. Estas quatro referências juntas formaram a base para o desenvolvimento de muitos métodos que surgiriam em seguida.

Uma importante publicação de Engeli et al (Engeli et al., 1959) considerou o método Gradiente Conjugado como um processo iterativo e mostrou que numa aritmética precisa de arredondamento, este método não terminava no número de passos (iterações) esperado, ou seja, igual, pelo menos, a ordem da matriz. Neste caso em particular, a ordem da matriz era igual a 64, e a convergência ocorria apenas após algumas centenas de iterações. Se não bastasse essa aparente deficiência, o método apareceu em outra publicação (Wilkinson et al., 1971) como um tipo de técnica direta cujo destaque era a qualidade amigável do uso de espaço de memória. Foi mencionado que a convergência poderia ocorrer apenas após $m$ iterações, onde m poderia ser de três a cinco vezes a ordem da matriz. Devido a não compreensão deste comportamento na aritmética de arredondamento, o método não foi incluído no primeiro programa computacional universal de álgebra linear, conhecido com LINPACK, isso em meados da década de setenta. No início da década de sessenta ficou claro que a convergência do Gradiente Conjugado dependia da distribuição dos autovalores da matriz, e não muito da sua ordem. Reid (Reid 1971) sugeriu o uso do Método Gradiente Conjugado como uma técnica iterativa, mas agora para sistemas esparsos de grande-porte referentes à discretização de Equações Diferenciais Parciais. Logo após, o pré-condicionamento (já proposto em (Hestenes et al., 1952)) tornou-se bem popular. Demorou aproximadamente vinte e cinco anos para o Método Gradiente Conjugado se tornar o método escolhido para matrizes simétricas definidas positivas.

As variantes não-simétricas dos métodos de Krylov levaram aproximadamente esses mesmos vinte e cinco anos para amadurecerem, sendo o final da década de sessenta 
e o início da de setenta o auge dessa descoberta. Técnicas conhecidas como ORTHODIR, ORTHOMIN, FOM, entre outras, foram introduzidas nas suas formulações originais; esses métodos apresentaram limitações como interrupções (tentativa de divisão por elemento nulo - pivô) e instabilidade numérica. A variante GMRES, introduzida por Saad e Schultz (Saad, 1986), foi desenvolvida para evitar esses problemas indesejáveis tornando-se muito popular. Entretanto, O GMRES apresentava a desvantagem de necessitar de grandes esforços computacionais à medida que aumentava o número de iterações. O método Gradiente Bi-Conjugado, uma variante do original, não apresentava esses problemas, e estava baseado no método não-simétrico de Lanczos (1952), introduzido por Fletcher (Fletcher, 1975). Entretanto, o Bi-GC estava sujeito a problemas conhecidos como interrupções de primeiro e segundo tipo. Apesar disso, o método se tornou muito popular, principalmente a variante conhecida como CGS (Sonneveld, 1989), o qual podia ser aplicado duas vezes, em sequência, dobrando a velocidade de convergência. Por outro lado, os problemas associados ao BI-GC também eram amplificados. Na década de oitenta, Parlett (Parlett et al., 1985) e mais tarde Freund e Nachtigal (Freund, 1990) mostraram como corrigir as deficiências do Bi-GC permitindo o desenvolvimento de programas computacionais confiáveis. Mais recentemente, variantes híbridas do Bi-GC e do GMRES têm sido desenvolvidas, sendo o Bi-GCSTAB (Van der Vorst, 1992) um dos mais populares.

Em 1989, Simon (Simon, 1989) apresentou resultados de matrizes da ordem de 55.000 para técnicas diretas de solução, e em supercomputadores estes cálculos consumiriam alguns minutos de tempo de CPU. O autor atestou que algoritmos diretos com esparsidade ainda era a melhor opção para problemas com estruturas matriciais irregulares. Embora isso seja verdade caso a estrutura da matriz permita o uso de um processo de eliminação eficiente, tornou-se claro que para muitos problemas relacionados a Equações Diferenciais Parciais, a complexidade do processo de eliminação aumentava bastante. Problemas com estruturas irregulares da ordem de 1.000.000, como vistos por Simon, podem ser resolvidos por métodos diretos em computadores de grande capacidade, principalmente de memória, mas a um custo proibitivo. Entretanto, alguns desses problemas poderiam ser resolvidos através de técnicas iterativas, certificando-se da existência de um pré-condicionador adequado. $\mathrm{Na}$ última década do século passado, esforços consideráveis foram feitos para a identificação de pré-condicionadores eficientes para classes de matrizes. Em 1992, Pommerell (Pommerell, 1992) reportou aplicações bem sucedidas de métodos de 
Krylov pré-condicionados para sistemas extremamente mal-condicionados, cuja ordem era de 210.000 .

\section{- Pré-Condicionamento}

A convergência dos métodos iterativos depende das condições espectrais da matriz do sistema linear. A fim de melhorar essas propriedades, é possível transformar o sistema linear original por um equivalente, cuja solução ofereça menos barreiras aritméticas, mas cuja solução seja idêntica a do sistema original. Este processo, abordado neste trabalho em várias oportunidades, e que continuará sendo abordado, é conhecido com pré-condicionamento da matriz original. O conceito de pré-condicionador surgiu por volta de 1952 num artigo de Lanczos (Lanczos, 1952), atestando que o objetivo do procedimento era reduzir as imperfeições iniciais do sistema, onde não se conseguia a solução exata.

Métodos modernos de pré-condicionamento começaram a surgir no final da década de 60 e no início da de 70. Evans (Evans, 1968) sugeriu para pré-condicionar uma matriz aproximada triangular e esparsa, em conjunto com o método Gradiente Conjugado. Em 1972, Alexsson (Axelsson 1972) propôs o uso do método SSOR como um précondicionador. Decomposições incompletas de Choleski (Meijerink \& Van Der Vorst, 1977), tornaram-se muito populares e levaram ao processo ICCG (Meijerink, 1977). Concus, Golub e O'Leary (Concus et al., 1976) escreveram um artigo relevante sobre o uso e o efeito do pré-condicionador no método Gradiente Conjugado.

\section{- Fatoração Incompleta}

A estratégia de pré-condicionar, de acordo com uma interpretação moderna, se refere a aproximar, ou aplicar o processo de fatoração incompleta á matriz A. Algumas das primeiras publicações sobre esses processos de fatoração citadas com frequência incluem, Buleev (Buleev, 1960), Varga (Varga 1960), e Oliphant (Oliphant 1962). No final dos anos 60 outros poucos procedimentos foram desenvolvidos, especificamente para matrizes associadas a aproximações por diferenças finitas. Em 1977 Meijerink e Van der Vorst introduziram a mais importante técnica de fatoração incompleta LU- ILU (Meijerink, 1977). Este artigo sugere que a o uso conjunto desta técnica e o método gradiente conjugado poderia resultar numa combinação muito rápida e robusta, sendo, portanto um grande estímulo para a ampla área de métodos iterativos. 
Várias contribuições foram surgindo, destacando-se duas diferentes formas de se desenvolver pré-condicionadores ILU com precisão melhorada. A primeira forma está baseada numa fatoração simbólica, isto é, requer apenas informações sobre a estrutura não-zero da matriz para se determinar quais elementos não-nulos devem ser desprezados. A segunda forma é modificar uma técnica direta incluindo uma regra de desconsideração, baseada no tamanho numérico dos preenchimentos introduzidos (Gallivan et al., 1990; Osterby, 1983; D’Azevedo et al., 1992a; D’Azevedo et al., 1992b; Zlatev, 1982; Young et al., 1989).

Embora a relação entre o tamanho dos elementos desprezados e o número de iterações necessário para atingir a convergência é de difícil compreensão, desprezar elementos pequenos parece ser mais adequado para se produzir um précondicionador de melhor qualidade, do que desprezar elementos grandes. Entretanto, a prática tem revelado que isto nem sempre é verdade. Outra dificuldade da estratégia baseada no nível de preenchimento está associada à previsão do montante de preenchimentos que serão gerados.

O número de variantes associadas à pré-condicionadores ILU é muito grande, sendo, portanto suficiente atestar que foram desenvolvidas para arquiteturas específicas de matrizes, ou para aplicações específicas, ou para explorar características específicas de equações, entre outras. A referência (Dongarra et al., 1998) oferece informações importantes sobre pré-condicionadores.

Saad (Saad, 1988) propôs algumas variantes da técnica ILU para a matriz A, sendo uma delas de fato uma decomposição LQ incompleta. Nesta estratégia não é necessário formar a matriz $\mathrm{Q}$ explicitamente, sendo que a matriz triangular inferior, $\mathrm{L}$, pode ser vista como o fator de uma fatoração incompleta Choleski da matriz $\mathrm{A}^{\mathrm{T}} \mathrm{A}$. Isto pode ser explorado na etapa de pré-condicionamento, evitando o uso de Q. A segunda estratégia foi introduzir pivotamento parcial no ILU, que aparentemente apresenta algumas vantagens para problemas dominados por convecção. Esta estratégia foi posteriormente melhorada devido à inclusão de uma técnica com limite (threshold em inglês) para os preenchimentos, como considerado no algoritmo ILUT (Saad, 1986).

A técnica é conhecida como fatoração incompleta porque durante o processo de fatoração, certos elementos não-nulos que aparecem no lugar de elementos inicialmente nulos, são ignorados. Tal pré-condicionador é então expresso na forma fatorada $\mathrm{M}=\mathrm{LU}$ com as matrizes triangular inferior $\mathrm{L}$ e triangular superior $\mathrm{U}$. A eficácia 
do pré-condicionador depende da capacidade de $\mathrm{M}^{-1}$ aproximar $\mathrm{A}^{-1}$. O método ILU está sujeito a condições de interrupções, ou resultam em matrizes indefinidas (pivôs negativos), mesmo se a fatoração completa da mesma matriz estiver garantida e levar a uma matriz definida positiva. Em casos onde elementos pivô são nulos ou negativos, estratégias têm sido propostas, tais como a substituição por um número positivo arbitrário (Reich, 1949), ou reinicializando a fatoração.

\subsubsection{Métodos e Estratégias no Subespaço Krylov - O Estado da Arte}

No início dos anos 50, um bom número de métodos novos surgiu influenciando positivamente o perfil dos métodos iterativos. Em contribuições separadas, Lanczos (Lanczos, 1952) e Hestenes/Stiefel (Hestenes, 1952) propuseram diferentes versões do conhecido método Gradiente Conjugado. Coincidentemente, Hestenes e Stiefel desenvolveram o mesmo método, mas de forma independente. O método proposto por Lanczos é, para matrizes simétricas definidas positivas, equivalente matematicamente ao método Gradiente Conjugado, mas foi desenvolvido também para matrizes nãosimétricas. Não há dúvidas que a origem desta classe de métodos estava fortemente enraizada na teoria da aproximação e, particularmente em polinômios ortogonais.

A ideia principal dos métodos Gradientes está baseada em alguma forma de minimização. Por exemplo, para uma matriz simétrica definida positiva A, o GC minimiza a norma- $A$ : $\left\|x_{i}-x\right\|_{A}^{2}\left(x_{i}-x, A\left(x_{i}-x\right)\right)$, para os $x_{i}$ que estão no subespaço Krylov $K_{i}\left(A, r_{0}\right)\left\{r_{0}, \cdots, A^{i-1} r_{0}\right\}$. Outra interpretação dos métodos gradiente é que 0 resíduo é ortogonal ao espaço de resíduos previamente gerados, ou a algum outro espaço relacionado. Ambas as interpretações são úteis para a formulação de métodos, bem como para análise. Uma consequência muito útil da base do subespaço Krylov é que $x_{i}$ pode ser expresso como um polinômio de A de grau $\mathrm{i}-1$, agindo sobre $r_{0}$ (resíduo inicial). A Expressão (3.1) indica o limite superior para matrizes simétricas definidas positivas, onde $\mathrm{k}=\lambda_{\max }(\mathrm{A}) \cdot \lambda_{\min }(\mathrm{A})^{-1}$ (Kaniel, 1966; Daniel, 1967; Concus et al., 1976; Axelsson, 1976). Este limite superior descreve bem o comportamento da convergência para matrizes A, onde os autovalores estão distribuídos de forma homogênea.

$$
\left\|x_{i}-x\right\|_{A} \sqrt{2}\left(\frac{\sqrt{k}-1}{\sqrt{k}+1}\right)^{i}\left\|x_{i}-x\right\|_{A}
$$


Para distribuições menos homogêneas, os limites podem ser obtidos através de escolhas mais adequadas dos polinômios de aproximação, por exemplo, polinômios de Chebyshev (Axelsson, 1976). Essas escolhas não revelam a convergência super linear geralmente observada no GC, e também em métodos no subespaço Krylov. A noção de convergência super linear se refere à observação de que o processo de convergência do GC é acelerado ao longo do processo. Provas de convergência super linear foram apresentadas pela primeira vez no início dos anos 50 (Karush, 1952; Hayes, 1954), mas não revelaram que o comportamento super linear poderia se manifestar nas etapas iniciais do processo de iteração. Concus (Concus et al., 1976) relacionou este comportamento às aproximações no subespaço Krylov, afirmando que:

"Os autovalores extremos são bem aproximados especialmente (pelos valores de Ritz correspondentes ao subespaço Krylov) à medida que o GC evolui, a iteração então se comporta como se os correspondentes autovetores não estivessem presentes."

Isto leva a um menor número efetivo de condição da matriz em (2.34), o que pode explicar o aumento na velocidade de convergência. Em 1986, provou-se este fato numa forma quantitativa (Van der Sluis, 1986) onde foi mostrado que, para que a aceleração ocorresse, os autovalores relevantes precisavam ser aproximados apenas por um modesto valor de Ritz.

Passou algum tempo antes que as idéias do GC fossem generalizadas para outras classes de matrizes. No MINRES, a norma residual $\left\|\mathrm{Ax}_{\mathrm{i}}-\mathrm{b}\right\|_{2}$ é minimizada, e isto requer cautela a fim de evitar interrupções. O método Gradiente Conjugado pode ser interpretado como um processo no qual a matriz A é projetada no subespaço Krylov, resultando numa matriz tri-diagonal $\mathrm{T}$ de dimensão pequena. $\mathrm{A}$ aproximação atual $\mathrm{x}_{\mathrm{i}} \mathrm{e}$ determinada solucionando-se um pequeno sistema linear com $\mathrm{T}$, sendo feito com fatoração LU sem pivotamento. Para matrizes indefinidas, a fatoração LU pode resultar em problemas numéricos, mas Paige e Saunders aplicaram decomposição QR sobre $\mathrm{T}$, levando à recorrências curtas e regulares, fazendo do MINRES um método atrativo principalmente devido a economia de armazenamento. Paige e Saunders também conseguiram minimizar $\left\|x_{i}-x\right\|_{2}$ sem conhecer a solução $x$, restringindo $x_{i} a$ $\mathrm{AK}_{\mathrm{i}}\left(\mathrm{A}, \mathrm{r}_{0}\right)$, sendo este método conhecido como SYMMLQ (SYMMetric LQ). A vantagem deste método sobre o MINRES parece estar na menor sensibilidade ao mau condicionamento de A, por outro lado número de iterações é, geralmente, maior. 
Com relação o Gradiente Bi-Conjugado-GBC (Fletcher, 1975), inicialmente não foi muito bem aceito pelos especialistas devido às várias condições de interrupção que podiam ocorrer. Também, este método não minimizava nenhuma norma de interesse e o comportamento da convergência podia ser irregular. Entretanto, ao longo dos anos, aprendeu-se a usar o GBC e o método de Lanczos de forma eficiente na solução de sistemas lineares esparsos de grande-porte, graças ao melhor entendimento desses processos, bem como as melhorias introduzidas ao longo dos anos.

As excelentes perspectivas associadas aos métodos baseados no subespaço Krylov inspirou os especialistas na construção de métodos similares, só que para matrizes não-simétricas. O método clássico de Lanczos levou a um sistema tri-diagonal, a projeção de A com relação ao subespaço Krylov. A fatoração desta matriz tri-diagonal como um produto de matrizes bi-diagonais superior e inferior conduz à dois termos de recorrência acoplados, como no Gradiente Bi-Conjugado. Como já mencionado, este método sofre de várias condições de interrupção, uma associada a indefinição com o sistema tri-diagonal implicitamente gerado, e a outra é mais séria, surgindo quando o processo de bi-ortogonalização conduz a um produto interno nulo (zero) dos dois novos vetores no subespaço Krylov. Existem soluções para essas condições de interrupção (apenas a proximidade para esta condição é suficiente para gerar imprecisões na solução aproximada) (Bank, 1993; Parlett et al., 1985).

Solucionar essas condições de interrupção no Gradiente Bi-Conjugado foi um passo importante para o reconhecimento dos aspectos promissores das técnicas iterativas, mas particularmente dois deles motivaram bastante os pesquisadores. $O$ comportamento da convergência do Bi-Conjugado era muito irregular, onde as normas dos sucessivos resíduos poderiam se comportar de forma irregular. Este fato motivou Freund e Nachtigal (Freund, 1990) a proporem um algoritmo no qual o sistema tridiagonal sobredeterminado resultante era resolvido na base dos mínimos quadrados. Uma vez que os vetores base do subespaço Krylov (gerados pelo método de Lanczos de dois lados) em geral são não-ortogonais, esta técnica não conduz a uma solução aproximada de resíduos mínimos (como o MINRES), justificando a sua identificação como Resíduo Quase-Mínimo (QMR - Quasi Minimum Residual). O método QMR completo inclui uma estratégia identificada como "olhar para frente" (look-ahead), mas também se tornou popular sem a inclusão desta estratégia, uma vez que a primeira condição de interrupção é corrigida através da solução dos mínimos quadrados do sistema tri-diagonal (Barrett et al., 1994). 
Outra clara desvantagem no método Lanczos (two-sided Lanczos method) está na necessidade de se construir dois subespaços Krylov: $K_{i}\left(A, r_{0}\right)$ e $K_{i}\left(A, s_{0}\right)$. Dos dois vetores base gerados, apenas um é explorado para a solução, o outro pode ser visto como um conjunto auxiliar usado para gerar produtos internos necessários para gerar a base bi-ortogonal. Sonneveld (Sonneveld, 1989) fez a importante observação de que operações com $\mathrm{A}^{\mathrm{T}}$ poderiam ser reformuladas para operações com $\mathrm{A}$, e que essas operações poderiam ser usadas para uma futura redução da norma residual. Apesar desses avanços, a velocidade da convergência ainda era um problema. Entretanto, Sonneveld propôs uma solução interessante para aumentar a velocidade de convergência, a praticamente o mesmo custo por iteração. A ideia está baseada na observação de que o resíduo $r_{i}$ pode ser expresso formalmente como $r_{i}=p_{i}(A) r_{0}$, com um polinômio $\mathrm{p}_{\mathrm{i}}$ de grau i. Similarmente, o resíduo equivalente no espaço adjacente pode ser expresso como $s_{i}=p_{i}\left(A^{T}\right) s_{0}$. Os coeficientes de iteração do BiConjugado são computados dos produtos internos como $\left(\mathrm{r}_{\mathrm{i}}, \mathrm{s}_{\mathrm{i}}\right)$, e tal produto interno pode ser reescrito formalmente como $\left(\mathrm{p}_{\mathrm{i}}(\mathrm{A}) \mathrm{r}_{0}, \mathrm{p}_{\mathrm{i}}\left(\mathrm{A}^{\mathrm{T}}\right) \mathrm{s}_{0}\right)=\left(\mathrm{p}_{\mathrm{i}}^{2}(\mathrm{~A}) \mathrm{r}_{0}, \mathrm{~s}_{0}\right)$. Esta observação leva a um algoritmo que gera $\tilde{x}_{i} \in K^{2 i}\left(A ; r_{0}\right)$, para o qual o correspondente resíduo $\tilde{r}_{i}$ pode ser expresso como $\tilde{r}_{i}=p_{i}^{2}(A) r_{0}$. Na situação onde o Bi-Conjugado fornece um resíduo $r_{i}=\left(p_{i}(A) r_{0}\right)$ que seja menor comparado a $r_{0}$, se pode concluir que $\mathrm{p}_{\mathrm{i}}(\mathrm{A})$ transformou $\mathrm{r}_{0}$ em um vetor menor, e se $\mathrm{p}_{\mathrm{i}}(\mathrm{A})$ for aplicado duas vezes, a redução é dobrada. De fato, a convergência do método resultante, Conjugado Gradiente Quadrado (CGS - Conjugate Gradients Squared), é obtida geralmente duas vezes mais rápida quando comparada ao Bi-Conjugado. Entretanto, a convergência do CGS é muito mais irregular do que a do Bi-GC, resultando possivelmente em sérios problemas de precisão quando se está num ambiente de aritmética de precisão finita. Este algoritmo também é conhecido como Bi-CGS.

Logo após o desenvolvimento do método CGS, foi reconhecido que operações com $A^{\top}$ também poderiam ser transformadas em outros polinômios em A. A primeira ideia neste sentido foi o Bi-CGSTAB (Van der Vorst, 1992), onde o Bi-Conjugado era combinado com passos de mínimos resíduos. O resultado foi uma convergência mais suave e mais rápida em comparação ao Bi-Conjugado, servindo também para outras combinações, como o Bi-CGSTAB(I) (Sleijpen, 1993), TFQMR (Freund, 1993, QMRSTAB (Chan et al., 1994).

Outro caminho a ser seguido era tentar minimizar a norma residual sobre todos os vetores no subespaço Krylov, similarmente ao MINRES. Um bom número de métodos 
foi proposto baseado nesta minimização, como o ORTHODIR (Jea, 1980) GCR (Eisenstat, 1983) e o ORTHOMIN (Vinsome, 1976). O problema foi que muitos desses métodos sofriam de algum tipo de instabilidade numérica. O método do Resíduo Mínimo Generalizado (GMRES) (Saad, 1986), desenvolvido em 1986, equivale matematicamente a essas técnicas, mas se tornou o preferido entre os especialistas e usuários devido ao seu melhor comportamento numérico e a sua economia, ambos em termos de espaço de memória e processo aritmético. Uma vantagem do GMRES é a sua garantia em computar a solução aproximada com uma mínima norma residual, mas os custos por iteração associados a computação da solução, além do produto matriz-vetor, aumentam linearmente com a evolução do processo iterativo. Além disso, todos os vetores base do subespaço Krylov precisam ser armazenados.

Como já mencionado no Capítulo 2, a forma de superar esta condição indesejada é introduzindo uma estratégia de reinicialização do processo iterativo, identificados como GMRES reinicializado ou simplesmente $\operatorname{GMRES}(\mathrm{m})$. Por outro lado, a tarefa de se escolher o número de iterações $(\mathrm{m})$ mais adequado para reinicializar o processo iterativo não é trivial, exigindo experiência e prática. Uma escolha inadequada pode comprometer o processo de convergência de forma significativa; e o método pode até falhar. Por esta razão, pesquisadores têm tentando encontrar formas para reduzir o número de passos associados ao processo iterativo através de estratégias de précondicionamento. Uma sugestão feita primeiramente por Eirola e Nevanlinna (Eirola, 1989) é tentar aprimorar o pré-condicionador com atualizações do subespaço Krylov.

Também foi visto no Capítulo 2 que a estratégia de pré-condicionar corresponde a encontrar um sistema algébrico linear equivalente ao original através de uma matriz de transformação $M$, cujo processo de solução seja mais simples, e a solução final seja idêntica a do sistema original, obviamente. O interessante é notar que existem também estratégias para a montagem dessas matrizes de transformação. Por exemplo, uma das estratégias corresponde a montar uma nova matriz a cada iteração, aproveitando informações prévias, sendo esta estratégia conhecida como pré-condicionamento atualizado. Por outro lado, está estratégia não pode ser aplicada diretamente ao GMRES, uma vez que a matriz de transformação irá variar dentro do processo iterativo, prejudicando a formação de um subespaço Krylov regular. Apesar disso, pode-se ainda minimizar o resíduo, Equação (2.13), sobre os novos subespaços. A ideia da estratégia do pré-condicionador atualizado tem sido abordada nesse sentido, por diferentes autores; Axelsson e Vassilevski (Axelsson, 1991) propõem um método gradiente generalizado com pré-condicionador atualizado; Saad (Saad, 1993) propõe 
um esquema muito similar ao GMRES, conhecido como GMRES flexível (FGMRES) e Van der Vorst e Vuik (Van der Vorst, 1994) propõem um esquema chamado GMRESR.

\subsection{Conceitos Associados ao Subespaço Krylov}

O item anterior apresentou numa forma sintetizada a evolução dos métodos iterativos no subespaço Krylov, muitos baseados nos processos de projeção, tanto ortogonais como oblíquas, aplicadas na solução de sistemas de equações lineares da forma:

$$
\begin{aligned}
& A x=b \\
& x=A^{-1} b
\end{aligned}
$$

O sistema (3.2) é aproximado por (3.3) onde p representa um polinômio adequado:

$$
\mathrm{p}(\mathrm{A}) \mathrm{v}
$$

A matriz A é quadrada, de grande porte, altamente esparsa, real simétrica e definida positiva. Também pode ser real assimétrica, ou complexa. A variável $x_{0}$ corresponde à valores iniciais para os métodos iterativos, $\mathrm{r}_{0}=\mathrm{b}-\mathrm{Ax}_{0}$ é o resíduo inicial e o vetor $\mathrm{z}$ deve satisfazer a Equação (3.4).

$$
A z=r_{0}
$$

Através do teorema de Cayley-Hamilton, a inversa da matriz não-singular $A_{n x n}$ pode ser representada como um polinômio de grau $n-1$, na seguinte forma (Watkins, 1991):

$$
z=p_{n-1}(A) r_{0}
$$

Uma propriedade interessante dos algoritmos no subespaço Krylov é a convergência em um número finito de passos de iteração. Pode-se conseguir a solução exata do sistema linear em até $\mathrm{n}$ iterações, onde $\mathrm{n}$ é a dimensão da matriz A. O método de projeção extrai uma solução aproximada $x_{m}$ de um subespaço $x_{0}+K_{m}$ de dimensão $\mathrm{m}$, resultante da aplicação de certas condições, como por exemplo, de Petrov-Galerkin (já mencionada no Capítulo 2), de acordo com (3.6) (Saad, 2003).

$$
\mathrm{b}-\mathrm{Ax} \mathrm{m}_{\mathrm{m}} \perp \zeta_{\mathrm{m}}
$$


Onde $\zeta_{\mathrm{m}}$ representa outro subespaço de dimensão $\mathrm{m}$. $\mathrm{O}$ parâmetro $\mathrm{K}_{\mathrm{m}}$ representa $\mathrm{O}$ subespaço Krylov, sendo expresso na seguinte forma:

$$
K_{m}\left(A, r_{0}\right)=\operatorname{span}\left(r_{0}, A r_{0}, A^{2} r_{0}, L, A^{m-1} r_{0}\right)
$$

As variantes dos métodos de Krylov resultam das diferentes escolhas dos subespaços $\zeta_{m}$, bem como da forma que o sistema é pré-condicionado.

\subsubsection{Algoritmos no Subespaço Krylov}

Métodos que fornecem melhores aproximações no subespaço Krylov são conhecidos como métodos de projeção de Krylov devido às classes de projeções usadas. Esses métodos podem ser classificados de acordo com quatro diferentes condições:

1. Condição de Ritz-Galerkin: constrói $x_{k}$ e o resíduo é ortogonal com relação ao mais recente subespaço construído: $\mathrm{b}-\mathrm{Ax}_{\mathrm{k}} \perp \mathrm{K}^{\mathrm{k}}\left(\mathrm{A} ; \mathrm{r}_{0}\right)$.

2. Condição da norma mínima residual: identifica $\mathrm{x}_{\mathrm{k}}$ cuja a norma Euclidiana $\left\|\mathrm{b}-\mathrm{Ax}_{\mathrm{k}}\right\|_{2}$ é mínima sobre $\mathrm{K}^{\mathrm{k}}\left(\mathrm{A} ; \mathrm{r}_{0}\right)$.

3. Condicão de Petrok-Galerkin: encontra um $\mathrm{x}_{\mathrm{k}}$ de forma que o resíduo $\mathrm{b}-\mathrm{Ax}_{\mathrm{k}}$ seja ortogonal a algum subespaço k-dimensional aceitável.

4. Condição da norma mínima do erro: determina $\mathrm{x}_{\mathrm{k}}$ em $\mathrm{A}^{\mathrm{T}} \mathrm{K}_{\mathrm{k}}\left(\mathrm{A}^{\mathrm{T}} ; \mathrm{r}_{0}\right)$ pelo qual a norma Euclidiana $\left\|\mathrm{x}_{\mathrm{k}}-\mathrm{x}\right\|_{2}$ é mínima.

A ideia básica é separar A em duas parcelas, uma identificada por P, e a outra por $Q$, de forma que $\mathrm{A}=\mathrm{P}-\mathrm{Q}$. Então, o processo iterativo para solucionar o sistema algébrico (3.2) apresenta a seguinte estrutura:

$$
\begin{aligned}
P x_{k+1} & =Q x_{k}+b \\
x_{k+1} & =P^{-1}\left(Q x_{k}+b\right) \\
& =x_{k}+P^{-1}\left(b-A x_{k}\right)
\end{aligned}
$$

Com o resíduo $\mathrm{r}_{0}=\mathrm{b}-\mathrm{Ax}_{0}$, tem-se:

$$
x_{k+1}=x_{0}+\beta_{0}\left(P^{-1} r_{0}\right)+\beta_{1}\left(P^{-1} A P^{-1}\right) r_{0}+\cdots \beta_{k}\left(P^{-1} A\right)^{k-1} P^{-1} r_{0}
$$


sendo $\beta_{0}, \beta_{1}, \ldots, \beta_{\mathrm{k}}$ constantes. Somou-se no lado direito de (3.9) um vetor que corresponde a uma combinação linear $\mathrm{M}^{-1} \mathrm{r}_{0},\left(\mathrm{M}^{-1} \mathrm{AM}^{-1}\right) \mathrm{r}_{0}, \ldots\left(\mathrm{M}^{-1} \mathrm{~A}\right)^{\mathrm{k}-1} \mathrm{M}^{-1}$, tem-se um vetor no subespaço k-dimensional ( $\mathrm{M}$ é o precondicionador). O espaço $\left\{f, B f, B^{2} f, \cdots, B^{(k-1)} r_{0}\right\}$ é denominado como o k-ésimo subespaço dimensional Krylov correspondente a f, e B é denotado como $\mathrm{K}^{\mathrm{k}}(\mathrm{B} ; \mathrm{f})$. Se $\mathrm{P}=\mathrm{I}$, então o subespaço Krylov é $\mathrm{K}^{\mathrm{k}}\left(\mathrm{A} ; \mathrm{r}_{0}\right)$. Portanto, em geral, tem-se:

$$
x_{k+1}=x_{0}+z \text { onde, } z \in K_{k}\left(P^{-1} A ; P^{-1} r_{0}\right)
$$

Note que numa simples iteração os parâmetros $\beta_{0}, \beta_{1}, \ldots, \beta_{\mathrm{k}}$ são números e existe uma liberdade em escolher esses parâmetros de forma que possam ser geradas muitas variantes no subespaço Krylov, sendo as mais conhecidas (Saad, 2003; Van der Vorst, 2003):

> Método do Gradiente Conjugado (CG); Lanczos, Método de Ortogonalização Completo (FOM) e Gradiente-Conjugado Generalizado.

$>\quad$ Método das Equações Normalizadas (GCN).

> Método do Gradiente Bi-Conjugado (GBC).

> Resíduo Mínimo Generalizado (GMRES), Resíduo Mínimo (MINRES) e ORTHODIR.

Qualquer método sobre o subespaço Krylov necessita de um procedimento para: gerar vetores base adequados (processo de Arnoldi, Lanczos entre os mais relevantes). Além disso, processos de ortogonalização são necessários (procedimento de GramSchmidt) e gerar iterações (Galerkin).

\subsection{O Método Resíduo Mínimo Generalizado (GMRES)}

Como já informado, o GMRES é um método de projeção que minimiza a norma residual sobre todos os vetores em $x_{0}+K_{m}$. Existem duas formas de se desenvolver 0 algoritmo do GMRES. A primeira aproveita a vantagem da propriedade de otimização e a seguinte equação (Saad, 2003):

$$
A V_{m}=V_{m} H_{m}+u_{m}^{\prime} e_{m}^{\top}=V_{m+1} \hat{H}_{m}
$$


Onde $\mathrm{V}_{\mathrm{m}}$ é a matriz nxn com vetores coluna $\mathrm{v}_{1}, \cdots, \mathrm{v}_{\mathrm{m}}$; $\widehat{\mathrm{H}}_{\mathrm{m}}$ é a matriz $(\mathrm{m}+1) \mathrm{x} \mathrm{m}$ de Hessenberg, e $\mathrm{H}_{\mathrm{m}}$ é a matriz obtida a partir de $\widehat{\mathrm{H}}_{\mathrm{m}}$ excluindo sua última linha. Qualquer vetor em $\mathrm{x}_{0}+\mathrm{K}_{\mathrm{m}}$ pode ser escrito como:

$$
\mathrm{x}=\mathrm{x}_{0}+\mathrm{V}_{\mathrm{m}} \mathrm{y}
$$

Onde y é um vetor m-dimensional. Definindo

$$
\mathrm{J}(\mathrm{y})=\|\mathrm{b}-\mathrm{Ax}\|_{2}=\left\|\mathrm{b}-\mathrm{A}\left(\mathrm{x}_{0}+\mathrm{V}_{\mathrm{m}} \mathrm{y}\right)\right\|_{2}
$$

A Equação (3.11) resulta em:

$$
b-A x=b-A\left(x_{0}+V_{m} y\right)=V_{m+1}\left(\beta e_{1}-\hat{H}_{m} y\right)
$$

Uma vez que os vetores coluna de $\mathrm{V}_{\mathrm{m}+1}$ são ortonormais, então:

$$
\mathrm{J}(\mathrm{y}) \equiv\left\|\mathrm{b}-\mathrm{A}\left(\mathrm{x}_{0}+\mathrm{V}_{\mathrm{m}} \mathrm{y}\right)\right\|_{2}=\left\|\beta \mathrm{e}_{1}-\hat{\mathrm{H}}_{\mathrm{m}} \mathrm{y}\right\|_{2}
$$

A aproximação do GMRES é através de um vetor único $x_{0}+K_{m}$ que minimiza a Equação (3.15). Pelas Equações (3.13) e (3.15), esta aproximação pode ser obtida simplesmente como $x_{m}=x_{0}+V_{m} y_{m}$, onde $y_{m}$ minimiza a função $\mathrm{J}(y)=\left\|\beta e_{1}-\widehat{H}_{m} y\right\|_{2}$; isto é:

$$
x_{m}=x_{0}+V_{m} y_{m} \text {, onde } y_{m}=\operatorname{argmin}_{y}\left\|\beta e_{1}-\hat{H}_{m} y\right\|_{2}
$$

A computação de $y_{m}$ não é uma tarefa difícil uma vez que requer a solução de um problema de mínimos quadrados de dimensão $(m+1) \times m$, onde $m$ é normalmente pequeno. Este conjunto de Equações (3.11)-(3.16) resulta no algoritmo GMRES na sua forma básica, como ilustrado na Figura 3.1 - . 


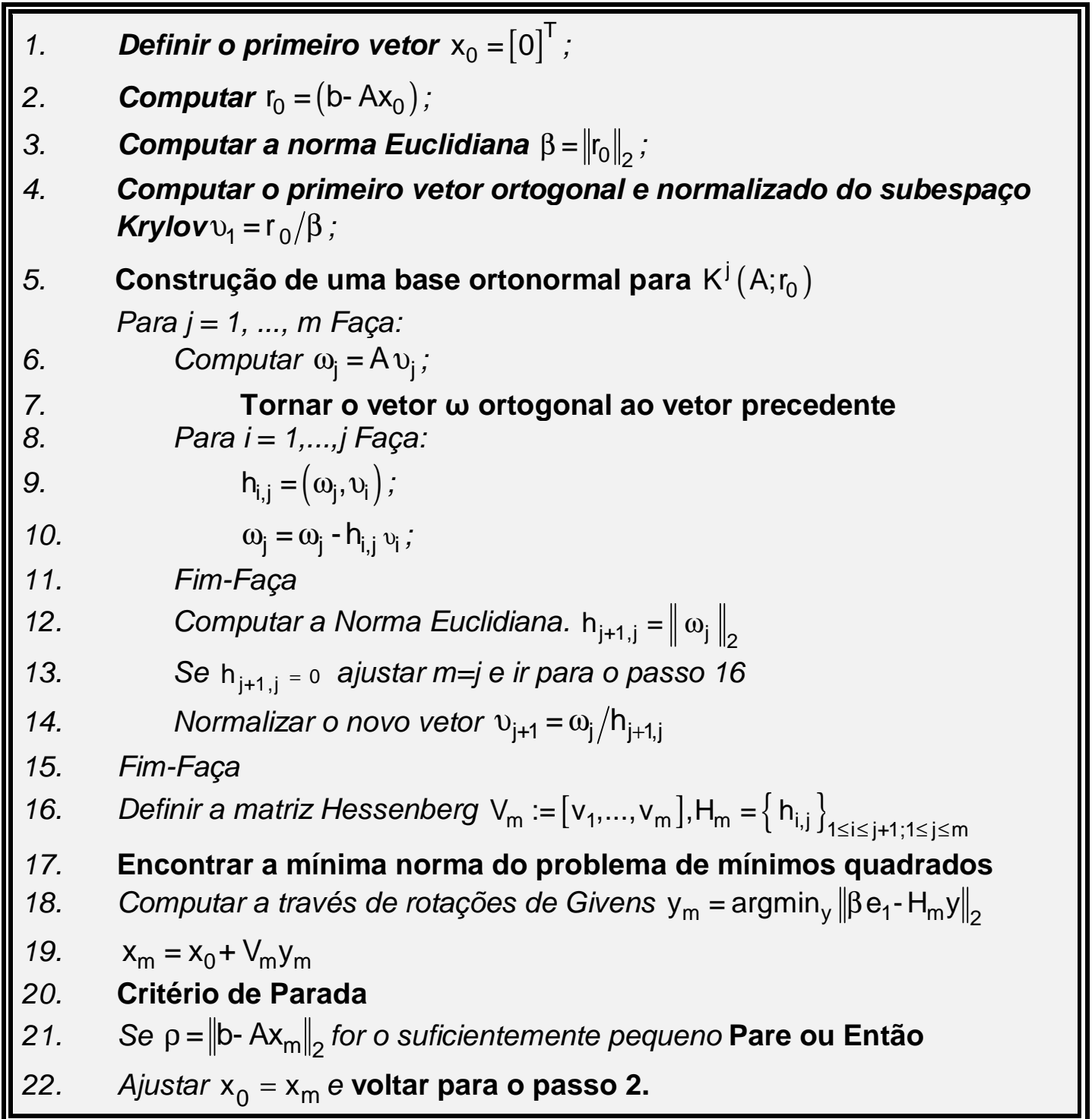

Figura 3.1 - O Algoritmo Básico do GMRES

\subsubsection{O Pré-Condicionamento}

O Pré-Condicionamento é uma estratégia comumente considerada nos métodos iterativos do subespaço Krylov, necessária na maioria dos casos envolvendo problemas práticos, e se resume a transformação do sistema original, conforme ilustra a Equação (3.17).

$$
\hat{A} \hat{x}=\hat{b}
$$


Onde $\widehat{A}=S A S^{T}$, e S representa uma matriz não-singular, escolhida de forma que:

$$
\begin{aligned}
& k(\hat{A})<k(A) \\
& \hat{x}=S^{-\top} x \\
& \hat{b}=S^{-1} b
\end{aligned}
$$

Lembrando que $k(\widehat{A})$ representa a condição espectral (distribuição de valores próprios, raio espectral, condição dos sistemas de autovalores, etc.) de A. Essa transformação linear é o pré-condicionamento e a matriz $\mathrm{M}=\left(\mathrm{SS}^{\mathrm{T}}\right)^{-1}$ é o pré-condicionador, sendo que este último não é calculado de forma explícita.

A apresentação destes algoritmos de projeção Krylov na sua forma básica, isto é, sem pré-condicionadores, é caracterizada pela baixa robustez no sentido de garantir uma aceitável aproximação da solução com tempo de CPU e requisitos de armazenagem adequados. Para alguns métodos, como o GMRES sem pré-condicionador, esses conduzem na aritmética exata à solução precisa em no máximo $\mathrm{n}$ iterações, no entanto, sob o ponto de vista computacional deixam a desejar (vide teste no Capítulo 2). Outros métodos são restritos a classes específicas de problemas (GC, MINRES) ou sofrem de efeitos de interrupção (GBC) (Saad, 2003; Van der Vorst, 2003). Esta fraca convergência depende, basicamente, das suas propriedades espectrais e essa informação não está disponível em situações práticas.

A dificuldade está em procurar um operador $\mathrm{M}$ tal que $\mathrm{M}^{-1} \mathrm{~A}$ apresente melhores propriedades espectrais. Isto se baseia na observação que para $M=A$, tem-se 0 sistema ideal da Equação (3.19), encontrando a solução em uma simples iteração.

$$
\underbrace{\left(M^{-1} A\right)}_{\widehat{A}} x=I x=\underbrace{M^{-1} b}_{\hat{b}}
$$

Portanto, a parte mais relevante do processo está em estabelecer um précondicionador apropriado, responsável por acelerar o processo de convergência em função da sua qualidade. Dentre as principais propriedades deste pré-condicionador M, destacam-se:

M deve ser uma boa aproximação para A; M não precisa ser determinado explicitamente. 
$>$ A construção de $\mathrm{M}$ não deve ser proibitiva; isto e, o custo computacional não deverá ser muito alto;

$>\quad \mathrm{O}$ sistema $\mathrm{My}=\mathrm{z}$ deve ser bem mais fácil de resolver do que o sistema original $\mathrm{Ax}=\mathrm{b}$.

\subsubsection{Reordenamento e Diferenças de Quocientes}

O objetivo primário das técnicas de reordenamento é reduzir os elementos não-nulos que surgem durante o processo de eliminação gaussiana. A dificuldade relacionada com tais estratégias, seja no contexto iterativo e/ou direto, está no fato de, um bom reordenamento para reduzir esses elementos pode resultar em fatores com baixa qualidade numérica (Saad, 2003). Por exemplo, durante o processo de ordenamento pode-se observar valores muito pequenos na diagonal, comprometendo o raio espectral de A $(\rho(A))$, que por sua vez influencia a taxa de convergência do método iterativo.

Dois tipos de permutações são frequentemente usadas para melhorar o processo de fatoração: uma primeira categoria consiste em permutações simétricas e uma segunda consiste em permutar só as linhas da matriz (ou colunas). Essas permutações nãosimétricas consideram outros aspectos, principalmente, evitando pivotamentos ineficientes na eliminação gaussiana.

Com relação à técnica conhecida como Diferenças de Quocientes (3.20), esta pode ser associada ao GMRES em duas situações. A primeira quando se tem multiplicação entre uma matriz $A$ e um vetor $v_{j}$, ou seja, quando a matriz de coeficientes é multiplicada por um vetor base contendo os resíduos (Passo 6 do Algoritmo GMRES). Dependendo da dimensão da matriz, essa operação pode ser crítica em função do tempo computacional gasto para efetuá-la. A estratégia em questão visa tornar o cálculo do vetor resultante mais eficiente, aproximando-o a partir de um aproveitamento das avaliações das funções não-lineares (2.33) já efetuadas, as quais demandam um baixo custo computacional. Uma vez que os métodos iterativos operam sobre mecanismos de aproximação, a diferença de quocientes se encaixa perfeitamente neste propósito, e melhor, também podem ser usadas em GMRES précondicionado. 
Uma segunda aplicação está relacionada ao pré-condicionamento do sistema original, caso o pré-condicionador de interesse seja do tipo banda, isto é, uma matriz com elementos formando diagonais na parte superior e inferior da diagonal principal, a partir das avaliações das funções não-lineares. A aplicabilidade deste tipo de précondicionamento usando a estratégia de diferença de quociente torna-se viável quando a matriz Jacobiana no regime permanente (3.21) ou a matriz de iteração $\mathrm{J}_{S D}$ na simulação dinâmica (3.22) tem uma estrutura caracterizada por diagonais na parte superior e inferior da diagonal principal.

$$
A v=F^{\prime}(y) v \approx \frac{F(t, y+\sigma v, \alpha(y+\sigma v)+\beta)-F(t, y, \alpha y+\beta)}{\sigma}
$$

Onde $\sigma$ representa a perturbação que será submetida ao conjunto de variáveis do sistema não-lineal.

$$
\begin{gathered}
J_{F C}=\left[\begin{array}{ll}
\frac{\partial P}{\partial \theta} & \frac{\partial P}{\partial V} \\
\frac{\partial Q}{\partial \theta} & \frac{\partial Q}{\partial V}
\end{array}\right] \\
J_{S D}=\left[\begin{array}{cc}
\frac{1}{h}[1]+\frac{\partial F_{1}}{\partial y_{1}} & \frac{\partial F_{1}}{\partial y_{2}} \\
\frac{\partial F_{2}}{\partial y_{1}} & \frac{\partial F_{2}}{\partial y_{2}}
\end{array}\right]
\end{gathered}
$$

Onde $\mathrm{h}$ representa o tamanho do passo de integração. Identificando esse tipo de estrutura pode-se obter um tempo de processamento muito pequeno quando comparado, por exemplo, a técnicas de fatoração incompleta. Entretanto, a aproximação da matriz Jacobiana e/ou de iteração não terá tão boa qualidade numérica se comparado com uma aproximação via fatoração incompleta com estratégias de eliminação por valor e/ou por posição.

\subsubsection{Estratégias de Pré-condicionamento Baseadas em Fatoração Incompleta}

Quando uma matriz esparsa é fatorada por eliminação Gaussiana, elementos nãonulos geralmente aparecem. Isto significa que fatores triangulares $L$ (inferior) e $U$ (superior) da matriz de coeficientes A são consideravelmente menos esparsos que A. Mesmo estando disponíveis técnicas de pivotação para preservação da esparsidade e redução desses novos elementos não-nulos, métodos diretos não são considerados 
adequados para resolver sistemas lineares muito grandes, devido ao esforço computacional associado (Benzi, 2002). Entretanto, descartando parte desses elementos ao longo do processo de fatoração, pré-condicionadores simples e eficientes podem ser obtidos na forma $M=\overline{L U}$, onde $\bar{L}$ e $\bar{U}$ são os fatores triangulares LU incompletos (aproximados). Os algoritmos de fatoração incompleta (ILU) diferem entre si com base na regra de eliminação dos elementos não-nulos, existindo diferentes critérios, tais como posição, valor, ou uma combinação de ambas, reduzindo o esforço computacional em termos de espaço e processamento.

Sendo $\mathrm{n}=\{1,2, \cdots\}$, pode-se estabelecer um subconjunto $\mathrm{S} \subseteq \mathrm{A}_{\mathrm{n} \times \mathrm{n}}$ de posições da matriz A, geralmente incluindo-se a diagonal principal e todos os $(i, j)$ tal que $a_{i j} \neq 0$ e permitir elementos não-nulos nos fatores LU apenas em posições de S. Formalmente, uma etapa da fatoração incompleta pode ser descrita por (3.23), para cada k e para $\mathrm{i}, \mathrm{j}>\mathrm{k}$.

$$
a_{i, j} \leftarrow\left\{\begin{array}{l}
a_{i, j}-a_{i, k} a_{k, k}^{-1} a_{k, j}, \text { se }(i, j) \in S \\
a_{i, j} \quad \text { caso contrário }
\end{array}\right.
$$

Se S coincidir com o conjunto de posições de elementos não-nulos de $\mathrm{A}$, é obtida a fatoração ILU sem elementos não-nulos, conhecido como ILU(0). A implementação deste tipo de pré-condicionador é simples, bem como a sua computação, e são eficientes para uma ampla faixa de problemas (Benzi, 2002). Entretanto, para problemas mais complexos e realísticos, este tipo de pré-condicionador resulta numa aproximação de A de baixa qualidade, sendo, portanto necessário optar por précondicionadores mais sofisticados, permitindo certo número de elementos não-nulos nos fatores incompletos.

Uma hierarquia de pré-condicionadores ILU pode ser obtida baseada no conceito de níveis de preenchimento ILU(l), atribuído a cada entrada que ocorre no processo de fatoração incompleta. Elementos não-nulos são eliminados baseados nos níveis de preenchimento $l$, e o nível inicial de um elemento $\mathrm{a}_{\mathrm{ij}}$ de uma matriz esparsa A será definido como:

$$
\operatorname{lev}_{i, j}=\left\{\begin{array}{l}
0, \text { se } a_{i, j} \neq 0 \text { ou } i=j \\
\infty, \quad \text { caso contrário }
\end{array}\right.
$$


Sempre que o elemento $a_{i j}$ for modificado pelo processo de fatoração ILU, seu nível de preenchimento deve ser atualizado de acordo com:

$$
\text { Level }_{\mathrm{i}, \mathrm{j}}=\min _{1 \leq \mathrm{k} \leq \min (\mathrm{i}, \mathrm{j})}\left\{\text { Level }_{\mathrm{i}, \mathrm{k}}+\text { Level }_{\mathrm{k}, \mathrm{j}}+1\right\}
$$

Com $l$ sendo um número inteiro positivo, em ILU $(l)$ todos os novos elementos nãonulos com nível superior a $l$ são descartados. Este método, entretanto, pode não ser robusto o bastante para certas classes de problemas. Para matrizes que não apresentem característica de diagonal dominante, ILU $(l)$ pode ter que armazenar muitos elementos não-nulos de valores muito pequenos, que pouco contribuem para a qualidade do pré-condicionador, além de apresentar um custo computacional alto. Um pré-condicionador mais eficiente pode ser obtido com elementos não-nulos sendo aceitos, ou não, em função de seus valores. Desta forma, apenas elementos nãonulos e que contribuem para a melhoria da qualidade do pré-condicionador são armazenados e usados.

A fatoração incompleta que necessita de níveis de controle do preenchimento de valores não-nulos durante a fatoração, é insensível aos valores numéricos uma vez que os elementos que são substituídos no processo de eliminação dependem da estrutura da matriz Jacobiana. Em problemas reais, este fato pode causar algumas dificuldades. Como já mencionado, alguns métodos se baseiam no esquema de eliminação Gaussiana em função da magnitude ao invés da sua localização. Nestes casos, o padrão de zeros $S$ é determinado dinamicamente (Saad, 2003).

Uma tolerância para descartar o elemento não-nulo é um número positivo $\tau$ que é usado como critério. Uma estratégia absoluta pode ser usada onde elementos nãonulos são aceitos apenas se maiores que $\tau$. Este critério pode não surtir o efeito esperado se a matriz estiver mal escalonada, sendo aconselhável neste caso usar uma estratégia relativa. Uma das dificuldades desta estratégia é a escolha do valor adequado de $\tau$, que pode ser feita através de tentativa e erro para algumas matrizes associadas ao problema. Em muitos casos, bons resultados são obtidos na faixa de $10^{-4}$ a $10^{-2}$, mas o valor ótimo é muito dependente do problema (Benzi, 2002).

Outra dificuldade é estimar o espaço de memória necessário para armazenar os fatores incompletos LU. Uma estratégia eficiente consiste em limitar a quantidade de elementos não-nulos em cada linha dos fatores triangulares. A referência (Saad, 2003) 
propôs uma estratégia que fixa uma tolerância $\tau$ e um número $\rho$ de elementos nãonulos que serão permitidos nas linhas dos fatores incompletos; a cada etapa do processo de eliminação, todos os elementos não-nulos inferiores a $\tau$ multiplicado pela norma-2 da linha correspondente são descartados; e os restantes pelo menos os $\rho$ maiores em magnitude são mantidos. Este pré-condicionador é conhecido como $\operatorname{ILUT}(\rho, \tau)$ e seu algoritmo está ilustrado na Figura 3.2 - .

A alternativa ILU(0) pode ser considerada como um caso particular do algoritmo $\operatorname{ILU}(p, \tau)$. A regra de eliminação para o caso ILU(0) é permutar elementos por zero que estão em posições não pertencentes à estrutura original da matriz de constantes.

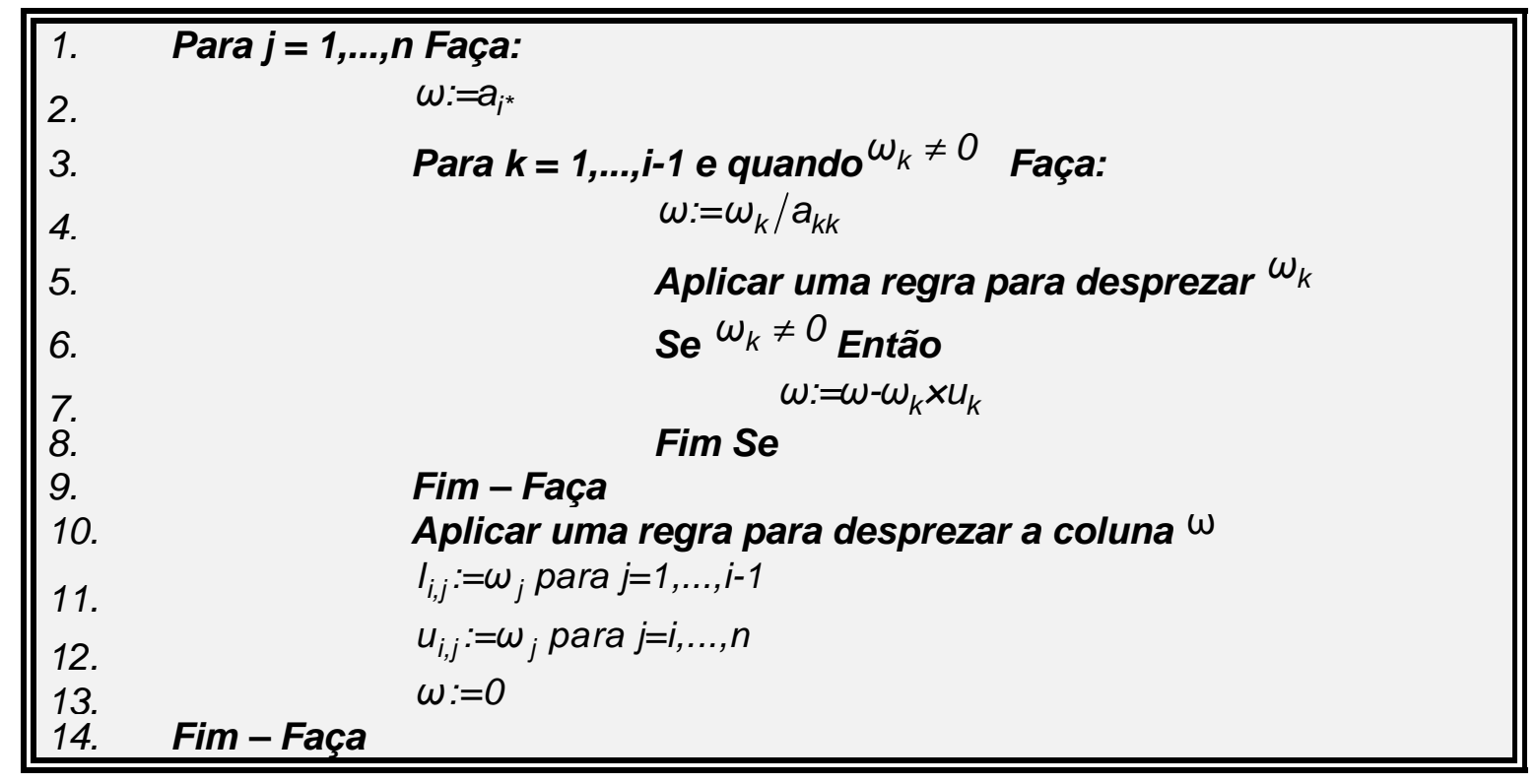

Figura 3.2 - Algoritmo básico do ILUT

Quando qualquer regra de eliminação não for usada, os fatores triangulares são calculados completamente. Neste caso, o pré-condicionador é igual à matriz de coeficientes, o que resulta na convergência do método iterativo em uma única iteração.

\subsubsection{Pré-Condicionando o GMRES}

Existem três formas de utilizar um pré-condicionador $M$, sendo estas: précondicionamento pelo lado esquerdo, pré-condicionamento pelo lado direito e précondicionamento por ambos os lados. As três formas produzem o mesmo sistema equivalente, com as mesmas propriedades espectrais e normalmente desempenhos 
similares do método iterativo. Porém, o pré-condicionamento pelo lado esquerdo é a forma mais simples e de fácil implementação computacional. Abaixo são apresentadas as três formas de se realizar o pré-condicionamento, para ambos os tipos: aproximação esparsa da matriz inversa e matriz descomposta.

A. Pré-condicionadores de aproximação esparsa da matriz inversa: $\mathbf{M} \approx \mathbf{A}^{-1}$
I. (Lado esquerdo)
$\mathrm{MAx}=\mathrm{Mb}$
II. (Lado direito)
$\mathrm{AMy}=\mathrm{b} \therefore \mathrm{x}=\mathrm{My}$
III. (Ambos os lados)
$\mathrm{M}_{2} \mathrm{AM}_{1} \mathrm{y}=\mathrm{M}_{2} \mathrm{~b} \therefore \mathrm{x}=\mathrm{M}_{1} \mathrm{y}$

B. Pré-condicionadores de matriz descomposta: $\mathbf{M} \approx \mathbf{A}$
I. (Lado esquerdo)
$\mathrm{M}^{-1} \mathrm{Ax}=\mathrm{M}^{-1} \mathrm{~b}$
II. (Lado direito)
$\mathrm{AM}^{-1} \mathrm{y}=\mathrm{b} \therefore \mathrm{x}=\mathrm{M}^{-1} \mathrm{y}$
III. (Ambos os lados)
$\mathrm{M}_{2}^{-1} \mathrm{AM}_{1}^{-1} \mathrm{y}=\mathrm{M}_{2}^{-1} \mathrm{~b} \therefore \mathrm{x}=\mathrm{M}_{1}^{-1} \mathrm{y}$

A estratégia considerada nesta pesquisa é o pré-condicionamento à esquerda. As outras não serão abordadas em detalhes, apenas em termos de comparação com o pré-condicionamento à esquerda para justificar a opção por esta estratégia. O précondicionamento à esquerda é aplicado da seguinte forma:

$$
M^{-1} A x=M^{-1} b
$$

É gerada uma base ortogonal do subespaço Krylov pré-condicionado a esquerda:

$$
\operatorname{span}\left\{r_{0}, M^{-1} A r_{0}, \ldots,\left(M^{-1} A\right)^{m-1} r_{0}\right\}
$$

Usando o processo modificado de Gram-Schmidt, onde o novo vetor a ser ortogonalizado é obtido do vetor resultante previamente no processo. Todos os vetores residuais e suas normas computadas pelo algoritmo correspondem a resíduos pré-condicionados $\left(\mathrm{Z}_{\mathrm{m}}=\mathrm{M}^{-1}(\mathrm{~b}-\mathrm{Ax} \mathrm{m})\right)$ ao invés dos resíduos originais não précondicionados $\left(\mathrm{b}-\mathrm{Ax}_{\mathrm{m}}\right)$. Além do mais, não existe um fácil acesso a esses resíduos não pré-condicionados, a menos que sejam computados explicitamente, isto é, multiplicando os resíduos pré-condicionados por $\mathrm{M}$. Isto pode ocasionar alguns 
problemas se for desejado que o critério de parada esteja baseado nos resíduos atuais, ao invés dos pré-condicionados.

Numa etapa j do algoritmo GMRES pré-condicionado, o $v_{j}$ prévio é multiplicado por $A$ a fim de se obter um vetor:

$$
\omega_{\mathrm{j}}=A v_{j}
$$

Então esse vetor é pré-condicionado para se obter:

$$
\mathrm{z}_{\mathrm{j}}=\mathrm{M}^{-1} \omega_{\mathrm{j}}
$$

Este vetor deve ser M-ortogonalizado contra todos os $\mathrm{v}_{\mathrm{i}}$ 's prévios. Se o processo padrão de Gram-Schmidt for usado, primeiro se deve computar os produtos internos:

$$
h_{i, j}=\left(z_{j}, v_{i}\right)_{M}=\left(M z_{j}, v_{i}\right)=\left(w_{j}, v_{i}\right), i=1, \ldots, j
$$

e então transformar o vetor $z_{j}$ em um novo vetor:

$$
\hat{z}_{j}:=z_{j}-\sum_{i=1}^{j} h_{i, j} v_{i}
$$

Para completar a etapa de ortonormalização, o $\hat{z}_{j}$ final deve ser normalizado. Devido à ortogonalidade de $\hat{\mathrm{z}}_{\mathrm{j}}$ versus todos os $\mathrm{v}_{\mathrm{i}}$ 's prévios, observe que:

$$
\left(\hat{z}_{j}, \hat{z}_{j}\right)_{M}=\left(z_{j}, \hat{z}_{j}\right)_{M}=\left(M^{-1} \omega_{j}, \hat{z}_{j}\right)_{M}=\left(\omega_{j}, \hat{z}_{j}\right)
$$

Então, a norma-M desejada pode ser obtida da Equação (3.30), através dos seguintes ajustes:

$$
h_{j+1, j}=\left(\hat{z}_{j}, \omega_{j}\right)^{1 / 2} \text { e } v_{j+1}=\hat{z}_{j} / h_{j+1, j}
$$

Uma dificuldade severa associada ao procedimento acima é que o produto interno $\left(\hat{\mathrm{z}}_{\mathrm{j}}, \mathrm{z}_{\mathrm{j}}\right)_{\mathrm{M}}$ computado pela Equação (3.32) pode ser negativo na presença de arredondamento. Existem duas alternativas para contornar esta situação. A norma-M 
pode ser computada explicitamente ao custo de uma multiplicação adicional matrizvetor com $\mathrm{M}$, ou o conjunto de vetores $\mathrm{Mv}_{\mathrm{i}}$ pode ser armazenado a fim de acumular a um baixo custo ambos os vetores $\hat{z}_{j}$ e $M \hat{z}_{j}$, através da equação:

$$
M \hat{z}_{j}=\omega_{j}-\sum_{i=1}^{j} h_{i, j} M v_{i}
$$

A aplicação direta do GMRES na Equação (3.26) resulta na versão pré-condicionada à esquerda, como ilustra a Figura 3.3 -

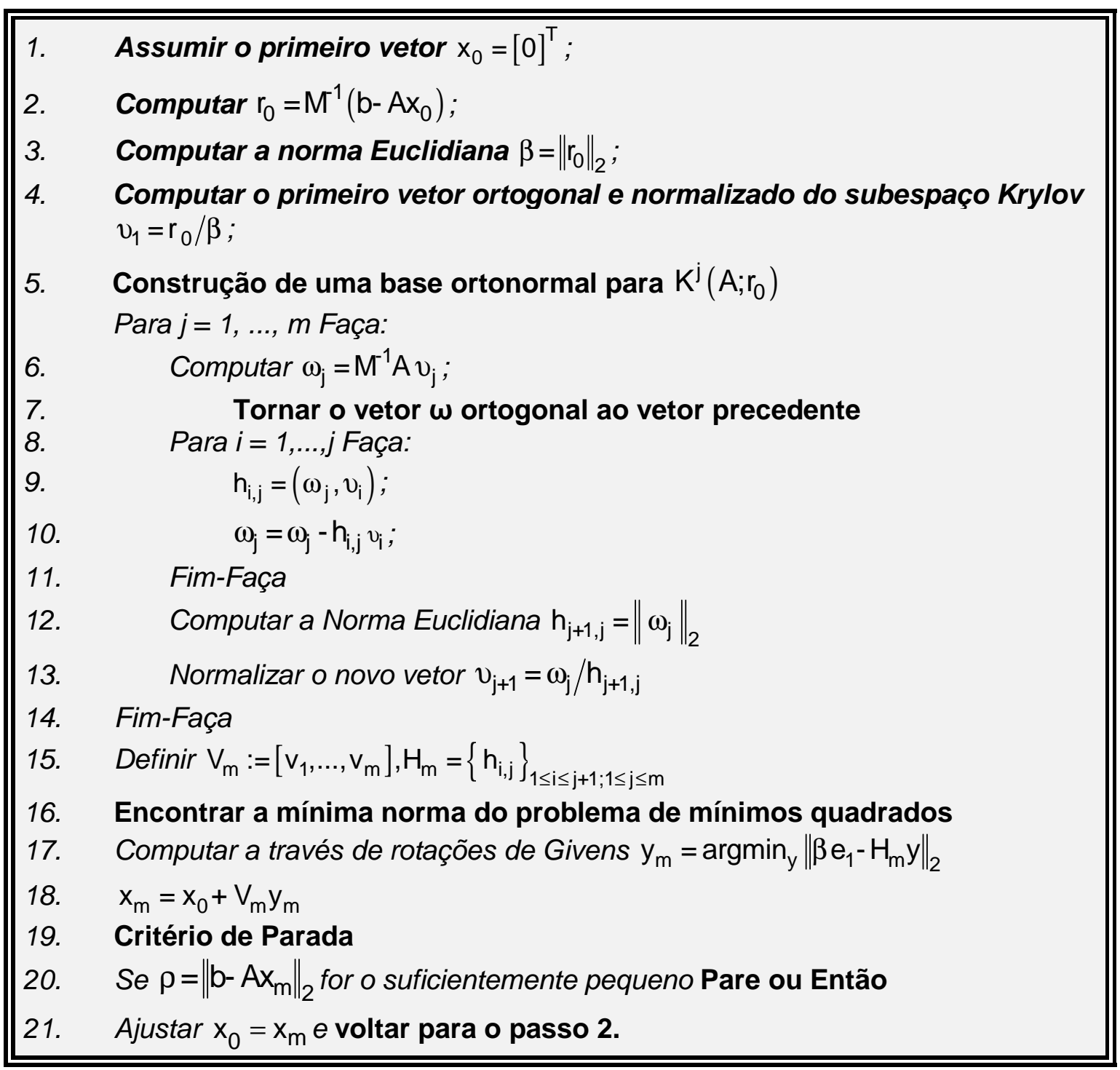

Figura 3.3 - Algoritmo do GMRES Pré-condicionado a esquerda

\section{Comparação entre as opções}


Quando se compara as três opções de pré-condicionamento, nota-se primeiramente que os espectros dos três operadores associados $M^{-1} A, A^{-1}$ e, $M^{-1} A^{-1}$ são idênticos. Portanto, a princípio é esperado que os comportamentos da convergência fossem similares, embora nem sempre os autovalores ditem as regras de convergência (Saad, 2003). No caso do pré-condicionamento à esquerda, o GMRES minimiza a norma residual:

$$
\left\|M^{-1} b-M^{-1} A x\right\|_{2}
$$

Entre todos os vetores do espaço:

$$
x_{0}+K_{m}^{L}=x_{0}+\operatorname{span}\left\{z_{0}, M^{-1} A z_{0}, \ldots,\left(M^{-1} A\right)^{m-1} z_{0}\right\}
$$

Onde $\mathrm{z}_{0}$ é o resíduo inicial pré-condicionado $\mathrm{Z}_{0}=\mathrm{M}^{-1} \mathrm{r}_{0}$. Então, a solução aproximada pode ser expressa como:

$$
x_{m}=x_{0}+M^{-1} s_{m-1}\left(M^{-1} A\right) z_{0}
$$

Onde $\mathrm{S}_{\mathrm{m}-1}$ é o polinômio de grau $\mathrm{m}-1$ que minimiza a norma:

$$
\left\|z_{0}-M^{-1} A s\left(M^{-1} A\right) z_{0}\right\|_{2}
$$

Entre todos os polinômios $s$ de grau $\leq m-1$. Também é possível expressar esta condição de otimização com relação ao vetor residual original $r_{0}$, de fato:

$$
z_{0}-M^{-1} A s\left(M^{-1} A\right) z_{0}=M^{-1}\left[r_{0}-A s\left(M^{-1} A\right) M^{-1} r_{0}\right]
$$

Uma simples manipulação algébrica mostra que para qualquer polinômio $s$ :

$$
s\left(M^{-1} A\right) M^{-1} r=M^{-1} s\left(A M^{-1}\right) r
$$

Obtendo-se a relação: 


$$
z_{0}-M^{-1} A s\left(M^{-1} A\right) z_{0}=M^{-1}\left[r_{0}-A M^{-1} s\left(A M^{-1}\right) r_{0}\right]
$$

Considere agora a situação com o GMRES pré-condicionado à direita. Aqui, é necessário distinguir entre a variável original x e a variável transformada u relacionada à $\mathrm{x}$ por $\mathrm{x}=\mathrm{M}^{-1} \mathrm{u}$. Para a variável $\mathrm{u}$, o GMRES pré-condicionado a direita minimiza a norma-2 de $r=b-A^{-1} u$, onde u pertence $a$ :

$$
u_{0}+K_{m}^{R}=u_{0}+\operatorname{span}\left\{r_{0}, A M^{-1} r_{0}, \ldots,\left(A M^{-1}\right)^{m-1} r_{0}\right\}
$$

No qual $\mathrm{r}_{0}$ é o resíduo $\mathrm{r}_{0}=\mathrm{b}-\mathrm{AM}^{-1} \mathrm{u}_{0}$. Este resíduo é idêntico ao resíduo associado com a variável $x$ original uma vez que $\mathrm{M}^{-1} \mathrm{u}_{0}=\mathrm{x}_{0}$. Multiplicando (3.42) por $\mathrm{M}^{-1} \mathrm{e}$ explorando (3.40), observe que a variável genérica $\mathrm{x}$ associada com um vetor do subespaço (3.42) pertence ao espaço:

$$
M^{-1} u_{0}+M^{-1} K_{m}^{R}=x_{0}+\operatorname{span}\left\{z_{0}, M^{-1} A z_{0}, \ldots,\left(M^{-1} A\right)^{m-1} z_{0}\right\}
$$

Esta última equação é idêntica ao espaço (3.36) visto no pré-condicionamento à esquerda. Em outras palavras, para o GMRES pré-condicionado a direita, a solução aproximada $x$ também pode ser expressa como:

$$
x_{m}=x_{0}+s_{m-1}\left(A M^{-1}\right) r_{0}
$$

Entretanto, agora $\mathrm{s}_{\mathrm{m}-1}$ é um polinômio que minimiza a norma:

$$
\left\|r_{0}-A M^{-1} s\left(A M^{-1}\right) r_{0}\right\|_{2}
$$

Entre todos os polinômios $s$ de grau menor ou igual a $\mathrm{m}-1$. O interessante é notar que as duas quantidades minimizadas, (3.41) e (3.45), diferem apenas por uma multiplicação por $\mathrm{M}^{-1}$. Especificamente, o GMRES pré-condicionado a esquerda minimiza $\mathrm{M}^{-1} \mathrm{r}$, enquanto o pré-condicionamento a esquerda minimiza $r$, onde $r$ é tomado sobre o mesmo subespaço em ambos os casos.

A solução aproximada obtida pelo GMRES pré-condicionado a esquerda, ou direita, tem a forma: 


$$
x_{m}=x_{0}+s_{m-1}\left(M^{-1} A\right) z_{0}=x_{0}+M^{-1} s_{m-1}\left(A M^{-1}\right) r_{0}
$$

Onde $\mathrm{z}_{0}=\mathrm{M}^{-1} \mathrm{r}_{0}$ e $\mathrm{s}_{\mathrm{m}-1}$ é um polinômio de grau . O polinômio $\mathrm{s}_{\mathrm{m}-1}$ minimiza a norma residual $\left\|\mathrm{b}-\mathrm{Ax}_{\mathrm{m}}\right\|_{2}$ no caso do pré-condicionamento à direita, e a norma residual précondicionada $\left\|\mathrm{M}^{-1}\left(\mathrm{~b}-\mathrm{Ax}_{\mathrm{m}}\right)\right\|_{2}$ no caso do pré-condicionamento a esquerda.

Na maioria das situações práticas, a diferença no comportamento da convergência entre as duas formas de pré-condicionamento não é significante. A única exceção é que, quando $\mathrm{M}$ for mal-condicionada, pode levar a diferenças substanciais.

\subsubsection{Experimentos Numéricos}

Este item apresenta resultados de experimentos numéricos envolvendo o GMRES e suas estratégias, incluindo pré-condicionamento, aplicado em sistemas de energia elétrica, envolvendo estudos de fluxo de carga enfatizando a solução do sistema algébrico resultante $(\mathrm{Ax}=\mathrm{b})$. $\mathrm{O}$ objetivo principal é avaliar isoladamente $\mathrm{O}$ desempenho do GMRES sem/com estratégias numéricas conforme descriminadas na oportunidade, sem incluir a solução das EDAs, ou seja, estão excluídas aqui simulações no domínio do tempo. Portanto, os resultados obtidos (número de iterações, norma residual e tempo de CPU) são "cristalinos" permitindo uma avaliação sem interferências. Os sistemas-teste usados são o IEEE30 e IEEE118 (Power, 2007) e a Tabela 3.1 apresenta informações com relação às combinações usadas envolvendo o GMRES. Essas combinações estão divididas em três grupos, assim distribuídos:

> Grupo 1 - GMRES sem pré-condicionamento, sem/com estratégias.

> Grupo 2 - GMRES com pré-condicionamento ILU(0), sem/com estratégias.

$>$ Grupo 3 - GMRES com pré-condicionamento ILUT $(\rho, \tau)$, sem/com estratégias.

As simulações do Grupo I se caracterizam pela falta do pré-condicionamento do sistema, incluindo em seguida estratégias de reinicialização e diferenças de quocientes. $\mathrm{O}$ uso dessas estratégias objetiva diminuir os requisitos de armazenagem de memória e de tempo computacional restringindo o número de iterações lineares quando o processo de reinicialização é considerado. Já as simulações do Grupo II contêm o pré-condicionamento do sistema original usando a fatoração incompleta LU (ILU(0)), além das estratégias de reinicialização e diferenças de quocientes; o pré- 
condicionamento, teoricamente, torna a solução do novo sistema mais "amigável" à medida que o pré-condicionador se aproximar da matriz Jacobiana $f\left(x_{k}\right)^{-1}$. As simulações do Grupo III utilizam um pré-condicionamento baseado em fatoração incompleta LU com estratégias de eliminação de elementos não-nulos por magnitude ou por posição $(\operatorname{ILUT}(\rho, \tau))$. Também são utilizadas as estratégias de reinicialização e diferenças de quocientes.

Tabela 3.1 - Descrição dos experimentos numéricos do GMRES e suas estratégias

\begin{tabular}{|c|c|c|}
\hline Grupo & Estratégia & Descrição \\
\hline \multirow{4}{*}{ I } & 1 & GMRES simples \\
\hline & 2 & GMRES sem pré-condicionamento; apenas com reinicialização \\
\hline & 3 & $\begin{array}{l}\text { GMRES sem pré-condicionamento; apenas com diferença de } \\
\text { quocientes }\end{array}$ \\
\hline & 4 & $\begin{array}{l}\text { GMRES sem pré-condicionamento com reinicialização e diferença de } \\
\text { quocientes }\end{array}$ \\
\hline \multirow{4}{*}{ II } & 5 & GMRES com apenas pré-condicionamento ILU(0) \\
\hline & 6 & GMRES com pré-condicionamento ILU(0) com reinicialização \\
\hline & 7 & GMRES com pré-condicionamento ILU(0) com diferença de quocientes \\
\hline & 8 & $\begin{array}{l}\text { GMRES com pré-condicionamento ILU(0) com reinicialização e } \\
\text { diferença de quocientes }\end{array}$ \\
\hline \multirow{4}{*}{ III } & 9 & GMRES com apenas pré-condicionamento ILUT $(\rho, \tau)$ \\
\hline & 10 & GMRES com pré-condicionamento ILUT $(\rho, \tau)$ com reinicialização \\
\hline & 11 & $\begin{array}{l}\text { GMRES com pré-condicionamento ILUT }(\rho, \tau) \text { com diferença de } \\
\text { quocientes }\end{array}$ \\
\hline & 12 & $\begin{array}{l}\text { GMRES com pré-condicionamento ILUT }(\rho, \tau) \text { com reinicialização e } \\
\text { diferença de quocientes }\end{array}$ \\
\hline
\end{tabular}

\subsubsection{Sistema-Teste de 30 barras (IEEE30)}

A Tabela 3.2 apresenta os parâmetros selecionados para o algoritmo GMRES. Os critérios de seleção de seus respectivos valores estão baseados em estratégias associadas com o algoritmo (reinicialização, diferença de quocientes e précondicionamento), e também a partir de informações da literatura especializada (Saad, 2003; Van der Vorst, 2003). Entretanto, estes critérios de escolha ainda estão sob investigação. Não se pode afirmar que estes correspondem aos valores ótimos para os propósitos aqui estabelecidos, ou seja, os melhores em termos de eficiência computacional. A Tabela 3.3 ilustra através de gráficos os parâmetros de interesse referentes aos testes envolvendo o sistema IEEE30. Note que o eixo z corresponde 
aos métodos considerados. A Figura 3.4 apresenta o diagrama unifilar do sistemateste IEEE30.

Tabela 3.2 - Definição de parâmetros para o algoritmo GMRES - IEEE30

\begin{tabular}{|c|c|c|c|c|c|c|c|c|c|c|c|c|}
\hline \multirow{2}{*}{$\begin{array}{c}\text { Grupos de } \\
\text { Experimento }\end{array}$} & \multicolumn{4}{|c|}{ Grupo I } & \multicolumn{4}{|c|}{ Grupo II } & \multicolumn{4}{|c|}{ Grupo III } \\
\hline & 1 & 2 & 3 & 4 & 5 & 6 & 7 & 8 & 9 & 10 & 11 & 12 \\
\hline ITKR & 60 & 60 & 60 & 60 & 60 & 5 & 60 & 5 & 60 & 5 & 60 & 5 \\
\hline VORT & 60 & 60 & 60 & 60 & 60 & 5 & 60 & 5 & 60 & 5 & 60 & 5 \\
\hline TITL & 0.01 & 0.01 & 0.01 & 0.01 & 0.01 & 0.01 & 0.01 & 0.01 & 0.01 & 0.01 & 0.01 & 0.01 \\
\hline M & 0 & 20 & 0 & 20 & 0 & 20 & 0 & 20 & 0 & 20 & 0 & 20 \\
\hline$\rho$ & -- & -- & -- & -- & -- & -- & -- & -- & 3 & 3 & 3 & 3 \\
\hline$\tau$ & -- & -- & -- & -- & -- & -- & -- & -- & 0.01 & 0.01 & 0.01 & 0.01 \\
\hline $\begin{array}{l}\text { ITKR } \\
\text { VORT } \\
\text { TITL } \\
m \\
\rho \\
\tau\end{array}$ & $\begin{array}{l}\text { Núme } \\
\text { Vetore } \\
\text { Tolerâ } \\
\text { Núme } \\
\text { Núme } \\
\text { Valor }\end{array}$ & $\begin{array}{l}\text { o de iter } \\
\text { usados } \\
\text { cia utiliz } \\
\text { o de rein } \\
\text { o de ele } \\
\text { aferên }\end{array}$ & $\begin{array}{l}\text { ções lin } \\
\text { na orto } \\
\text { ada no } \\
\text { cializaç } \\
\text { eentos n } \\
\text { para ca }\end{array}$ & $\begin{array}{l}\text { eares. } \\
\text { onalizas } \\
\text { ritério de } \\
\text { es. } \\
\text { ão-nulos } \\
\text { fcelar v }\end{array}$ & $\begin{array}{l}\text { ão de no } \\
\text { parada } \\
\text { permitic } \\
\text { lores pe }\end{array}$ & $\begin{array}{l}\text { vos veto } \\
\text { do proce } \\
\text { os. } \\
\text { quenos. }\end{array}$ & $\begin{array}{l}\text { res base } \\
\text { sso } \mathrm{GM}\end{array}$ & SES. & & & & \\
\hline
\end{tabular}

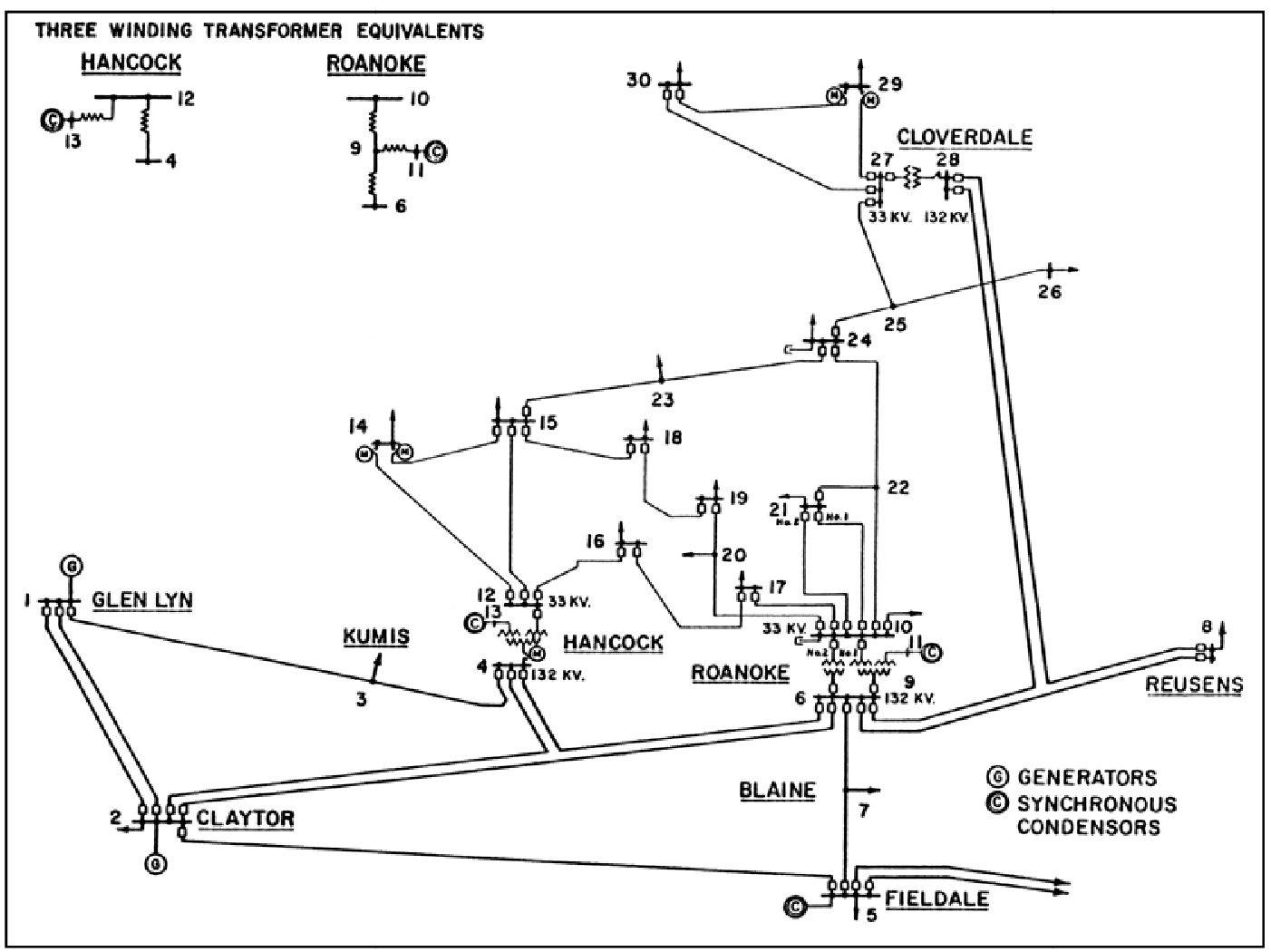

Figura 3.4 - Diagrama unifilar do sistema-teste IEEE30 (Power, 2007) 
Tabela 3.3 - Resultados das simulações - Sistema IEEE30
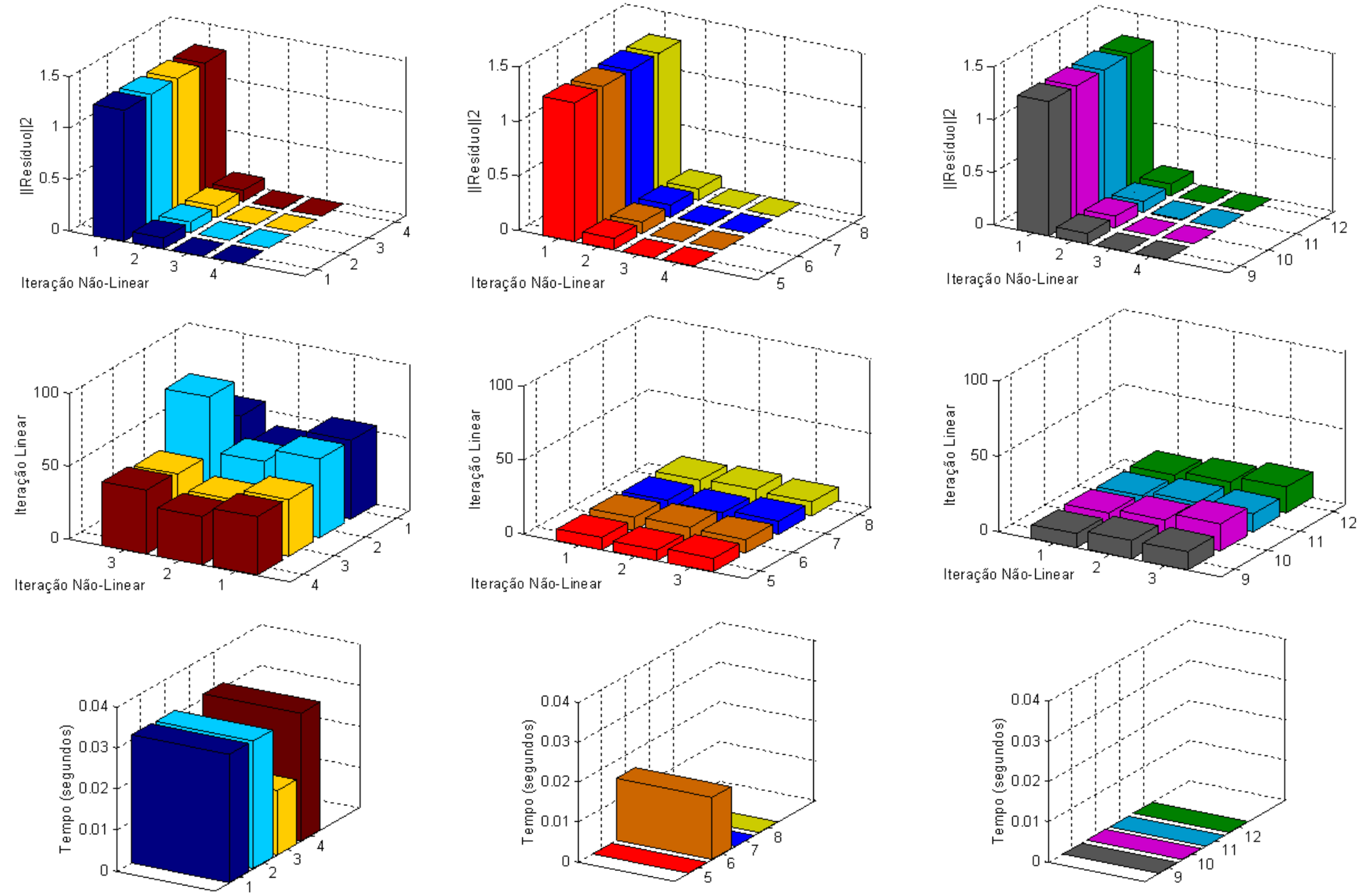


\section{A. Análise dos Resultados - Grupo I (sem pré-condicionamento)}

\section{Resíduos}

$\checkmark$ Todas as estratégias atingiram seus objetivos com relação a norma residual mínima, como esperado.

\section{Número de Iterações Lineares e Tempo de CPU}

$\checkmark$ Entre todas as estratégias consideradas nesse grupo, a 2 (apenas técnica de reinicialização) é a que apresenta o maior número de iterações lineares, inclusive se comparada ao GMRES sem qualquer tipo de estratégia (1). Esse é um dos riscos associados a reinicialização, como comentado anteriormente.

$\checkmark$ Já a estratégia 3 usando apenas a técnica de diferença de quocientes apresenta o menor número de iterações lineares, como também o menor tempo de CPU. A estratégia 4 considera as técnicas de reinicialização e diferença de quocientes, mantendo inalterado o número de iterações lineares em relação a estratégia 3.

\section{B. Análise dos Resultados - Grupo 2 (com pré-condicionamento ILU(0))}

\section{Resíduos}

$\checkmark$ Todas as estratégias atingiram seus objetivos com relação a norma residual mínima, como esperado.

\section{Número de lterações Lineares e Tempo de CPU}

Dentro do mesmo grupo, nota-se uma ligeira diferença entre o número de iterações lineares, quase que imperceptível.

$\checkmark$ O tempo de CPU gasto pelas estratégias 5,7 e 8 é muito pequeno. $\mathrm{O}$ tempo gasto pela estratégia 6 foi elevado em comparação aos demais, mostrando mais uma vez a influência inadequada da reinicialização.

\section{Análise dos Resultados - Grupo 3 (com pré-condicionamento ILUT( $\rho, \tau)$ )}

\section{Resíduos}

$\checkmark$ Todas as estratégias atingiram seus objetivos com relação à norma residual mínima, como esperado. 


\section{Número de Iterações Lineares e Tempo de CPU}

Nota-se uma pequena diferença entre o número de iterações lineares, diferença essa que não se reflete no tempo de CPU, onde todos são muito pequenos.

\section{Análise Comparativa}

A Figura 3.5 e Figura 3.6 ilustram o desempenho dos melhores métodos de cada grupo em função do número de iterações e do tempo de CPU, respectivamente. Notase que é difícil apontar qual o melhor. Entretanto, pode-se descartar a estratégia 3 uma vez que o número de iterações e o tempo de CPU são elevados em comparação aos demais. Como os tempos de CPU são iguais, o número de iterações passa a ser a opção de escolha, e neste caso as estratégias 5 e 7 apresentaram melhor desempenho.

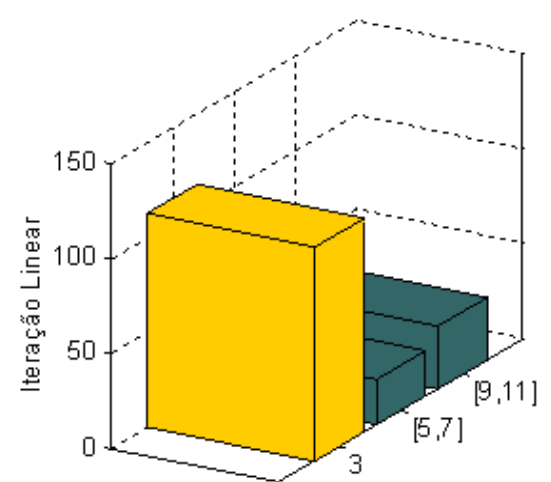

Figura 3.5 - Melhores desempenhos em termos de número de iterações - IEEE30

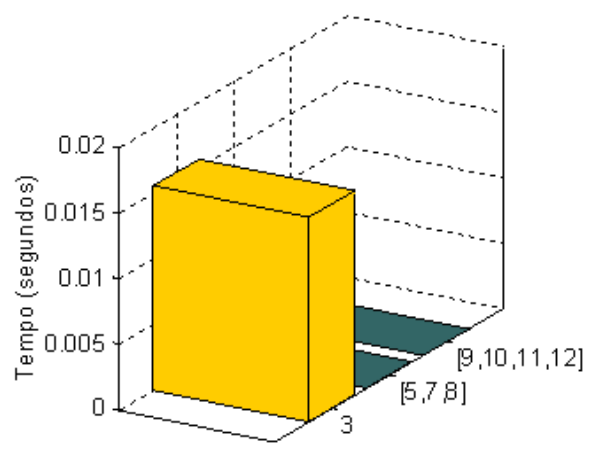

Figura 3.6 - Melhores tempos de CPU IEEE30

\subsubsection{Sistema-Teste de 118 barras (IEEE118)}

A Tabela 3.4 apresenta os parâmetros selecionados para o algoritmo GMRES. Os critérios de seleção de seus respectivos valores são os mesmos do sistema-teste IEEE30. A Figura 3.7 apresenta o diagrama unifilar do sistema-teste IEEE30

Embora os objetivos aqui sejam os mesmos que os associados ao sistema de 30 barras, este de 118 apresenta algumas características pouco amigáveis (abordadas no Capítulo 4) podendo dificultar a processo de solução, independentemente se o estudo 
é em regime permanente ou dinâmico. Isto é um bom sinal uma vez se deseja também avaliar a robustez da técnica iterativa.

Tabela 3.4 - Definição de parâmetros para o algoritmo GMRES - IEEE118

\begin{tabular}{|c|c|c|c|c|c|c|c|c|c|c|c|c|}
\hline \multirow{2}{*}{$\begin{array}{c}\text { Grupos de } \\
\text { Experimento }\end{array}$} & \multicolumn{4}{|c|}{ Grupo I } & \multicolumn{4}{|c|}{ Grupo II } & \multicolumn{4}{|c|}{ Grupo III } \\
\hline & 1 & 2 & 3 & 4 & 5 & 6 & 7 & 8 & 9 & 10 & 11 & 12 \\
\hline ITKR & 236 & 236 & 236 & 50 & 236 & 8 & 236 & 8 & 236 & 8 & 236 & 8 \\
\hline VORT & 236 & 236 & 236 & 50 & 236 & 8 & 236 & 8 & 236 & 8 & 236 & 8 \\
\hline TITL & 0.01 & 0.01 & 0.01 & 0.01 & 0.01 & 0.01 & 0.01 & 0.01 & 0.01 & 0.01 & 0.01 & 0.01 \\
\hline m & 0 & 20 & 0 & 20 & 0 & 20 & 0 & 20 & 0 & 20 & 0 & 20 \\
\hline$\rho$ & -- & -- & -- & -- & -- & -- & -- & -- & 4 & 4 & 4 & 4 \\
\hline$\tau$ & -- & -- & -- & -- & -- & -- & -- & -- & 0.01 & 0.01 & 0.01 & 0.01 \\
\hline $\begin{array}{l}\text { ITKR } \\
\text { VORT } \\
\text { TITL } \\
m \\
\rho \\
\tau\end{array}$ & $\begin{array}{l}\text { Númerc } \\
\text { Vetores } \\
\text { Tolerân } \\
\text { Númerc } \\
\text { Númerc } \\
\text { Valor re }\end{array}$ & $\begin{array}{l}\text { o de itera } \\
\text { susados } \\
\text { cia utiliz } \\
\text { o de rein } \\
\text { o de elen } \\
\text { fererencia }\end{array}$ & $\begin{array}{l}\text { acões lin } \\
\text { na orto } \\
\text { ada no } \\
\text { icializaç } \\
\text { nentos } \\
\text { para ca }\end{array}$ & $\begin{array}{l}\text { eares. } \\
\text { jonalizac } \\
\text { ritério de } \\
\text { zes. } \\
\text { âo-nulos } \\
\text { ncelar }\end{array}$ & $\begin{array}{l}\text { parada } \\
\text { ermitid } \\
\text { bres pe }\end{array}$ & $\begin{array}{l}\text { do proce } \\
\text { os. } \\
\text { quenos. }\end{array}$ & $\begin{array}{l}\text { res base } \\
\text { sso GM }\end{array}$ & SES. & & & & \\
\hline
\end{tabular}

A Tabela 3.5 ilustra através de gráficos os parâmetros de interesse referentes aos testes envolvendo o sistema IEEE118. Note que o eixo z corresponde aos métodos considerados. 


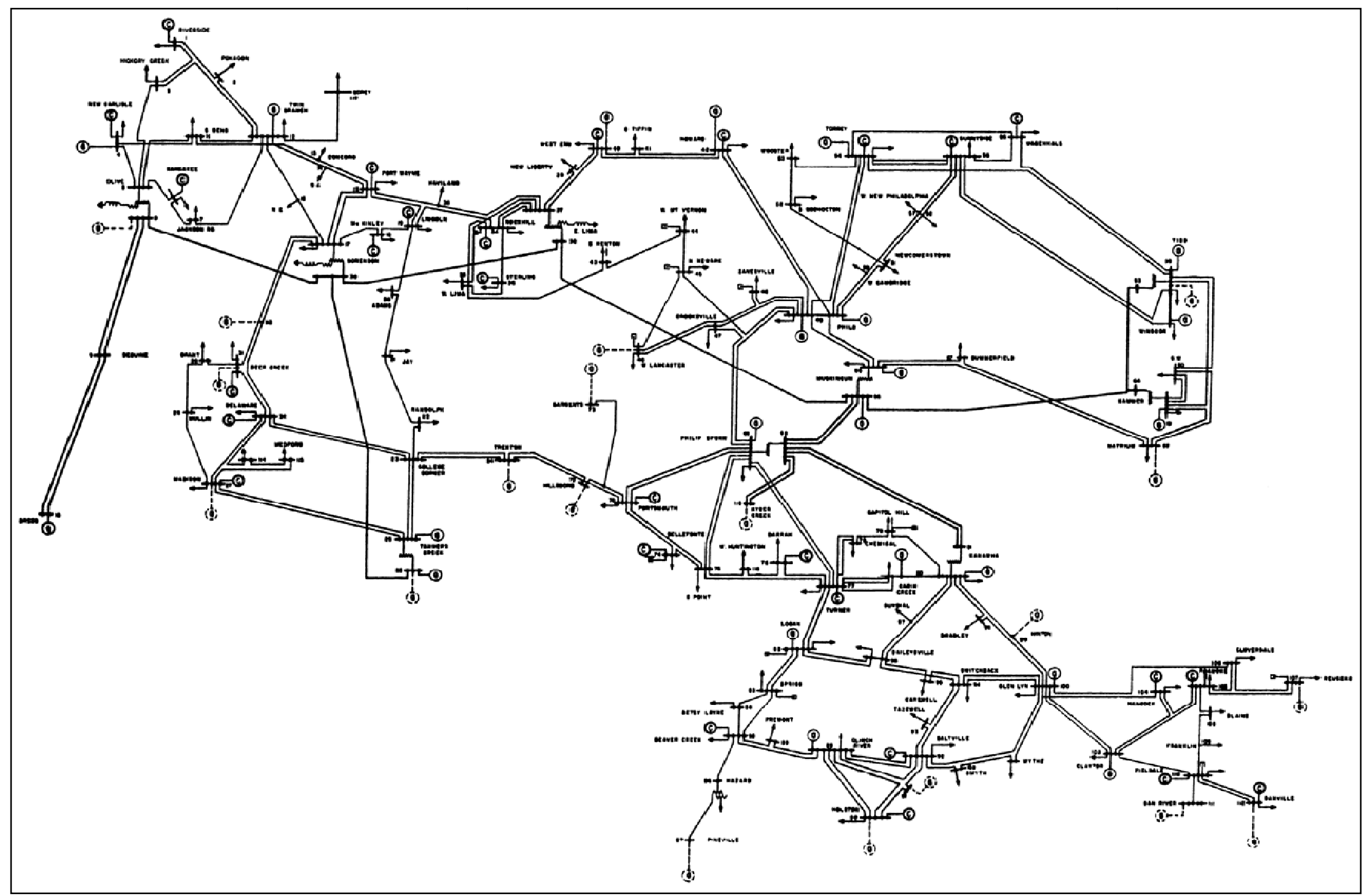

Figura 3.7 - Diagrama unifilar do sistema-teste IEEE118 (Power, 2007) 
Tabela 3.5 - Resultados das simulações - Sistema IEEE118
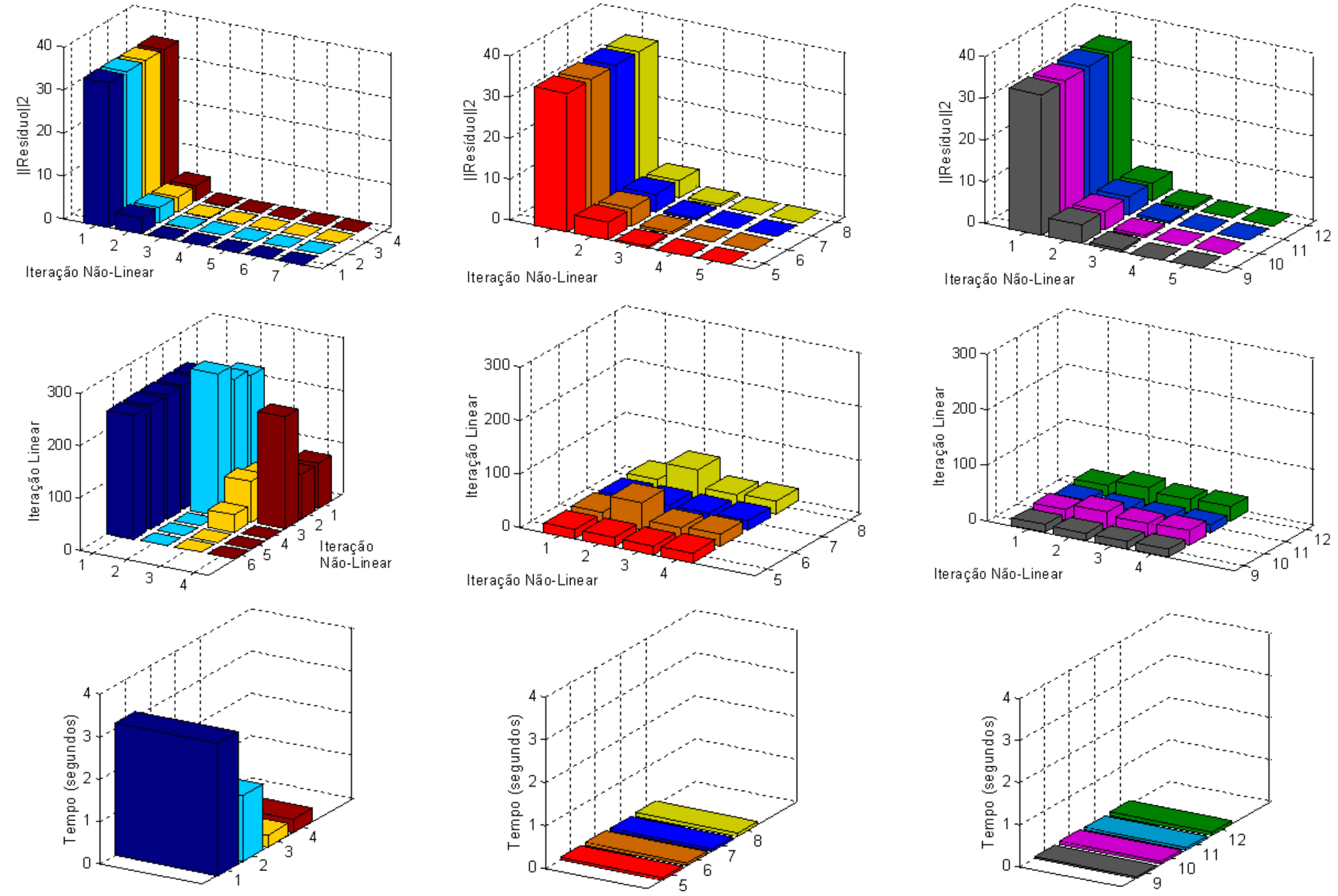


\section{A. Análise dos Resultados - Grupo 1 (sem pré-condicionamento)}

\section{Resíduos}

$\checkmark$ Todas as estratégias atingiram seus objetivos com relação a norma residual mínima, como esperado.

\section{Número de Iterações Lineares e Não-Lineares}

$\checkmark$ A estratégia 1 explora ao máximo o número de iterações lineares na tentativa de atingir o critério de convergência estabelecido, resultando em resíduos muito próximos da tolerância especificada. Como consequência tem-se um maior número de iterações não-lineares, conforme é visualizado no gráfico de Resíduos.

$\checkmark$ Já a estratégia 3 com diferenças de quocientes gera boas aproximações quando a operação matriz-vetor é solicitada, resultando em poucas iterações lineares, se comparada a estratégia 1, onde a matriz Jacobiana é construída e operada explicitamente. Embora ambas as estratégias forneçam resíduos muitos próximos dos estabelecidos no critério de convergência linear, a estratégia 3 economiza $70 \%$ aproximadamente das iterações disponíveis para tal fim.

$\checkmark$ As estratégias 2 e 4 usam reinicialização e satisfazem a tolerância estabelecida com um número maior de iterações lineares em comparação as estratégias 1 e 3.

\section{Tempo de CPU}

Como esperado, os menores tempos de CPU estão associados às estratégias 3 e 4 em função do menor número de iterações lineares, embora a estratégia 3 não tenha atingido estritamente o critério de convergência linear especificado.

\section{B. Análise dos Resultados - Grupo 2 (com pré-condicionamento ILU(0))}

\section{Resíduos}

$\checkmark$ Todas as estratégias atingiram seus objetivos com relação a norma residual mínima, como esperado. 


\section{Número de Iterações Lineares e Não-Lineares}

Observa-se, como no caso do sistema-teste IEEE30, a influência positiva do pré-condicionamento reduzindo drasticamente o número de iterações lineares exigidas. Destacam-se aqui as estratégias 5 e 7 com um número total de 68 iterações cada. A estratégia 7 aplica satisfatoriamente a técnica de diferença de quocientes.

$\checkmark$ Mais uma vez a técnica de reinicialização empregada nas estratégias 6 e 8 aumenta o número de iterações lineares. Embora seja pequeno o número extra de iterações lineares correspondente a cada iteração não-linear, observa-se uma diferença de aproximadamente $300 \%$ quando a $2 \mathrm{a}$ iteração não-linear é executada, esse pode ser um problema clássico de estagnação resultante da reinicialização.

\section{Tempo de CPU}

$\checkmark$ Como esperado, os menores tempos de CPU estão associados às estratégias 5 e 7 em função do menor número de iterações lineares.

\section{Análise dos Resultados - Grupo 3 (com pré-condicionamento ILUT( $(\rho, \tau)$ )}

\section{Resíduos}

$\checkmark$ Todas as estratégias atingiram seus objetivos com relação a norma residual mínima, como esperado.

\section{Número de Iterações Lineares e Não-Lineares.}

Observa-se a redução no número de iterações lineares quando o précondicionamento é considerado e quando comparado aos casos do Grupo II usando o pré-condicionador ILUO. Mais uma vez as simulações sem reinicialização apresentam os melhores resultados, como no caso das estratégias 9 e 11 com 54 iterações lineares associadas, sendo que a estratégia 11 aplica a técnica de diferença de quocientes. O fenômeno da estagnação também está associado as estratégias 10 e 12, resultado da reinicialização. 


\section{Tempo de CPU}

Embora a diferença entre os tempos de CPU seja muito pequena, resultado da pequena quantidade de iterações lineares executadas, a estratégia 9 é a que apresenta o menor tempo.

\section{Análise Comparativa}

As Figura 3.8 e Figura 3.9 ilustram o desempenho dos melhores métodos de cada grupo em função do número de iterações e do tempo de CPU, respectivamente. A estratégia 9 parece ser superior as demais, embora a diferença seja muito pequena, tanto no número global de iterações quanto no tempo de CPU (exceto a estratégia 3).

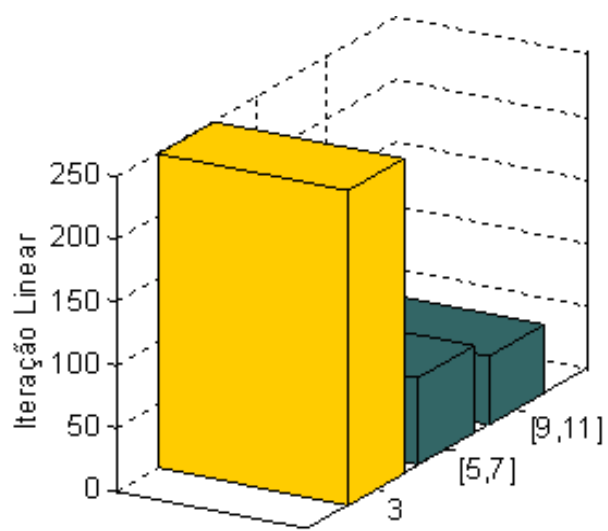

Figura 3.8 - Melhores desempenhos em termos de número de iterações - IEEE118

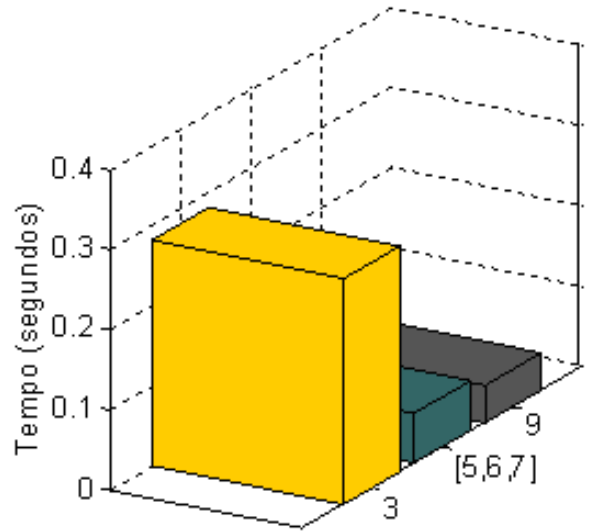

Figura 3.9 - Melhores tempos de CPU IEEE118

\subsubsection{Comentários Finais}

Destacam-se alguns pontos interessantes associados aos resultados dos testes computacionais (apenas em regime-permanente - fluxo de carga) envolvendo os sistemas de energia elétrica IEEE30 e IEEE118. Estes são:

> Técnicas de pré-condicionamento são primordiais para aumentar a eficiência da solução, principalmente no aspecto computacional;

> Diferença de quocientes é uma estratégia que por si só melhora a eficiência da solução, devendo, portanto, ser considerada sempre que possível; 
> Estratégias que fazem uso da técnica de re-inicialização estão sujeitas ao fenômeno conhecido como estagnação, associado ao aumento no número de iterações lineares. Embora nos testes realizados este fenômeno não tenha comprometido o tempo de CPU, pelo menos aparentemente, não se pode afirmar a priori que isto sempre ocorrerá. Não se pode garantir esta "imparcialidade" para sistemas de grande-porte.

> Vários parâmetros matemáticos (Tabela 3.2 e Tabela 3.4) estão associados à estratégia considerada e o critério de seleção desses parâmetros foi baseado em informações da literatura. A bibliografia consultada foi unânime em afirmar que escolhas adequadas estão associadas a experiência do usuário e a classe do problema sob investigação. 


\section{Experimentos Numéricos}

\subsection{Introdução}

Este capítulo apresenta experimentos numéricos que verificam a robustez e a eficiência do BDF-GMRES em estudos de estabilidade de sistemas de energia elétrica, utilizando-se dois sistemas-teste, um hipotético (IEEE-118 Barras) e outro real (Norte-Nordeste Brasileiro). Todos os experimentos foram realizados num computador pessoal (Notebook Intel core 2 - $2.00 \mathrm{GHz} ; 1 \mathrm{~GB}$ - RAM). O FORTRAN (Digital Visual FORTRAN) foi a linguagem computacional usada com compilador Compaq otimizado e fez-se uso parcial de recursos do solucionador DASPK2.0 de domínio público (http://www.cs.ucsb.edu/ cse/) em todos os experimentos.

O solucionador foi implementado em um programa computacional desenvolvido para sistemas multi-máquinas cobrindo desde simples configurações, até sistemas mais complexos incluindo diversos dispositivos de controle. A fim de capturar os efeitos relevantes aos fenômenos de estabilidade de curta e de longa duração, são considerados os seguintes modelos, cujos diagramas de blocos estão presentes no Apêndice B: Máquina Síncrona - Modelos Clássico e IV (representa os efeitos transitórios, sub-transitórios, de campo, amortecimento e saturação), Regulador Automático de Tensão, Sinais Estabilizadores, Limitador de Sobre-excitação, Transformador de Tape Variável (contínuo), Acréscimo linear de carga, Carga estática polinomial (parcela de potência, corrente e impedância constante), Carga dinâmica tipo potência constante.

É necessária uma forma de comunicação a fim de enviar e receber informações relevantes para o solucionador sobre o problema a ser resolvido. Para este fim, foi desenvolvido um sistema-gerenciador para entrada/saída de informações para análise de fenômenos de estabilidade, ilustrado na Figura 4.1 


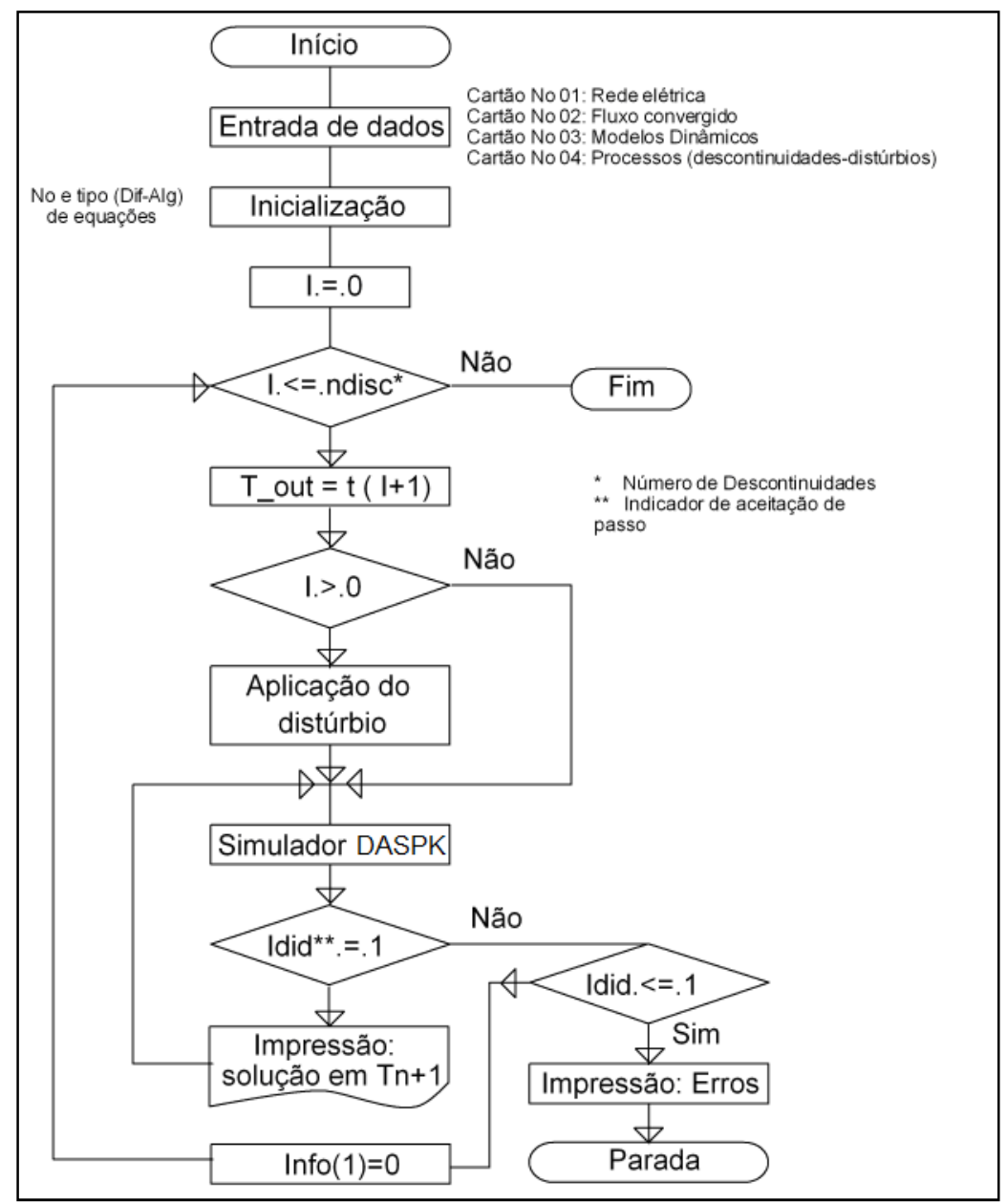

Figura 4.1 - Fluxograma do Gerenciador do protótipo computacional

Com relação aos dados de entrada/saída para/do solucionador, as seguintes informações são pertinentes:

- O usuário define o sistema de equações diferenciais e algébricas através de uma sub-rotina externa, bem como o número de equações a serem resolvidas.

- Informações com relação às descontinuidades podem ser fornecidas pelo usuário, ou geradas internamente.

- Tolerâncias relativas e absolutas também são fornecidas pelo usuário para indicar a precisão desejada para a solução (diferencial e algébrica). Podem ser tanto escalares ou vetores e devem ser definidas como variáveis porque podem ser trocadas pelo solver. As tolerâncias são usadas pelo solver para teste local de erro em cada intervalo.

- $\quad$ O código disponibiliza a opção para o usuário de fornecer a matriz de derivadas parciais do sistema de equações diferenciais através de uma sub-rotina externa. 
- Se a matriz não for fornecida, o solucionador aproxima a solução através de uma diferença numérica, que, algumas vezes, é menos trabalhoso do que avaliar as derivadas na matriz correspondente, e algumas vezes não é. Isto depende do problema sendo resolvido.

\subsection{Considerações Gerais}

Antes de apresentar os experimentos numéricos, é necessário determinar os parâmetros ótimos dos pré-condicionadores e do $\operatorname{GMRES}(\mathrm{m})$. A estratégia considerada aqui está baseada em várias simulações com os sistemas-teste de interesse (10-Barras (Kundur, 1994), IEEE 118 barras e Norte-Nordeste Brasileiro) e usou-se o tempo de CPU como critério de seleção, ou seja, quanto menor, melhor. Laços de programação tornaram a procura inexpressiva em termos de esforço computacional e os resultados estão informados a cada experimento. Os dados de simulação associados aos métodos numéricos estão presentes no Apêndice $C$ e aos sistemas-teste no Apêndice D. Com relação aos sistemas de EDAs, tem se que:

- O sistema de EDAs é formulado na forma semiexplícita.

- O índice do sistema de EDAs é igual a 1.

- O problema é descrito como sendo rígido: as constantes de tempo dos diferentes processos variam em um amplo intervalo - desde dezenas de milissegundos associados aos fenômenos de curta-duração até centenas de segundos associados aos de longa-duração.

Com relação à matriz Jacobiana: quando atualizá-la e/ou o pré-condicionador?

- Baixa taxa de convergência.

- Ocorre grande mudança de passo de integração.

- Não se obtém convergência em 4 iterações.

- Ocorrem grandes descontinuidades nas equações do sistema. 


\subsection{Experimentos}

\subsubsection{Experimento Numérico I}

O objetivo deste primeiro conjunto de experimentos é fazer uma avaliação inicial do desempenho do método GMRES em análises no domínio do tempo, além de se verificar a necessidade de considerar estratégias para melhorar seu desempenho. Para tal, foi considerado um sistema hipotético de energia elétrica de 10 Barras (Figura 4.2) retirado da referência (Kundur, 1994), contendo 3 geradores, diversos dispositivos de controle (Reguladores de tensão, Limitador de sobreexcitação e transformador de tape variável). Esses experimentos foram realizados de acordo com as informações da Tabela 4.1 e comparados com os resultados obtidos pelo programa computacional ANATEM, versão V09-12/05 (Anatem, 2000), para fins de validação da solução do problema via GMRES(m) e das estratégias de pré-processamento da matriz Jacobiana, visto que o pré-condicionador é construído a partir desta. Este programa utiliza o trapezoidal implícito com passo fixo para algebrização das equações diferenciais e soluciona as equações lineares através do método direto fatoração LU. Já a Tabela 4.2 informa os dados numéricos associados às equações diferenciais ordinárias (EDO) e algébricas (EA) do problema. A Tabela 4.3 descreve o evento simulado.

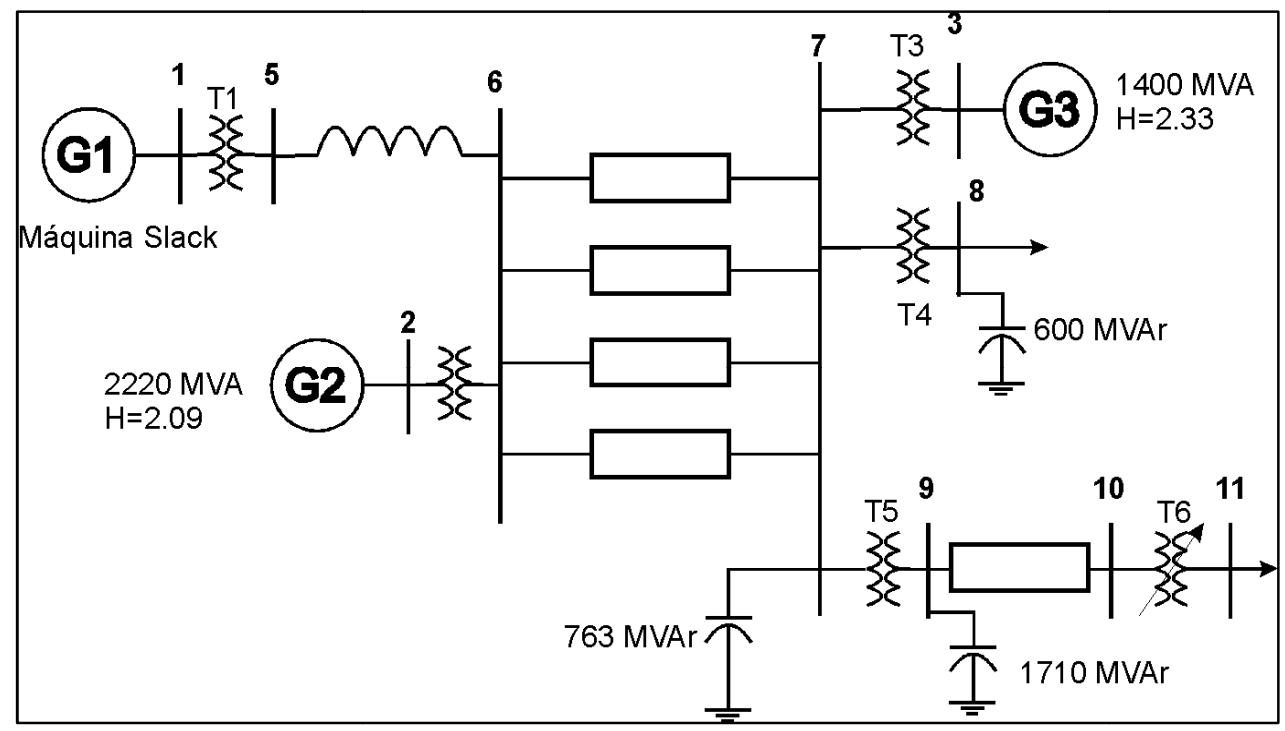

Figura 4.2 - Sistema-teste do Experimento I (Kundur, 1994) 
Tabela 4.1 - Dados sobre as simulações do Experimento I

\begin{tabular}{|c|c|c|c|}
\hline Caso & Método & Pré-condicionador & Pré-processamento \\
\hline (a) & GMRES-(0) & - & - \\
\hline (b) & GMRES-(5)* & - & - \\
\hline (c) & GMRES-(5) & ILUT $(0,02 ; 5)$ & Reordenamento - RCM \\
\hline (d) & GMRES-(5) & ILUT $(0,02 ; 5)$ & $\begin{array}{l}\text { Escalonamento } \\
\text { Normalização - Euclidiana } \\
\text { Reordenamento - RCM }\end{array}$ \\
\hline
\end{tabular}

*10\% do total aproximado do número de equações diferenciais e algébricas (40)

Tabela 4.2 - Dados sobre as equações diferenciais ordinárias (EDO) e algébricas (EA) do Experimento I

\begin{tabular}{|c|c|c|}
\hline EDO & EA & Total (EDAs) \\
\hline 16 & 22 & 38 \\
\hline
\end{tabular}

Tabela 4.3 - Lista de contingências do Experimento I

\begin{tabular}{|l|c|c|c|}
\hline Evento & $\begin{array}{l}\text { Barra } \\
\text { De-Para }\end{array}$ & Circuito & $\begin{array}{l}\text { Instante do } \\
\text { distúrbio (s) }\end{array}$ \\
\hline Desconexão de linha & $6-7$ & 1 & 1,0 \\
\hline Final da Simulação & & & 100,0 \\
\hline
\end{tabular}

A Figura 4.3(a) e Figura 4.3(b) ilustram, respectivamente, a estrutura original da matriz Jacobiana e após a fatoração incompleta (ILU) e reordenada (RCM), este último com os elementos não-nulos confinados numa determinada região. Já a Tabela 4.4 informa os resultados dos experimentos numéricos.

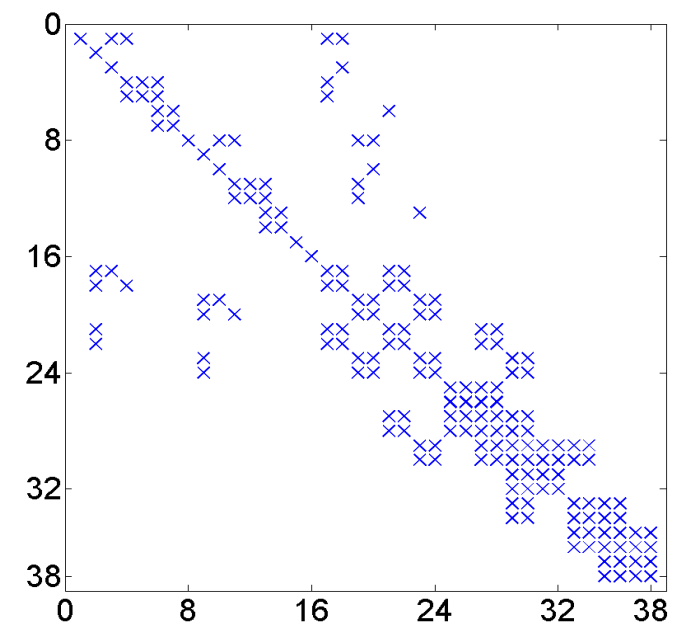

a) Estrutura Original

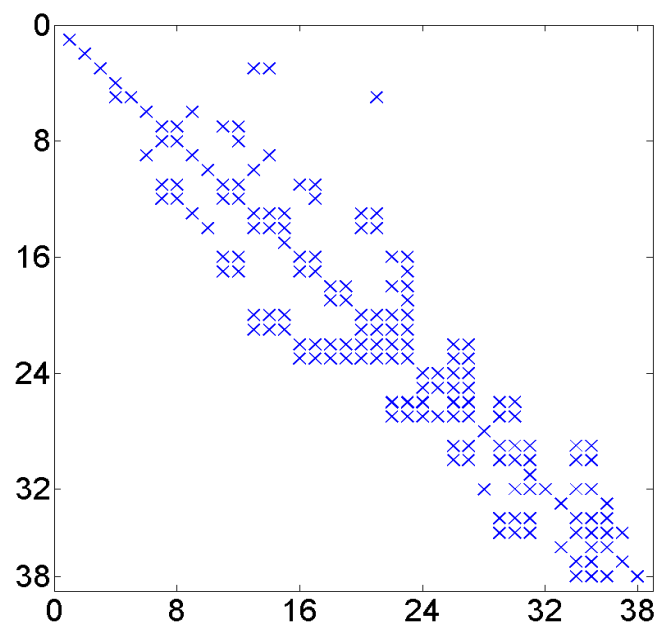

b) Fatorada ILU com reordenamento RCM

Figura 4.3 - Estrutura da Matriz Jacobiana - Sistema-teste de 10 Barras 
Tabela 4.4 - Dados associados aos resultados do Experimento I

\begin{tabular}{|c|c|c|c|c|c|c|}
\hline Casos & $\begin{array}{l}\text { Passos de } \\
\text { integração }\end{array}$ & $\begin{array}{l}\text { Avaliação } \\
\text { das EDAs }\end{array}$ & $\begin{array}{l}\text { Iterações } \\
\text { não- } \\
\text { lineares }\end{array}$ & $\begin{array}{l}\text { Avaliação da } \\
\text { Jacobiana }^{1}\end{array}$ & $\begin{array}{c}\text { Tempo } \\
\text { CPU }\end{array}$ & $\begin{array}{l}\text { Tempo } \\
\text { Relógio }^{2}\end{array}$ \\
\hline ANATEM & 60000 & -- & 60000 & 60000 & $1.05 \mathrm{~s}$ & $1.48 \mathrm{~s}$ \\
\hline Caso (a) & \multicolumn{6}{|c|}{ FALHOU } \\
\hline Caso (b) & \multicolumn{6}{|c|}{ FALHOU } \\
\hline Caso (c) & \multicolumn{6}{|c|}{ FALHOU } \\
\hline Caso (d) & 513 & 2109 & 1016 & 51 & $5.13 \mathrm{~s}$ & $4.96 \mathrm{~s}$ \\
\hline
\end{tabular}

As informações da Tabela 4.4 mostram a superioridade do método direto (ANATEM) em relação ao GMRES, neste experimento, em termos de robustez e eficiência computacional, já que solucionou o problema em um menor tempo de CPU. O método iterativo foi capaz de solucionar apenas quando o GMRES foi pré-condicionado e todas as etapas de pré-processamento da matriz Jacobiana foram executadas (Caso d). A melhoria das características da matriz Jacobiana pode ser comprovada através da Tabela 4.5 que informa o seu número de condicionamento antes e após cada etapa de pré-processamento, bem como os correspondentes autovalores máximo é mínimo. Outro fato interessante é que o programa ANATEM usa um algoritmo de integração de passo fixo (método trapezoidal), enquanto que o ILUT-GMRES é parte integrante de um algoritmo de integração de passo variável (método BDF).

A Figura 4.4 ilustra o efeito positivo das estratégias de pré-processamento através da distribuição espectral dos autovalores da matriz Jacobiana original $\left(\mathrm{J}_{\mathrm{SD}}\right)$, reduzidos e agrupados próximos da origem após cada etapa de pré-processamento, melhorando a sua qualidade, fato comprovado também pelo menor número de condicionamento. Um número de condicionamento grande, como se observa neste experimento, pode indicar proximidade à singularidade e consequentemente dificuldades na solução do subproblema linear, justificando as falhas observadas. Portanto, o pré-processamento resulta num pré-condicionador de melhor qualidade uma vez que este é construído a partir da matriz Jacobiana pré-processada, aumentando a robustez e eficiência do processo iterativo pré-condicionado. 
Tabela 4.5 - Número de condicionamento e autovalores da matriz Jacobiana do Experimento I

\begin{tabular}{|c|c|c|c|}
\hline \multirow{2}{*}{ Matriz Jacobiana } & \multirow{2}{*}{$\begin{array}{c}\text { Número de } \\
\text { Condicionamento }\end{array}$} & \multicolumn{2}{|c|}{ Autovalores } \\
\hline & & Máximo & Mínimo \\
\hline \multirow{2}{*}{ Original } & \multirow{2}{*}{$6.579 e+3$} & $+1.282 \mathrm{e}+3$ & -0.006 \\
\hline & & $+j 1.786 e+3$ & $-j 0.363$ \\
\hline \multirow{2}{*}{ Escalonada } & \multirow{2}{*}{$8.602 e+4$} & +1.417 & $-5.020 e-6$ \\
\hline & & $+\mathrm{j} 1.956$ & $-j 3.431 e-4$ \\
\hline Escalonada, Normalizada e Reordenada & $1.444 \mathrm{e}+3$ & $\begin{array}{r}0.6829 \\
+j 1.321\end{array}$ & -0.0136 \\
\hline
\end{tabular}

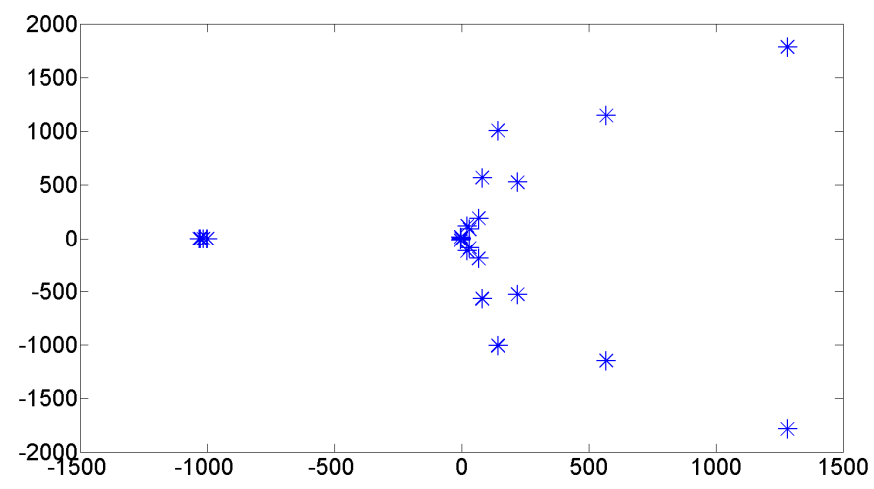

a) GMRES sem nenhum tipo de estratégia $(6.579 \mathrm{e}+3)$

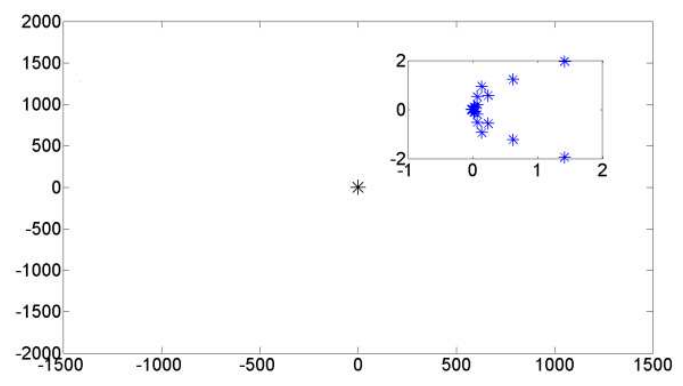

b) Escalonada $(8.602 \mathrm{e}+4)$

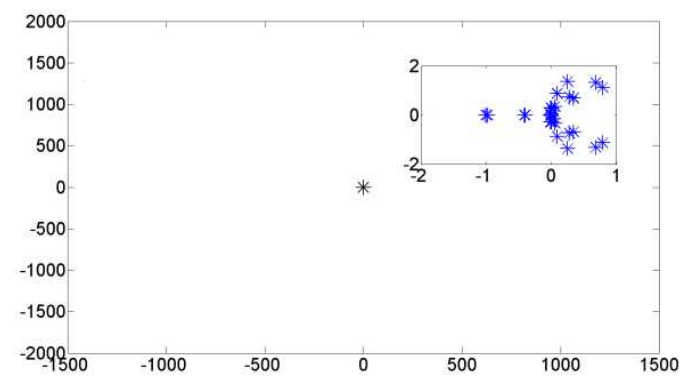

c) Escalonada, Normalizada e Reordenada $(1.444 \mathrm{e}+3)$

Figura 4.4 - Distribuição espectral da matriz Jacobiana para os Casos (a) - (d) do sistema 10 barras

Por fim, as curvas da Figura 4.5 comparam os resultados obtidos pelo programa computacional ANATEM (LU-Trapezoidal) e o BDF-GMRES, a fim de validar a solução iterativa do problema. Note que o programa ANATEM usa um modelo discreto de transformador de tape variável, enquanto que o BDF-GMRES um modelo contínuo. Este fato não compromete a validação, uma vez que em ambos os casos os equipamentos foram ajustados para a mesma tensão de referência e apresentam boa concordância, como pode ser visto pelas curvas. 


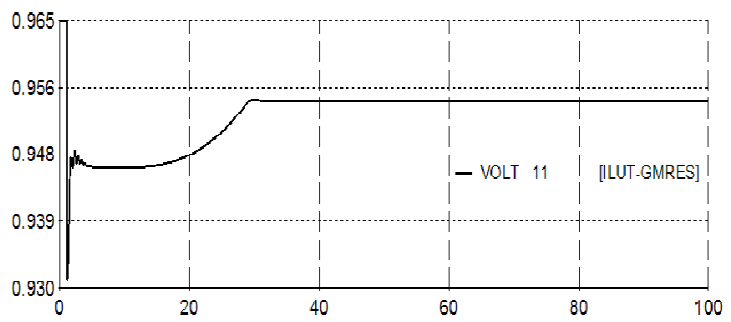

a) Perfil de tensão na barra 11 em p.u (ILUT-GMRES)

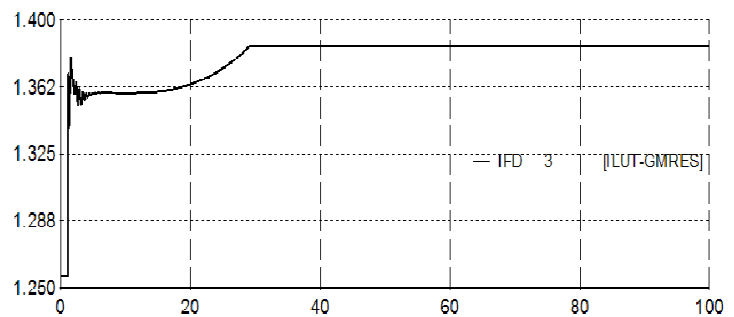

C) Corrente de campo do gerador 3 em p.u (ILUT-GMRES)

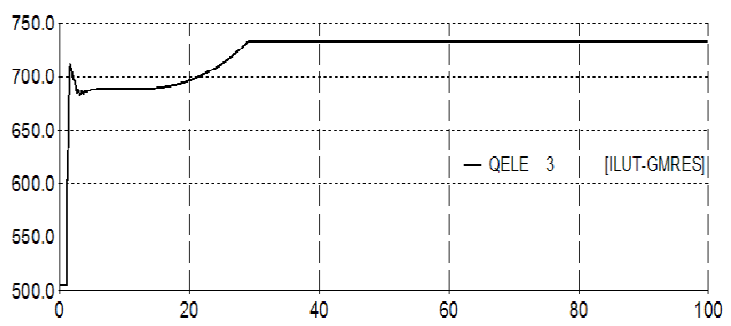

e) Potência reativa do gerador 3 em MVAr (ILUT-GMRES)

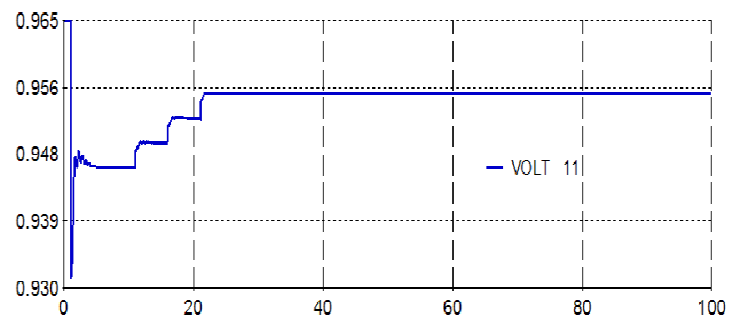

b) Perfil de tensão na barra 11 em p.u (ANATEM)

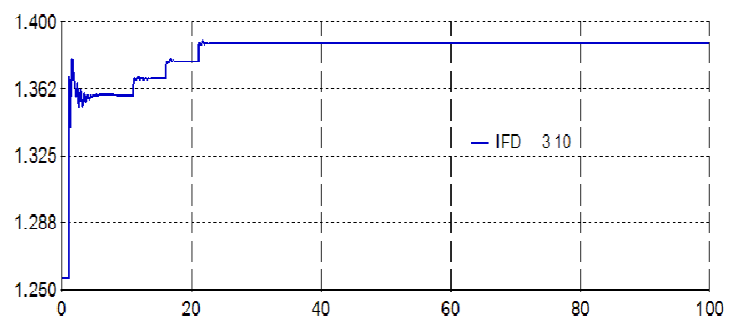

d) Corrente de campo do gerador 3 em p.u (ANATEM)

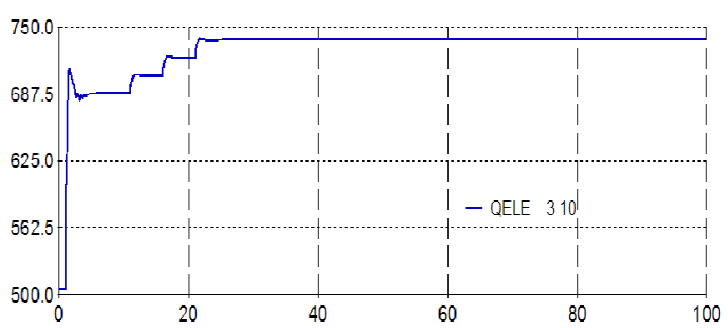

f) Potência reativa do gerador 3 em MVAr (ANATEM)

Figura 4.5 - Curvas obtidas pelo ILUT-GMRES e pelo programa ANATEM - Experimento I

\subsubsection{Experimento Numérico II}

O objetivo deste conjunto de experimentos é fazer uma avaliação do desempenho do método GMRES para um sistema de maior dimensão que o anterior, usando-se para tal fim o sistema hipotético de energia elétrica IEEE-118 barras com 54 geradores, e verificar a necessidade de considerar estratégias de pré-processamento para melhorar seu desempenho. Esses experimentos foram realizados de acordo com as 
informações da Tabela 4.6 seguindo a sequência de eventos da Tabela 4.7, simulados em ordem de severidade. Os resultados das simulações também foram validados através de comparação com os resultados obtidos pelo programa ANATEM, também apresentando boa concordância.

Tabela 4.6 - Dados sobre as simulações do Experimento II

\begin{tabular}{|c|c|c|c|}
\hline Caso & Método & Pré-condicionador & Pré-processamento \\
\hline (a) & GMRES & - & - \\
\hline (b) & GMRES- $(100)^{*}$ & - & - \\
\hline (c) & GMRES-(100) & ILUT $(0,001 ; 100)$ & Reordenamento - RCM \\
\hline (d) & GMRES-(100) & ILUT $(0,001 ; 100)$ & $\begin{array}{l}\text { Escalonamento } \\
\text { Normalização } \\
\text { Reordenamento - RCM }\end{array}$ \\
\hline
\end{tabular}

Tabela 4.7 - Lista de contingências do Experimento II

\begin{tabular}{|c|c|c|}
\hline $\begin{array}{c}\text { Barra } \\
\text { De - Para } \\
82-83\end{array}$ & $\begin{array}{c}\text { Número do } \\
\text { Circuito }\end{array}$ & $\begin{array}{c}\text { Instante do } \\
\text { distúrbio (s) }\end{array}$ \\
\hline $89-92$ & 1 & 0,005 \\
$26-30$ & 1 & 60,0 \\
\hline $94-96$ & 1 & 300,0 \\
\hline $65-68$ & 1 & 370,0 \\
\hline Final da Simulação & 550,0 \\
\hline
\end{tabular}

A Figura 4.6 ilustra a estrutura da matriz Jacobiana do sistema elétrico antes e depois do reordenamento, este último também com os elementos não-nulos confinados numa determinada região. Já a Figura 4.7, como no experimento anterior, ilustra o efeito das estratégias de pré-processamento na robustez do processo iterativo através da distribuição espectral dos autovalores da matriz Jacobiana $\left(\mathrm{J}_{\mathrm{SD}}\right)$ para cada caso simulado. 


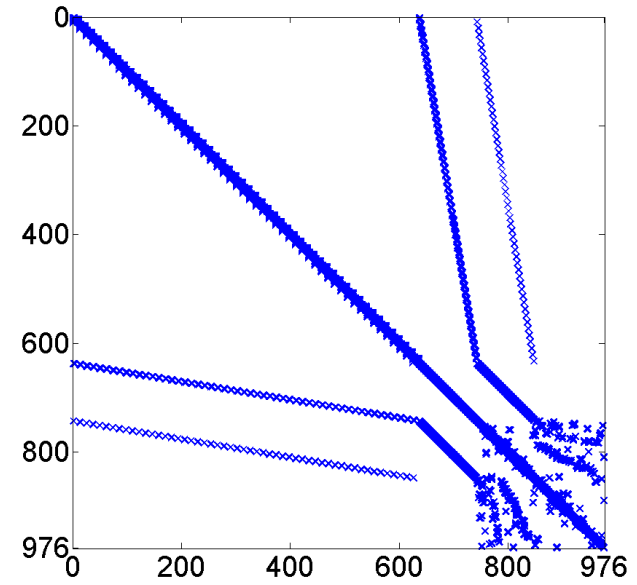

a) Estrutura Original

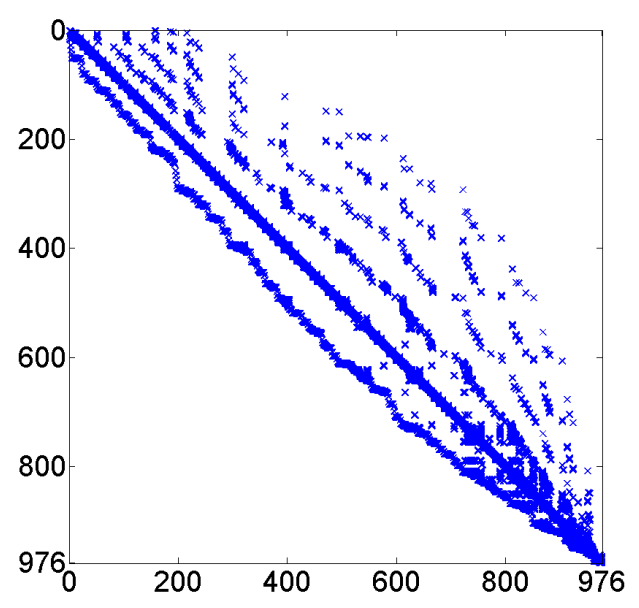

b) Fatorada ILU com reordenamento RCM

Figura 4.6 - Estrutura da Matriz Jacobiana IEEE118 - 118 Barras

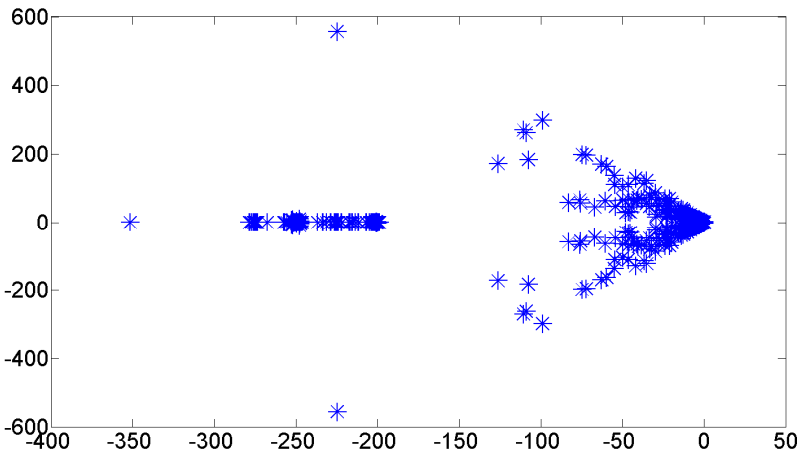

a) GMRES sem nenhum tipo de estratégia $(8.636 \mathrm{e}+6)$

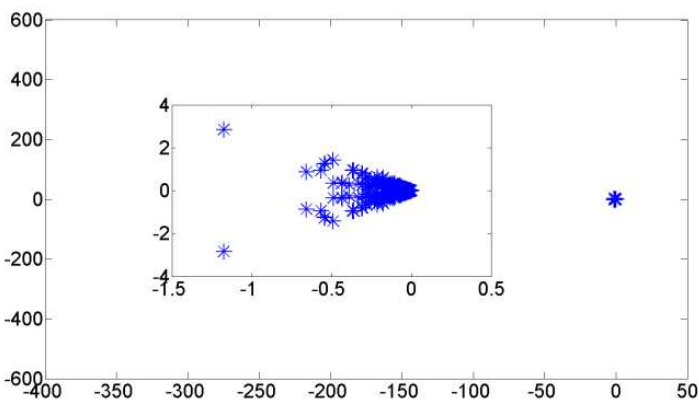

b) ILUT- GMRES Escalonada $(2.148 \mathrm{e}+6)$

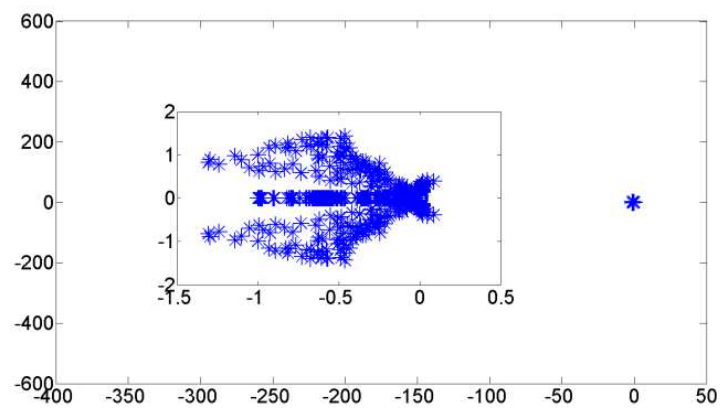

c) ILUT-GMRES com estratégias adicionais $(2.374 \mathrm{e}+3)$

Figura 4.7 - Distribuição espectral da matriz Jacobiana para os Casos (a) - (d) do sistema IEEE118 - 118 barras

A Tabela 4.8 ilustra os dados estatísticos relativos aos Casos (a)-(d) simulados, onde para (a) e (b) o tempo de CPU ultrapassou seis (6) horas, forçando, portanto a interrupção antes do cenário atingir 60 segundos, instante no qual a segunda 
contingência, abertura do circuito 89-92, seria efetuada. Diferentemente do experimento anterior, neste, apenas duas falhas foram observadas para a solução iterativa. A Tabela 4.9 informa os dados numéricos associados às equações diferenciais ordinárias (EDO) e algébricas (EA) do problema.

Tabela 4.8 - Dados associados aos resultados do Experimento II

\begin{tabular}{|l|c|c|c|c|c|c|}
\hline Casos & $\begin{array}{c}\text { Passos de } \\
\text { integração }\end{array}$ & $\begin{array}{c}\text { Avaliação } \\
\text { das EDAs }\end{array}$ & $\begin{array}{c}\text { Iterações } \\
\text { não-lineares }\end{array}$ & $\begin{array}{c}\text { Avaliação } \\
\text { da } \\
\text { Jacobiana }\end{array}$ & $\begin{array}{c}\text { Tempo } \\
\text { CPU }\end{array}$ & $\begin{array}{c}\text { Tempo } \\
\text { Relógio }\end{array}$ \\
\hline ANATEM & 15188 & 7512 & 7512 & 186 & $1 \mathrm{~m} 27 \mathrm{~s}$ & $27 \mathrm{~s} 82 \mathrm{~ms}$ \\
\hline Caso (a) & \multicolumn{5}{|c}{ FALHOU } \\
\hline Caso (b) & \multicolumn{7}{|c|}{ FALHOU } \\
\hline Caso (c) & 14535 & 65922 & 29133 & 36789 & $57,8 \mathrm{~s}$ & $30 \mathrm{~s} 13 \mathrm{~ms}$ \\
\hline Caso (d) & 14392 & 68888 & 28844 & 39944 & $56,0 \mathrm{~s}$ & $28 \mathrm{~s}$ \\
\hline
\end{tabular}

${ }^{1}$ Número de avaliações da matriz Jacobiana (método direto) e do pré-condicionador (método iterativo)

${ }^{2}$ Tempo determinado pela sub-rotina GETTIM no programa (hora, minuto, segundo e milisegundos)

Tabela 4.9 - Dados sobre as equações diferenciais ordinárias (EDO) e algébricas (EA) do Experimento II

\begin{tabular}{|c|c|c|}
\hline EDO & EA & Total (EDAs) \\
\hline 636 & 340 & 976 \\
\hline
\end{tabular}

Escalonando a matriz Jacobiana e o vetor b antes da construção do pré-condicionador ILUT, como feito em (c), as dificuldades encontradas foram eliminadas e não foram registradas falhas de convergência no processo iterativo GMRES. Os resultados foram bem melhores que os conseguidos anteriormente e o método direto ainda é superior ao iterativo em termos de eficiência computacional (tempos de CPU e de relógio). No Caso (d) os resultados foram superiores aos conseguidos em (c), com o método iterativo superior ao direto em termos de eficiência computacional (tempo de CPU).

A Tabela 4.10 também informa o número de condicionamento da matriz Jacobiana antes e após cada etapa de pré-processamento, bem como os correspondentes autovalores máximo é mínimo. Por outro lado, a Figura 4.8 apresenta uma comparação entre o programa ANATEM e o BDF-GMRES, através de curvas. 0 objetivo aqui também é validar a solução iterativa do problema no domínio do tempo através do BDF-GMRES. 
Tabela 4.10 - Número de condicionamento e autovalores da matriz Jacobiana do Experimento II

\begin{tabular}{|l|c|r|r|}
\hline \multirow{2}{*}{ Matriz Jacobiana } & Número de & \multicolumn{2}{c|}{ Autovalores } \\
\cline { 3 - 4 } & Condicionamento & \multicolumn{1}{c|}{ Máximo } & \multicolumn{1}{c|}{ Mínimo } \\
\hline Original & \multirow{2}{*}{$8.636 \mathrm{e}+6$} & $+2.247 \mathrm{e}+2$ & -0.007 \\
& & $+\mathrm{j} 5.564 \mathrm{e}+2$ & $-\mathrm{j} 0.224$ \\
\hline Escalonada & $2.148 \mathrm{e}+6$ & -1.174 & $-2.632 \mathrm{e}-5$ \\
\hline \multirow{2}{*}{ Escalonada, Normalizada e Reordenada } & $2.374 \mathrm{e}+3$ & $+\mathrm{j} 2.843$ & $-\mathrm{j} 7.679 \mathrm{e}-4$ \\
& & -1.296 & -0.0016 \\
\hline
\end{tabular}
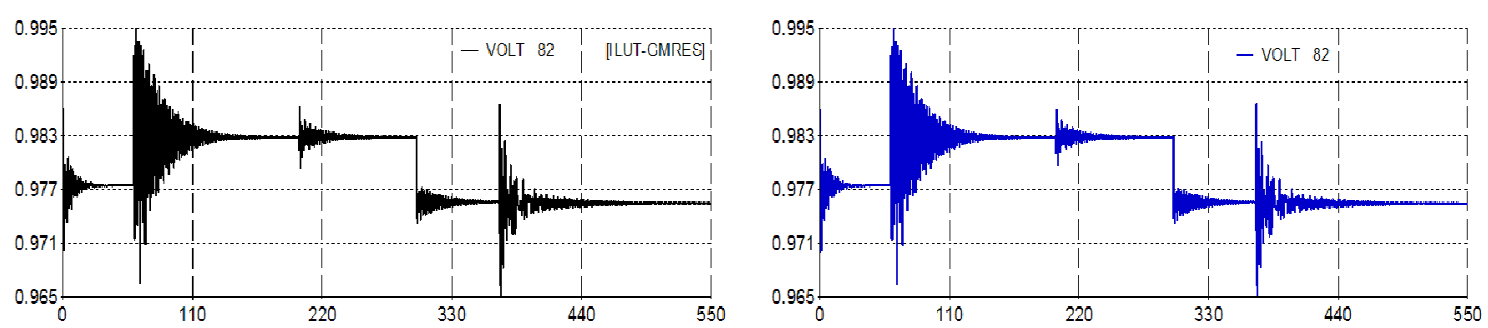

a) Perfil de tensão na barra 82 (pu). BDF-GMRES)

b) Perfil de tensão na barra $82 \quad(\mathrm{pu})$
(ANATEM)
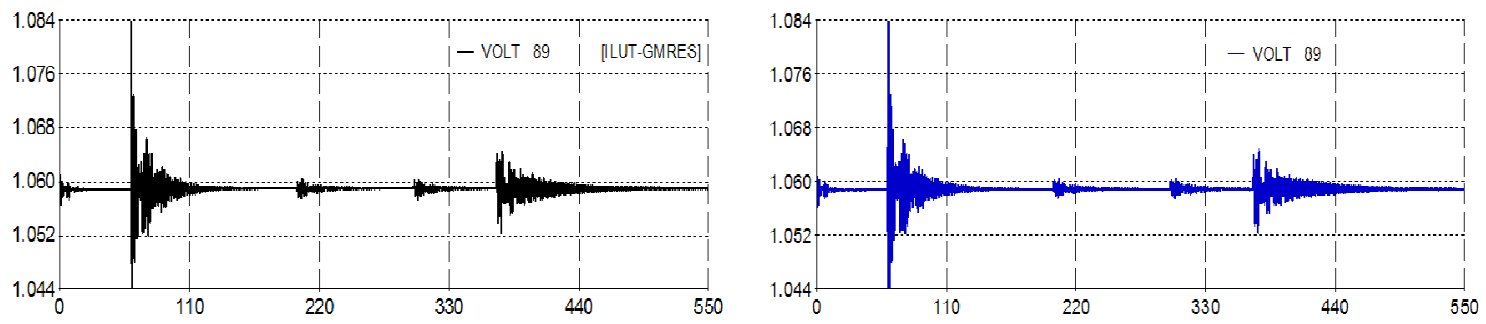

C) Perfil de tensão na barra $89 \quad(\mathrm{pu})$ (BDF-GMRES)

d) Perfil de tensão na barra $89 \quad(p u)$
(ANATEM)
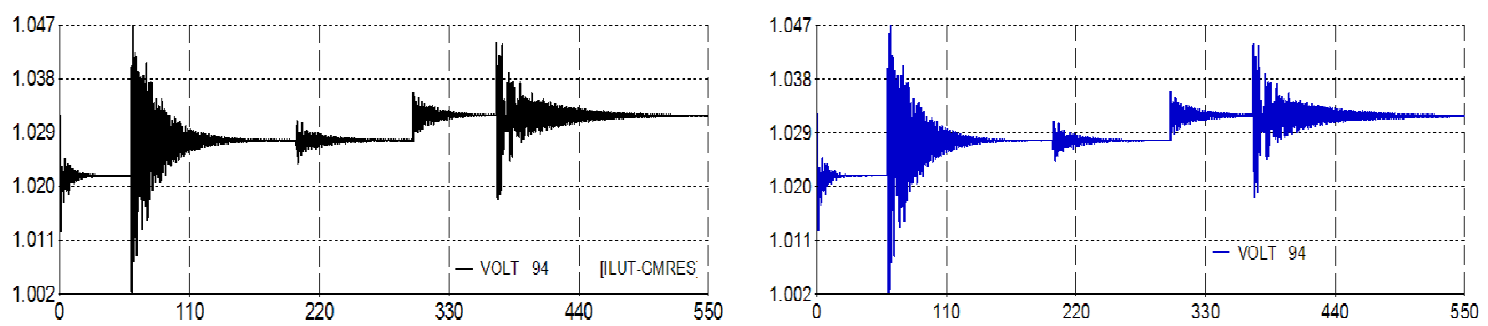

e) Perfil de tensão na barra 94
(BDF-GMRES)

Figura 4.8 - Curvas obtidas pelo BDF-GMRES e pelo programa ANATEM - Experimento II 


\subsubsection{Experimento Numérico III}

O sistema-teste usado aqui é real e corresponde aos subsistemas Norte-Nordeste do Sistema Interligado Nacional (Figura 4.9) e a modelagem completa destes subsistemas também é parte integrante deste trabalho. Esse sistema é constituído por 564 barras, 831 linhas e 56 geradores, considerando a configuração da operação do mês Abril do ano 2005 e perfil de carga pesada (ONS, 2005).

Uma série de contingências é simulada consistindo na remoção sequencial (Tabela 4.11) de várias unidades geradoras das principais usinas (Tabela 4.12) e respectivos sistemas de controle presentes nos subsistemas Norte-Nordeste. Com isto, fenômenos de curta- e de longa-duração se manifestam não apenas em função dos impactos causados por esta sequência de distúrbios, mas também pela ação dos dispositivos de controle de respostas rápidas e lentas com a finalidade de estabilizar os perfis de tensão. A perda total de geração ativa foi de $3.692 \mathrm{MW}$, e a reativa foi de 788,4 MVAr (449,65 capacitivo e 338,78 indutivo), principalmente, pelos compensadores síncronos localizados na subestação de Presidente Dutra, operada pelas Centrais Elétricas do Norte do Brasil S.A - Eletronorte, regional do estado do Maranhão.

Para os experimentos numéricos foi estabelecida a ordem máxima das Fórmulas BDF como sendo cinco (5), exceto para o experimento que analisa os efeitos resultantes da restrição dessa ordem para dois (2). A reinicialização do GMRES não está sendo considerada, pois se pretende verificar se o GMRES apenas pré-condicionado é capaz de solucionar o problema.

Tabela 4.11 - Sequência de eventos do Experimento III

\begin{tabular}{|l|c|c|}
\hline Remoção de Unidades & Unidades Retiradas & Instante do distúrbio (seg) \\
\hline Tucurui1-5GR & 4 & 0,005 \\
\hline Tucurui3-4GR & 3 & 20,0 \\
\hline Presidente Dutra-2CS & 1 & 30,0 \\
\hline Paulo Alfonso-4G1-5GR & 4 & 60,0 \\
\hline Final da Simulação & & 200,0 \\
\hline
\end{tabular}




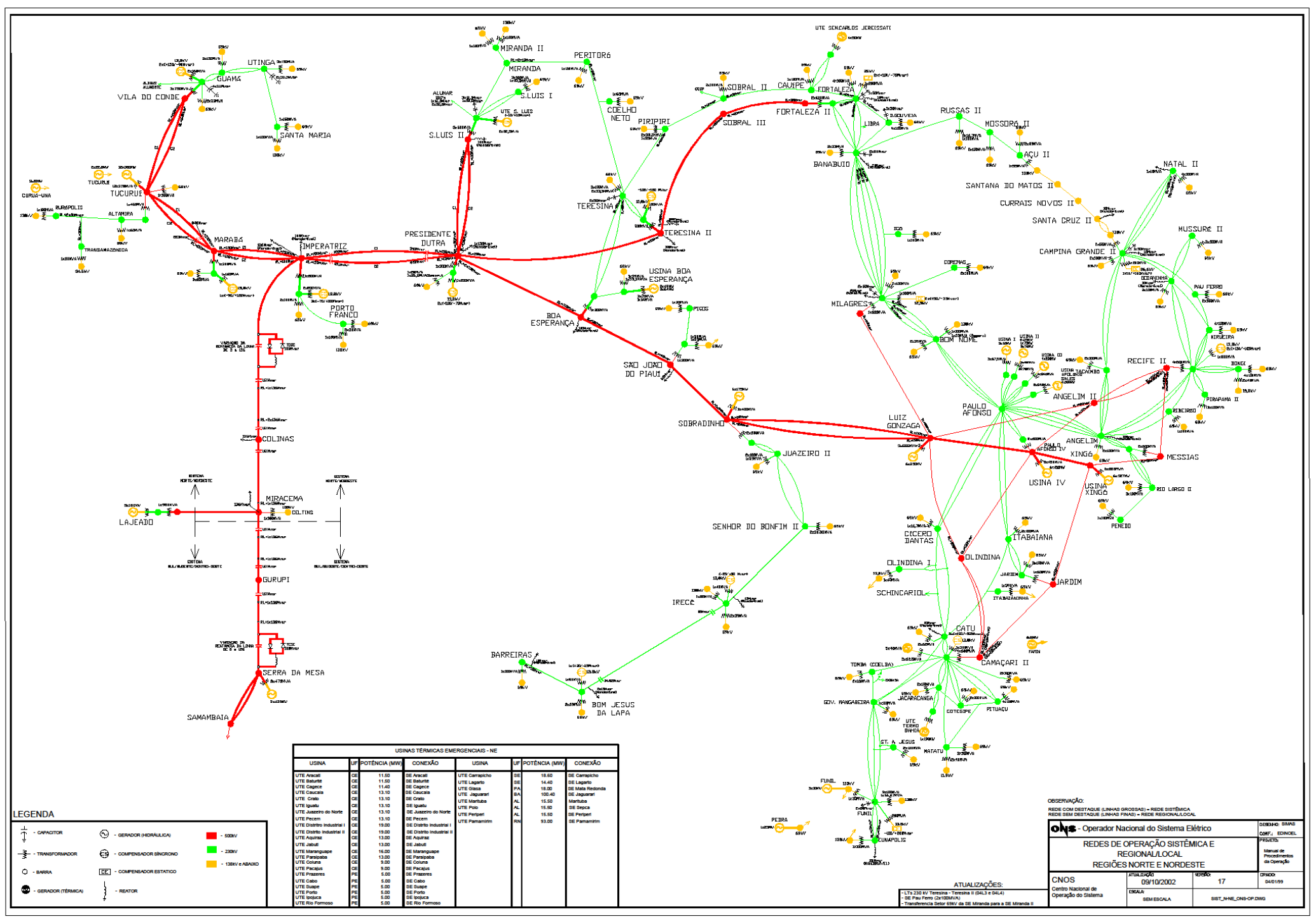

Figura 4.9 - Diagrama unifilar do sistema Norte-Nordeste Brasileiro 
A Tabela 4.13 informa os dados numéricos associados às equações diferenciais ordinárias (EDO) e algébricas (EA) do problema e a Tabela 4.14 o número de condicionamento da matriz Jacobiana antes e após cada etapa de pré-processamento, bem como os correspondentes autovalores máximo é mínimo.

Tabela 4.12 - Informações das máquinas síncronas do sistema N-NE Brasileiro

\begin{tabular}{|c|c|c|c|c|c|c|c|}
\hline \multirow{3}{*}{ Usina } & \multirow{3}{*}{ Tipo } & \multirow{3}{*}{ Barra Terminal } & \multirow{3}{*}{ No } & \multicolumn{4}{|c|}{ Faixa Operativa } \\
\hline & & & & \multicolumn{2}{|c|}{ MW } & \multicolumn{2}{|c|}{ MVAr } \\
\hline & & & & Mín & Máx & - & + \\
\hline \multirow{2}{*}{ Tucuruí } & GER & 6419 & 5 & 250.0 & 340.0 & 105.0 & 105.0 \\
\hline & GER & 6420 & 3 & 250.0 & 340.0 & 105.0 & 105.0 \\
\hline \multirow{2}{*}{ Tucuruí } & CS & 6421 & 2 & - & - & 350.0 & 161.0 \\
\hline & GER & 6422 & 4 & 250.0 & 340.0 & 105.0 & 105.0 \\
\hline Tucuruí & CS & 6423 & 2 & - & - & 350.0 & 210.0 \\
\hline \multirow{2}{*}{ Tucuruí } & GER & 6424 & 2 & & 340.0 & 168.0 & 168.0 \\
\hline & GER & 6425 & 5 & & 182.7 & 118.0 & 118.0 \\
\hline Vila do Conde & CS & 6465 & 2 & - & - & 90.0 & 150.0 \\
\hline Marabá & CS & 6405 & 1 & - & - & 90.0 & 150.0 \\
\hline Presidente Dutra & CS & 5586 & 2 & - & - & 70.0 & 100.0 \\
\hline São Luís & CS & 5556 & 1 & - & - & 25.0 & 25.0 \\
\hline Imperatriz & CS & 5596 & 3 & - & - & 70.0 & 100.0 \\
\hline
\end{tabular}

Tabela 4.13 - Dados sobre as equações diferenciais ordinárias (EDO) e algébricas (EA) do Experimento III

\begin{tabular}{|c|c|c|}
\hline EDO & EA & Total (EDAs) \\
\hline 415 & 1186 & 1601 \\
\hline
\end{tabular}

Tabela 4.14 - Número de condicionamento e autovalores da matriz Jacobiana do Experimento III

\begin{tabular}{|c|c|c|c|}
\hline \multirow{2}{*}{ Matriz Jacobiana } & \multirow{2}{*}{$\begin{array}{c}\text { Número de } \\
\text { Condicionamento }\end{array}$} & \multicolumn{2}{|c|}{ Autovalores } \\
\hline & & Máximo & Mínimo \\
\hline Original & $2,00 e+16$ & $-6.927 e+11$ & +0.063 \\
\hline & & & $-j 0.151$ \\
\hline Escalonada & $1,85 e+14$ & $-2.772 e+08$ & $\begin{array}{r}+1 \mathrm{e}-4 \\
-\mathrm{i} 0.012\end{array}$ \\
\hline Escalonada, Normalizada e Reordenada & $3,61 e+07$ & $\begin{array}{r}+1.103 \\
+\mathrm{j} 1.381\end{array}$ & $-2.043 e-04$ \\
\hline
\end{tabular}


A estrutura da matriz Jacobiana do sistema N-NE é apresentada na Figura 4.10 onde se pode notar que as equações diferenciais e algébricas formam blocos na diagonal principal tornando a matriz altamente esparsa e não simétrica numericamente; o número de elementos não-nulos é de 9468. Pode-se observar que não existe um padrão de não-zeros das submatrizes pertencentes aos geradores do sistema, por essa razão, no processo de aproximação da matriz Jacobiana se utiliza a maior banda para todos os geradores, mesmo que alguns deles não tenham nenhum tipo de dispositivo de controle.

A distribuição espectral dos autovalores da matriz Jacobiana original como mostra a Figura 4.11(a), conjuntamente com seu número de condicionamento entre parênteses, caracterizam o seu mau condicionamento, este melhorado após o pré-processamento da matriz Jacobiana, como mostram as Figura 4.11 (b) e (c). Embora o processo de escalonamento aprimore a característica de diagonal dominante através da permutação de seus valores, ainda existem valores próprios que dominam o mau condicionamento, conforme pode ser observado no espectro da Figura 4.11 (b) e 0 número de condicionamento da matriz continua bastante alto. Entretanto, quando o escalonamento é realizado junto com a normalização euclidiana, a distribuição espectral é melhorada, conforme pode ser verificado na Figura 4.11 (c). A disposição de alguns valores próprios no lado direito do espectro pode justificar o número de condicionamento de a matriz continuar elevado.

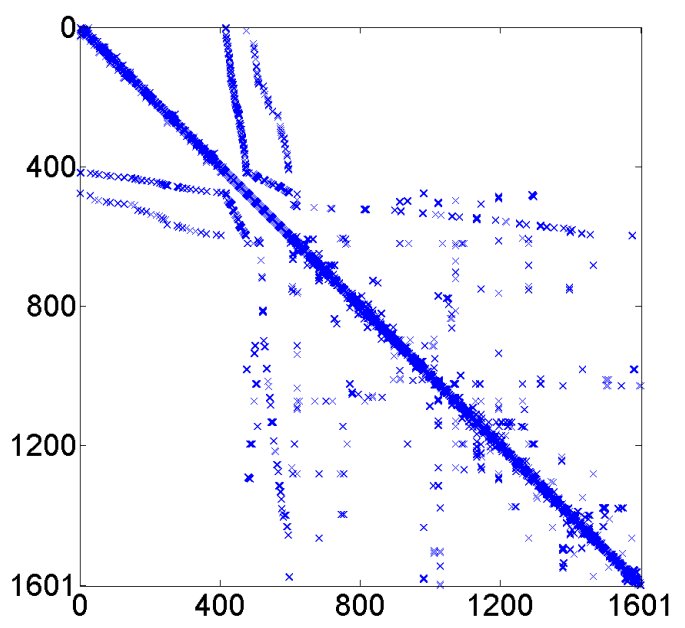

a) Estrutura Original

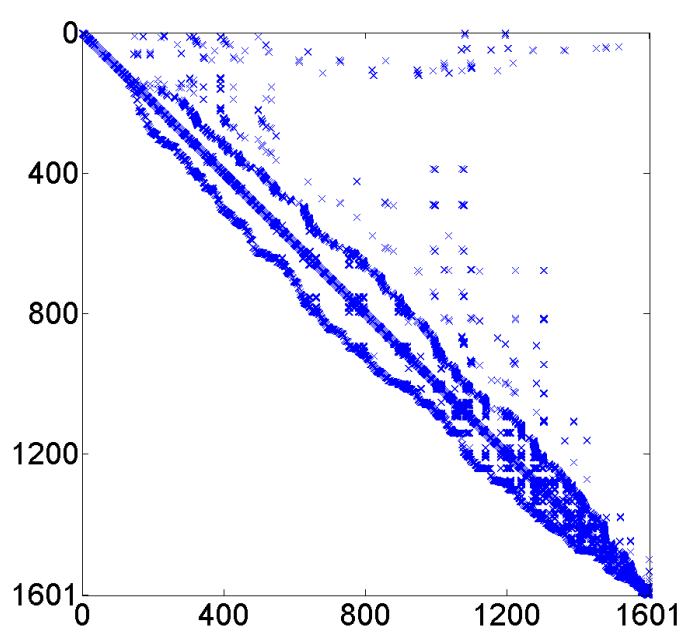

b) Fatorada ILU com reordenamento RCM

Figura 4.10 - Estrutura da matriz Jacobiana do sistema N/NE - 564 Barras 
No experimento anterior foram usados os métodos BDF-GMRES e o Trapezoidal-LU, este último com passo de integração fixo e, portanto, uma comparação em termos de eficiência computacional seria injusta. Agora, o BDF-LU é usado, possibilitando uma análise comparativa mais justa para fenômenos de longa duração.

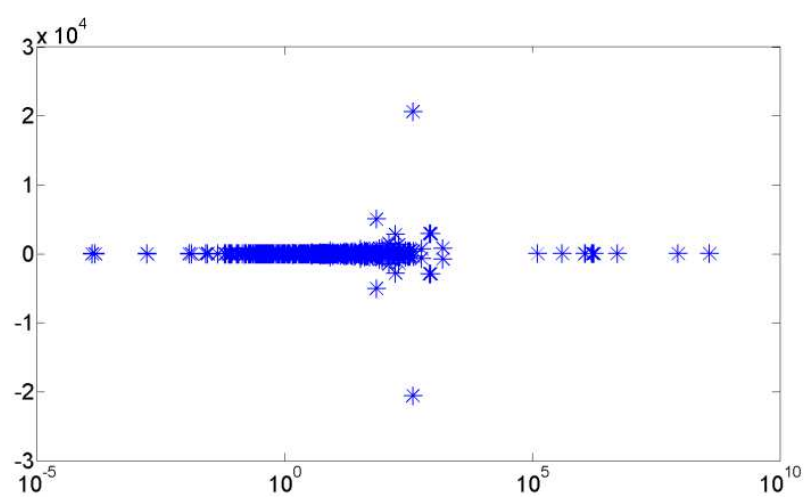

a) GMRES sem nenhum tipo de estratégia $(2,00 \mathrm{E}+16)$

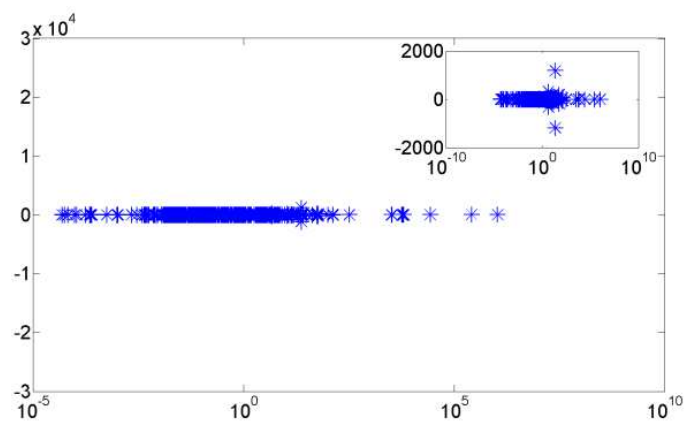

b) ILUT- GMRES, escalonamento e reordenamento $(1,85 \mathrm{E}+14)$

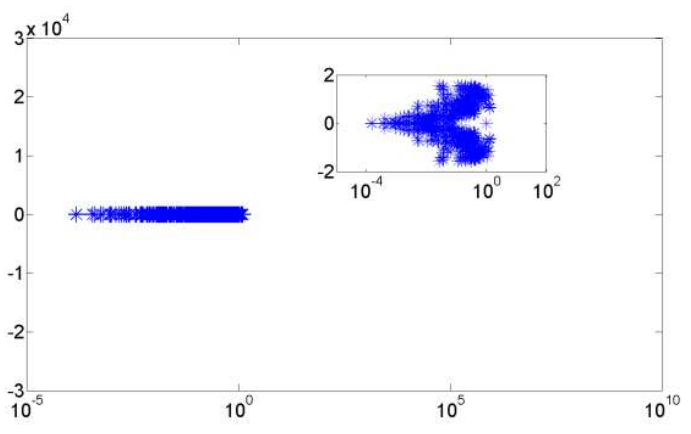

c) ILUT-GMRES escalonamento, normalização e reordenamento $(3,61 \mathrm{E}+07)$

Figura 4.11 - Distribuição espectral da matriz Jacobiana do sistema N/NE

O tempo de CPU obtido por cada método é informado na Figura 4.12 atestando uma melhor eficiência deste último sobre os demais, inclusive sobre o GMRES.

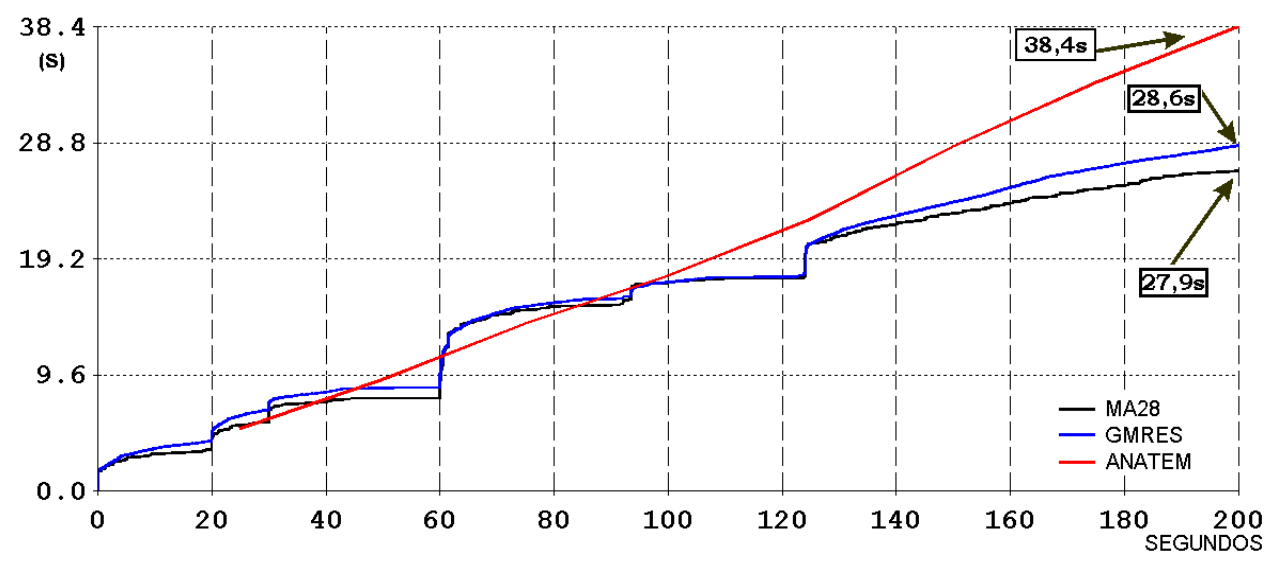

Figura 4.12 - Tempo de CPU para diferentes métodos 
A Figura 4.13 apresenta curvas obtidas pelo ANATEM e pelo BDF-GMRES para fins de validação.

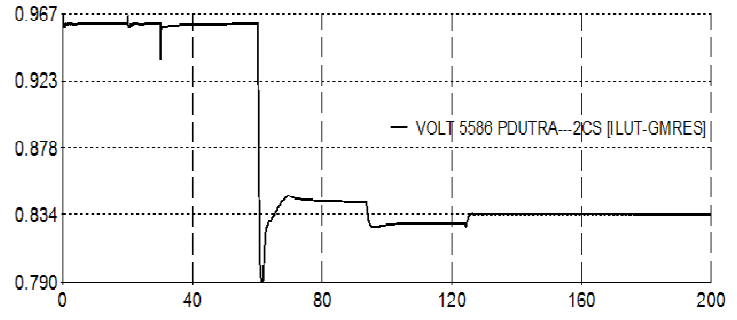

a) Perfil de tensão na barra 5586 PDutra-2CS (pu) (BDF-GMRES)

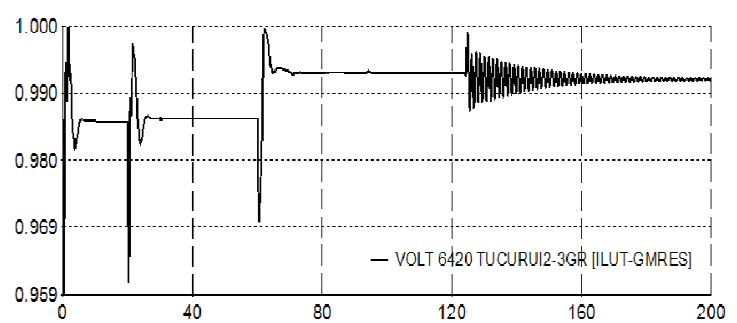

c) Perfil de tensão na barra 6420 Tucurui2-3GR (pu) (BDF-GMRES)

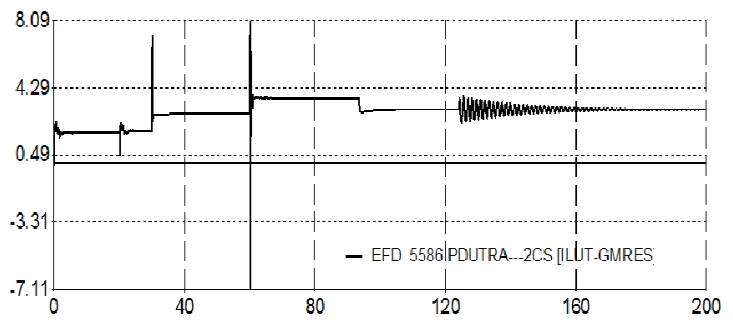

e) Tensão de campo na barra 5586 PDutra-2CS (pu) (BDF-GMRES)

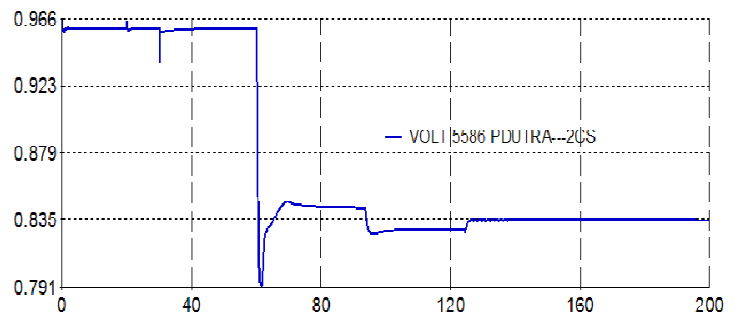

b) Perfil de tensão na barra 5586 PDutra-2CS (pu) (ANATEM)

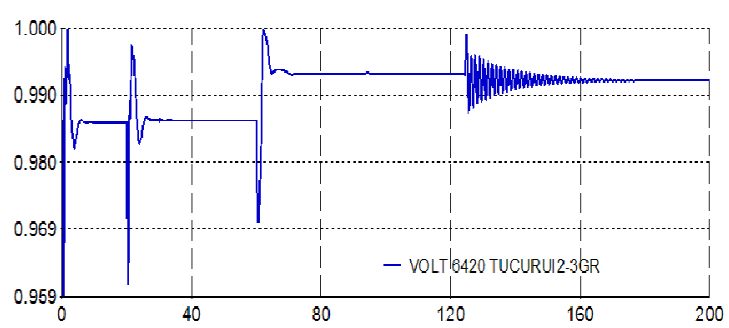

d) Perfil de tensão na barra 6420 Tucurui2-3GR (pu) (ANATEM)

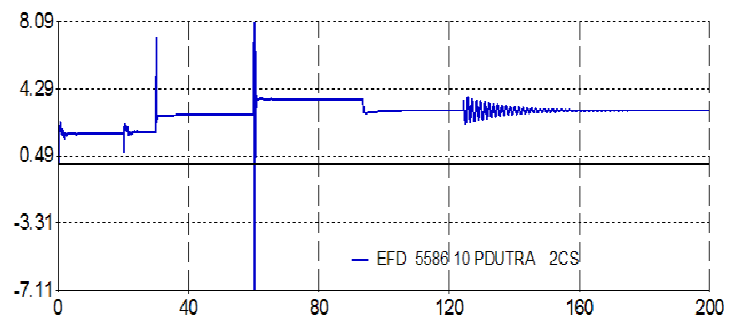

f) Tensão de campo na barra 5586 PDutra-2CS (pu) (ANATEM)

Figura 4.13 - Curvas obtidas pelo BDF-GMRES e pelo programa ANATEM - Experimento III

\subsubsection{Comentários Gerais sobre os Experimentos I, II e III}

Para oferecer uma melhor visão em termos comparativos, os principais resultados obtidos nos experimentos anteriores estão resumidos nas Tabela 4.15 e Tabela 4.16. A primeira apresenta o número de condicionamento da matriz Jacobiana de cada 
experimento, antes, durante e após o pré-processamento. Já a segunda informa o tempo de CPU para diferentes métodos. O reordenamento não está mostrado na Tabela 4.15 por não alterar esta grandeza, já que esta estratégia não influencia a magnitude dos elementos da matriz. Um número de condicionamento grande, como se observa para todas as matrizes originais com destaque para o do Experimento III, pode indicar proximidade à singularidade e consequentemente dificuldades na solução do subproblema linear. Estes indicadores justificam a necessidade do préprocessamento para os sistemas considerados, notando que o efeito da normalização Euclidiana fica mais evidente em III.

Tabela 4.15 - Número de condicionamento das matrizes Jacobianas

\begin{tabular}{|c|c|c|c|}
\hline Experimento & Original & Escalonada & Normalizada \\
\hline I (a) & $6,579 \mathrm{e}+3$ & - & - \\
\hline I (d) & $6,579 \mathrm{e}+3$ & $8,602 \mathrm{e}+4$ & $1,444 \mathrm{e}+3$ \\
\hline II & $8,636 \mathrm{e}+6$ & $2,148 \mathrm{e}+6$ & $2,374 \mathrm{e}+3$ \\
\hline III & $2,00 \mathrm{e}+16$ & $1,85 \mathrm{e}+14$ & $3,61 \mathrm{e}+07$ \\
\hline
\end{tabular}

Tabela 4.16 - Tempo CPU

\begin{tabular}{|c|c|c|}
\hline Experimento & BDF-GMRES & Trapezoidal-LU \\
\hline I (a) & Falhou & $1,05 \mathrm{~s}$ \\
\hline I (d) & $5,13 \mathrm{~s}$ & $1,05 \mathrm{~s}$ \\
\hline II & $56,0 \mathrm{~s}$ & $1 \mathrm{~min} 27 \mathrm{~s}$ \\
\hline III & $28,6 \mathrm{~s}$ & $38,4 \mathrm{~s}$ \\
\hline
\end{tabular}

A decisão sobre qual método usar (iterativo ou direto) depende de diversos fatores relacionados ao problema e infelizmente esta decisão não é fácil. Entretanto, com base nos experimentos numéricos I, II e III, tem-se que:

1. A velocidade de convergência do método iterativo, bem como a sua taxa de convergência, é muito dependente da qualidade do pré-condicionador que, quanto mais simples, maior será o número de operações realizadas pelo método, resultando em um elevado número de iterações para convergir, podendo até falhar. 
2. Um pré-condicionador de melhor qualidade necessita de um maior número de operações para a sua construção, mas o método iterativo tende a convergir rapidamente para a solução desejada.

3. Sob o ponto de vista de aplicação, o usuário deve ter alguma experiência com métodos iterativos, principalmente com relação aos pré-condicionadores.

4. Geralmente, métodos iterativos pré-condicionados precisam de uma maior quantidade de parâmetros em comparação aos diretos.

5. Métodos iterativos usam menos espaço de memória em relação aos diretos. Por outro lado, esta vantagem é perdida quando for necessário armazenar duas matrizes, a de coeficientes e a de pré-condicionamento.

6. Ambos os métodos são eficientes para matrizes esparsas.

7. O método BDF-GMRES foi superior ao Trapezoidal-LU, porém, ligeiramente inferior ao BDF-LU no experimento com sistema real e nível de carga pesada (ver Figura 4.12)

As informações apresentadas acima podem ajudar no processo de escolha, mas a decisão final deve ficar a critério do usuário, o qual deve ter pleno conhecimento do problema e das características da matriz de coeficientes do sistema linear. Nesta tese, o problema enfoca estudos de estabilidade de sistemas elétricos, sendo a solução do sistema linear apenas parte dele.

\subsubsection{Experimento Numérico IV}

Tem sido observado através de experimentos numéricos que, geralmente, o GMRES pré-condicionado apresenta os menores tempos de CPU quando comparado com métodos diretos, tanto em análises em regime-permanente quanto no domínio do tempo. Uma desvantagem está na procura por valores ótimos para $\tau$ com base em tentativa e erro, mas a literatura (Benzi, 2002) indica uma faixa de valores $\left(10 e^{-2}-\right.$ $10 e^{-4}$ ) que pode ser usada. Para verificar a solução usando um valor desta faixa $\left(10 e^{-3}\right)$, o Experimento III foi repetido mantendo-se o mesmo valor para $\rho$. Os resultados estão mostrados na Tabela 4.17 e indicam um aumento no tempo de CPU de $12,75 \%$ em relação ao experimento com $\tau$ ótimo $\left(10 e^{-5}\right)$. Esse comportamento se justifica pela maior quantidade de elementos não-nulos eliminados durante a construção do pré-condicionador, reduzindo a sua qualidade bem como a taxa de convergência do GMRES refletindo no tempo de CPU. Apesar disso, o experimento mostra que o problema sublinear pode ser solucionado sem uma busca exaustiva por 
um valor ótimo para $\tau$. Se o ILUT falhasse, a solução poderia ser obtida reduzindo 0 valor de $\tau$ e/ou aumentando-se o de $\rho$ (Benzi, 2002), mas neste experimento tais procedimentos não foram necessários.

Tabela 4.17 - Resultados para valor sugerido de
\begin{tabular}{|c|c|c|c|}
\hline$\tau$ & $10 \mathrm{e}-03$ & $10 \mathrm{e}-05$ & BDF-LU \\
\hline CPU & $32,28 \mathrm{~s}$ & $28,63 \mathrm{~s}$ & $27,98 \mathrm{~s}$ \\
\hline
\end{tabular}

\subsubsection{Experimento Numérico $\mathrm{V}$}

Aqui, é repetido o Experimento III fazendo uso de filtros digitais a fim de analisar o comportamento dos métodos numéricos de integração na seleção do comprimento do passo. Os filtros (Tabela 4.18) considerados aqui foram retirados da literatura (Meeker, 2004) e foram implementados na versão do solucionador DASPK usada nas simulações. A Tabela 4.19 e Tabela 4.20 informam os parâmetros e o desempenho computacional para cada filtro considerado.

Tabela 4.18 - Descrição dos filtros considerados

\begin{tabular}{|c|c|c|c|}
\hline Filtro & B1 & B2 & A2 \\
\hline H211B4 & $0,25 / T_{k}$ & $0,25 / T_{k}$ & 0,25 \\
\hline PI42 & $0,60 / T_{k}$ & $-0,20 / T_{k}$ & -- \\
\hline
\end{tabular}


Tabela 4.19 - Simulações envolvendo o Filtro H211B4

\begin{tabular}{|c|c|c|c|c|c|c|c|c|c|c|c|c|c|c|c|c|c|}
\hline \multirow[b]{2}{*}{ H211B4 } & \multirow[b]{2}{*}{ CP } & \multirow{2}{*}{\begin{tabular}{c|}
$\mathrm{BDF}$ \\
$\mathrm{K}$
\end{tabular}} & \multicolumn{4}{|c|}{ FILTRO } & \multicolumn{3}{|c|}{ GMRES } & \multicolumn{2}{|c|}{ ILUT } & \multirow{2}{*}{$\begin{array}{l}\text { CPU } \\
\text { Seg }\end{array}$} & \multirow{2}{*}{$\begin{array}{l}\text { PASSOS DE } \\
\text { INTEGRAÇÃO }\end{array}$} & \multirow{2}{*}{ REJEIÇÕES } & \multicolumn{2}{|c|}{ NEWTON } & \multirow{2}{*}{$\begin{array}{c}\text { GMRES } \\
\text { CONV }\end{array}$} \\
\hline & & & PARCELA & B1 & B2 & A2 & NIL & TOL & m & $\rho$ & $\tau$ & & & & NCONV & CONV & \\
\hline H211B4(1) & 0,033 & 5 & $10 \mathrm{E}-04$ & 0,25 & 0,25 & 0,25 & 20 & 5,0E-02 & 5 & 150 & $10 \mathrm{E}-05$ & 1.843 & 10.944 & 21.651 & 32 & 65.272 & 34.348 \\
\hline H211B4(2) & 0,033 & 5 & $10 E-04$ & 0,75 & 0,75 & 0,75 & 20 & $5,0 \mathrm{E}-02$ & 5 & 150 & $10 \mathrm{E}-05$ & 1.660 & 10.389 & 16.566 & 40 & 54.027 & 33.277 \\
\hline H211B4(3) & 0,33 & 5 & 10E-04 & 0,25 & 0,25 & 0,25 & 20 & 5,0E-02 & 5 & 150 & $10 \mathrm{E}-05$ & 3.528 & 10.941 & 21.660 & 25 & 65.262 & 33.245 \\
\hline H211B4(4) & 0,033 & 5 & $10 \mathrm{E}-08$ & 0,25 & 0,25 & 0,25 & 20 & 5.0E-02 & 5 & 150 & $10 \mathrm{E}-05$ & 614 & 4.139 & 7.160 & 33 & 22.730 & 16.704 \\
\hline H211B4(5) & 0,033 & 5 & $10 \mathrm{E}-04$ & 0,25 & 0,25 & 0,25 & 20 & 5,0E-02 & 5 & 150 & $10 \mathrm{E}-05$ & 291 & 3.665 & 3.321 & 14 & 14.036 & 12.254 \\
\hline H211B4(6) & 0,033 & 5 & $10 \mathrm{E}-04$ & 0,001 & 0,25 & 0,25 & 20 & $5,0 \mathrm{E}-02$ & 5 & 150 & $10 \mathrm{E}-05$ & 1.201 & 7.073 & 13.795 & 29 & 41.831 & 24.720 \\
\hline H211B4(7) & 0,033 & 5 & $10 \mathrm{E}-04$ & 0,25 & 0,001 & 0,25 & 20 & 5,0E-02 & 5 & 150 & 10E-05 & 65,5 & 7.479 & 60 & 15 & 15.121 & 22.595 \\
\hline H211B4(8) & 0,33 & 5 & $10 \mathrm{E}-04$ & 0,25 & 0 & 0,25 & 20 & $5,0 \mathrm{E}-02$ & 5 & 150 & $10 \mathrm{E}-05$ & 69,3 & 7.465 & 60 & 15 & 15.079 & 16.063 \\
\hline H211B4(9) & 0,033 & 5 & 10E-04 & 0,25 & 0,25 & 0 & 20 & 5,0E-02 & 5 & 150 & 10E-05 & 936,4 & 5.595 & 10.915 & 31 & 33.126 & 21.408 \\
\hline $\mathrm{CP}$ & & \multicolumn{16}{|c|}{ Critério de parada } \\
\hline K & & \multicolumn{16}{|c|}{ Ordem das fórmulas BDF } \\
\hline PARCELA & & \multicolumn{16}{|c|}{ Valor residual utilizada na fórmula do filtro digital } \\
\hline $\mathrm{B} 1, \mathrm{~B} 1, \mathrm{~A} 2$ & & \multicolumn{16}{|c|}{ Expoente da fórmula do filtro digital } \\
\hline NIL & & \multicolumn{16}{|c|}{ Número de iterações lineares } \\
\hline TOL & & \multirow{2}{*}{\multicolumn{16}{|c|}{$\begin{array}{l}\text { Tolerância de convergência no processo iterativo linear GMRES } \\
\text { Número de reinicializações }\end{array}$}} \\
\hline $\mathrm{m}$ & & & & & & & & & & & & & & & & & \\
\hline$\rho$ & & \multicolumn{16}{|c|}{ Número de elementos não-nulos permitidos no processo de fatoração ILU } \\
\hline$\tau$ & & \multicolumn{16}{|c|}{ Tolerância estabelecida para o processo de eliminação em ILU. } \\
\hline NCONV & & \multirow{2}{*}{\multicolumn{16}{|c|}{$\begin{array}{l}\text { Número de não-convergência do processo iterativo Newton. } \\
\text { Convergência do processo iterativo Newton. }\end{array}$}} \\
\hline CONV & & Con & ivergência do & processc & iterativ & Newto & & & & & & & & & & & \\
\hline
\end{tabular}


Tabela 4.20 - Simulações envolvendo o Filtro PI42

\begin{tabular}{|c|c|c|c|c|c|c|c|c|c|c|c|c|c|c|c|c|c|}
\hline \multirow[b]{2}{*}{ PI42 } & \multirow[t]{2}{*}{ CP } & \multirow{2}{*}{\begin{tabular}{c|} 
BDF \\
$\mathrm{K}$
\end{tabular}} & \multicolumn{4}{|c|}{ FILTROS } & \multicolumn{3}{|c|}{ GMRES } & \multicolumn{2}{|c|}{ ILUT } & \multirow{2}{*}{\begin{tabular}{|l|} 
CPU \\
Seg
\end{tabular}} & \multirow{2}{*}{$\begin{array}{l}\text { PASSOS DE } \\
\text { INTEGRACAO }\end{array}$} & \multirow{2}{*}{ REJEICOES } & \multicolumn{2}{|c|}{ NEWTON } & \multirow{2}{*}{$\begin{array}{c}\text { GMRES } \\
\text { CONV }\end{array}$} \\
\hline & & & PARCELA & B1 & B2 & A2 & NIL & TOL & m & $\rho$ & $\tau$ & & & & NCONV & CONV & \\
\hline PI42(1) & 0,033 & 5 & $10 E-04$ & 0,6 & -0.2 & 0 & 20 & 5,0E-02 & 5 & 150 & 10E-05 & 302,5 & 49.129 & 25 & 18 & 98.341 & 86.691 \\
\hline PI42(2) & 0,33 & 5 & $10 \mathrm{E}-04$ & 0,6 & -0.2 & 0 & 20 & 5,0E-02 & 5 & 150 & $10 \mathrm{E}-05$ & 275,7 & 50.037 & 29 & 15 & 100.135 & 52.627 \\
\hline PI42(3) & 0,033 & 5 & $10 \mathrm{E}-08$ & 0,6 & -0.2 & 0 & 20 & 5,0E-02 & 5 & 150 & 10E-05 & 113,2 & 12.835 & 32 & 28 & 25.477 & 16.021 \\
\hline PI42(4) & 0,033 & 5 & $10 \mathrm{E}-04$ & 0,6 & -0.2 & 0 & 20 & 5,0E-02 & 5 & 150 & 10E-05 & 34,4 & 3.932 & 36 & 8 & 7.956 & 8.970 \\
\hline PI42(5) & 0,033 & 5 & $10 E-04$ & 0,25 & 0 & 0 & 20 & 5,0E-02 & 5 & 150 & 10E-05 & 66,1 & 7.452 & 57 & 18 & 15.061 & 22.518 \\
\hline PI42(6) & 0,033 & 5 & $10 \mathrm{E}-04$ & 0,6 & 0.2 & 0 & 20 & 5,0E-02 & 5 & 150 & 10E-05 & 3.130 & 11.833 & 21.054 & 23 & 65.832 & 38.463 \\
\hline PI42(7) & 0,033 & 5 & $10 \mathrm{E}-04$ & 0,6 & 0.1 & 0 & 20 & 5,0E-02 & 5 & 150 & 10E-05 & 1.835 & 11.481 & 11.108 & 27 & 45.237 & 29.635 \\
\hline PI42(8) & 0,033 & 5 & $10 \mathrm{E}-04$ & 0,6 & 0.001 & 0 & 20 & $5,0 \mathrm{E}-02$ & 5 & 150 & 10E-05 & 165,3 & 7.325 & 53 & 19 & 14.618 & 22.113 \\
\hline PI42(9) & 0,033 & 5 & $10 \mathrm{E}-04$ & 0,6 & 0 & 0 & 20 & 5,0E-02 & 5 & 150 & 10E-05 & 71,8 & 7.315 & 52 & 18 & 14.780 & 22.361 \\
\hline PI42(10) & 0,033 & 5 & $10 \mathrm{E}-04$ & 0,6 & -0.001 & 0 & 20 & 5,0E-02 & 5 & 150 & 10E-05 & 281,0 & 7.383 & 47 & 22 & 14.917 & 22.544 \\
\hline PI42(11) & 0,033 & 5 & $10 \mathrm{E}-04$ & 0,6 & -0.1 & 0 & 20 & 5,0E-02 & 5 & 150 & 10E-05 & 138,3 & 19.250 & 28 & 20 & 38.608 & 46.184 \\
\hline $\mathrm{CP}$ & \multicolumn{17}{|c|}{ Critério de parada } \\
\hline $\mathrm{K}$ & & \multicolumn{16}{|c|}{ Ordem das fórmulas BDF } \\
\hline PARCELA & & \multicolumn{16}{|c|}{ Valor residual utilizada na fórmula do filtro digital } \\
\hline $\mathrm{B} 1, \mathrm{~B} 1, \mathrm{~A} 2$ & & \multicolumn{16}{|c|}{ Expoente da fórmula do filtro digital } \\
\hline NIL & & \multicolumn{16}{|c|}{ Número de iterações lineares } \\
\hline TOL & & \multirow{2}{*}{\multicolumn{16}{|c|}{$\begin{array}{l}\text { Tolerância de convergência } \\
\text { Número de reinicializacões }\end{array}$}} \\
\hline $\mathrm{m}$ & & & & & & & & & & & & & & & & & \\
\hline$\rho$ & & \multicolumn{16}{|c|}{ Número de elementos não-nulos permitidos no processo de fatoração ILU } \\
\hline$\tau$ & & \multicolumn{16}{|c|}{ Tolerância estabelecida para o processo de eliminação em ILU. } \\
\hline NCONV & & \multirow{2}{*}{\multicolumn{16}{|c|}{ Número de não-convergência do processo iterativo Newton. }} \\
\hline CONV & & & nvergência do & proces & so iterati & vo $\mathrm{Ne}$ & ewton. & & & & & & & & & & \\
\hline
\end{tabular}


Os resultados mostrados na Tabela 4.19 e Tabela 4.20 indicam que a inclusão dos filtros digitais na simulação em questão pode degenerar a eficiência computacional das simulações, caracterizada pelos elevados tempos de CPU. A Figura 4.14 e Figura 4.15 ilustram o comportamento do passo de integração e do erro de truncamento ao longo das simulações com os filtros (H211B4(6) e PI42(4)) comparado com simulações sem os filtros digitais.

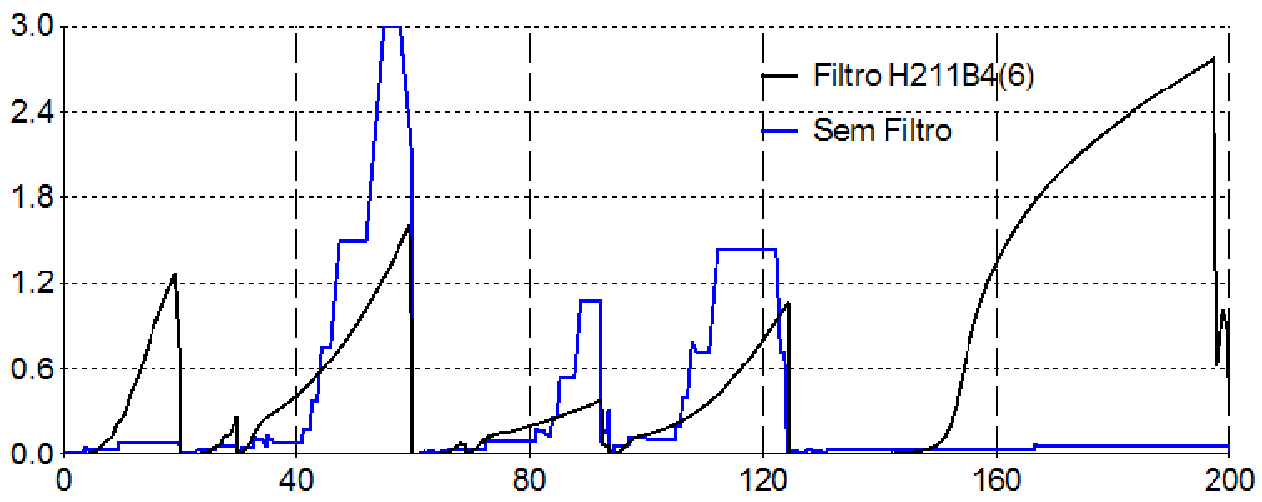

a) Comportamento do passo de integração ao longo da simulação

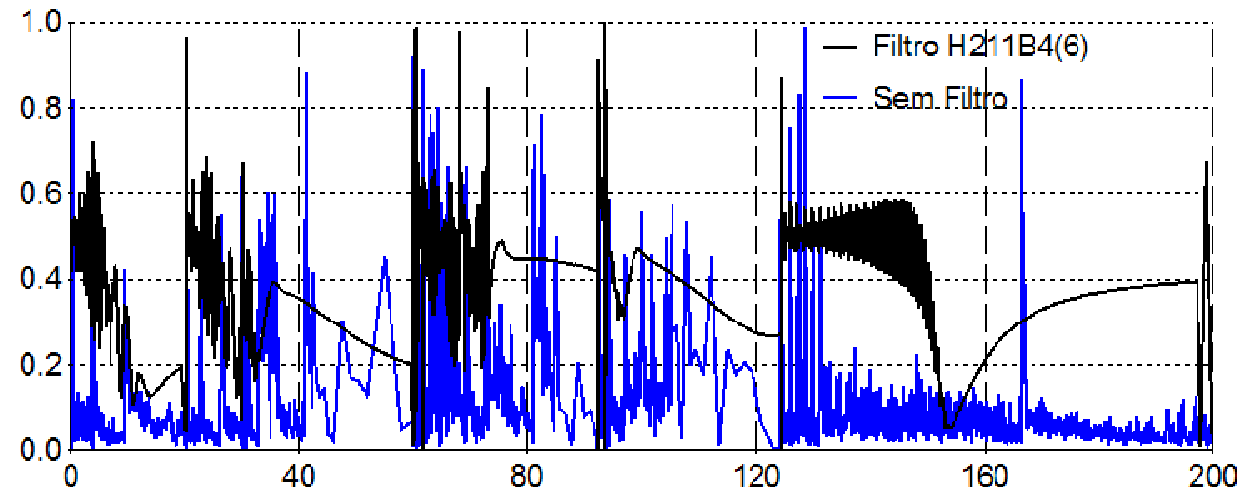

b) Comportamento do erro de truncamento ao longo da simulação

Figura 4.14 - Efeitos do filtro H211B4(6)

Da Tabela 4.20 observa-se que o tempo de CPU de 34,4 s associado ao filtro PI42(4) foi o menor obtido em todas as configurações com filtros, mas ainda superior ao tempo de CPU registrado para a simulação sem o filtro (28,6 s). Já os gráficos da Figura 4.14 e Figura 4.15 mostram uma variação mais suave do passo de integração (a) e um melhor controle do erro (b), comportamentos conseguidos com a presença dos filtros. A referência (Soderling \& Wang, 2003) atesta que, em geral, esses filtros atuam positivamente na estabilidade computacional do processo, ou seja, se ocorrer uma 
pequena variação em qualquer parâmetro envolvido na simulação, deve-se observar um pequeno efeito nos resultados (neste caso, diz-se que o processo computacional é bem condicionado). Entretanto, os filtros considerados foram desenvolvidos para aplicações que fazem uso de equações diferenciais e algébricas para análise de sensibilidade e otimização. Os resultados obtidos não mostram vantagens em se usar esses filtros para o problema em questão.

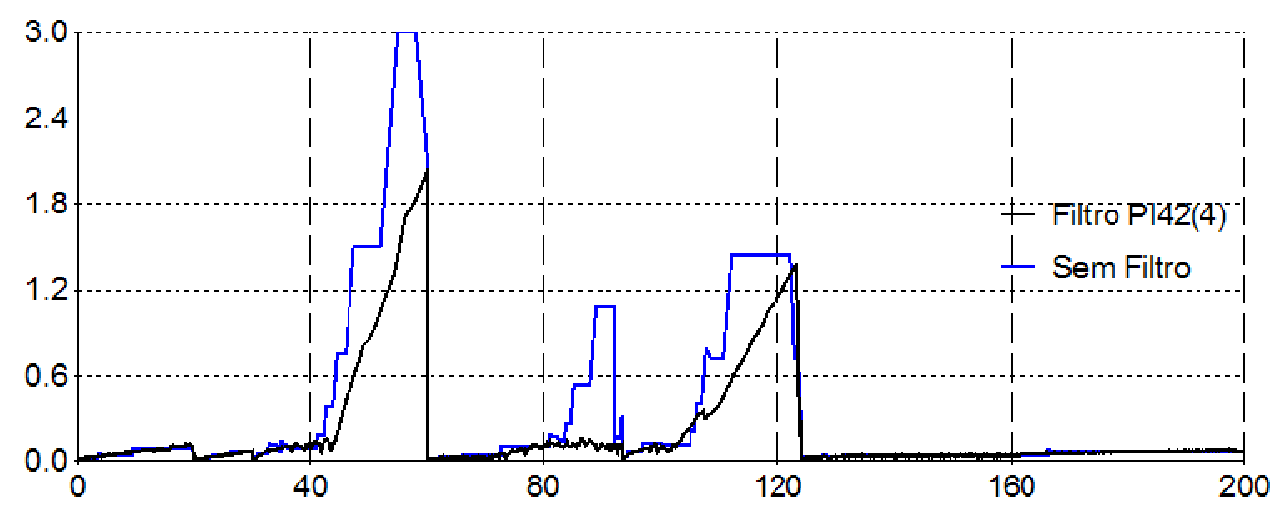

a) Comportamento do passo de integração ao longo da simulação

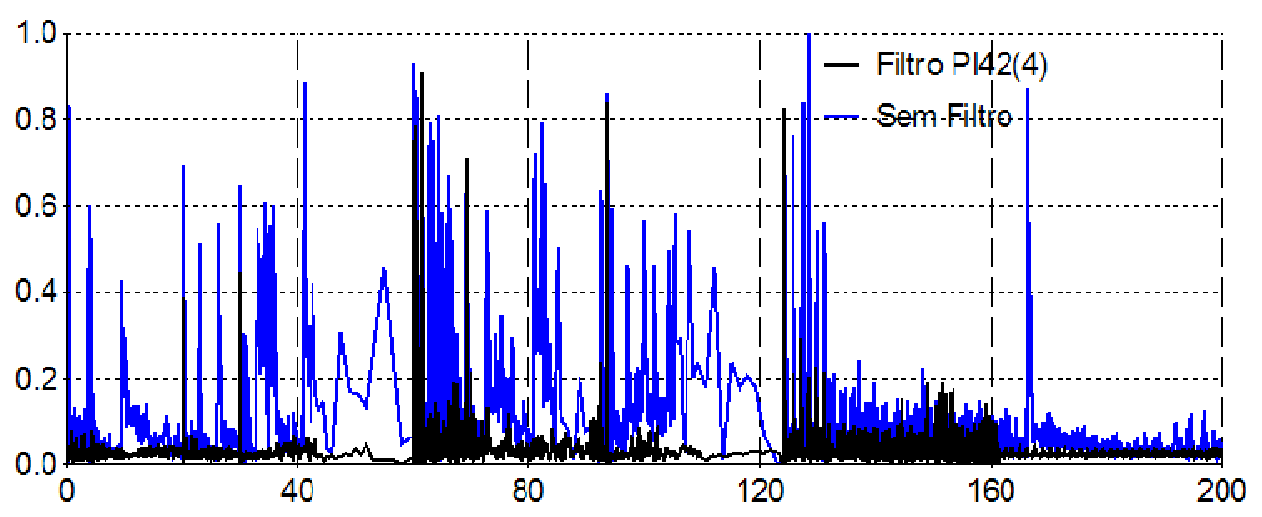

b) Comportamento do erro de truncamento ao longo da simulação

Figura 4.15 - Efeitos do filtro PI42(4) 


\section{Conclusões e Trabalhos Futuros}

\subsection{Introdução}

O uso de métodos iterativos requer conhecimento, habilidade e experiência, e um grande esforço tem sido feito para uma melhor aproximação desses métodos com problemas reais. Ainda, a solução de sistemas lineares relacionados a problemas complexos e práticos, como no caso de sistemas de energia elétrica, através de métodos iterativos é um desafio devido à complexidade matemática inerente aos métodos e as suas estratégias. Ao longo desta pesquisa, notou-se um reduzido número de artigos encontrados na literatura abordando aplicações em problemas de sistemas elétricos de potência em ambiente serial, embora haja um consenso com relação ao aspecto promissor desses métodos. Outros fatores que ajudam em justificar esse reduzido número de publicações são:

- De uma forma geral os métodos diretos baseados em eliminação Gaussiana ou fatoração LU, por exemplo, atenderam/atendem de forma eficiente, confiável e satisfatória os requisitos de solução.

- Os primeiros métodos iterativos apresentavam deficiências que poderiam comprometer a solução do problema. Muitas vezes tinha que se recorrer a algum método direto em substituição ao iterativo.

- Os sistemas elétricos de potência eram menores em termos de dimensão, menos complexos em termos de configuração, continham menos dispositivos de controle, e as características das cargas eram mais amigáveis. Tudo isso refletia no modelo matemático final, independente do cenário sob investigação, ou seja, comparado aos sistemas atuais ofereciam menos barreiras à solução dos sistemas de equações matemáticas, fossem algébricas ou diferenciais. Por outro lado, os recursos computacionais eram bem inferiores aos atuais, mas mesmo assim os métodos diretos atenderam de forma satisfatória as necessidades. 
Por outro lado, também existem justificativas para explorar os métodos iterativos, e de outros métodos numéricos em geral, sendo estas:

- Atualmente, os sistemas de energia elétrica são muito maiores em termos de dimensão, muito mais complexos em termos de configuração, contêm muito mais dispositivos de controle, e as características das cargas podem não ser amigáveis. Tudo isso reflete no modelo matemático final, agora dependendo do cenário sob investigação. Devido à variedade de fenômenos presentes nos sistemas de energia elétrica, houve a necessidade de classificá-los em função, por exemplo, dos objetivos/parâmetros de interesse e da velocidade do fenômeno (intervalo de duração). Em alguns casos a modelagem matemática é específica para certo tipo de fenômeno. Os sistemas atuais se comparados aos passados oferecem muito mais barreiras à solução dos sistemas de equações, sejam algébricas ou diferenciais. Em contra partida, os recursos computacionais atuais são bem superiores, mas mesmo assim os métodos convencionais podem não atender de forma satisfatória as necessidades, influenciando negativamente no desempenho computacional sob o ponto de vista de tempo de CPU, memória e estabilidade numérica. Portanto, há uma clara necessidade de se procurar por novas estratégias numéricas, e este é um dos pontos a se destacar nesta pesquisa.

- Houve uma clara evolução dos métodos numéricos cobrindo uma variedade de problemas, acompanhada pela evolução dos computadores. Pelo histórico apresentado e pelos artigos mais recentes abordados, os métodos iterativos evoluíram bastante desde as duas últimas décadas do século passado até os tempos atuais.

- Recentes estratégias numéricas referentes à construção do pré-condicionador, como também estratégias de reinicialização e de diferenças de quocientes, influenciam positivamente no desempenho dos métodos iterativos. Essas estratégias numéricas, e outras encontradas na literatura especializada, tornaram esses métodos promissores e atrativos.

- A robustez de alguns métodos iterativos, como por exemplo, do GMRES em conjunto com estratégias eficientes, pode ser um fator importante e diferencial sob o ponto de vista matemático. Alguns algoritmos numéricos falham quando o cenário investigado envolver condições críticas de operação, como por exemplo, 
uma condição de extremo carregamento e com déficit de potência reativa, próxima de um colapso de tensão.

Com relação à aplicação de método iterativo ou direto para solucionar um determinado problema, este é um dilema que tem merecido bastante atenção já que a decisão sobre qual é o mais adequado depende de diversos fatores relacionados ao problema pode não ser fácil. Entretanto, verificou-se que:

- A velocidade de convergência do método iterativo, bem como a sua taxa de convergência, é muito dependente da qualidade do pré-condicionador que, quanto mais simples, maior será o número de operações realizadas pelo método, resultando em um elevado número de iterações para convergir, podendo até falhar.

- Um pré-condicionador de melhor qualidade necessita de um maior número de operações para a sua construção, mas o método iterativo tende a convergir rapidamente para a solução desejada.

- Sob o ponto de vista de aplicação, o usuário deve ter alguma experiência com métodos iterativos, principalmente com relação aos pré-condicionadores.

- Geralmente, métodos iterativos pré-condicionados precisam de uma maior quantidade de parâmetros em comparação aos diretos.

- Métodos iterativos usam menos espaço de memória em relação aos diretos. Por outro lado, esta vantagem é perdida quando for necessário armazenar duas matrizes, a de coeficientes e a de pré-condicionamento.

- Ambos os métodos são eficientes para matrizes esparsas.

- A situação ótima para a solução iterativa foi a com o ponto de operação próximo do máximo carregamento, com $173,6 \%$ de ganho em comparação ao direto no tempo de CPU.

- Nos experimentos, o método direto usado com o BDF faz uso de fatoração LU, ordenamento mínimo grau e pivotação parcial.

- O método direto foi ligeiramente superior ao iterativo no experimento com sistema real e nível de carga pesada (distante do máximo carregamento). 
As informações apresentadas acima podem ajudar no processo de escolha, mas a decisão final deve ficar a critério do usuário, o qual deve ter pleno conhecimento do problema e das características da matriz de coeficientes do sistema linear. $\mathrm{Na}$ presente tese, o problema enfoca estudos de estabilidade de sistemas elétricos de potencia, sendo a solução do sistema linear apenas parte dele.

\subsection{A Proposta e as Contribuições}

O problema investigado nesta tese enfoca a solução das EDAs inerentes aos estudos de estabilidade de curta e de longa-duração, com particular interesse na solução dos sistemas lineares através do GMRES pré-condicionado. Propostas com métodos iterativos para este tipo de problema têm sido apresentadas fazendo uso do trapezoidal implícito com passo fixo, restritas aos fenômenos de curta-duração. Nesta tese o BDF de ordem e passo variável foi considerado para a solução das equações diferenciais, resultando no BDF-GMRES. Investigações mostraram que o método GMRES mesmo pré-condicionado pode apresentar dificuldades de convergência. Procurou-se amenizar essas dificuldades enfocando a qualidade do pré-condicionador e uma vez que este é construído a partir da matriz Jacobiana do sistema elétrico (incluindo dispositivos de controle), optou-se por pré-processar esta matriz antes da sua construção. O pré-processamento consistiu em escalonar, normalizar e ordenar a matriz Jacobiana e análises envolvendo a distribuição espectral dos seus autovalores bem como seu número de condicionamento corroboraram as melhorias nas suas características e o pré-condicionador construído a partir desta matriz passou a apresentar qualidade muito superior ao construído sem pré-processamento, melhorando consequentemente o desempenho do GMRES. Estas estratégias se mostram muito eficientes quando o cenário envolver uma matriz Jacobiana malcondicionada, indefinida e próxima da singularidade, normalmente associada a uma condição de operação adversa (elevado carregamento, p.ex.).

Um pré-condicionador de qualidade não apenas possibilita ao GMRES solucionar sistemas lineares com matrizes Jacobianas mal-condicionadas como também pode solucionar o problema sem uma busca exaustiva por valores ótimos para seus parâmetros, além de evitar a estratégia de reinicialização já que a convergência pode ser obtida em poucas iterações como mostrado em um dos experimentos (exceto no instante do distúrbio). 
Por fim, foram implementados filtros digitais (opcional) disponíveis na literatura para o controle do erro resultante da variação do passo de integração e para a maioria das configurações testadas não foram observadas melhorias em termos de eficiência (redução no tempo de CPU) na solução do problema, e sim uma piora. As configurações testadas não foram desenvolvidas para o problema de interesse, pois esta tarefa não fazia parte dos objetivos da tese. Por outro lado, esta investigação fezse necessária por se tratar de uma sugestão feita por um membro da banca da defesa de proposta de tese.

\subsection{Trabalhos Publicados}

Como resultado do presente trabalho de pesquisa têm sido submetido e aprovado para publicação em revistas de âmbito nacional e internacional os seguintes:

- Pessanha, J.E.O; Paz, A.R.A; Poma, C.P.; Prada, R.B. Making Use of BDFGMRES Methods for Solving Short and Long-Term Dynamics In Power Systems. International Journal of Electrical Power \& Energy Systems, Volume 45, Issue 1, Pages 293-302, February 2013.

- Pessanha, J.E.O; Paz, A.R.A; Poma, C.P.; Prada, R.B. Solucionadores Iterativos para Simulação de Sistemas Elétricos de Potencia. XII Simpósio de Especialistas em Planejamento da Operação e Expansão Elétrica - Rio de Janeiro, SEPOPE 2012. Maio, 2012.

- Pessanha, J.E.O.; Paz, A.R.A.; Prada R.B. Aplicação do Método GMRES em Estudos de Estabilidade de Sistemas de Energia Elétrica. SBA - Sociedade Brasileira Automática. Julho, 2011.

\subsection{Trabalhos Futuros}

Como sugestões para futuros trabalhos, propõem-se:

- Avaliar o desempenho do GMRES usando o pré-condicionador baseado no erro (Portugal, 2010).

- Avaliar a eficiência do solucionador iterativo para sistemas de energia elétrica de maior-porte (Sistema Interligado Nacional completo - SIN) sob condições adversas de operação (níveis elevados de carga). 
- Usar ordenamento mínimo grau (Tinney 2) em substituição ao RCM e comparar desempenho.

- Implementação do algoritmo de pré-condicionamento utilizando técnicas de processamento paralelo.

- Averiguar adequação de um solucionador baseado nos métodos de Jacobianalivre e Newton-Krylov com pré-condicionador baseado no erro resultante, visando descartar o ajuste das tolerâncias relativa e absoluta do método GMRES.

- Desenvolver filtros digitais para o problema de interesse a fim de melhorar a variação do passo de integração sem comprometimento da eficiência computacional. 


\section{Referências Bibliográficas}

ALVARADO, F.L. Computational Complexity in Power Systems. IEEE Transactions on Power Apparatus and Systems, vol.1-95, n4, pp.1 028-1037, 1976.

ALVARADO, F.L.; DAG, H.; BRUGGENCATE, M.T. Block-Bordered Diagonalization and Parallel Iterative Solvers. In Proceedings of Colorado Mountain Conference on Iterative Methods, April 5-9, 1994.

AMESTOY, P.; DAVIS, T.A.; DUFF, I.S. An Approximate Minimum Degree Ordering Algorithm. SIAM J. Matrix Anal. Appl. 17, 4, 886-905, 1996.

ANAREDE. Manual de Treinamento do Programa de Análise de Redes ANAREDE/CEPEL. versão 9.1.3, 2007.

ANATEM. Manual de Treinamento do Programa de Análise de Transitórios Eletromecânicos ANATEM/CEPEL. versão V07-08/99. Maio 2000.

ARNOLDI, W.E. The Principle of Minimized Iteration in the Solution of the Matrix Eigenvalue Problem. Quart. Appl. Math., 9: 17-29, 1951.

ASTIC, J.Y.; BIHAIN, A.; JEROSOLIMSKI, M. The Mixed Adams-BDF Variable Step Size Algorithm to Simulate Transient and Long-Term Phenomena in Power Systems. IEEE Transactions on Power Systems, vol.9, n2, M ay 1994.

AXELSSON, O. A Generalized SSOR Method. BIT, 12: 443-467, 1972.

AXELSSON, O. Solution of Linear Systems of Equations: Iterative Methods. In V. A. Barker. Editor, Sparse Matrix Techniques, pages 1-51. Copenhagen 1976, Springer Verlag. Berlin, 1977.

AXELSSON, O.; VASSILEVSKI, P.S. A Black Box Generalized Conjugate Gradient Solver with Inner Iterations and Variable Step Preconditioning. SIAM, J. Matrix. Anal. Applic. 12(4): 625-644, 1991.

AXELSSON, O. Iterative Solution Methods. Cambridge Univ. Press, 1994.

BANK, R.E.; CHAN, T.F. An Analysis of the Composite Step Biconjugate Gradient Methods. Numer. Anal., 66: 295-319, 1993.

BACHER, R; BULLINGER, E. Application of Nonstationary Iterative Methods to an Exact Newton-Raphson Solution Process for Power Flow Equations. Proc. PSCC Conference, August 19-23, Dresden, Germany, pp. 453-459. 1996. 
BARRETT, R.; BERRY, M.; CHAN, T.F.; DEMMEL, J.; DONATO, I.J.; DONGARRA, J.; EIJKHOUT, V.; POZO, R.; ROMINE, C.; VAN DER VORST, H. Templates for the Solution of Linear Systems: Building Blocks for Iterative Methods. SIAM, Philadelphia, 2006.

BENZI, M.; TUMA, M. Orderings for Factorized Approximate Inverse Preconditioners. SIAM J. Sci. Comput. 21, p. 1851, 2000.

BENZI, M.B.; HAWS, J.C.; TUMA, M. Preconditioning Highly Indefinite and Nonsymmetric Matrices. SIAM, J. Sci. Comput. 22, p. 1333, 2000.

BENZI, M. Preconditioning Techniques for Large Linear Systems: A Survey. Journal of Computational Physics, 182(2): pp. 418-477, 2002.

BENZI, M.; JOUBERT, W.D.; MATEESCU, G. Numerical Experiments with Parallel Orderings for ILU Preconditioners. Electronic Transactions on Numerical Analysis 8, pp. 88-114, 1999a.

BENZI, M.; SZYLD, D.B.; VAN DUIN, A. Orderings for Incomplete Factorization Preconditioning of Nonsymmetric Problems. SIAM J. Sci. Comput. 20, p. 1652, 1999b.

BISSELING, R.H. Parallel Iterative Solution of Sparse Linear Systems on a Transputer Network, in Parallel Computation, eds. A. E. Fincham and B. Ford, Oxford University Press, Oxford, pp. 253-271, 1993.

BORGES, C.L.; COUTINHO, A.L.G.A.; FALCÃO, D.M. Solução de Fluxo de Potência em Ambiente Vetorial usando o Método do Gradiente Bi-Conjugado Estabilizado. XI Congresso Brasileiro de Automática, São Paulo. Anais do 11ํㅜ 1996.

BORGES, C.L.; FALCÃO, D.M.; COUTINHO, A.L.G.A. Utilização de Método Tipo Gradiente Conjugado na Aceleração do Fluxo de Potência em Computação Vetorial. XIV Seminário Nacional de Produção e Transmissão de Energia Elétrica, Belém, 1997.

BRAND, C.W. An Incomplete Factorization Preconditioning Using Repeated Red/Black Ordering. Numer. Math. 61, p. 433, 1992.

BRENAN, K.; CAMPBELL, S.; PETZOLD, L. Numerical Solution of Initial-Value Problems in Differential-Algebraic Equations. SIAM, Philadelphia, 1996.

BROWN, P.N.; HINDMARSH, A.C.; PETZOLD, L.R. Using Krylov Methods in the Solution of Large-Scale Differential-Algebraic Systems. SIAM J. Sci. Comp., 15, pp. 1467-1488, 1994. 
BULEEV, N. I. A Numerical Method for the Solution of Two-Dimensional and Three-Dimensional Equations of Diffusion. Math. Sb, 51:227-238 (in Russian), 1960.

BURDEN, R.L.; FAIRES, J.D. Numerical Analysis. PWS-KENT Publishing Company, Boston, 1989.

BUZAR, J.C. Análise em Regime Permanente e no Domínio do Tempo para Detecção e Visualização de Problemas de Controle de Tensão. Dissertação submetida à coordenação do Programa de Pós-Graduação da UFMA, 2003.

BYRNE, G.D.; HINDMARCH, A.C. A Polyalgorithm for the Numerical Solution of Ordinary Differential Equations. ACM, Transactions on Mathematical Software, vol. 1, no 1, pp. 71-96, 1975.

CANIZARES, C. Voltage Stability Assessment: Concepts, Practices and Tools. IEEE/PES, Product Number SP101PSS (ISBN 0780378695), May 2003.

CARVALHO MENDES, P. P. Aplicação de Redes Neurais Artificiais na Análise em Tempo Real da Estabilidade de Tensão de Regime-Permanente de Sistemas Elétricos de Potência. Proposta de Tese de Doutorado, COPPE-UFRJ, Dezembro 1997.

CHANIOTIS, D.; PAI, M.A. Iterative Solver Techniques in the Dynamic Simulation of Power System. Power Engineering Society Summer Meeting, 2000. IEEE vol.1, 1620 Page(s):609 - 613, July 2000.

CHAN, T.F.; GALLOPOULOS, E.; SIMONCINI, V.; SZETO, T; TONG, C.H. A Quasi Minimal Residual Variant of the Bi-CGSTAB Algorithm for Nonsymmetric systems. SIAM J.Sci.Comput., 15: 338-347, 1994.

CHEN, K. Matrix Preconditioning Techniques and Applications. Cambridge Monographs on Applied and Computational Mathematics, 2005.

CHEN, Y.; SHEN, C. A Jacobian-Free Newton-GMRES(m) Method with Adaptive Preconditioner and Its Application for Power Flow Calculations. IEEE Trans. on Power Systems, vol.21, n3, pp.1096-1103, August 2006.

CHEN, Y.; SHEN, C.; WANG, J. Distributed Transient Stability Simulation of Power Systems Based on a Jacobian-Free Newton-GMRES Method. IEEE Trans. on Power Systems, vol.24, n9, pp. 146-156, February 2009.

CHRISTIE, R.D. Power System Test Case Archive. The archive is available at http://www.ee.washington.edu/research/pstca, 1999. 
CHOWDHURY, B.H.; TAYLOR, C.W. Voltage Stability Analysis: V-Q Power Flow Simulation versus Dynamic Simulation. Power Systems IEEE Transactions on, vol.15 Issue:4, pp. $1354-1359,2000$.

CHOW, E.; SAAD, Y. Experimental Study of ILU Preconditioners for Indefinite Matrices. J. Comput. Appl. Math. 86, p. 387, 1997.

CIGRÉ Task Force 38-02-10. Modeling of Voltage Collapse Including Dynamic Phenomena. CIGRÉ Brochure No. 75 Summary in Electra, pp. 71-77, April 1993.

CIMMINO, G. Calcolo Approssimato per le Soluzioni dei Sistemi di Equazioni Lineari. Ric. Sci. Progr. Tecn. Econom. Naz., 9:326-333, 1939.

CONCORDIA, C.; DAVIDSON, D.R.; EWART, D.N.; KIRCHMAYER, L.K.; SCHULZ, R. P. Long-Term Power System Dynamics - A New Planning Dimension. CIGRÉ Paper 32-13, 1976.

CONCUS, P.; GOLUB, G.H.; O' LEARY, D.P. A Generalized Conjugate Gradient Method for the Numerical Solution of Elliptic Partial Differential Equations. In James R.Bunch and Donald J.Rose, Editors, Sparse Matrix Computations, pages 309332, Academic Press, New York, 1976.

CUTHILL, E. Several Strategies for Reducing the Bandwidth of Matrices. D. J. Rose and R. A. Willoughby, Plenum, New York, 1972.

CUTSEN, T.V. Voltage Stability: Fast Simulation and Decision Tree Approaches. NERC/EPRI Forum on Operational and Planning Aspects of Voltage Stability, Breckenridge, Colorado, September 14-15, 1992.

CUTSEN, T.V. An Approach to Corrective Control of Voltage Instability Using Simulation and Sensitivity. Athens Power Tech Conference, Athens, Greece, September 5-8, 1993a.

CUTSEN, T.V. Analysis of Emergency Voltage Situations. Proc. 11th Power Systems Computation Conference, Avignon, France, vol.1, pp. 323-330, 1993b.

CUTSEN, T.V.; JACQUEMART, Y.; MARQUET, J.N.; PRUVOT, P.A. Comprehensive Analysis of Mid-term Voltage Stability. IEEE Trans. on Power Systems, SM 511-6, Summer Meeting, 1994.

CUTSEN, T.V.; JACQUEMART, Y.; MARQUET, J.N.; PRUVOT, P. Extensions and Applications of a Mid-Term Voltage Stability Analysis Method. Proceedings of the 3rd International Workshop on Bulk Power System Voltage Phenomena - Voltage Stability and Security, Davos Switzerland, pp. 251-270, August 1994. 
CUTSEN, T.V.; MAILHOT, R. Validation of a Fast Voltage Stability Analysis Method on the Hydro-Québec Systems. IEEE/PES Winter Meeting, Baltimore, MD, January 21-25, 1996.

DAG, H.; ALVARADO, F.L. Direct Methods versus GMRES and PCG for Power Flow Problems. In the proceedings of NAPS, pp.274-278, October 5-9, 1993.

D'AZEVEDO, E.F.; FORSYTH, P.A.; TANG, P. Ordering Methods for Preconditioned Conjugate Gradient Methods Applied to Unstructured Grid Problems. SIAM J. Matrix Anal. Appl. 13, p. 944, 1992a.

D'AZEVEDO, E.F.; FORSYTH, P.A.; TANG, P. Towards a Cost Effective ILU Preconditioner With High Level Fill. BIT, 31:442-463, 1992b.

DANIEL, J.W. The Conjugate Gradient Method for Linear and Nonlinear Operator Equations. SIAM J. Numer. Anal., 4:10-26, 1967.

DAVIDSON, D.R.; EWART, D.N.; KIRCHMAYER, L.K. Long-Term Dynamic Response of Power System Disturbance: An Analysis of Major Disturbances. IEEE Trans., vol. PAS-94, n³, pp. 819-826, May/Jun e 1975.

DA CUNHA, R.D.; HOPKINS, T. A Parallel Implementation of the Restarted GMRES Iterative Algorithm for Nonsymmetric Systems of Linear Equations. Adv. Comp. Math., 2 (1994), pp. 261-277, 1994.

DECKER, I.C.; FALCÃO, D.M.; KASZKUREWICZ, E. Parallel Implementation of Power System Dynamic Simulation Methodology Using The Conjugate Gradient Method. IEEE Transactions on Power Systems, USA, vol.7, pp. 458-465, 1992.

DECKER, I.C.; FALCAO, D.M.; KASZKUREWICZ, E. Conjugate Gradient Methods for Power Systems Dynamic on Parallel Computers. IEEE Transactions on Power Systems, vol. 11, no. 3 , pp. 1218-1227, 1996.

DE STURLER, E. Incomplete Block LU Preconditioners on Slightly Overlapping Subdomains for a Massively Parallel Computer. Appl. Num. Math. 19, pp. 129-146, 1995.

DEUSE, J.; STUBBE, M. Dynamic Simulation of Voltage Collapse, paper 92 SM 396-2 PWRS, IEEE/PES Summer Meeting, July 12-16, 1992.

DI BROZOLO, G.R.; ROBERT, Y. Parallel Conjugate Gradient-like Algorithms for Solving Sparse Nonsymmetric Linear Systems on a Vector Multiprocessor. Parallel Comput., 11, pp. 223-239, 1989. 
DOI, S.; WASHIO, T. Ordering Strategies and Related Techniques to Overcome The Trade-Off between Parallelism and Convergence in Incomplete Factorizations. Parallel Comput. 25, p. 1995, 1999.

DONGORRA, J.J.; DUFF, I.S.; SORENSEN, D.C.; VAN DER VORST, H.A. Numerical Linear Algebra for High-Performance Computers. SIAM, Philadelphia, PA, 1998.

DUFF, I.S. MA28. Duff (Harwell Report 8730), 1977.

DUFF, I.S.; ERISMAN, A.M.; REID, J.K. Direct Methods for Sparse Matrices. Clarendon, Oxford, 1986.

DUFF, I.S.; MEURANT, G. The Effect of Ordering on Preconditioned Conjugate Gradients. BIT 29, p. 635, 1989.

DUFF, I.S.; KOSTER, J. The Design and Use of Algorithms for Permuting Large Entries to The Diagonal of Sparse Matrices. SIAM J. Matrix Anal. Appl. 20, p. 889, 1999.

DUFF, I.S.; VAN DER VORST, H.A. Developments and Trends in the Parallel Solution of Linear Systems, 1999.

DUFF, I.S.; KOSTER, J.K. On Algorithms for Permuting Large Entries to the Diagonal of a Sparse Matrix. SIAM, J. Matrix Anal. Appl. 22, p. 973, 2001.

DUTTO, L.C. The Effect of Ordering on Preconditioned GMRES Algorithm, for Solving the Compressible Navier-Stokes Equations. Int. J. Numer. Methods Eng. 36 , p. $457,1993$.

EIJKHOUT, V. Overview of Iterative Linear System Solver Packages. http://www.netlib.org/lapack/lawnspdf/lawn141.pdf.

EISENSTAT, S.C.; ELMAN, H.C.; SCHULTZ, M.H. Variational Iterative Methods for Nonsymmetric Systems of Linear Equations. SIAM Journal on Numerical Analysis, 20:345-357, 1983.

ENGELI, M.; GINSBURG, T.; RUTISHAUSER, H.; STIEFEL, E. Rened Iterative Methods for Computation of the Solution and the Eigenvalues of Self_Adjoint Boundary Value Problems. Birkhauser, Basel/Stuttgart, 1959.

EPRI. Report EL-6627. Long-Term Power System Dynamics. Final Report of Project 90-7, General Electric Company, April 1974.

EPRI Report EL-596. Midterm Simulation of Electric Power Systems. Project RP745, June 1975. 
EPRI Report EL-983. Long-Term Power System Dynamics, Phase III. Research Project 764-2, May 1982.

EPRI EL 4610: Extended Transient Midterm Stability Program, January 1987.

EPRI. User's Manual-Extended Transient/Midterm Stability Program Package (ETMSP Version 3.0), prepared by Ontario Hydro, June 1992.

EPRI. Operator Training Simulator. Final Report EL-7244, May 1991, prepared by EMPROS Systems International, 1991.

ERHEL, A.J. Parallel GMRES Version for General Sparse Matrices. Electronic Transactions on Numerical Analysis. vol3, pp. 160-176, December 1995.

EIROLA, T.; NEVANLINNA, O. Accelerating with Rank-One Updates. Linear Alg. Appl. 121:511-520, 1989.

EVANS, D.J. The Use of Pre-Conditioning in Iterative Methods for Solving Linear Equations with Symmetric Positive Definite Matrices. J. Inst. Maths. Applics., 4: 295-314, 1968.

FALCÃO, D.M.; MANZONI, A.; TARANTO, G. Combined Full and Fast Time-Domain Simulation. Proceedings of IX Symposium of Specialists in Electric Operational and Expansion Planning, SEPOPE, Rio de Janeiro, 2004.

FENG, T.; FLUECK, A.J.A. Message-passing Distributed-Memory Newton-GMRES Parallel Power Flow Algorithm. Power Engineering Society Summer Meeting, 2002. IEEE, pp.1477-1482 vol\%3, 25-25 July 2002a.

FENG, T.; FLUECK, A.J.A. Message-passing Distributed-Memory Parallel Power Flow Algorithm. Power Engineering Society Winter Meeting, 2002. IEEE, volo, pp. 211- 216, 2002b.

FLETCHER, R. Conjugate Gradient Methods for Indefinite Systems. In G.A Watson, Editor, Proceedings of the Dundee Biennal Conference on Numerical Analysis 1974, pages 73-89, Springer Verlag, New York, 1975.

FLUECK, A.; CHIANG, H.D. Solving the Nonlinear Power Flow Equations with an Newton Process and GMRES. In Proceedings of the IEEE International Symposium on Circuits and Systems, Atlanta, Georgia, 1996.

FLUECK, A.; CHIANG, H.D. Solving the Nonlinear Power Flow Equations with an Inexact Newton Method Using GMRES. Power Systems, IEEE Transactions on, vol.13, Issue 2, pp. $267-273$, May 1998. 
FREUND, R.W.; NACHTIGAL, N.M. An Implementation of the Look-Ahead Lanczos Algorithm for Non-Hermitian Matrices, Part 2. Technical Report 90.46, RIACS NASA Ames Research Center, 1990.

FREUND, R.W.A. Transpose Free Quasi-Minimal Residual Algorithm for NonHermitian Linear Systems. SIAM Journal on Scientific Computing, 14(2): 470-482, 1993.

FROWD, R.J.; GIRI, J.C.; PODMORE, R. Transient Stability and Long-Term Dynamics Unified. IEEE Transactions on Power Apparatus and Systems, vol. PAS-101, No10, pp. 3841-3849, October 1982.

GALIANA, F.D.; JAVIDI, H.; McFEE, S. On the Application of a Preconditioned Conjugate Gradient Algorithm to Power Network Analysis. IEEE Transactions on Power Systems, vol. 9, no. 2, pp. 629-636, 1994.

GALLIVAN, K.; SAMEH, A.; ZLATEV, Z. A Parallel Hybrid Sparse Linear System Solver. Computing Systems in Engineering 1(2-4): 183-195, 1990.

GEAR, C.W. Simultaneous Numerical Solution of Differential-Algebraic Equations. IEEE Transactions on Circuits Theory, vol. 18, n 1, pp. 90-95, 1971.

GEORGE, A. Nested Dissection of a Regular Finite Element Mesh. SIAM J. Numer. Anal. 10, pp. 345, 1973.

GEORGE, A.; LIU, J.W. Computer Solution of Large Sparse Positive Definite Systems. Prentice-Hall, Englewood Cliffs, NJ, 1981.

GEORGE, A.; LIU, J.W. The Evolution of the Minimum Degree Algorithm. SIAM Rev. 31, p. 1, 1989.

GIBBS, N.E.; POOLE, W.G.; STOCKMEYER, P.K. An Algorithm for Reducing the Bandwidth and Profile of a Sparse Matrix. SIAM J. Numer. Anal. 13, p. 236, 1976.

GOLUB, G.H.; VAN LOAB, C. Matrix Computations, 3 Edition. The Johns Hopkins University Press, 1996.

GREENBAUM, A. Iterative Methods for Solving Linear Systems. SIAM, Philadelphia, PA, 1997.

HALMOS, P.R. Finite-Dimensional Vector Spaces. Springer Verlag New York Inc, 1987.

HAYES, R.M. Iterative Methods of Solving Linear Systems on Hilbert Space. National Bureau of standards, Appl math Ser., 39:71-103, 1954. 
HEMMAPLARDH, K.; MANKE, J.W.; PAULY, W.R.; LAMONT, J.W. Considerations for Long-Term Dynamic Simulation Program. IEEE Trans., vol. PAS-95, No. 1, pp. 96-104, January/February 1976.

HESTENES, M.R.; STIEFEL, E.L. Methods of Conjugate Gradients for Solving Linear Systems. J. Res. Natl. Bur. Stand. 49, p. 409, 1952.

HILL, D.J.; LOF, PER-ANDERS.; ANDERSSON, G. Analysis of Long-Term Voltage Stability. Tenth Power System Computing Conference, pp. 1252-1259, Graz, Austria, 1990.

HISKENS, I. Analysis Tools For Power Systems Contending with Nonlinearities. IEEE Proceedings, vol.83, n`11, pp. 1573-1587, Nove mber 1995.

HONG, C.; SHEN, C.M. Implementation of Parallel Algorithms for Transient Stability Analysis on a Message Passing Multicomputer. Power Engineering Society Winter Meeting, 2000. IEEE, pp.1410-1415 vol.2, 2000.

IEEE PES Power Syst. Eng. Comm Parallel Processing in Power Systems Computation. Power Systems, IEEE Transactions on, vol.7, no.2, pp.629-638, May 1992.

JACKSON, K.R.; SACKS-DAVIS, R. An Alternative Implementation of Variable Step Size Multistep Formulas for Stiff ODEs. ACM Trans. Math. Software, 295-318, 1980.

JARDIM, J.L.; FERNANDES, M.A.; DA SILVA NETO, C.A. Uma Ferramenta para Simulação de Fenômenos Dinâmicos de Longa Duração. XV SNPTEE, Foz do Iguaçu-PA, Brasil, 1999.

JARDIM J.L.; NETO C.; SANTOS M.G. Brazilian System Operator Online Security Assesment System. In Proceeding of IEEE Power System Conference and Exhibition, Atlanta, GA, Oct 30-Nov2 , 2006.

JEA, K.C.; YOUNG, D.M. Generalized Conjugate-Gradient Acceleration of Nonsymmetrizable Iterative Methods. Linear Alg Appl., 34:159-194, 1980.

KACZMARZ, S. Angenaherte Auflosung von Systemen Linearer Gleichungen. Bulletin International de l'Academie Polonaise des Sciences et Letters, pages 355-357, 1939.

KANIEL, S. Estimates for Some Computational Techniques in Linear Algebra. Math. Comp., 20:369-378, 1966.

KARUSH, W. Convergence of a Method of Solving Linear Problems. Proc. Amer. Math Soc., 3:839-851, 1952. 
KULKANI, A.W; PAI, M.A; SAUER, P. Iterative Solver Techniques in Fast Dynamic Calculations of Power Systems. Energy Power \& Electric Systems, 23, 237-244, 2001.

KUNDUR, P. Power System Stability and Control, McGraw-Hill, 1994.

KUNDUR, P.; MORISON, G.K. A Review of Definitions and Classification of Stability Problems in Today's Power Systems. Panel Session on Stability Terms and Definitions, IEEE PES Meeting, February 2-6, New York, N.Y, 1997.

KURITA, A.; OKUBO, H.; OKI, K.; AGEMATSU, S.; KLAPPER, D. B.; MILLER, N. W.; PRICE, W.W.; SANCHEZ-GASCA, J.J.; WIRAGAU, K.A.; YOUNKINS, T.D. Multiple Time-Scale Power System Dynamic Simulation. paper 92 WM 128-9 PWRS, 1992 IEEE/PES Winter Meeting, New York, January 1992.

LACHS, W.R. Dynamic Study of an Extreme System Reactive Deficit. IEEE Transactions on Power Apparatus and Systems. vol. PAS-104, N99, pp. 2420-2426, September 1985.

LANCZOS, C. An Iteration Method for The Solution of The Eigenvalue Problem of Linear Differential and Integral Operators. Journal of Research of the National Bureau of Standards, 45: pp. 255-282, 1950.

LANCZOS, C. Solution of Systems of Linear Equations by Minimized Iterations. Journal of Research of the National Bureau of Standards 49:33-53, 1952.

LE BORNE, S. Ordering Techniques for Two- and Three-Dimensional ConvectionDominated Elliptic Boundary Value Problems. Computing 64, p. 123, 2000.

LOF, P.A. On Static Analysis of Long-Term Voltage Stability in Electric Power Systems. Ph.D. Thesis, Kungl Tekniska Hogskolan - Royal Institute of Technology, Stockholm, Sweden, 1995.

LOUD, L.; ROUSSEAUX, P; LefEBVRE, D.; VAN CUTSEM, T.A. Time-Scale Decomposition-Based Simulation Tool for Voltage Stability Analysis. Power Tech Proceedings, 2001. IEEE Porto, vol.2, pp.6, 2001.

MAYER, C.D. Matrix Analysis and Applied Linear Algebra. SIAM, 2004.

MEEKER, K. Digital Filter Stepsize Control of DASPK and its Effect on Control Optimization Performance. Master of Science Thesis in Computer Science in the Graduate Division of the University of California, Santa Barbara, 2004. 
MEIJERINK, J.A.; VAN DER VORST, H.A. An Iterative Solution Method for Linear Systems of Which the Coefficient Matrix is a Symmetric M-Matrix. Mathematics of Computations, 31(137): 148-162, 1977.

MILLER, R.K.; MICHEL, A.N. Ordinary Differential Equations. Academic Press, 1982.

MORGAN, R.B. A Restarted GMRES Method Augmented by Eigenvectros. SIAM J. Matrix Analysis Appl., vol.16, n\%, pp.1154-1171, 1995.

OLIPHANT, T.A. An Extrapolation Process for Solving Linear Systems. Quart. Appl. Math., 20:257-267, 1962.

ONS. Operador Nacional do Sistema Brasileiro. Arquivo Anatem correspondente ao mês Abril do ano 2005 e perfil de carga pesada (http://www.ons.org.br), 2005.

OSTERBY, O.; ZLATEV, Z. Direct Methods for Sparse Matrices. Springer Verlag, New York, 1983.

PAIGE, C.C.; SAUNDERS, M.A. Solution of Sparse Indefinite Systems of Linear Equations. SIAM J. Numer. Anal., 12:617-629, 1975.

PAI, M.A.; SAUER, P.W.; KULKARNI, A.Y. A Preconditioned Iterative Solver for Dynamic Simulation of Power Systems. Circuits and Systems, ISCAS '95, 1995 IEEE International Symposium, vol.2, pp. 1279-1282, Seattle, WA, USA, 1995.

PAI, M.; DAG, H. Iterative Solver Techniques in Large Scale Power System Computation. Decision and Control Proceedings of the 36th IEEE Conference on, pp. 3861 - 3866, 1997.

PAL, M.K. Voltage Stability Conditions Considering Load Characteristics. IEEE Transactions on Power System, vol.7, n`1, pp. 243-2 49, February 1992.

PARLETT, B.N.; TAYLOR, D.R.; LIU, Z.S. A Look-Ahead Lanczos Algorithm for Nonsymmetric Matrices. Mathematics of Computation, 44:105-124, 1985.

PESSANHA, J.E.O. Análise do Fenômeno da Estabilidade de Tensão no Domínio do Tempo: Simulação dos Períodos Transitório e de Longo-Termo. Tese de Doutorado, PUC-RJ, Departamento de Engenharia Elétrica, 1997.

PESSANHA, J.E.O.; PRADA, R.B. Avaliação de Condições de Instabilidade Transitória de Tensão. XIV Congresso Chileno de Ingenieria Elétrica, vol.1, pp. 162166, Antofogasta, Chile, 2001.

POMMERELL, C. Solution of Large Unsymmetric Systems of Linear Equations. PhD thesis, Swiss Federal Institute of Technology, Zurich, 1992. 
PORTUGAL, C.E. Um Solucionador Iterativo Para Sistemas-Lineares: Aplicação no Problema do Fluxo de Carga. Tese de Doutorado PUC-RJ, 2010.

POWER SYSTEM TEST CASE. www.ee.washington.edu/research/pstca. 2007.

PRAIS, M.; ZHANG, G.; BOSE, A.; CURTICE, D. Operator Training Simulator: Algorithms and Test Results. IEEE Transactions on Power Systems, vol.4, n⿳⺈, p p. 1154-1159, August 1989a.

PRAIS, M.; JOHNSON, C.; BOSE, A.; CURTICE, D. Operator Training Simulator: Components Models. IEEE Transactions on Power Systems, vol.4, n3, p p. 11601166, August 1989b.

PRESS, W.H.; FLANNERY, B.P.; TEUKOLSKY, S.A. VETTERLING, W.T. Numerical Recipes. Cambridge University Press, 1988.

QUINTANA, V.H.; VARGAS, L. Voltage Stability as Affected by Discrete Changes in the Topology of Power Networks. IEE Proceedings Generation, Transmission and Distribution, vol.141, n\%4, pp. 346-352, July 1994.

REID, J.K. On the Method of Conjugate Gradients for the Solution of Large Sparse Systems of Linear Equations. In. J. K. Reid, Editor, Large Sparse Sets of Linear Equations, pages 231-254. Academic Press, 1971.

$\mathrm{REICH}, \mathrm{E}$. On the Convergence of the Classical Iterative Method of Solving Linear Simultaneous Equations. Ann. Math. Statist., 20:448-451, 1949.

SAAD, Y.; SCHULTZ, M. H. Parallel Implementations of Preconditioned: Conjugate Gradient Methods. Research Report YALEU/DCS/RR-425. October 1985.

SAAD, Y.; SCHULTZ, M.H. GMRES: A Generalized Minimal Residual Algorithm for Solving Nonsymmetric Linear Systems. SIAM J. Sci. Stat. Comput. 7, p. 856, 1986.

SAAD, Y. Preconditioning Techniques for Indefinite and Nonsymmetric Linear Systems. Journal of Computational and Applied Mathematics 24: 89-105, 1988.

SAAD, Y. Iterative Methods for Sparse Linear Systems, 2nd ed. Society for Industrial and Applied Mathematics, Philadelpha, 2003.

SAUER, P.W.; Pai, M.A. A Comparison of Discrete vs Continuos Dynamic Model of Tap-Changing-Under-Load Transformers. III Seminar on Voltage Stability, Security \& Control, 22-26 August 1994. Davos, Switzerland, 1994. 
SEMLYEN, A. Fundamental Concepts of a Krylov Subspace Power Flow Methodology. Power Systems, IEEE Transactions on, vol.11, Issue 3, Page(s):1528 1537, 1996.

SCHULZ, R.P. Capabilities of System Simulation Tools for Analyzing Severe Upsets. Proceedings of International Symposium on Power System Stability, Ames, Iwoa, pp. 209-215, May 13-15, 1985.

SHAMPINE, L.F.; GORDON, M.K. Computer Solution of Ordinary Diferential Equations. W.H. Freeman and Co. San Francisco, CA, 1975.

SHADID J.N.; TUMINARO R.S. Sparse Iterative Algorithm Software for LargeScale MIMD Machine: An Initial Discussion and Implementation. Tech. Rep., DOE's Massively Parallel Computing Research Laboratory, Sandia National Laboratories, Albuquerque, 1991.

SEAGER, M. K. Parallelizing Conjugate Gradient for the CRAY X-MP. Parallel Computing, vol.3, Issue 1, pp. 35-47, March 1986.

SIMON, H. D. Direct Sparse Matrix Methods. In James C. Almond and David M. Young, Editors, Modern Numerical Algorithms for Supercomputers, pages 325-444, Austin. The University of Texas at Austin, Center of High Performance Computing, 1989.

SLEIJPEN, G. L. G.; FOKKEMA, D. R. BICGSTAB(I) for Linear Equations Involving Unsymmetric Matrices with Complex Spectrum. ETNA, 1:11-32, 1993.

SLOAN, S.W. An Algorithm for Profile and Wavefront Reduction of Sparse Matrices. Int. J. Numer. Methods Eng. 23, p. 239, 1986.

SODERLING, G. Digital Filters in Adaptive Time-Stepping. ACM Trans. Math. Software, 29:1-26, 2003.

SODERLING, G.; WANG, L. Adaptive Time-Stepping and Computational Stability. Journal of Computational Methods in Sciences and Engineering, vol.2, n⿳3, 2, pp. 1-3, 2003.

SONNEVELD, P. CGS: A Fast Lanczos-type Solver for Nonsymmetric Linear Systems. SIAM J. Sci. Statist. Comput., 10:36-52, 1989.

STOER, J. Introduction to Numerical Analysis. 2 Edition. Springer-Verlag, 1993.

STURLER, E.; VAN DER VORST, H.A. Reducing the Effect of Global Communication in GMRES(m) and CG on Parallel Distributed Memory 
Computers. Journal Applied Numerical Mathematics archive, vol.18. Issue 4, Oct. 1995.

STUBBE, M.; BIHAIN, A.; DEUSE, J.; BAADER, J.C. STAG - A New Unified Software Program for the Study of the Dynamic Behavior of Electrical Power Systems. IEEE Trans., Vol. PWRS-4, No. 1, pp. 129-138, February 1989.

TAYLOR C.W. Modeling of Voltage Collapse Including Dynamic Phenomena. Task Force 38.02.10, Cigré, March, 1993.

TAYLOR C.W. Power System Voltage Stability. McGraw-Hill, NewYork, USA, 1994.

TAYLOR C.W. Maybe I Can't Define Stability but I Know It When I See It, IEEE/PES panel on Stability Terms and Definitions, New York, February, 1997.

WATKINS, D.S. Fundamentals of Matrix Computations. John Wiley and Sons, New York, 1991.

WILKINSON, J.H.; REINSCH, C. Handbook for Automatic Computation. vol. II, Linear Algebra. Springer Verlag, New York, 1971.

VAN DER VORST, H.A. Bi-CGSTAB: A Fast and Smoothly Converging Variant of $\mathrm{Bi}-\mathrm{CG}$ for the Solution of Non-symmetric Linear Systems. SIAM J.Sci.Statist.Comput., 13:631-644, 1992.

VAN DER VORST, H.A. Iterative Krylov Methods for Large Linear Systems. Cambridge University Press, Cambridge: vol. 13 of Cambridge Monographs on Applied and Computational Mathematics, 2003.

VAN DER SLUIS, A.; VAN DER VORST, H.A. The Rate of Convergence of Conjugate Gradients. Numericshe Mathematik, 48: 543-560, 1986.

VARGA, R.S. Factorization and Normalized Iterative Methods. In R.E. Langer, editor, Boundary Problems in Differential Equations, pages 121-142. Univ. of Wisconsin Press, Madison, 1960.

VALLI, A.M.P.; CAREY, G.F.; COUTINHO, A.L.G.A. Control Strategies for Timestep Selection in Infinite Element Simulation of Incompressible Flows and Coupled Reaction-Convection-Difusion Processes. Int. J. Numer. Meth. Fluids, 47: 201-231, 2004.

VINSOME, P.K.W. ORTHOMIN: An Iterative Method for Solving Sparse Sets of Simultaneous Linear Equations. In Proc. Fourth Symposium on Reservoir Simulation, pages 149-159. Society of Petroleum Engineers of AIME, 1976. 
VOURNAS, C.D.; CUTSEM, T.V. Voltage Oscillations with Cascade Load Restoration. IEEE /KTH Stockholm Power Tech Conference, Stockholm, Sweden, June 18-22, 1995.

YOUNG, D.P.; MELVIN, R.G. JOHNSON, F.T.; BUSSOLETTI, J.E., WIGTON, L. B.; SAMANT, S.S. Application of Sparse Matrix Solvers as Effective Preconditioners. SIAM Journal on Scientic and Statistical Computing 10: 1186-1199, 1989.

ZHANG, J.A. Multilevel Dual Reordering Strategy For Robust Incomplete LU Factorization of Indefinite Matrices. SIAM J. Matrix Anal. Appl. 22, 925, 2001.

ZLATEV, Z. Use of Iterative Refinement in the Solution of Sparse Linear Systems. SIAM Journal on Numerical Analysis, 19: 381-399, 1982. 


\section{Apêndice A - Fórmulas de Diferenciação Regressiva (BDF)}

Esta é uma importante classe de métodos multipasso e de particular de interesse para o presente trabalho, em particular pelo seu desempenho nas aplicações a sistemas rígidos de equações diferenciais. Está baseado na interpolação nos pontos de solução $\mathrm{x}_{\mathrm{n}+1-\mathrm{i}}$ ao invés das derivadas.

$$
\dot{x}_{n+1-i}=f\left(t_{n+1}, x_{n+1-i}\right)
$$

Considera-se $\Pi_{\mathrm{k}}^{\mathrm{p}}$ um polinômio de grau $\mathrm{k}-1$, que interpola os $\mathrm{k}$ pontos

$$
x_{n+1-i} \quad i=1, \ldots \ldots, k
$$

Então, usando a formulação polinomial de Lagrange, (A.2) pode ser expressa por:

$$
\begin{gathered}
\pi_{k}^{p}(t)=\sum_{i=1}^{k} L_{i}^{k-1}(t) x_{n+1-i} \\
L_{i}^{k}=\frac{\left(x-x_{0}\right)\left(x-x_{1}\right) L\left(x-x_{k-1}\right)\left(x-x_{k+1}\right) L\left(x-x_{i}\right)}{\left(x_{k}-x_{0}\right)\left(x_{k}-x_{1}\right) L\left(x_{k}-x_{k-1}\right)\left(x_{k}-x_{k+1}\right) L\left(x_{k}-x_{i}\right)}
\end{gathered}
$$

Extrapolando este polinômio, um novo ponto de solução $\mathrm{x}_{\mathrm{n}+1}^{\mathrm{p}}$ pode ser previsto como:

$$
x_{n+1}^{p}=\pi_{k}^{p}\left(t_{n+1}\right)=\sum_{i=1}^{k} L_{i}^{k-1}\left(t_{n+1}\right) x_{n+1-i}
$$

Introduzindo os coeficientes $\alpha_{k-i}^{p}=-L_{i}^{k-1}\left(t_{n+1}\right)$ em (A.4), resulta em:

$$
x_{n+1}^{p}=-\sum_{i=1}^{k} \alpha_{k-i}^{p} x_{n+1-i}
$$

Nesta fórmula, a informação referente à função f da Equação (A.1) não é incorporada, sendo útil num esquema de predição (superíndice p) - correção (superíndice c). A fórmula corretor BDF é obtida considerando o polinômio $\pi_{\mathrm{k}+1}^{\mathrm{c}}$ de grado k satisfazendo as condições:

$$
\begin{aligned}
& \pi_{k+1}^{c}\left(t_{n+1-i}\right)=x_{n+1-i}, \quad i=0, \ldots \ldots, k \\
& \dot{\pi}_{k+1}^{c}\left(t_{n+1-i}\right)=f\left(t_{n+1-i}, x_{n+1-i}\right) \quad i=0, \ldots \ldots, k
\end{aligned}
$$


As primeiras são condições de interpolação usando valores desconhecidos $x_{n+1}$, definido implicitamente por (A.7). Com os coeficientes

$$
\alpha_{k-i}^{c}=\frac{L_{i}^{k}\left(t_{n+1}\right)}{L_{0}^{k}\left(t_{n+1}\right)} \quad \beta_{k}^{c}=\frac{1}{h_{n} L_{0}^{k}\left(t_{n+1}\right)}
$$

Onde $L_{i}^{k}$ agora corresponde aos pontos de interpolação $x_{n+1-i}, i=0, \cdots, k$. A Equação (A.7) pode ser representada por:

$$
x_{n+1}=-\sum_{i=1}^{k} \alpha_{k-i}^{c} x_{n+1-i}+h_{n} \beta_{k}^{c} f\left(t_{n+1}, x_{n+1}\right)
$$

Este é o esquema corretor das fórmulas de diferenciação regressiva (BDF). O esquema predição-correção para o método BDF tem a seguinte forma:

$$
\begin{array}{ll}
\text { Predição (P) } & x_{n+1}^{P}=-\sum_{i=1}^{k} \alpha_{k-i}^{p} x_{n+1-i} \\
\text { Avaliação (E) } & \dot{x}_{n+1}=f\left(t_{n+1}, x_{n+1}^{p}\right) \\
\text { Correção (C) } & x_{n+1}=x_{n+1}^{p}-\sum_{i=1}^{k} \bar{\alpha}_{k-i}^{c} x_{n+1-i}+h_{n} \bar{\beta}_{k}^{c} \dot{x}_{n+1} \\
\text { Avaliação (E) } & \dot{x}_{n+1}=f\left(t_{n+1}, x_{n+1}\right)
\end{array}
$$

com $\bar{\alpha}^{c}=\alpha^{c}-\alpha^{p}$. A fórmula implícita pode ser resolvida iterativamente pela aplicação de um dos esquemas já mencionado, $\mathrm{P}(\mathrm{EC})^{\mathrm{m}} \mathrm{E}$ com $\mathrm{m} \geq 1$, embora, na prática, geralmente os métodos BDF sejam implementados com método Newton. 


\section{Apêndice B - Diagramas de Blocos dos Principais Controles Dinâmicos Implementados no Programa Computacional}

\section{B.1 Modelos implementados no programa computacional}

Em virtude a grande quantidade de informação dos diferentes dispositivos de controle associado aos sistemas de energia elétrica se considera por conveniente apresentar unicamente os diagramas de blocos dos controles mais representativos do sistema interligado norte-nordeste brasileiro e dos sistemas-testes utilizados nos experimentos numéricos do Capítulo 4. Na sequência são listadas as empresas elétricas do setor Brasileiro com seus correspondentes controles definidos pelo usuário - CDU (Anatem, 2000):

Centrais Elétricas do Norte do Brasil S.A - ELETRONORTE

- CS Vila do conde CDU 1306

- CS Marabá CDU 1307

- CS Presidente Dutra CDU 1308

- CS Imperatriz CDU 1310

- UHE Tucurui 2 Grupo $5 \quad$ CDU 1305

- UHE Tucurui 2 Grupo $5 \quad$ CDU 1343

- UHE Tucurui 2 Grupo 5 CDU 1373

- UHE Tucurui 2 Grupo $6 \quad$ CDU 1311

- UHE Tucurui 2 Grupo $6 \quad$ CDU 1344

- UHE Tucurui 2 Grupo $6 \quad$ CDU 1374

Companhia de Energia Elétrica do estado do Tocantins - CELTINS

- UHE Lajeado CDU 1500

- UHE Lajeado CDU 1540

- UHE Lajeado CDU 1570

Centrais Hidrelétricas São Francisco - CHESF

- CS Camaçari CDU 1234 
- CS Teresina

CDU 1233

- CS Bom Jesus da Lapa

CDU 1237

- CS Irecê

CDU 1238

ITAPEBI Geração de Energia S/A - ITAPEBI

- UHE Itapebi CDU 2100

- UHE Itapebi CDU 2140

- UHE Itapebi CDU 2270

Empresa de Geração e Transmissão de Energia - FURNAS

- CS Serra da Mesa CDU 117 (RAT- UNITROL-P-ABB)

Os valores dos parâmetros de cada CDU podem ser encontrados no site oficial do Operador Nacional do Sistema correspondente ao patamar carga pesada do mês de Abril do ano 2005 (ONS, 2005). 
B.2 Máquina síncrona de polos salientes - MS

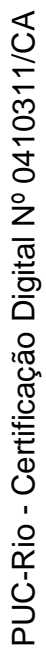

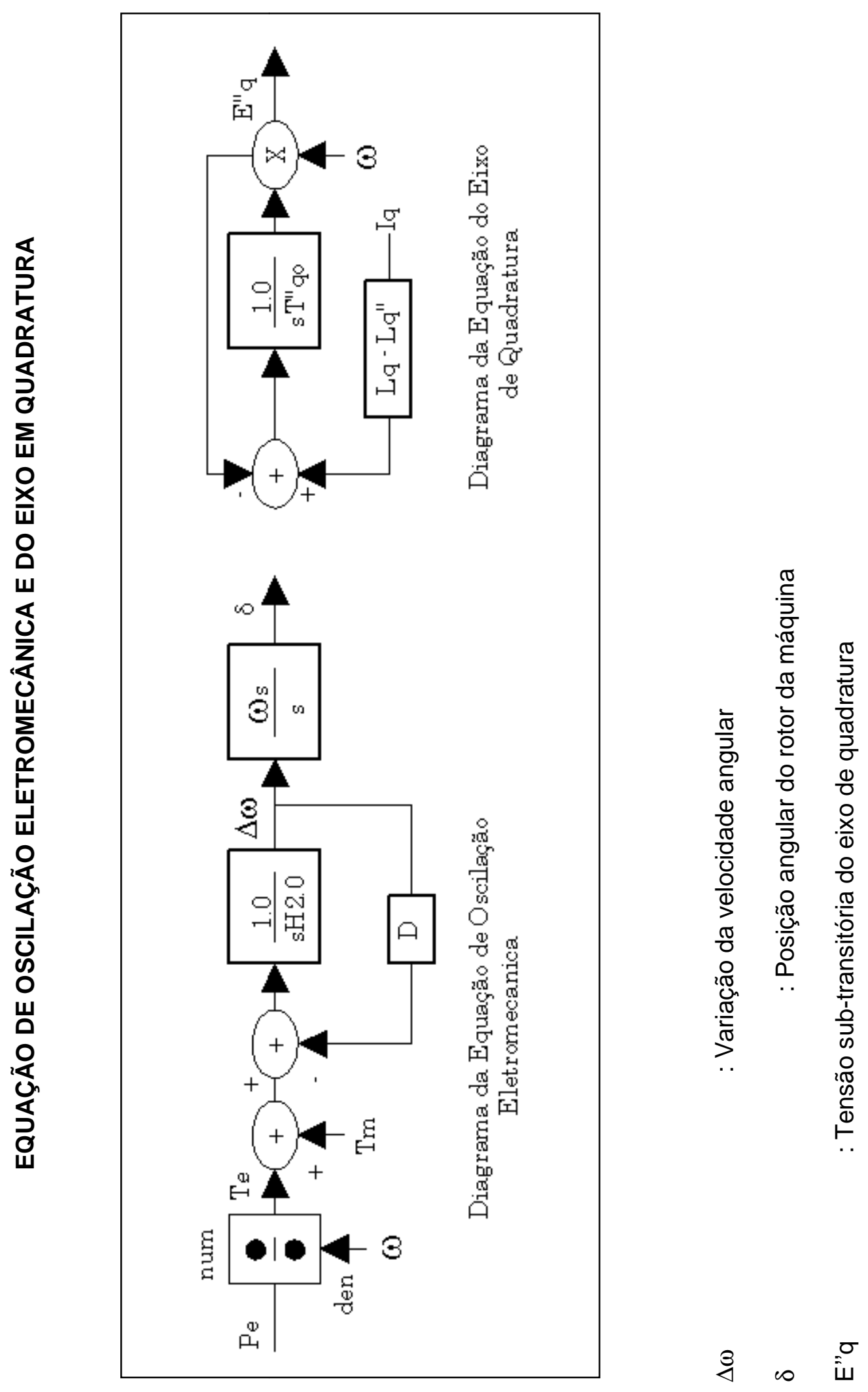




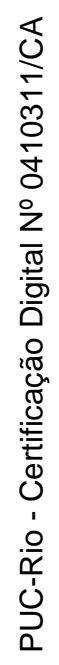

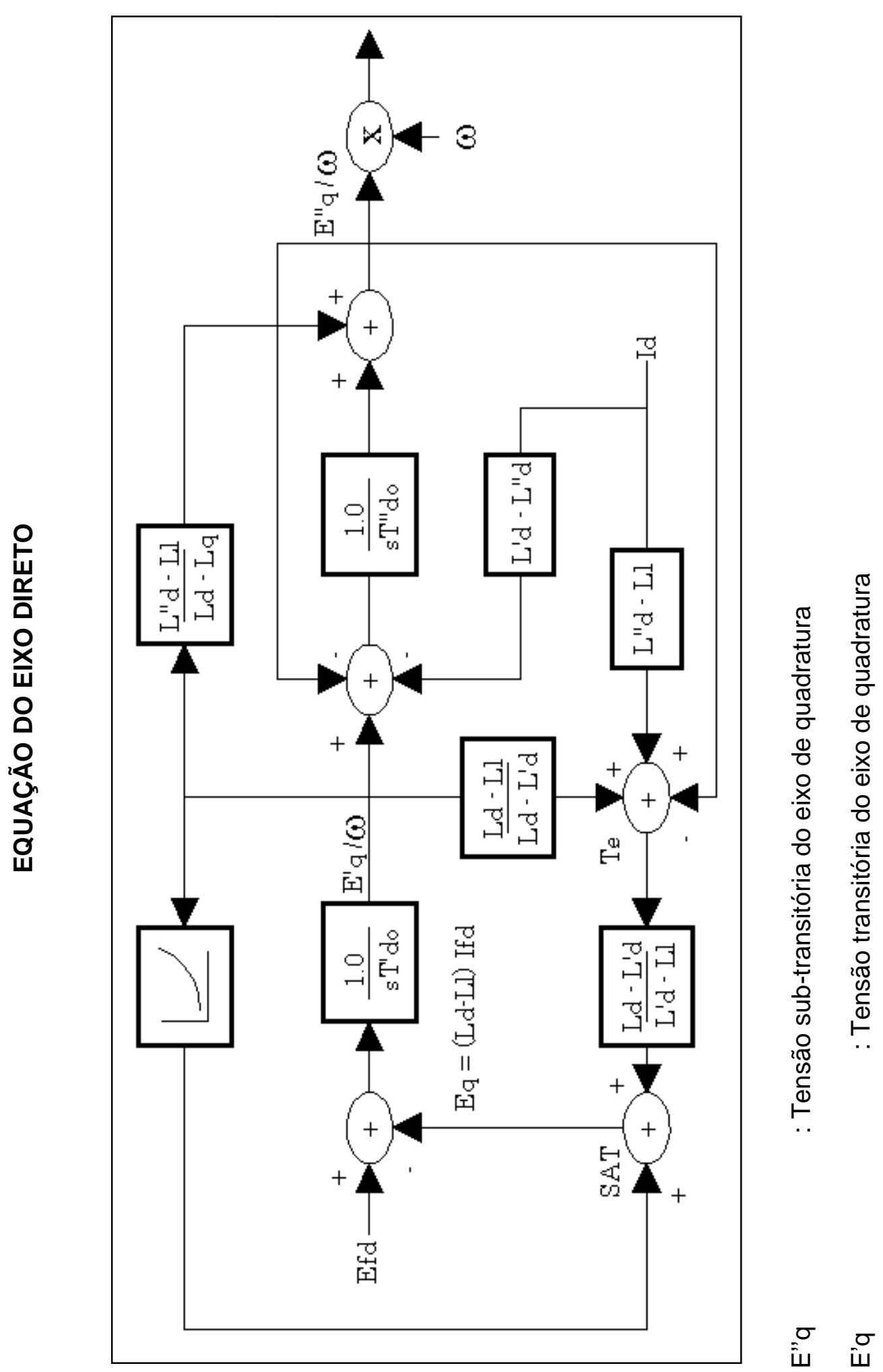


B.3 Regulador automático de tensão - RAT

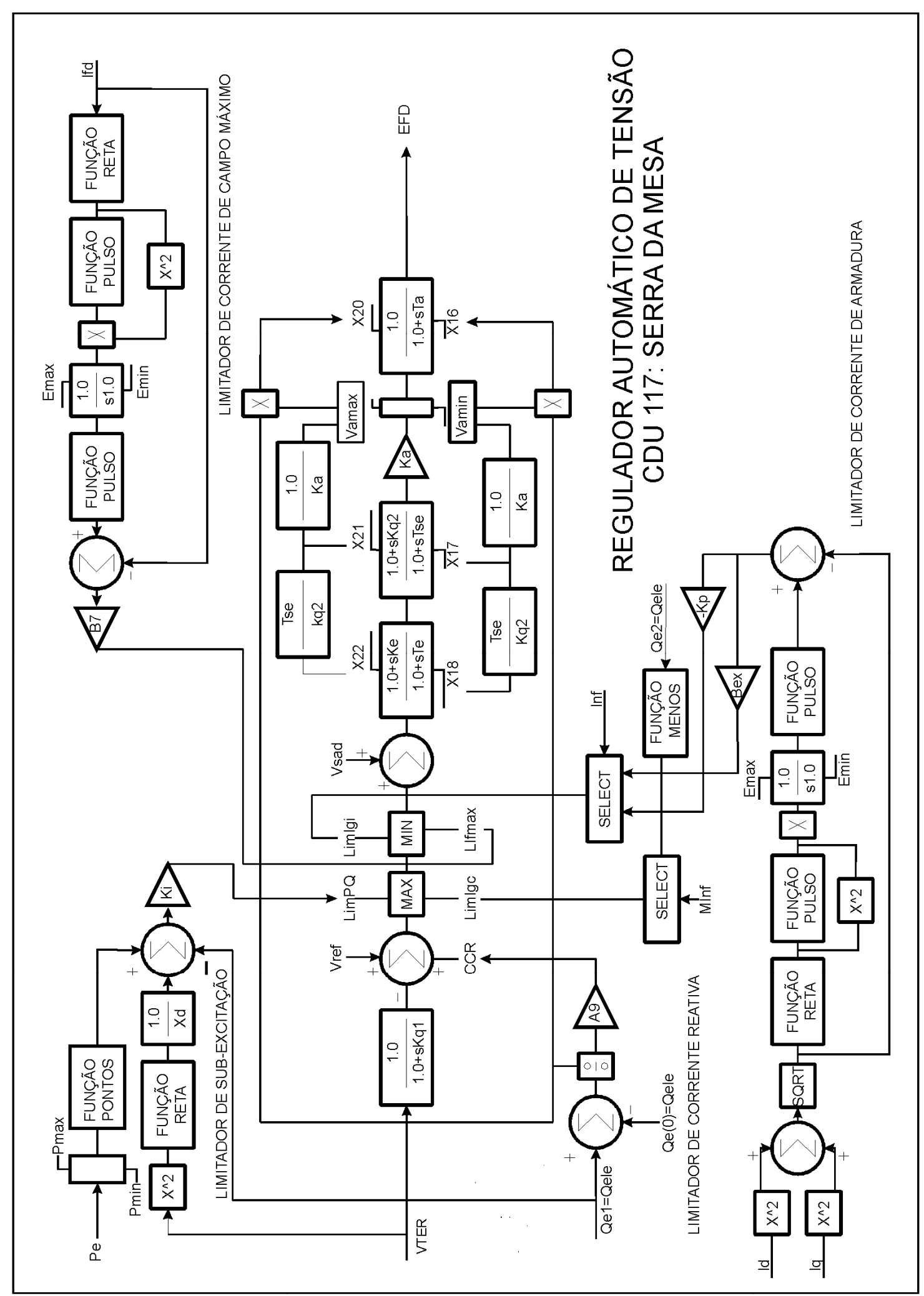




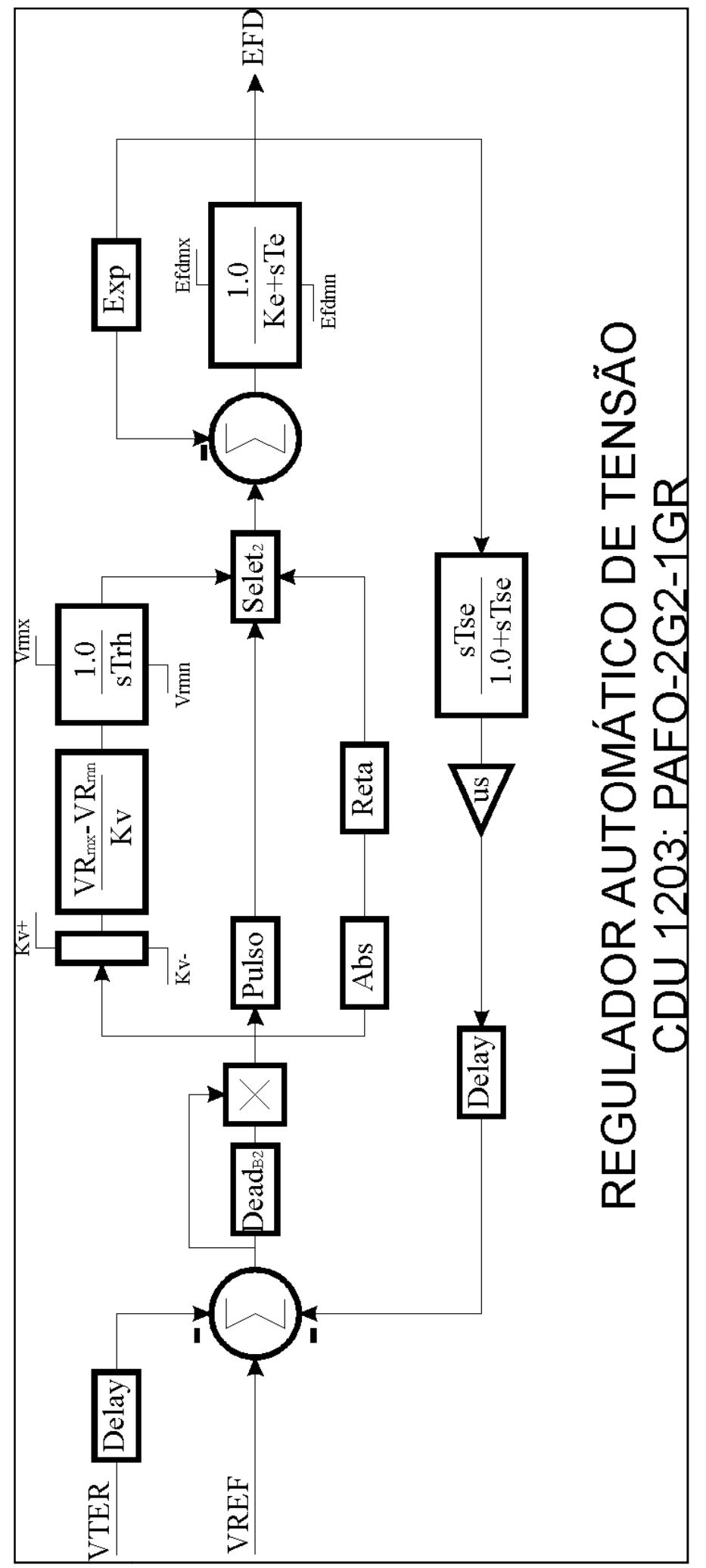




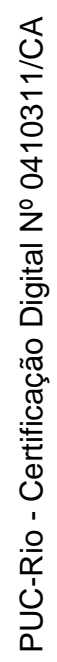

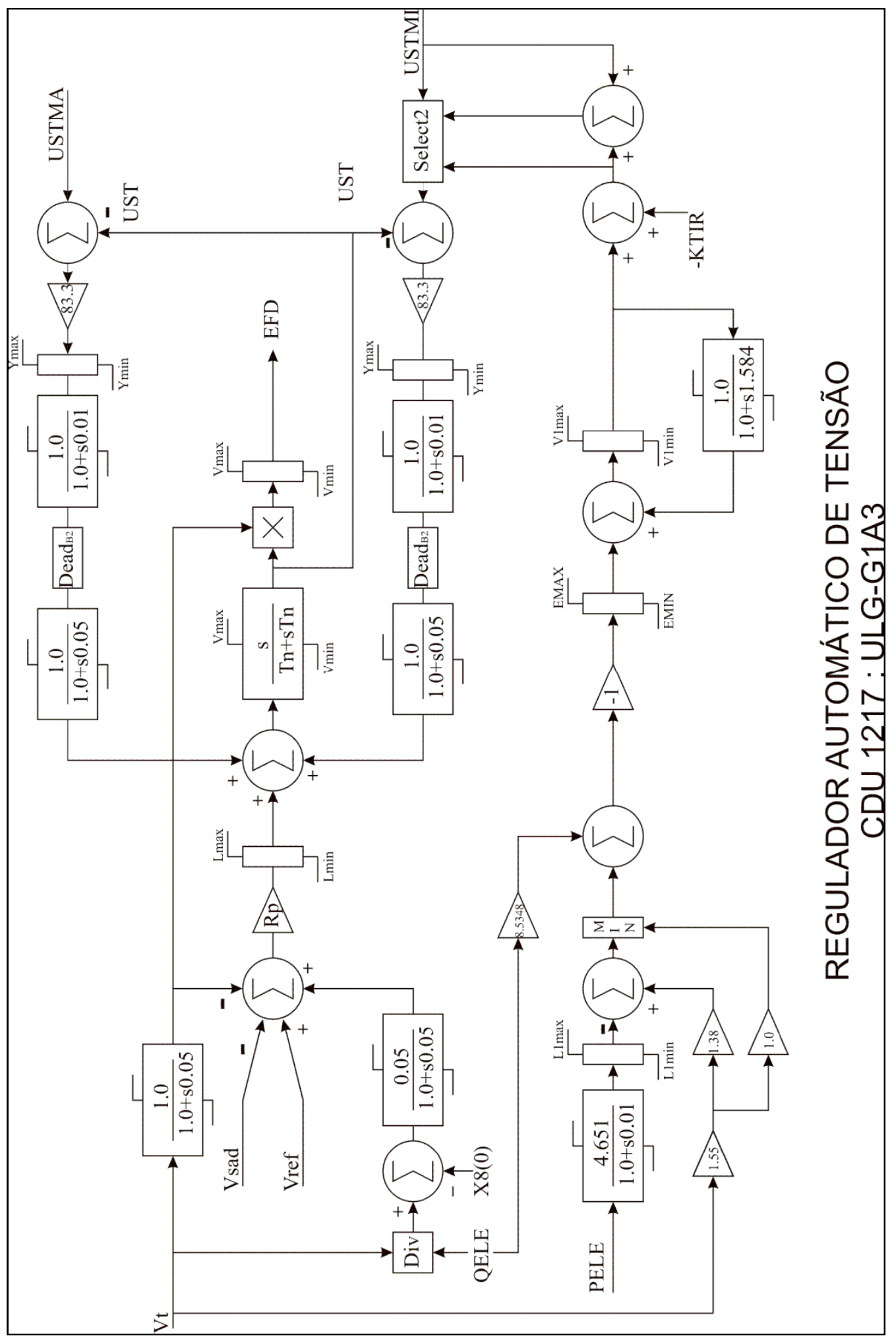




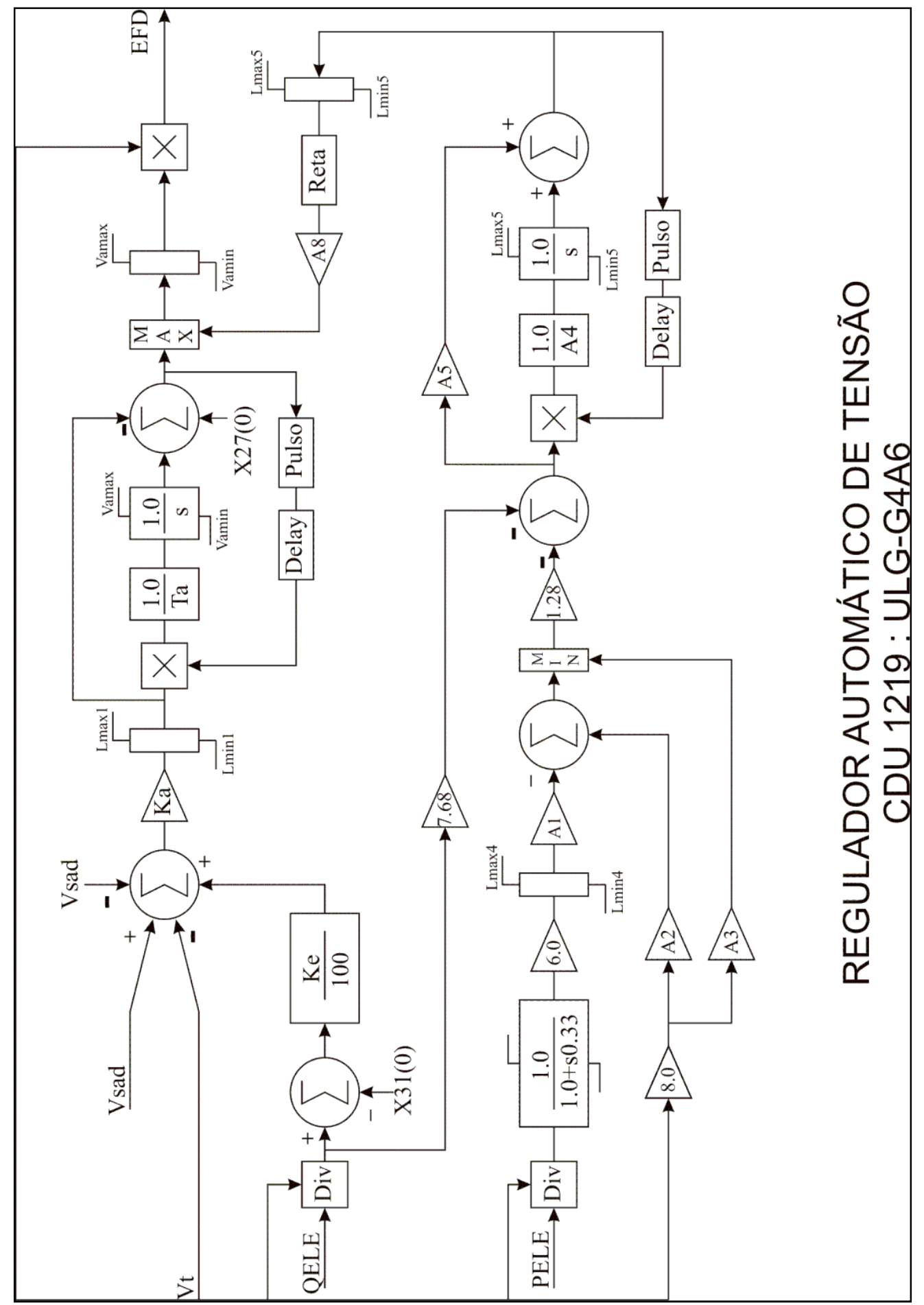




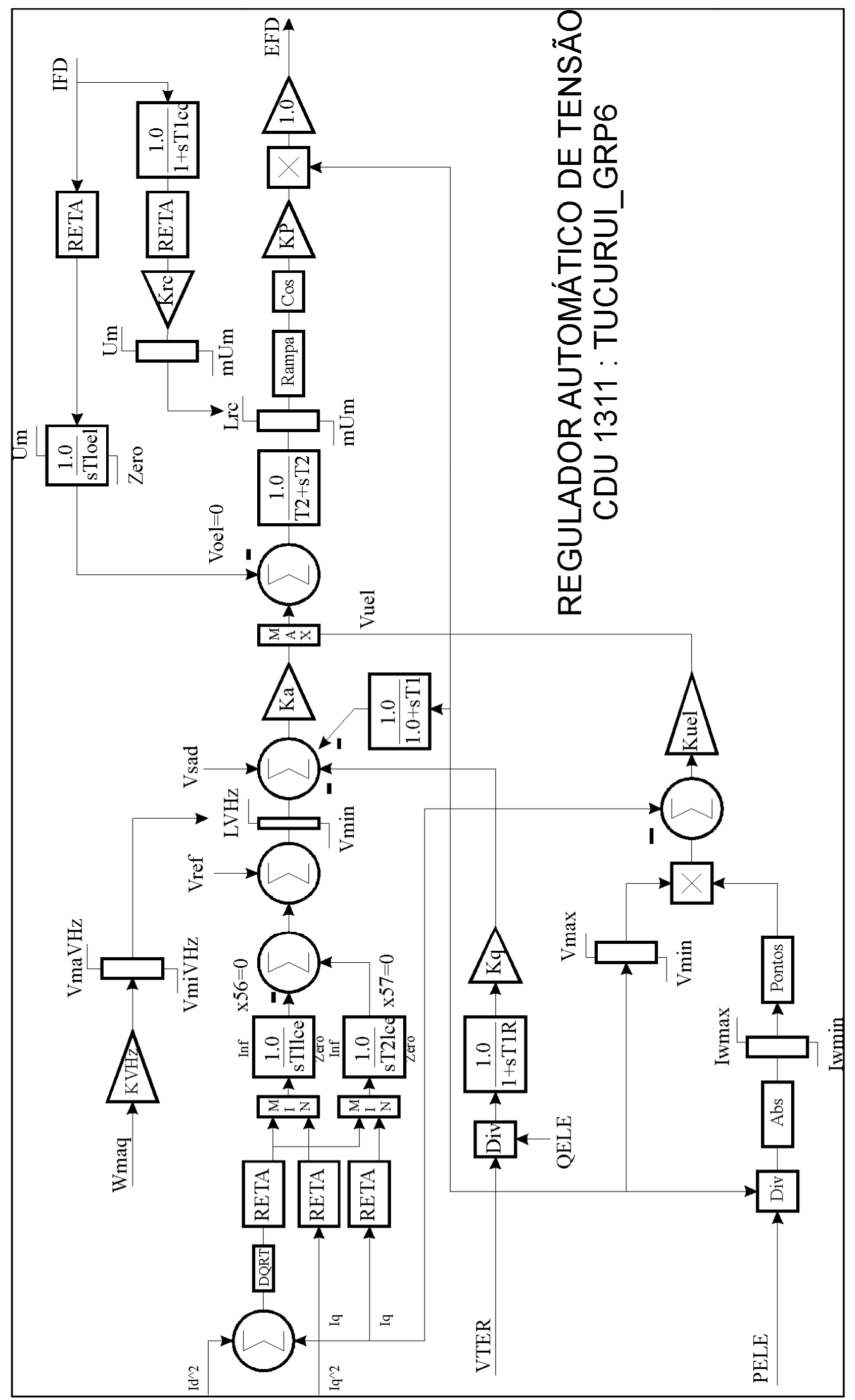




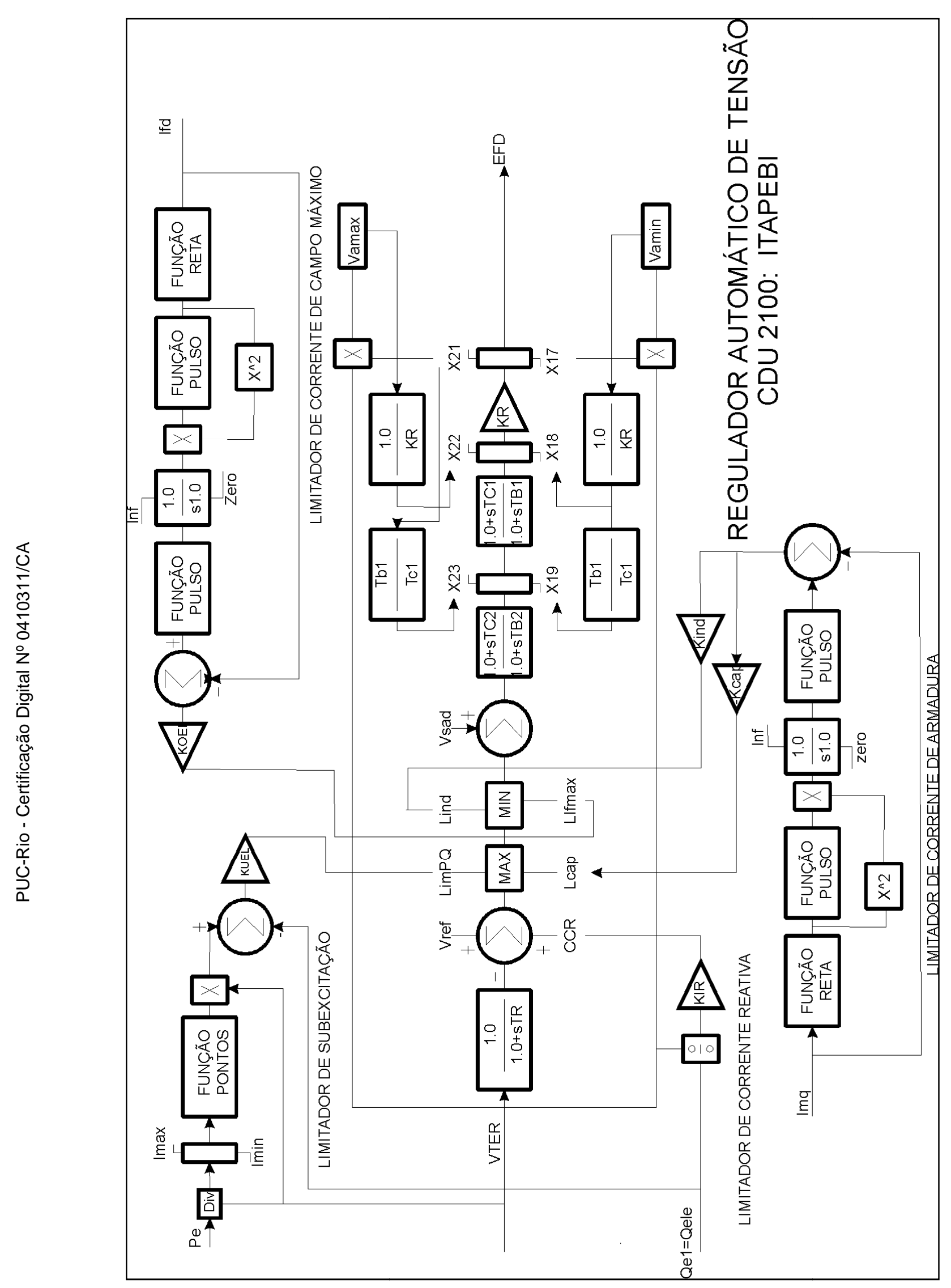




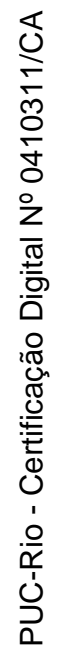

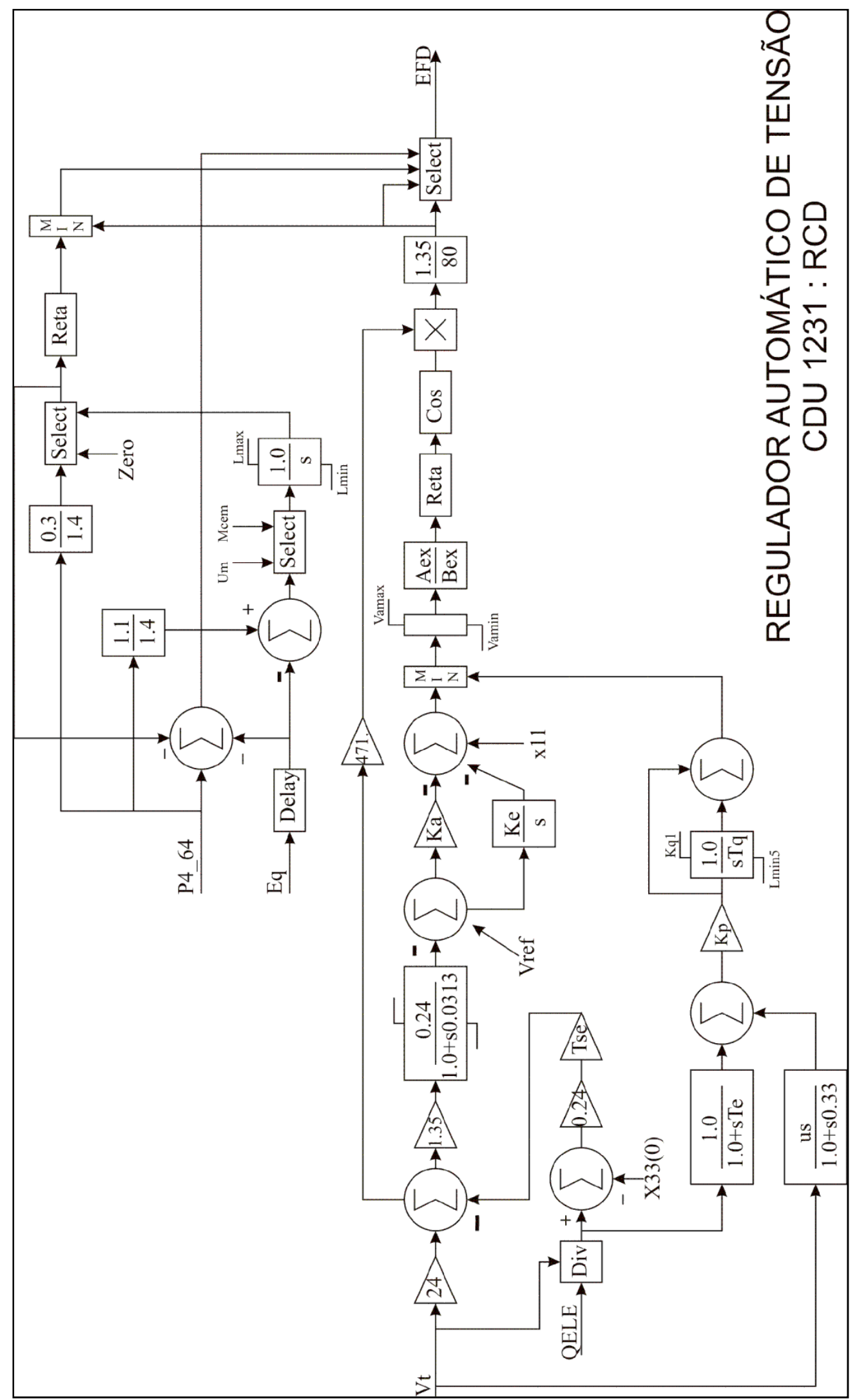




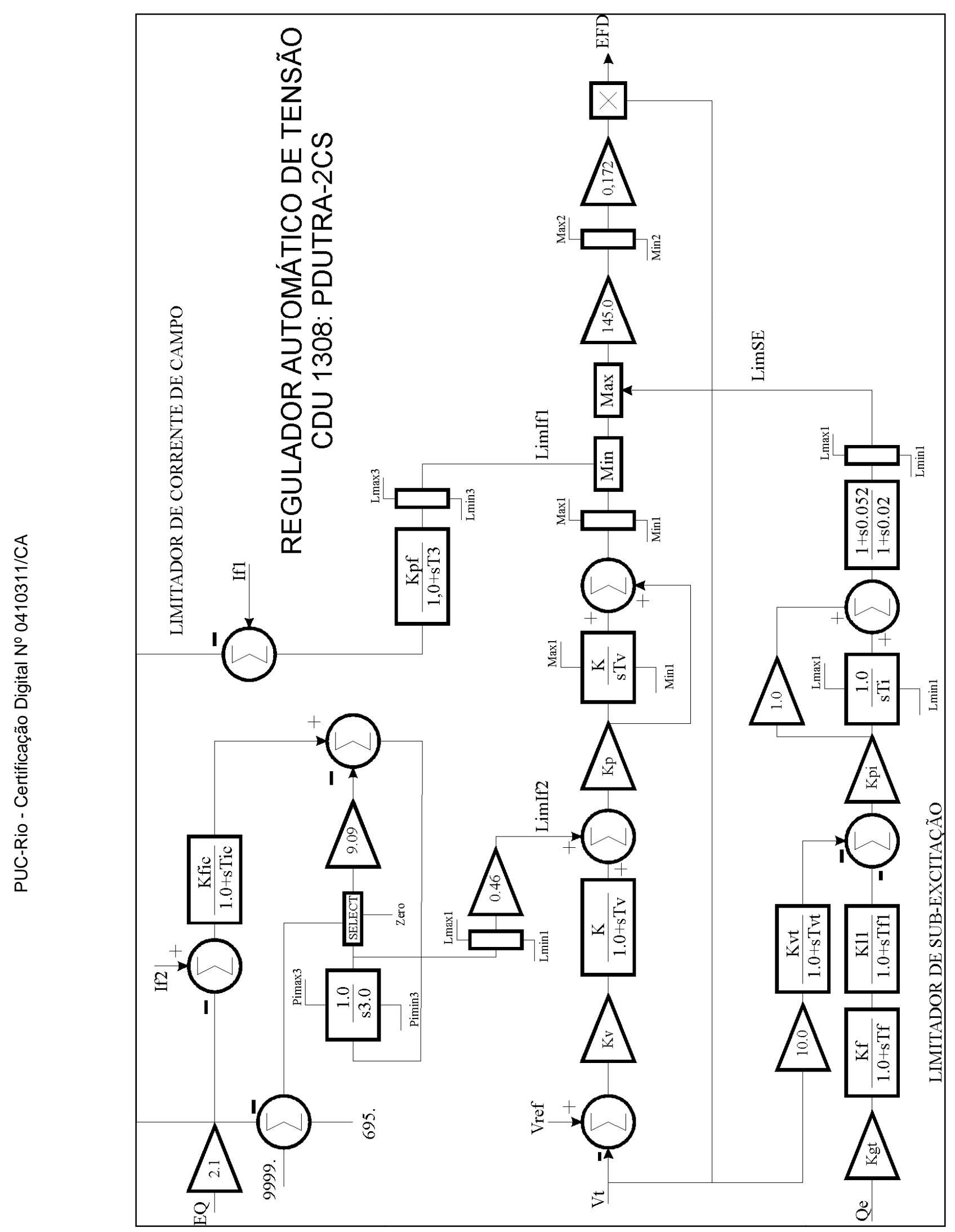




\section{B.4 Estabilizadores de potencia - PSS}

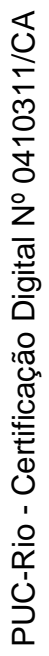

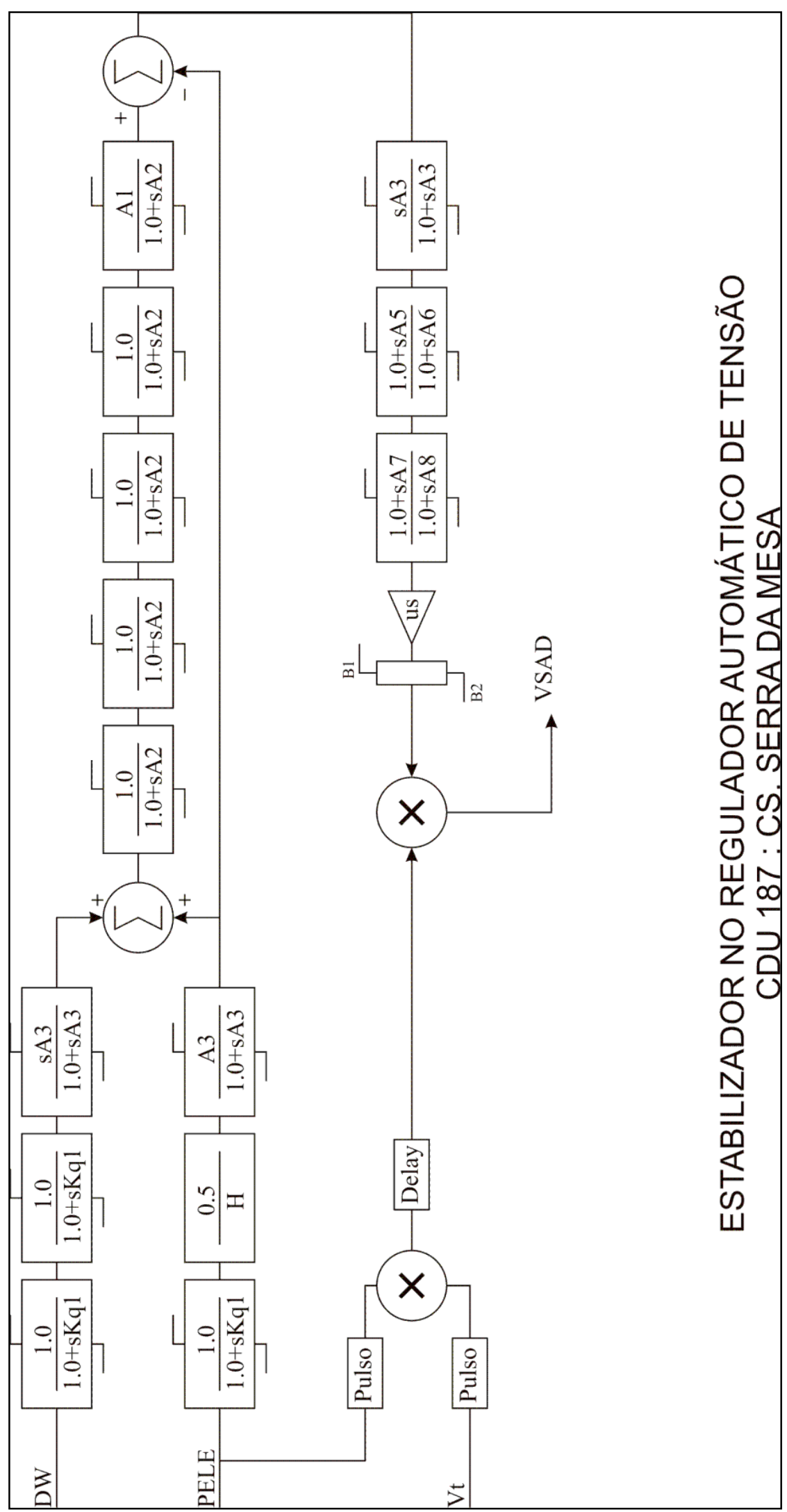




\section{B.5 Reguladores de velocidade - RV}

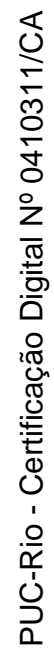

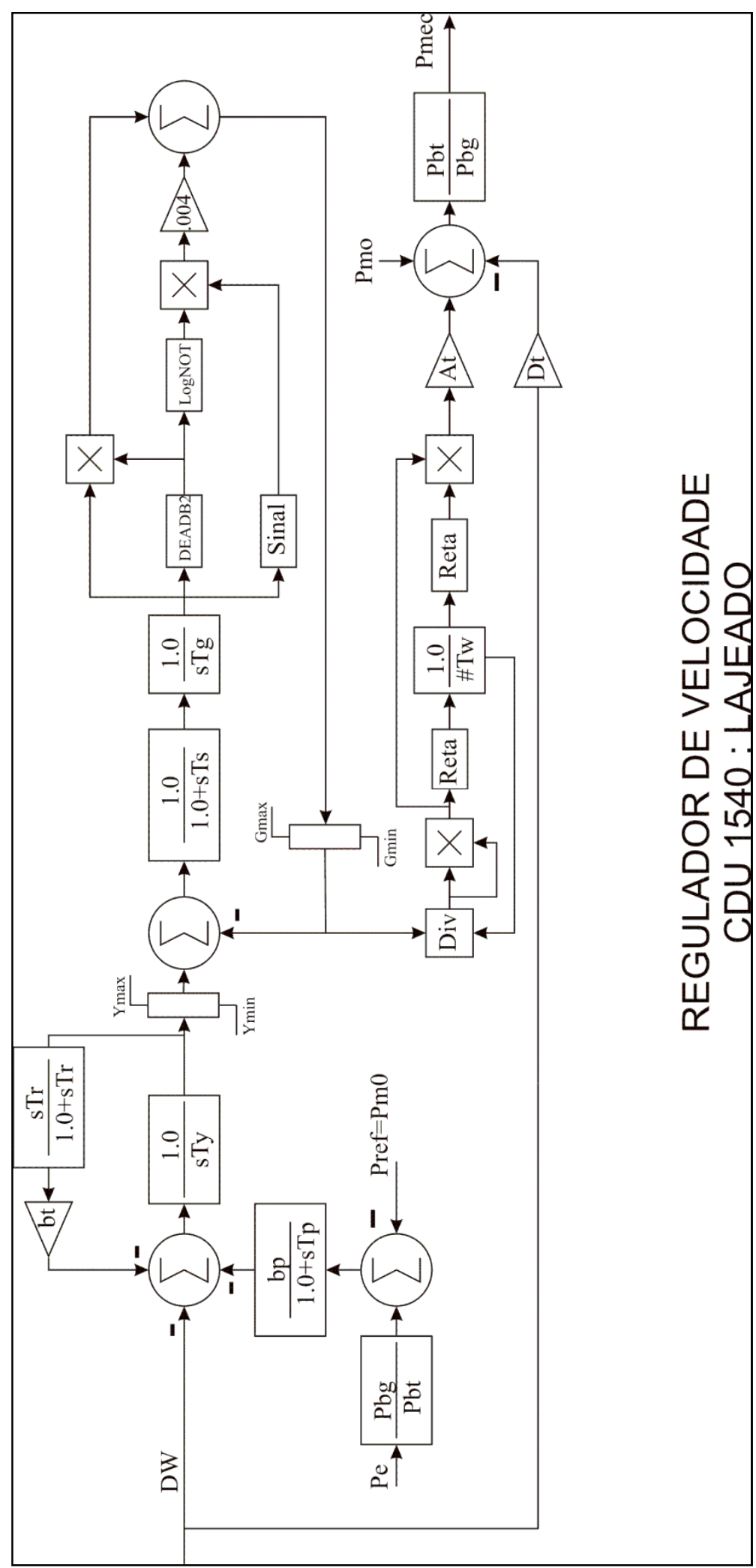




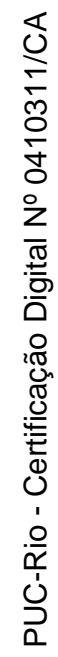

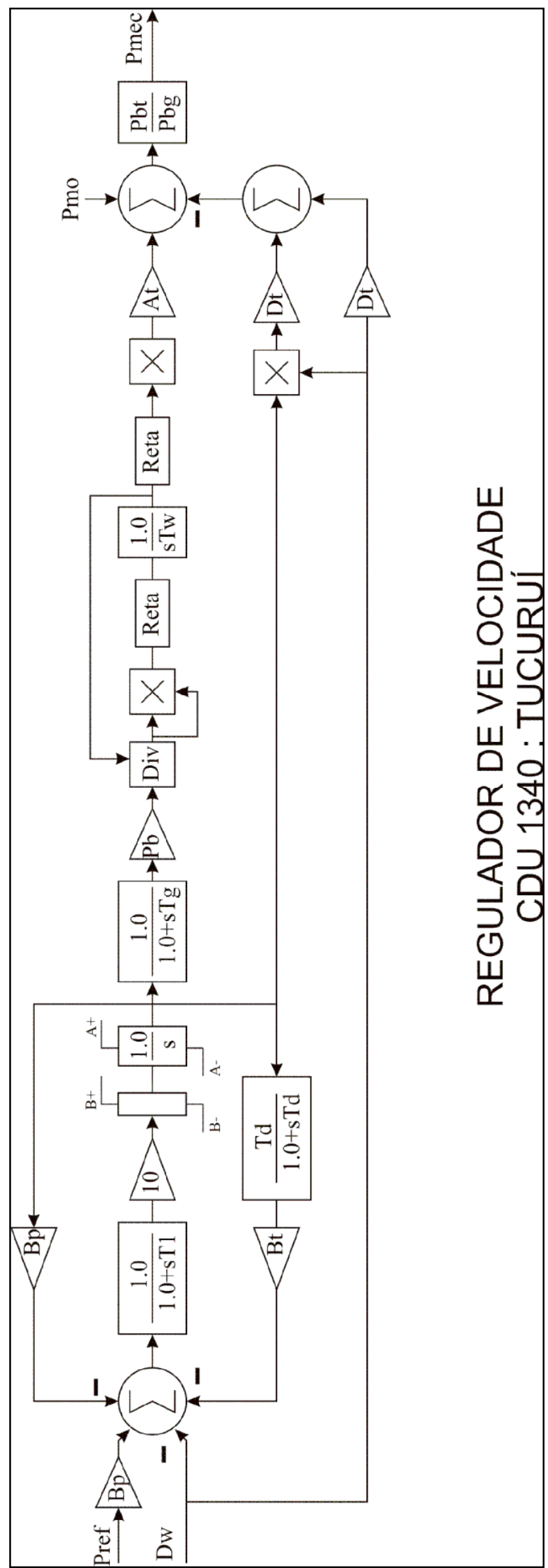




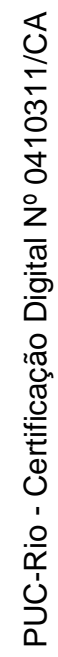

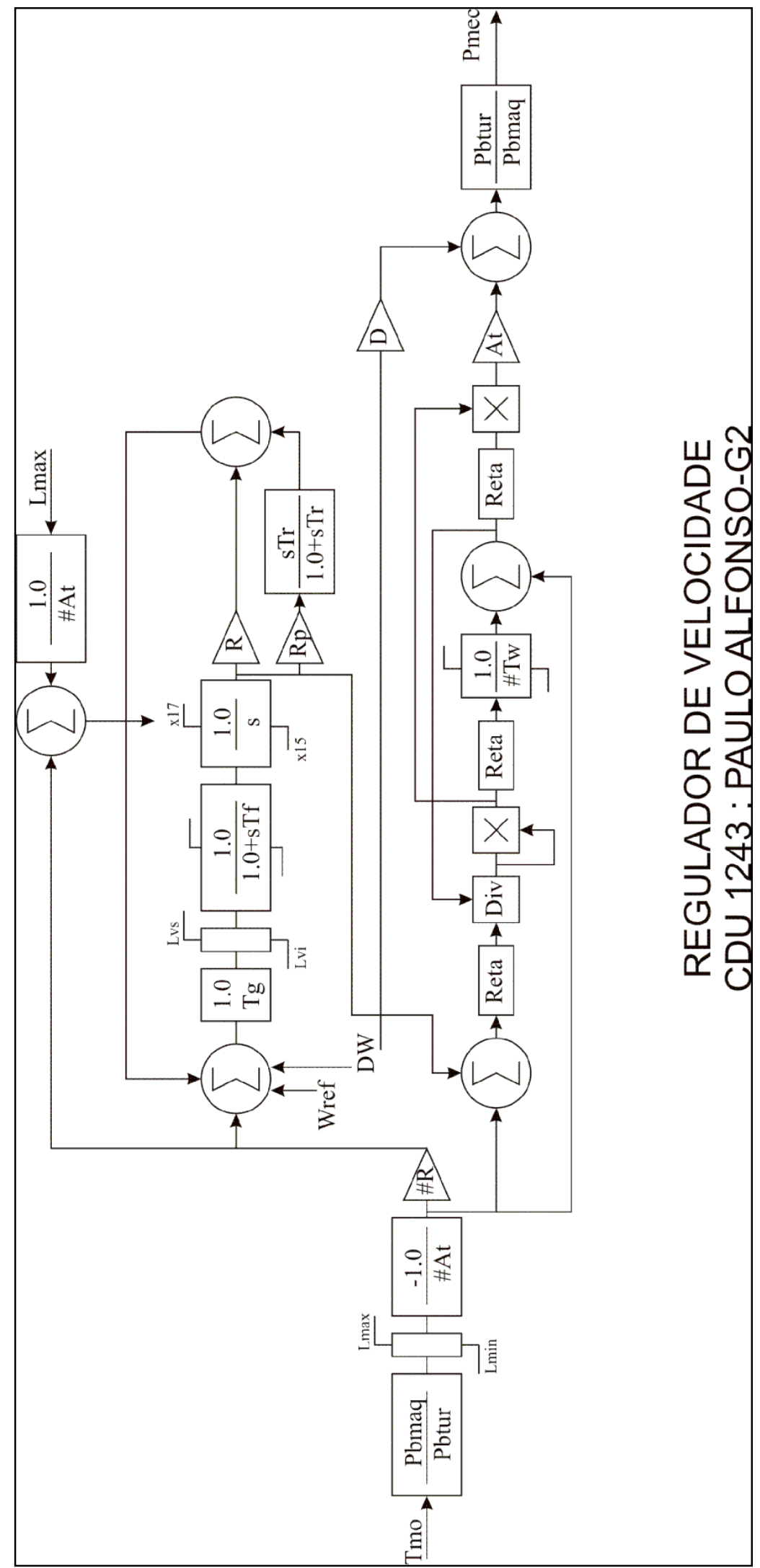


B.6 Regulador automático de tensão - TYPE G (Kundur, 1994)

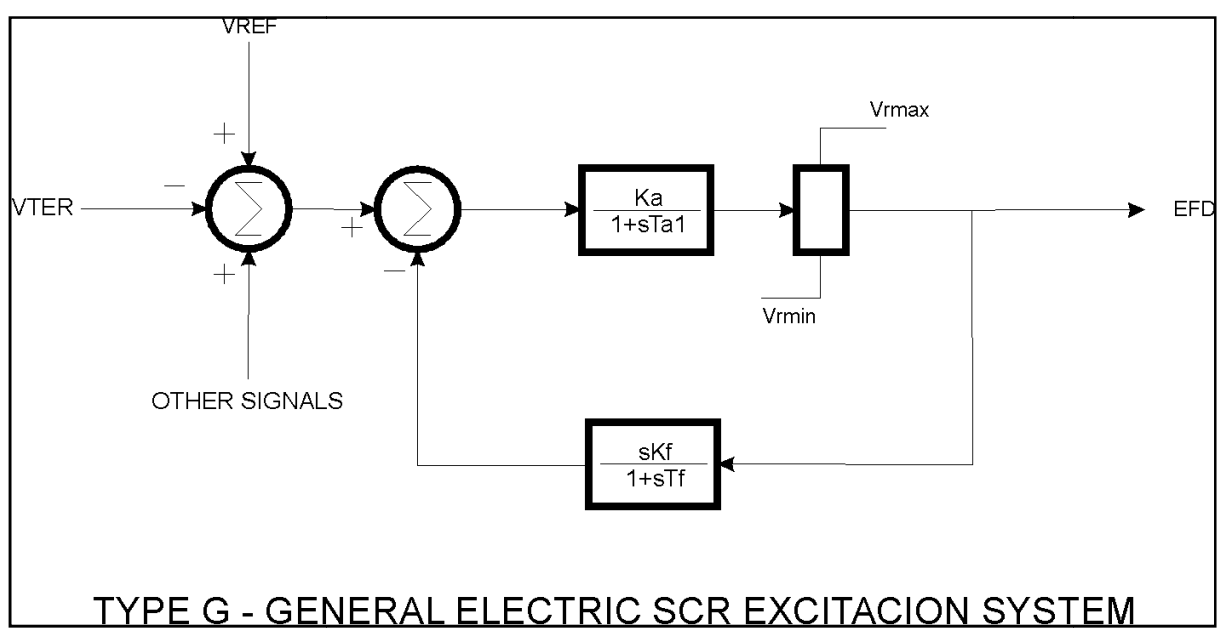

\begin{tabular}{|cl|}
\hline Parâmetro & \multicolumn{1}{c|}{ Descrição } \\
\hline Ka & Ganho do regulador (em contínua atuação do regulador p.u) \\
\hline Ta1 & Constante 1 de tempo do regulador (s) \\
\hline Kf & Ganho do circuito estabilizante do regulador (p.u) \\
\hline Tf & Constante de tempo do circuito estabilizante do regulador (s) \\
\hline Vrmax,Vrmin & Limites máximo e mínimo da tensão de campo - EFD \\
\hline
\end{tabular}

B.7 Limitador de sobre-excitação - OXL (Kundur, 1994)

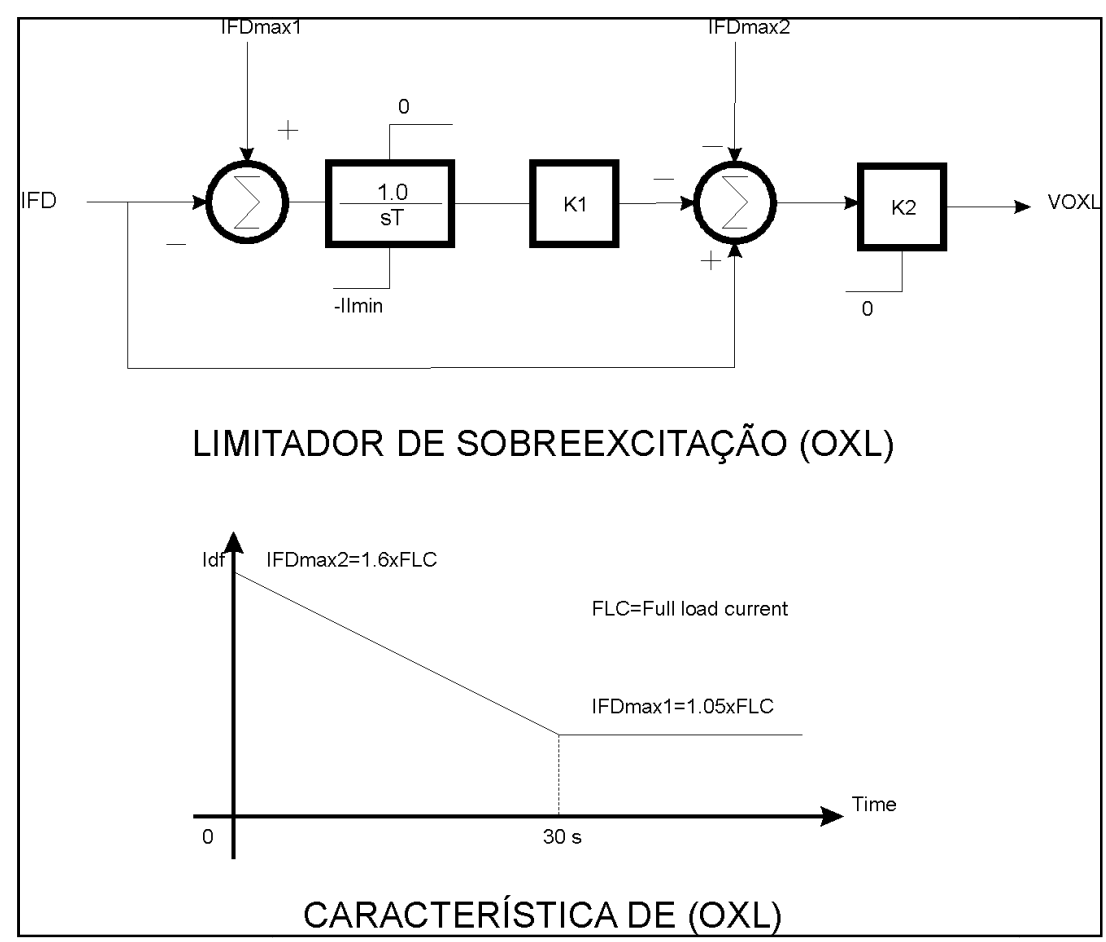




\section{B.8 Transformador de potência com tape variável - ULTC}

Também conhecido como Under Load Tap Changer (em inglês) é representado no protótipo computacional a través de um modelo dinâmico contínuo, de acordo às seguintes equações de estado (Sauer, 1994):

$$
\begin{gathered}
T_{d}^{\prime}=T_{d l}^{\prime}+T_{d 0}^{\prime} \frac{\frac{D B^{\prime}}{2}}{\| V_{k}\left|-V_{\text {ref }}\right|} \\
T_{C 3}^{\prime} \frac{d a}{d t}=-\left|V_{k}\right|-V_{\text {ref }}, \quad a_{\text {min }} \leq a \leq a_{\text {max }} \\
T_{C 3}^{\prime}=\frac{T_{d 0}^{\prime} \frac{D B^{\prime}}{2}+\left(T_{m}^{\prime}+T_{d 1}^{\prime}\right)|| V_{k}\left|-V_{\text {ref }}\right|}{\Delta n^{\prime}}
\end{gathered}
$$

\begin{tabular}{|cl|}
\hline Parâmetro & Descrição \\
\hline a & Valor do tape \\
\hline T'do & Tempo fixo de retardo na decisão da mudança do tape \\
\hline T'dl & Tempo variável de retardo na decisão da mudança do tape \\
\hline T'm & Tempo fixo utilizado na troca mecânica do tape \\
\hline DB & Banda morta \\
\hline
\end{tabular}

\section{B.9 Carga dinâmica}

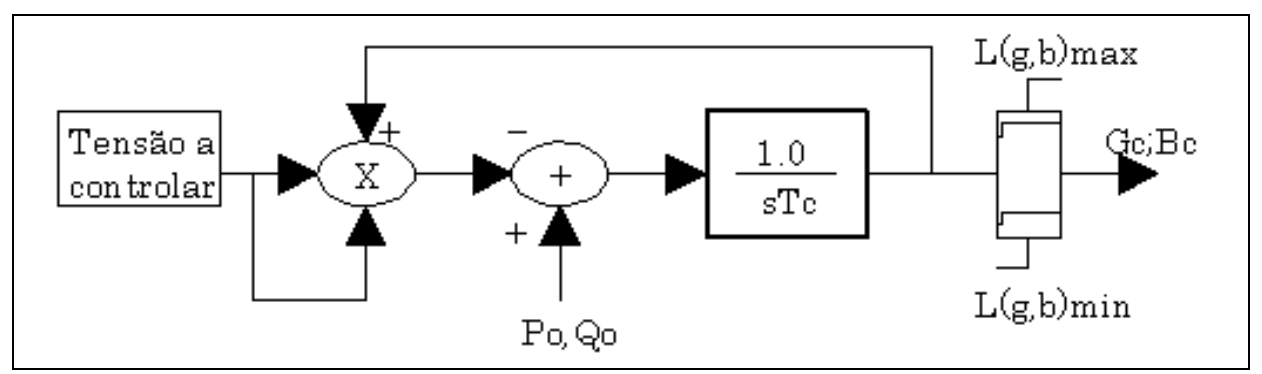

\begin{tabular}{|cl|}
\hline Parâmetro & \multicolumn{1}{c|}{ Descrição } \\
\hline GC & Condutância da carga em p.u \\
\hline BC & Suceptância da carga em p.u \\
Tc & Constante de tempo em segundos \\
Pó,Qo & Potência ativa e reativa da carga em p.u \\
\hline
\end{tabular}




\section{Apêndice C}

\section{Dados de Simulação Associados aos Métodos Numéricos}

\section{C.1 Parâmetros do experimento I}

Tabela C.1a Parâmetros usados no Experimento I - Fluxo de carga

\begin{tabular}{|c|c|c|c|c|c|}
\hline \multirow{2}{*}{ Sistema-Teste } & \multicolumn{3}{|c|}{ GMRES } & \multicolumn{3}{c|}{ ILUT $(\rho, \tau)$} \\
\cline { 2 - 7 } & $\mathbf{m}$ & Tol & Reini & $\tau$ & $\rho$ \\
\hline Kundur 10 barras (Nivel de carga la) & 4 & 1. E-3 & 5 & $1 . E-4$ & 4 \\
\hline Kundur 10 barras (Nivel de carga lb) & 4 & $1 . E-3$ & 5 & $1 . E-4$ & 4 \\
\hline
\end{tabular}

Tabela C.1b Parâmetros usados na Simulação no Domínio do Tempo do Experimento I

\begin{tabular}{|c|c|c|c|c|c|c|c|c|c|}
\hline \multirow{2}{*}{ Sistema-Teste } & \multicolumn{3}{|c|}{ BDF } & \multicolumn{3}{c|}{ GMRES } & \multicolumn{3}{c|}{ ILUT } \\
\cline { 2 - 13 } & K & T.abs & T.rel & m & Tol & Reini & NZJC & FLJC & Tdrop \\
\hline Kundur 10 barras (la) & 5 & $1.0 \mathrm{E}-6$ & $1.0 \mathrm{E}-4$ & 10 & $5.0 \mathrm{E}-2$ & 5 & 37 & 37 & $1.0 \mathrm{E}-2$ \\
\hline Kundur 10 barras (lb) & 5 & $1.0 \mathrm{E}-6$ & $1.0 \mathrm{E}-4$ & 10 & $5.0 \mathrm{E}-2$ & 5 & 37 & 37 & $1.0 \mathrm{E}-2$ \\
\hline
\end{tabular}

\section{C.2 Parâmetros do experimento II}

Tabela C.2a Parâmetros usados no Experimento II - Fluxo de carga

\begin{tabular}{|c|c|c|c|c|c|}
\hline \multirow{2}{*}{ Sistema-Teste } & \multicolumn{4}{|c|}{ GMRES } & \multicolumn{2}{c|}{ ILUT $(\rho, \tau)$} \\
\cline { 2 - 6 } & $\mathbf{m}$ & Tol & Reini & $\tau$ & $\rho$ \\
\hline IEEE118 barras & 8 & $1 . \mathrm{E}-2$ & 20 & 0.01 & 4 \\
\hline
\end{tabular}

Tabela C.2b Parâmetros usados na Simulação no Domínio do Tempo do Experimento II

\begin{tabular}{|l|c|c|c|c|c|c|c|c|c|}
\hline \multirow{2}{*}{ Sistema-Teste } & \multicolumn{3}{|c|}{ BDF } & \multicolumn{3}{c|}{ GMRES } & \multicolumn{3}{c|}{ ILUT } \\
\cline { 2 - 12 } & K & T.abs & T.rel & m & Tol & Reini & NZJC & FLJC & Tdrop \\
\hline IEEE118 barras & 5 & $1.0 \mathrm{E}-6$ & $1.0 \mathrm{E}-6$ & 10 & $5.0 \mathrm{E}-2$ & 10 & 100 & 100 & $1.0 \mathrm{E}-5$ \\
\hline
\end{tabular}




\section{C.3 Parâmetros do experimento III}

Tabela C.3a Parâmetros usados no Experimento III - Fluxo de carga

\begin{tabular}{|c|c|c|c|c|c|}
\hline Sistema-Teste & \multicolumn{3}{|c|}{ GMRES } & \multicolumn{2}{c|}{ ILUT( $\rho, \tau)$} \\
\hline Sistema Norte-Nordeste Brasileiro 564 barras (NNE 564) & $\mathbf{m}$ & Tol & Reini & $\boldsymbol{\tau}$ & $\boldsymbol{\rho}$ \\
\hline & 300 & $1 . \mathrm{E}-2$ & 20 & $1.0 \mathrm{E}-4$ & 12 \\
\hline
\end{tabular}

Tabela C.3b Parâmetros usados na Simulação no Domínio do Tempo do Experimento III

\begin{tabular}{|c|c|c|c|c|c|c|c|c|c|}
\hline \multirow{2}{*}{ Sistema-Teste } & \multicolumn{3}{|c|}{ BDF } & \multicolumn{3}{c|}{ GMRES } & \multicolumn{3}{c|}{ ILUT } \\
\cline { 2 - 12 } & K & T.abs & T.rel & $\mathbf{m}$ & Tol & Reini & NZJC & FLJC & Tdrop \\
\hline N-NE Brasileiro-564 & 5 & $1 . E-5$ & $1 . E-5$ & 20 & $5 . E-2$ & 10 & 150 & 150 & $1 . E-5$ \\
\hline
\end{tabular}


Apêndice D

Dados de Simulação Associados aos Sistemas -Testes

\section{D.1 Sistema-Teste Kundur - 10 barras}

\section{D.1.1 Regime-Permanente}

\section{Parâmetros de barras}

\begin{tabular}{|c|c|c|c|c|c|c|c|c|}
\hline \multirow{2}{*}{ BARRA } & \multirow{2}{*}{$\mathbf{T}$} & \multirow{2}{*}{$\begin{array}{c}\text { TENSÃO } \\
\text { P.U }\end{array}$} & \multirow{2}{*}{$\begin{array}{c}\text { ANGULO } \\
\text { RAD }\end{array}$} & \multicolumn{2}{|c|}{ INJEÇÃO POTENCIA } & \multicolumn{2}{|c|}{ CARGA } & \multirow{2}{*}{$\begin{array}{c}\text { SHUNT } \\
\text { MVAR }\end{array}$} \\
\hline & & & & MW & MVAR & MW & MVAR & \\
\hline 1 & 2 & 980 & 0.00 & 3987.2 & 602.7 & 0.0 & 0.0 & 0.0 \\
\hline 2 & 1 & 965 & -7.63 & 1736.0 & -83.6 & 0.0 & 0.0 & 0.0 \\
\hline 3 & 1 & 1040 & -20.64 & 1154.0 & 504.9 & 0.0 & 0.0 & 0.0 \\
\hline 5 & 0 & 1097 & -3.76 & 0.0 & 0.0 & 0.0 & 0.0 & 0.0 \\
\hline 6 & 0 & 1095 & -11.38 & 0.0 & 0.0 & 0.0 & 0.0 & 0.0 \\
\hline 7 & 0 & 1104 & -27.14 & 0.0 & 0.0 & 0.0 & 0.0 & 0.0 \\
\hline 8 & 0 & 1019 & -32.48 & 0.0 & 0.0 & 3276 & 1015 & 0.0 \\
\hline 9 & 0 & 1026 & -32.15 & 0.0 & 0.0 & 0.0 & 0.0 & 0.0 \\
\hline 10 & 0 & 951 & -37.47 & 0.0 & 0.0 & 0.0 & 0.0 & 0.0 \\
\hline 11 & 0 & 964 & -39.53 & 0.0 & 0.0 & 3384 & 971 & 0.0 \\
\hline
\end{tabular}

Parâmetros de linhas de transmissão e transformadores de potencia

\begin{tabular}{|c|c|c|c|c|c|c|c|c|c|c|}
\hline \multirow{2}{*}{$\mathrm{DE}$} & \multirow{2}{*}{ PARA } & \multirow{2}{*}{$\begin{array}{l}\text { NÚM } \\
\text { СTO }\end{array}$} & \multirow{2}{*}{$\begin{array}{c}\text { RESIS } \\
\frac{\circ}{0}\end{array}$} & \multirow{2}{*}{$\begin{array}{c}\text { REAT } \\
\frac{\circ}{0}\end{array}$} & \multirow{2}{*}{$\begin{array}{l}\text { SUCEP } \\
\text { MVAR }\end{array}$} & \multicolumn{3}{|c|}{ POSIÇÃO DO TAPE } & \multirow{2}{*}{ BC } & \multirow{2}{*}{$\begin{array}{c}\mathbf{N}^{\circ} \\
\text { TAPS }\end{array}$} \\
\hline & & & & & & TAPNOM & TAPMIN & TAPMAX & & \\
\hline 1 & 5 & 1 & 0.0 & 0.2 & 0.0 & 0.8857 & -- & -- & -- & -- \\
\hline 2 & 6 & 1 & 0.0 & 0.45 & 0.0 & 0.8857 & -- & -- & -- & -- \\
\hline 3 & 7 & 1 & 0.0 & 1.25 & 0.0 & 0.9024 & -- & -- & -- & -- \\
\hline 5 & 6 & 1 & 0.0 & 0.4 & 0.0 & -- & -- & -- & -- & -- \\
\hline 6 & 7 & 1 & 0.15 & 2.88 & 234.6 & -- & -- & -- & -- & -- \\
\hline 6 & 7 & 2 & 0.15 & 2.88 & 234.6 & -- & -- & -- & -- & -- \\
\hline 6 & 7 & 3 & 0.15 & 2.88 & 234.6 & -- & -- & -- & -- & -- \\
\hline 6 & 7 & 4 & 0.15 & 2.88 & 234.6 & -- & -- & -- & -- & -- \\
\hline 6 & 7 & 5 & 0.15 & 2.88 & 234.6 & -- & -- & -- & -- & -- \\
\hline 7 & 8 & 1 & 0.0 & 0.3 & 0.0 & 1.067 & -- & -- & -- & -- \\
\hline 7 & 9 & 1 & 0.0 & 0.26 & 0.0 & 1.080 & -- & -- & -- & -- \\
\hline 9 & 10 & 1 & 0.1 & 0.3 & 0.0 & -- & -- & -- & -- & -- \\
\hline 10 & 11 & 1 & 0.0 & 0.1 & 0.0 & 0.975 & 0.9 & 1.1 & -11 & 32 \\
\hline
\end{tabular}


Níveis de carga

\begin{tabular}{||c||c||c||c|}
\hline BARRA & P (MW) & Q (MVAR) & NIVEL DE CARGA \\
\hline \hline \multirow{2}{*}{8} & 3271 & 1015 & 1 \\
\cline { 2 - 4 } & 3320 & 1030 & 2 \\
\hline \multirow{2}{*}{11} & 3384 & 971 & 1 \\
\cline { 2 - 4 } & 3435 & 985 & 2 \\
\hline
\end{tabular}

Posição do tape do transformador de potencia T6 (ULTC)

\begin{tabular}{|c|c|c|}
\hline \multirow{2}{*}{ TRANSFORMADOR } & NÍVEL DE CARGA & POSIÇÃO DO TAPE \\
\hline \hline $10-11 \quad \mathrm{~T} 6)$ & 1 & 0.9750 \\
\cline { 2 - 3 } & 2 & 0.9938 \\
\hline
\end{tabular}

\section{D.1.2 Parâmetros associados aos modelos dinâmicos no sistema-teste Kundur -10 barras}

Máquina Síncrona de pólos salientes (Anatem, 2000)

O modelo 0001 está associado ao tipo MD01; tensão e ângulo fixo.

\begin{tabular}{|c|c|c|c|c|c|c|c|c|c|}
\hline Mode & CS & Ld $(\%$ & $\operatorname{Lq}\left(\frac{\circ}{0}\right)$ & $L^{\prime} d\left(\frac{\circ}{0}\right)$ & $L^{\prime \prime} d\left(\frac{\circ}{0}\right)$ & Ll (\%) & $T^{\prime} \mathrm{do}\left(\frac{\circ}{0}\right)$ & T"do (\%) & T"q0 (\%) \\
\hline & & $\operatorname{Ra}\left(\frac{\circ}{0}\right)$ & H (seg) & D & MVA & $\mathrm{Hz}$ & & & \\
\hline 2 & 0 & 207.0 & 199.0 & 28.0 & 21.5 & 15.5 & 4.1 & 0.033 & 0.62 \\
\hline 2 & & .46 & 2.09 & & 2200 & 60 & & & \\
\hline 3 & 0 & 207.0 & 199.0 & 28.0 & 21.5 & 15.5 & 4.1 & 0.033 & 0.62 \\
\hline 3 & & .46 & 2.09 & & 2200 & 60 & & & \\
\hline
\end{tabular}

Regulador Automático de Tensão (AVR)

\begin{tabular}{|c||c|c|c|c|c|}
\hline Modelo & T1 & T2 & T3 & Vmin & Vmax \\
\hline \hline 0001 & 400 & 0.3575 & 0.02 & -3.0 & 5.73 \\
\hline \hline 0002 & 400 & 0.3575 & 0.02 & -3.0 & 5.73 \\
\hline
\end{tabular}

\section{Limitador Sobre-Excitação (OXL)}

\begin{tabular}{|c|c|c||c||c|c|}
\hline Modelo & K11 & K21 & T11 & If1 & If2 \\
\hline \hline 0001 & 0.45 & 6.0 & 1.0 & 1.45 & 2.22 \\
\hline
\end{tabular}

Transformador de Tape Variável (ULTC)

\begin{tabular}{|c|c|c|c|c|}
\hline \hline Modelo & $\mathbf{T}^{\prime} \mathbf{d 0}$ & $\mathbf{T}^{\prime} \mathbf{d} 1$ & $\mathbf{T}^{\prime} \mathbf{m} \mathbf{0}$ & DB \\
\hline \hline 0001 & 30.0 & 1.0 & 5.0 & 0.01 \\
\hline
\end{tabular}




\section{D.2 Sistema-Teste IEEE118 - 118 barras}

\section{D.2.1 Regime-Permanente}

Parâmetros de barras

\begin{tabular}{|c|c|c|c|c|c|c|c|c|}
\hline \multirow{2}{*}{ BARRA } & \multirow{2}{*}{$\mathbf{T}$} & \multirow{2}{*}{$\begin{array}{c}\text { TENSÃO } \\
\text { P.U }\end{array}$} & \multirow{2}{*}{$\begin{array}{l}\text { ANGULO } \\
\text { RAD }\end{array}$} & \multicolumn{2}{|c|}{ "INJEÇÃO POTENCIA } & \multicolumn{2}{|c|}{ CARGA } & \multirow{2}{*}{$\begin{array}{l}\text { SHUNT } \\
\text { MVAR }\end{array}$} \\
\hline & & & & MW & MVAR & MW & MVAR & \\
\hline 1 & 2 & 1051 & 0.00 & 0.00 & 0.00 & 51.00 & 27.00 & 0.00 \\
\hline 2 & 0 & 1000 & 0.00 & 0.00 & 0.00 & 20.00 & 9.00 & 0.00 \\
\hline 3 & 0 & 1000 & 0.00 & 0.00 & 0.00 & 39.00 & 10.00 & 0.00 \\
\hline 4 & 1 & 1100 & 0.00 & 100.00 & 14.00 & 39.00 & 12.00 & 0.00 \\
\hline 5 & 0 & 1000 & 0.00 & 0.00 & 0.00 & 0.00 & 0.00 & -40.00 \\
\hline 6 & 1 & 1085 & 0.00 & 5.00 & 18.00 & 52.00 & 22.00 & 0.00 \\
\hline 7 & 0 & 1000 & 0.00 & 0.00 & 0.00 & 19.00 & 2.00 & 0.00 \\
\hline 8 & 1 & 1055 & 0.00 & 100.00 & -8.00 & 28.00 & 0.00 & 0.00 \\
\hline 9 & 0 & 1000 & 0.00 & 0.00 & 0.00 & 0.00 & 0.00 & 0.00 \\
\hline 10 & 1 & 1100 & 0.00 & 100.00 & -71.00 & 0.00 & 0.00 & 0.00 \\
\hline 11 & 0 & 1000 & 0.00 & 0.00 & 0.00 & 70.00 & 23.00 & 0.00 \\
\hline 12 & 1 & 1080 & 0.00 & 30.00 & 75.00 & 47.00 & 10.00 & 0.00 \\
\hline 13 & 0 & 1000 & 0.00 & 0.00 & 0.00 & 34.00 & 16.00 & 0.00 \\
\hline 14 & 0 & 1000 & 0.00 & 0.00 & 0.00 & 14.00 & 1.00 & 0.00 \\
\hline 15 & 1 & 1063 & 0.00 & 5.00 & 5.00 & 90.00 & 30.00 & 0.00 \\
\hline 16 & 0 & 1000 & 0.00 & 0.00 & 0.00 & 25.00 & 10.00 & 0.00 \\
\hline 17 & 0 & 1000 & 0.00 & 0.00 & 0.00 & 11.00 & 3.00 & 0.00 \\
\hline 18 & 1 & 1068 & 0.00 & 5.00 & 23.00 & 60.00 & 34.00 & 0.00 \\
\hline 19 & 1 & 1060 & 0.00 & 5.00 & 14.00 & 45.00 & 25.00 & 0.00 \\
\hline 20 & 0 & 1000 & 0.00 & 0.00 & 0.00 & 18.00 & 3.00 & 0.00 \\
\hline 21 & 0 & 1000 & 0.00 & 0.00 & 0.00 & 14.00 & 8.00 & 0.00 \\
\hline 22 & 0 & 1000 & 0.00 & 0.00 & 0.00 & 10.00 & 5.00 & 0.00 \\
\hline 23 & 0 & 1000 & 0.00 & 0.00 & 0.00 & 7.00 & 3.00 & 0.00 \\
\hline 24 & 1 & 1080 & 0.00 & 100.00 & 91.00 & 13.00 & 0.00 & 0.00 \\
\hline 25 & 1 & 1100 & 0.00 & 100.00 & 33.00 & 0.00 & 0.00 & 0.00 \\
\hline 26 & 1 & 976 & 0.00 & 300.00 & -118.00 & 0.00 & 0.00 & 0.00 \\
\hline 27 & 1 & 1095 & 0.00 & 100.00 & 9.00 & 71.00 & 13.00 & 0.00 \\
\hline 28 & 0 & 1000 & 0.00 & 0.00 & 0.00 & 17.00 & 7.00 & 0.00 \\
\hline 29 & 0 & 1000 & 0.00 & 0.00 & 0.00 & 24.00 & 4.00 & 0.00 \\
\hline 30 & 0 & 1000 & 0.00 & 0.00 & 0.00 & 0.00 & 0.00 & 0.00 \\
\hline 31 & 1 & 1100 & 0.00 & 100.00 & 37.00 & 43.00 & 27.00 & 0.00 \\
\hline 32 & 1 & 1089 & 0.00 & 5.00 & 12.00 & 59.00 & 23.00 & 0.00 \\
\hline 33 & 0 & 1000 & 0.00 & 0.00 & 0.00 & 23.00 & 9.00 & 0.00 \\
\hline 34 & 1 & 1049 & 0.00 & 5.00 & 15.00 & 59.00 & 26.00 & 14.00 \\
\hline 35 & 0 & 1000 & 0.00 & 0.00 & 0.00 & 33.00 & 9.00 & 0.00 \\
\hline 36 & 1 & 1041 & 0.00 & 5.00 & -5.00 & 31.00 & 17.00 & 0.00 \\
\hline 37 & 0 & 1000 & 0.00 & 0.00 & 0.00 & 0.00 & 0.00 & -25.00 \\
\hline 38 & 0 & 1000 & 0.00 & 0.00 & 0.00 & 0.00 & 0.00 & 0.00 \\
\hline 39 & 0 & 1000 & 0.00 & 0.00 & 0.00 & 27.00 & 11.00 & 0.00 \\
\hline 40 & 1 & 965 & 0.00 & 101.70 & -100.00 & 66.00 & 23.00 & 0.00 \\
\hline 41 & 0 & 1000 & 0.00 & 0.00 & 0.00 & 37.00 & 10.00 & 0.00 \\
\hline 42 & 1 & 1005 & 0.00 & 106.60 & 9.00 & 96.00 & 23.00 & 0.00 \\
\hline
\end{tabular}




\begin{tabular}{|c|c|c|c|c|c|c|c|c|}
\hline BARRA & $\mathbf{T}$ & TENSÃO & ANGULO & INJEÇÃO & OTENCIA & CA & & SHUNT \\
\hline DERTNA & 1 & P.U & RAD & MW & MVAR & MW & MVAR & MVAR \\
\hline 43 & 0 & 1000 & 0.00 & 0.00 & 0.00 & 18.00 & 7.00 & 0.00 \\
\hline 44 & 0 & 1000 & 0.00 & 0.00 & 0.00 & 16.00 & 8.00 & 10.00 \\
\hline 45 & 0 & 1000 & 0.00 & 0.00 & 0.00 & 53.00 & 22.00 & 10.00 \\
\hline 46 & 1 & 1077 & 0.00 & 101.10 & -6.00 & 28.00 & 10.00 & 10.00 \\
\hline 47 & 0 & 1000 & 0.00 & 0.00 & 0.00 & 34.00 & 0.00 & 0.00 \\
\hline 48 & 0 & 1000 & 0.00 & 0.00 & 0.00 & 20.00 & 11.00 & 15.00 \\
\hline 49 & 1 & 1077 & 0.00 & 100.00 & 139.00 & 87.00 & 30.00 & 0.00 \\
\hline 50 & 0 & 1000 & 0.00 & 0.00 & 0.00 & 17.00 & 4.00 & 0.00 \\
\hline 51 & 0 & 1000 & 0.00 & 0.00 & 0.00 & 17.00 & 8.00 & 0.00 \\
\hline 52 & 0 & 1000 & 0.00 & 0.00 & 0.00 & 18.00 & 5.00 & 0.00 \\
\hline 53 & 0 & 1000 & 0.00 & 0.00 & 0.00 & 23.00 & 11.00 & 0.00 \\
\hline 54 & 1 & 1100 & 0.00 & 109.40 & 148.00 & 113.00 & 32.00 & 0.00 \\
\hline 55 & 1 & 1091 & 0.00 & 15.00 & 5.00 & 63.00 & 22.00 & 0.00 \\
\hline 56 & 1 & 1093 & 0.00 & 7.20 & -5.00 & 84.00 & 18.00 & 0.00 \\
\hline 57 & 0 & 1000 & 0.00 & 0.00 & 0.00 & 12.00 & 3.00 & 0.00 \\
\hline 58 & 0 & 1000 & 0.00 & 0.00 & 0.00 & 12.00 & 3.00 & 0.00 \\
\hline 59 & 1 & 1090 & 0.00 & 120.10 & 74.00 & 277.00 & 113.00 & 0.00 \\
\hline 60 & 0 & 1000 & 0.00 & 0.00 & 0.00 & 78.00 & 3.00 & 0.00 \\
\hline 61 & 1 & 998 & 0.00 & 205.00 & -46.00 & 0.00 & 0.00 & 0.00 \\
\hline 62 & 1 & 1006 & 0.00 & 10.00 & 2.00 & 77.00 & 14.00 & 0.00 \\
\hline 63 & 0 & 1000 & 0.00 & 0.00 & 0.00 & 0.00 & 0.00 & 0.00 \\
\hline 64 & 0 & 1000 & 0.00 & 0.00 & 0.00 & 0.00 & 0.00 & 0.00 \\
\hline 65 & 1 & 1068 & 0.00 & 100.00 & 114.00 & 0.00 & 0.00 & 0.00 \\
\hline 66 & 1 & 1064 & 0.00 & 100.00 & -28.00 & 39.00 & 18.00 & 0.00 \\
\hline 67 & 0 & 1000 & 0.00 & 0.00 & 0.00 & 28.00 & 7.00 & 0.00 \\
\hline 68 & 0 & 1000 & 0.00 & 0.00 & 0.00 & 0.00 & 0.00 & 0.00 \\
\hline 69 & 1 & 950 & 0.00 & 200.00 & 0.00 & 0.00 & 0.00 & 0.00 \\
\hline 70 & 1 & 915 & 0.00 & 10.00 & 0.00 & 66.00 & 20.00 & 0.00 \\
\hline 71 & 0 & 1000 & 0.00 & 0.00 & 0.00 & 0.00 & 0.00 & 0.00 \\
\hline 72 & 1 & 900 & 0.00 & 100.00 & -100.00 & 12.00 & 0.00 & 0.00 \\
\hline 73 & 1 & 900 & 0.00 & 100.00 & -27.00 & 6.00 & 0.00 & 0.00 \\
\hline 74 & 1 & 900 & 0.00 & 5.00 & 0.00 & 68.00 & 27.00 & 12.00 \\
\hline 75 & 0 & 1000 & 0.00 & 0.00 & 0.00 & 47.00 & 11.00 & 0.00 \\
\hline 76 & 1 & 900 & 0.00 & 0.00 & 8.00 & 68.00 & 36.00 & 0.00 \\
\hline 77 & 1 & 978 & 0.00 & 30.70 & 38.00 & 61.00 & 28.00 & 0.00 \\
\hline 78 & 0 & 1000 & 0.00 & 0.00 & 0.00 & 71.00 & 26.00 & 0.00 \\
\hline 79 & 0 & 1000 & 0.00 & 0.00 & 0.00 & 39.00 & 32.00 & 20.00 \\
\hline 80 & 1 & 1021 & 0.00 & 100.00 & -31.00 & 130.00 & 26.00 & 0.00 \\
\hline 81 & 0 & 1000 & 0.00 & 0.00 & 0.00 & 0.00 & 0.00 & 0.00 \\
\hline 82 & 0 & 1000 & 0.00 & 0.00 & 0.00 & 54.00 & 27.00 & 20.00 \\
\hline 83 & 0 & 1000 & 0.00 & 0.00 & 0.00 & 20.00 & 10.00 & 10.00 \\
\hline 84 & 0 & 1000 & 0.00 & 0.00 & 0.00 & 11.00 & 7.00 & 0.00 \\
\hline 85 & 1 & 1013 & 0.00 & 10.00 & 3.00 & 24.00 & 15.00 & 0.00 \\
\hline 86 & 0 & 1000 & 0.00 & 0.00 & 0.00 & 21.00 & 10.00 & 0.00 \\
\hline 87 & 1 & 1100 & 0.00 & 124.20 & 32.00 & 0.00 & 0.00 & 0.00 \\
\hline 88 & 0 & 1000 & 0.00 & 0.00 & 0.00 & 48.00 & 10.00 & 0.00 \\
\hline 89 & 1 & 1059 & 0.00 & 400.00 & -5.00 & 0.00 & 0.00 & 0.00 \\
\hline 90 & 1 & 1074 & 0.00 & 150.70 & 60.00 & 163.00 & 42.00 & 0.00 \\
\hline 91 & 1 & 1074 & 0.00 & 125.60 & -19.00 & 10.00 & 0.00 & 0.00 \\
\hline 92 & 1 & 1049 & 0.00 & 10.00 & 0.00 & 65.00 & 10.00 & 0.00 \\
\hline
\end{tabular}




\begin{tabular}{|c|c|c|c|c|c|c|c|c|}
\hline \multirow{2}{*}{ BARRA } & \multirow{2}{*}{$\mathbf{T}$} & \multirow{2}{*}{$\begin{array}{c}\text { TENSÃO } \\
\text { P.U }\end{array}$} & \multirow{2}{*}{$\begin{array}{l}\text { ANGULO } \\
\text { RAD }\end{array}$} & \multicolumn{2}{|c|}{ INJEÇÃO POTENCIA } & \multicolumn{2}{|c|}{ CARGA } & \multirow{2}{*}{$\begin{array}{l}\text { SHUNT } \\
\text { MVAR }\end{array}$} \\
\hline & & & & MW & MVAR & MW & MVAR & \\
\hline 93 & 0 & 1000 & 0.00 & 0.00 & 0.00 & 12.00 & 7.00 & 0.00 \\
\hline 94 & 0 & 1000 & 0.00 & 0.00 & 0.00 & 30.00 & 16.00 & 0.00 \\
\hline 95 & 0 & 1000 & 0.00 & 0.00 & 0.00 & 42.00 & 31.00 & 0.00 \\
\hline 96 & 0 & 1000 & 0.00 & 0.00 & 0.00 & 38.00 & 15.00 & 0.00 \\
\hline 97 & 0 & 1000 & 0.00 & 0.00 & 0.00 & 15.00 & 9.00 & 0.00 \\
\hline 98 & 0 & 1000 & 0.00 & 0.00 & 0.00 & 34.00 & 8.00 & 0.00 \\
\hline 99 & 1 & 1071 & 0.00 & 124.90 & -23.00 & 42.00 & 0.00 & 0.00 \\
\hline 100 & 1 & 1100 & 0.00 & 100.00 & 300.00 & 37.00 & 18.00 & 0.00 \\
\hline 101 & 0 & 1000 & 0.00 & 0.00 & 0.00 & 22.00 & 15.00 & 0.00 \\
\hline 102 & 0 & 1000 & 0.00 & 0.00 & 0.00 & 5.00 & 3.00 & 0.00 \\
\hline 103 & 1 & 1091 & 0.00 & 18.70 & 11.00 & 23.00 & 16.00 & 0.00 \\
\hline 104 & 1 & 1079 & 0.00 & 20.00 & 5.00 & 38.00 & 25.00 & 0.00 \\
\hline 105 & 1 & 1079 & 0.00 & 20.00 & -5.00 & 31.00 & 26.00 & 20.00 \\
\hline 106 & 0 & 1000 & 0.00 & 0.00 & 0.00 & 43.00 & 16.00 & 0.00 \\
\hline 107 & 1 & 1100 & 0.00 & 120.10 & 0.00 & 50.00 & 12.00 & 6.00 \\
\hline 108 & 0 & 1000 & 0.00 & 0.00 & 0.00 & 2.00 & 1.00 & 0.00 \\
\hline 109 & 0 & 1000 & 0.00 & 0.00 & 0.00 & 8.00 & 3.00 & 0.00 \\
\hline 110 & 1 & 1083 & 0.00 & 0.00 & 0.00 & 39.00 & 30.00 & 6.00 \\
\hline 111 & 1 & 1100 & 0.00 & 100.00 & -8.00 & 0.00 & 0.00 & 0.00 \\
\hline 112 & 1 & 1100 & 0.00 & 118.10 & 13.00 & 68.00 & 13.00 & 0.00 \\
\hline 113 & 1 & 1100 & 0.00 & 100.00 & 6.00 & 6.00 & 0.00 & 0.00 \\
\hline 114 & 0 & 1000 & 0.00 & 0.00 & 0.00 & 8.00 & 3.00 & 0.00 \\
\hline 115 & 0 & 1000 & 0.00 & 0.00 & 0.00 & 22.00 & 7.00 & 0.00 \\
\hline 116 & 1 & 1062 & 0.00 & 250.00 & 115.00 & 184.00 & 0.00 & 0.00 \\
\hline 117 & 0 & 1000 & 0.00 & 0.00 & 0.00 & 20.00 & 8.00 & 0.00 \\
\hline 118 & 0 & 1000 & 0.00 & 0.00 & 0.00 & 33.00 & 15.00 & 0.00 \\
\hline
\end{tabular}

\section{Parâmetros de Linhas de Transmissão e Transformadores de potencia}

\begin{tabular}{|c|c|c|c|c|c|c|c|c|c|}
\hline \multirow{2}{*}{$\mathrm{DE}$} & \multirow{2}{*}{ PARA } & \multirow{2}{*}{ RESIS \% } & \multirow{2}{*}{ REAT \% } & \multirow{2}{*}{ SUCEP \% } & \multicolumn{3}{|c|}{ POSIÇÃO DE TAPE } & \multirow{2}{*}{$\mathrm{BC}$} & \multirow{2}{*}{$\begin{array}{c}\mathrm{N}^{\circ} \\
\text { TAPS }\end{array}$} \\
\hline & & & & & TAPNOM & TAPMIN & TAPMAX & & \\
\hline 1 & 2 & 3.03 & 9.99 & 2.54 & & & & & 144 \\
\hline 1 & 3 & 1.29 & 4.24 & 1.08 & & & & & 144 \\
\hline 2 & 12 & 1.87 & 6.16 & 1.566 & & & & & 144 \\
\hline 3 & 5 & 2.41 & 10.8 & 2.84 & & & & & 350 \\
\hline 3 & 12 & 4.84 & 16 & 4.06 & & & & & 144 \\
\hline 4 & 5 & 0.18 & 0.8 & 0.2 & & & & & 310 \\
\hline 4 & 11 & 2.09 & 6.88 & 1.74 & & & & & 144 \\
\hline 5 & 6 & 1.19 & 5.4 & 1.42 & & & & & 175 \\
\hline 8 & 5 & .0 & 2.67 & 0 & 0.937 & 0.9 & 1.1 & 8 & 9999 \\
\hline 5 & 11 & 2.03 & 6.82 & 1.74 & & & & & 144 \\
\hline 6 & 7 & 0.45 & 2.08 & 0.54 & & & & & 175 \\
\hline 7 & 12 & 0.86 & 3.4 & 0.86 & & & & & 160 \\
\hline 8 & 9 & 0.24 & 3.05 & 116.2 & & & & & 1550 \\
\hline 8 & 30 & 0.43 & 5.04 & 51.4 & & & & & 776 \\
\hline 9 & 10 & 0.26 & 3.22 & 123 & & & & & 1550 \\
\hline 11 & 12 & 0.59 & 1.96 & 0.5 & & & & & 144 \\
\hline
\end{tabular}




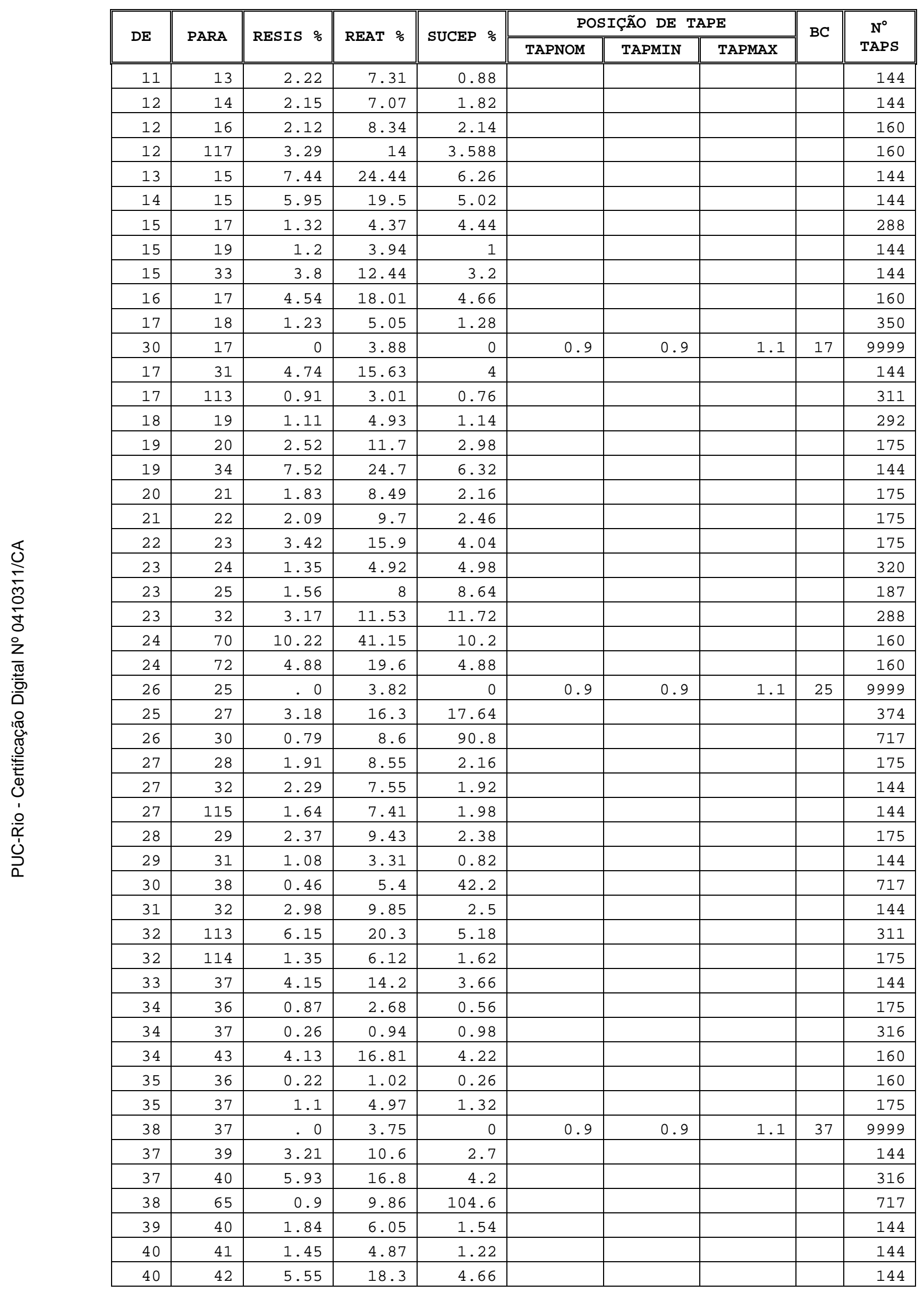




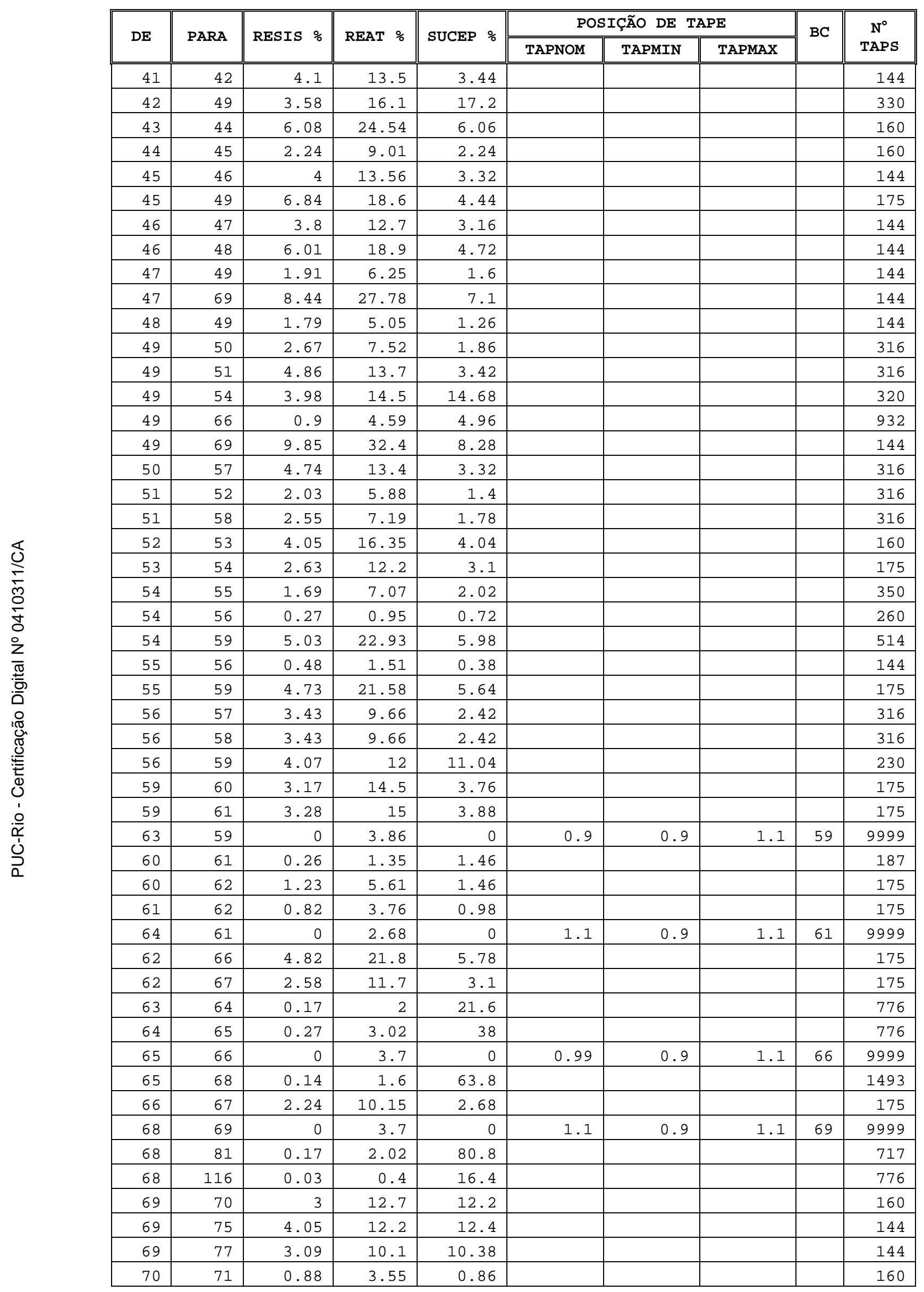




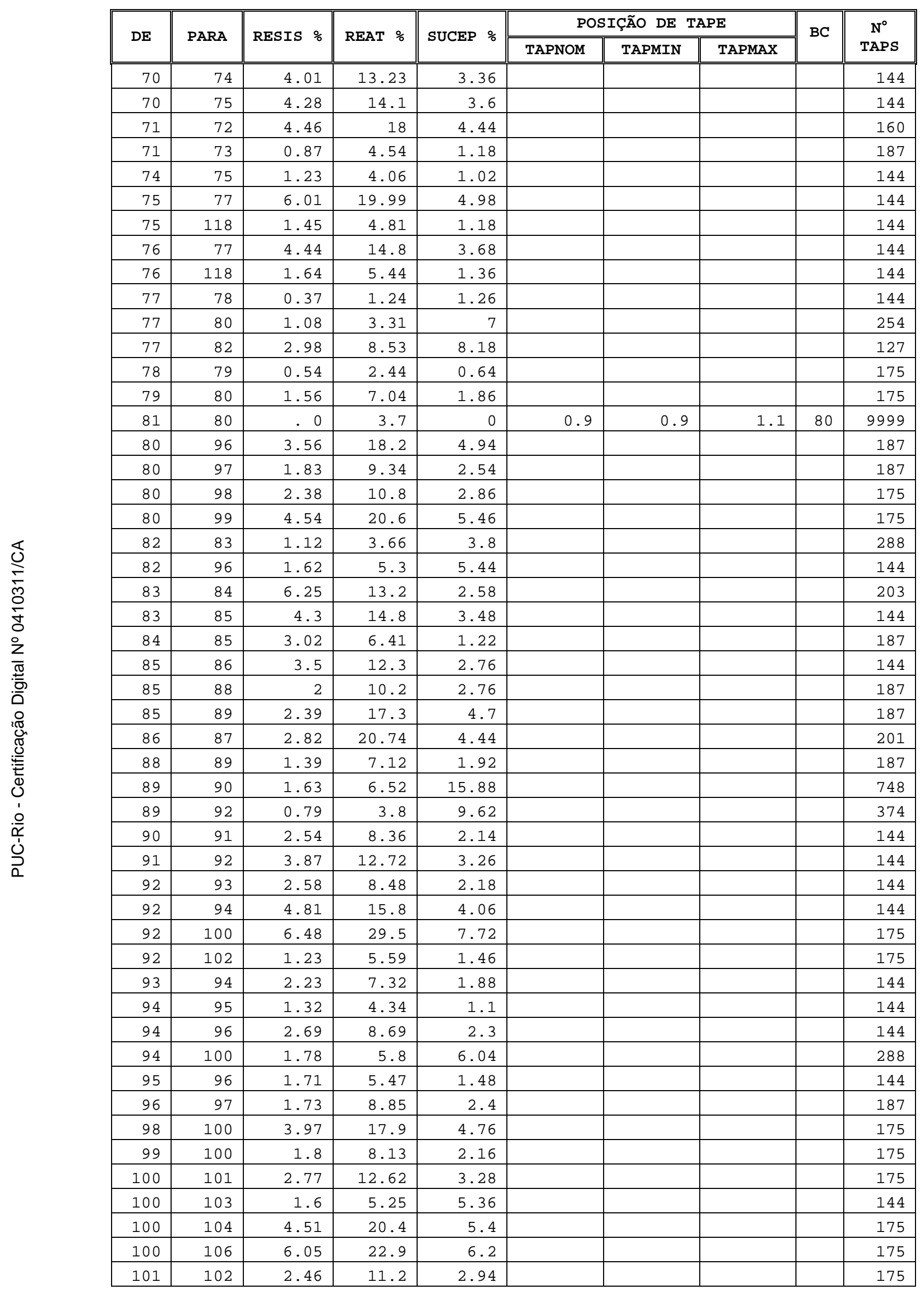




\begin{tabular}{|c|c|c|c|c|c|c|c|c|c|}
\hline \multirow{2}{*}{$\mathrm{DE}$} & \multirow{2}{*}{ PARA } & \multirow{2}{*}{ RESIS $\frac{\circ}{\circ}$} & \multirow{2}{*}{ REAT $\frac{\circ}{\circ}$} & \multirow{2}{*}{ SUCEP $\%$} & \multicolumn{3}{|c|}{ POSIÇÃO DE TAPE } & \multirow{2}{*}{$\mathrm{BC}$} & \multirow{2}{*}{$\begin{array}{c}\mathbf{N}^{\circ} \\
\text { TAPS }\end{array}$} \\
\hline & & & & & TAPNOM & TAPMIN & TAPMAX & & \\
\hline 103 & 104 & 4.66 & 15.84 & 4.06 & & & & & 144 \\
\hline 103 & 105 & 5.35 & 16.25 & 4.08 & & & & & 144 \\
\hline 103 & 110 & 3.91 & 18.13 & 4.6 & & & & & 175 \\
\hline 104 & 105 & 0.99 & 3.78 & 0.98 & & & & & 144 \\
\hline 105 & 106 & 1.4 & 5.47 & 1.44 & & & & & 144 \\
\hline 105 & 107 & 5.3 & 18.3 & 4.72 & & & & & 144 \\
\hline 105 & 108 & 2.61 & 7.03 & 1.84 & & & & & 127 \\
\hline 106 & 107 & 5.3 & 18.3 & 4.72 & & & & & 144 \\
\hline 108 & 109 & 1.05 & 2.88 & 0.76 & & & & & 127 \\
\hline 109 & 110 & 2.78 & 7.62 & 2.02 & & & & & 127 \\
\hline 110 & 111 & 2.2 & 7.55 & 2 & & & & & 144 \\
\hline 110 & 112 & 2.47 & 6.4 & 6.2 & & & & & 127 \\
\hline 114 & 115 & 0.23 & 1.04 & 0.28 & & & & & 175 \\
\hline
\end{tabular}

\section{D.2.2 Parâmetros associados aos modelos dinâmicos no sistema-teste IEEE118}

Máquina Síncrona de pólos salientes (Anatem, 2000)

O modelo 0001 está associado ao tipo MD01; tensão e ângulo fixo.

\begin{tabular}{|c|c|c|c|c|c|c|c|c|c|}
\hline & & $\operatorname{Ra}\left(\frac{\circ}{0}\right)$ & H (seg) & D & MVA & $\mathrm{Hz}$ & & & \\
\hline 2 & & 0 & 1.311 & 0 & 483 & 60 & & & \\
\hline 3 & 0 & 190 & 180 & 27 & 17 & 15 & 8.3 & 0.04 & 0.15 \\
\hline 4 & 0 & 93.4 & 61.1 & 28.9 & 27.2 & 22 & 5.303 & 0.091 & 0.205 \\
\hline 4 & & 0 & 5.5 & 0 & 472.6 & 60 & & & \\
\hline 5 & 0 & 73 & 52 & 26 & 20 & 19 & 8.3 & 0.06 & 0.03 \\
\hline 5 & & 0 & 4.31 & 0 & 365 & 60 & & & \\
\hline 7 & & 0 & 4.98 & 0 & 216 & 60 & & & \\
\hline 8 & 0 & 214 & 200 & 21 & 16 & 14 & 9.79 & 0.021 & 0.032 \\
\hline 8 & & 0 & 1.76 & 0 & 208 & 60 & & & \\
\hline 9 & 0 & 217 & 205 & 22.3 & 16.9 & 15 & 9.48 & 0.023 & 0.035 \\
\hline 9 & & 0 & 6.4 & 0 & 300 & 60 & & & \\
\hline 10 & 0 & 73 & 52 & 26 & 20 & 19 & 8.3 & 0.06 & 0.03 \\
\hline 10 & & 0 & 4.31 & 0 & 365 & 60 & & & \\
\hline 11 & 0 & 170 & 100 & 37 & 25 & 17.5 & 9 & 0.06 & 0.2 \\
\hline 14 & 0 & 94.81 & 64.5 & 24.99 & 18.96 & 14.01 & 7 & 0.066 & 0.14 \\
\hline 14 & & 0 & 6.228 & 0 & 283 & 60 & & & \\
\hline
\end{tabular}




\begin{tabular}{|c|c|c|c|c|c|c|c|c|c|}
\hline Mode & $\mathrm{CS}$ & Ld $(\%$ & $\mathrm{Lq}\left(\frac{\circ}{0}\right)$ & $L^{\prime} d(\%)$ & $L^{\prime \prime} d(\%)$ & Ll (\%) & $T^{\prime}$ do (\%) & $T^{\prime \prime} \mathrm{dO}(\%)$ & T"q0 (\%) \\
\hline & & $\operatorname{Ra}(\%)$ & H (seg) & D & MVA & $\mathrm{Hz}$ & & & \\
\hline 15 & 0 & 91 & 57 & 26 & 20 & 15 & 6.2 & 0.043 & 0.074 \\
\hline 15 & & 0 & 4.42 & 0 & 250 & 60 & & & \\
\hline 16 & 0 & 158.9 & 149.4 & 24.15 & 18.55 & 15.4 & 6.66 & 0.018 & 0.03 \\
\hline 16 & & 0 & 3.229 & 0 & 350 & 60 & & & \\
\hline 17 & 0 & 186.7 & 177.3 & 22.6 & 16.7 & 13 & 9.22 & 0.041 & 0.15 \\
\hline 17 & & 0 & 4.98 & 0 & 216 & 60 & & & \\
\hline 18 & 0 & 214 & 200 & 21 & 16 & 14 & 9.79 & 0.021 & 0.032 \\
\hline 18 & & 0 & 1.76 & 0 & 208 & 60 & & & \\
\hline 19 & 0 & 217 & 205 & 22.3 & 16.9 & 15 & 9.48 & 0.023 & 0.035 \\
\hline 19 & & 0 & 6.4 & 0 & 300 & 60 & & & \\
\hline 20 & 0 & 73 & 52 & 26 & 20 & 19 & 8.3 & 0.06 & 0.03 \\
\hline 20 & & 0 & 4.31 & 0 & 365 & 60 & & & \\
\hline 21 & 0 & 186.7 & 177.3 & 22.6 & 16.7 & 13 & 9.22 & 0.041 & 0.15 \\
\hline 21 & & 0 & 4.98 & 0 & 216 & 60 & & & \\
\hline 22 & 0 & 158.9 & 149.4 & 24.15 & 18.55 & 15.4 & 6.66 & 0.018 & 0.03 \\
\hline 22 & & 0 & 3.229 & 0 & 350 & 60 & & & \\
\hline 23 & 0 & 217 & 205 & 22.3 & 16.9 & 15 & 9.48 & 0.023 & 0.035 \\
\hline 23 & & 0 & 6.4 & 0 & 300 & 60 & & & \\
\hline 24 & 0 & 73 & 52 & 26 & 20 & 19 & 8.3 & 0.06 & 0.03 \\
\hline 24 & & 0 & 4.31 & 0 & 365 & 60 & & & \\
\hline 25 & 0 & 170 & 100 & 37 & 25 & 17.5 & 9 & 0.06 & 0.2 \\
\hline 25 & & 0 & 1.6 & 0 & 300 & 60 & & & \\
\hline 26 & 0 & 172 & 167.9 & 48.8 & 33.7 & 26.6 & 5.62 & 0.048 & 0.066 \\
\hline 26 & & 0 & 2.731 & 0 & 760 & 60 & & & \\
\hline 27 & 0 & 94.81 & 64.5 & 24.99 & 18.96 & 14.01 & 7 & 0.066 & 0.14 \\
\hline 27 & & 0 & 6.228 & 0 & 283 & 60 & & & \\
\hline 28 & 0 & 91 & 57 & 26 & 20 & 15 & 6.2 & 0.043 & 0.074 \\
\hline 28 & & 0 & 4.42 & 0 & 250 & 60 & & & \\
\hline 29 & 0 & 158.9 & 149.4 & 24.15 & 18.55 & 15.4 & 6.66 & 0.018 & 0.03 \\
\hline 29 & & 0 & 3.229 & 0 & 350 & 60 & & & \\
\hline 30 & 0 & 172 & 167.9 & 48.8 & 33.7 & 26.6 & 5.62 & 0.048 & 0.066 \\
\hline 30 & & 0 & 2.731 & 0 & 760 & 60 & & & \\
\hline 31 & 0 & 170 & 100 & 37 & 25 & 17.5 & 9 & 0.06 & 0.2 \\
\hline 31 & & 0 & 1.6 & 0 & 300 & 60 & & & \\
\hline 32 & 0 & 92.89 & 68.99 & 31.99 & 25.59 & 13.99 & 5 & 0.065 & 0.085 \\
\hline 32 & & 0 & 4.722 & 0 & 313.6 & 60 & & & \\
\hline 33 & 0 & 94.81 & 64.5 & 24.99 & 18.96 & 14.01 & 7 & 0.066 & 0.14 \\
\hline 33 & & 0 & 6.228 & 0 & 283 & 60 & & & \\
\hline 34 & 0 & 91 & 57 & 26 & 20 & 15 & 6.2 & 0.043 & 0.074 \\
\hline 34 & & 0 & 4.42 & 0 & 250 & 60 & & & \\
\hline 35 & 0 & 158.9 & 149.4 & 24.15 & 18.55 & 15.4 & 6.66 & 0.018 & 0.03 \\
\hline 35 & & 0 & 3.229 & 0 & 350 & 60 & & & \\
\hline 36 & 0 & 186.7 & 177.3 & 22.6 & 16.7 & 13 & 9.22 & 0.041 & 0.15 \\
\hline 36 & & 0 & 4.98 & 0 & 216 & 60 & & & \\
\hline 37 & 0 & 91 & 57 & 26 & 20 & 15 & 6.2 & 0.043 & 0.074 \\
\hline 37 & & 0 & 4.42 & 0 & 250 & 60 & & & \\
\hline 38 & 0 & 158.9 & 149.4 & 24.15 & 18.55 & 15.4 & 6.66 & 0.018 & 0.03 \\
\hline 38 & & 0 & 3.229 & 0 & 350 & 60 & & & \\
\hline 39 & 0 & 91 & 57 & 26 & 20 & 15 & 6.2 & 0.043 & 0.074 \\
\hline 39 & & 0 & 4.42 & 0 & 250 & 60 & & & \\
\hline
\end{tabular}




\begin{tabular}{|c|c|c|c|c|c|c|c|c|c|}
\hline Mode & $\mathrm{CS}$ & Ld $(\%$ & $\mathrm{Lq}\left(\frac{\circ}{0}\right)$ & $L^{\prime} d\left(\frac{\circ}{0}\right)$ & L"d (\%) & Ll (\%) & $T^{\prime} \mathrm{do}\left(\frac{\circ}{0}\right)$ & T"do (\%) & T"q0 (\%) \\
\hline & & $\operatorname{Ra}\left(\frac{\circ}{0}\right)$ & H (seg) & D & MVA & $\mathrm{Hz}$ & & & \\
\hline 40 & 0 & 172 & 167.9 & 48.8 & 33.7 & 26.6 & 5.62 & 0.048 & 0.066 \\
\hline 40 & & 0 & 2.731 & 0 & 760 & 60 & & & \\
\hline 41 & 0 & 158.9 & 149.4 & 24.15 & 18.55 & 15.4 & 6.66 & 0.018 & 0.03 \\
\hline 41 & & 0 & 3.229 & 0 & 350 & 60 & & & \\
\hline 42 & 0 & 217 & 205 & 22.3 & 16.9 & 15 & 9.48 & 0.023 & 0.035 \\
\hline 42 & & 0 & 6.4 & 0 & 300 & 60 & & & \\
\hline 43 & 0 & 217 & 205 & 22.3 & 16.9 & 15 & 9.48 & 0.023 & 0.035 \\
\hline 43 & & 0 & 6.4 & 0 & 300 & 60 & & & \\
\hline 44 & 0 & 73 & 52 & 26 & 20 & 19 & 8.3 & 0.06 & 0.03 \\
\hline 44 & & 0 & 4.31 & 0 & 365 & 60 & & & \\
\hline 45 & 0 & 186.7 & 177.3 & 22.6 & 16.7 & 13 & 9.22 & 0.041 & 0.15 \\
\hline 45 & & 0 & 4.98 & 0 & 216 & 60 & & & \\
\hline 46 & 0 & 214 & 200 & 21 & 16 & 14 & 9.79 & 0.021 & 0.032 \\
\hline 46 & & 0 & 1.76 & 0 & 208 & 60 & & & \\
\hline 47 & 0 & 217 & 205 & 22.3 & 16.9 & 15 & 9.48 & 0.023 & 0.035 \\
\hline 47 & & 0 & 6.4 & 0 & 300 & 60 & & & \\
\hline 48 & 0 & 73 & 52 & 26 & 20 & 19 & 8.3 & 0.06 & 0.03 \\
\hline 48 & & 0 & 4.31 & 0 & 365 & 60 & & & \\
\hline 49 & 0 & 170 & 100 & 37 & 25 & 17.5 & 9 & 0.06 & 0.2 \\
\hline 49 & & 0 & 1.6 & 0 & 300 & 60 & & & \\
\hline 50 & 0 & 92.89 & 68.99 & 31.99 & 25.59 & 13.99 & 5 & 0.065 & 0.085 \\
\hline 50 & & 0 & 4.722 & 0 & 313.6 & 60 & & & \\
\hline 51 & 0 & 94.81 & 64.5 & 24.99 & 18.96 & 14.01 & 7 & 0.066 & 0.14 \\
\hline 51 & & 0 & 6.228 & 0 & 283 & 60 & & & \\
\hline 52 & 0 & 172 & 167.9 & 48.8 & 33.7 & 26.6 & 5.62 & 0.048 & 0.066 \\
\hline 52 & & 0 & 2.731 & 0 & 760 & 60 & & & \\
\hline 53 & 0 & 186.3 & 183.3 & 34.3 & 28.7 & 20.9 & 5.36 & 0.042 & 0.253 \\
\hline 53 & & 0 & 3.02 & 0 & 256 & 60 & & & \\
\hline 54 & 0 & 172 & 167.9 & 48.8 & 33.7 & 26.6 & 5.62 & 0.048 & 0.066 \\
\hline 54 & & 0 & 2.731 & 0 & 760 & 60 & & & \\
\hline
\end{tabular}

\section{Regulador Automático de Tensão (AVR)}

Os valores do modelo 01 serão considerados como padrão para o restante dos reguladores de tensão (modelo $01, .$. , modelo 53) associado às máquinas síncronas do sistema teste IEEE118; o tipo de regulador de tensão usado é o DRGT MD20 (Anatem, 2000)

\begin{tabular}{|r||c|c|c||c||c|c|c||c|}
\hline Modelo & Tm & Ka & T1 & T2 & T3 & T4 & Lmin & Lmax \\
\hline \hline 0001 & 0.02 & 190.8 & 3 & 12 & 0.07 & 0.0133 & -3.87 & 5.87 \\
\hline
\end{tabular}




\section{Estabilizadores de Potência (PSS)}

Os valores do modelo 01 serão considerados como padrão para o restante dos estabilizadores (modelo 01,... modelo 53) associado às máquinas síncronas do sistema teste IEEE118; o tipo de estabilizador usado é o DEST MD01 (Anatem, 2000).

\begin{tabular}{|c|c|c|c|c|c|c|c|c|}
\hline Modelo & $\mathbf{K}$ & $T$ & $\mathrm{~T} 1$ & $\mathrm{~T} 2$ & T3 & T4 & Imin & Imax \\
\hline 0001 & 22.78 & 1 & 1.5 & 0.02 & 0.2927 & 12 & -0.05 & 0.05 \\
\hline
\end{tabular}

\section{D.3 Sistema Interligado Norte-Nordeste Brasileiro - 564 barras}

\section{D.3.1 Estado Estacionário}

\section{Parâmetros de barra}

\begin{tabular}{|c|c|c|c|c|c|c|c|c|c|}
\hline \multirow{2}{*}{ BAR } & \multirow{2}{*}{$\mathbf{T}$} & \multirow{2}{*}{ NOME DA BARRA } & \multirow{2}{*}{$\begin{array}{c}\text { TENSAO } \\
\text { P.U }\end{array}$} & \multirow{2}{*}{$\begin{array}{c}\text { ANGULO } \\
\text { RAD }\end{array}$} & \multicolumn{2}{|c|}{ INJEÇÃO DE POTENCIA } & \multicolumn{2}{|c|}{ CARGA } & \multirow{2}{*}{$\begin{array}{l}\text { SHUNT } \\
\text { MVAR }\end{array}$} \\
\hline & & & & & MW & MVAR & MW & MVAR & \\
\hline 36 & 1 & S.MESA---3GR & 1030 & 35.8 & 900.0 & 146.20 & & & \\
\hline 235 & & CS.MESA---500 & 1072 & 31.7 & & & 2372 & -404 & \\
\hline 5001 & & CP.AFONSO-500 & 1070 & 16.9 & & & & & \\
\hline 5003 & & $\mathrm{FPAF}-\mathrm{BP}-1-230$ & 996 & 14.4 & & & & & \\
\hline 5004 & & $\mathrm{FPAF}-\mathrm{BP}-2-230$ & 1003 & 15.6 & & & & & \\
\hline 5005 & & QUSU-01G1-0MQ & 1003 & 15.6 & & & & & \\
\hline 5006 & 1 & QPAFO-1G1-000 & 1000 & 15.6 & 0.0 & 19.94 & & & \\
\hline 5007 & & QUSU-01G3-0MQ & 1003 & 15.6 & & & & & \\
\hline 5009 & 1 & QPAFO-2G1-000 & 1000 & 14.4 & 0.0 & -8.19 & & & \\
\hline 5010 & 1 & $\mathrm{QPAFO}-2 \mathrm{G} 2-1 \mathrm{GR}$ & 1000 & 21.8 & 70.0 & -3.18 & & & \\
\hline 5011 & 1 & $\mathrm{QPAFO}-2 \mathrm{G} 3-000$ & 1007 & 14.4 & 0.0 & -4.82 & & & \\
\hline 5012 & 1 & $\mathrm{QPAFO}-2 \mathrm{G} 4-000$ & 1007 & 14.4 & 0.0 & -5.65 & & & \\
\hline 5013 & 1 & QPAFO-2G5-000 & 1007 & 14.4 & 0.0 & -6.08 & & & \\
\hline 5014 & 1 & $\mathrm{QPAFO}-2 \mathrm{G} 6-000$ & 1007 & 14.4 & 0.0 & -6.18 & & & \\
\hline 5015 & 1 & QPAFO-3G1-000 & 971 & 14.4 & 0.0 & 3.46 & & & \\
\hline 5016 & 1 & $\mathrm{QPAFO}-3 \mathrm{G} 2-1 \mathrm{GR}$ & 993 & 21.3 & 160.0 & 34.41 & & & \\
\hline 5017 & & QUST-01G3-0MQ & 970 & 14.4 & & & & & \\
\hline 5018 & & QUST-01G4-0MQ & 977 & 15.6 & & & & & \\
\hline 5022 & 1 & $\mathrm{QPAFO}-4 \mathrm{G} 1-5 \mathrm{GR}$ & 1017 & 21.6 & 1640.0 & -453.00 & & & \\
\hline 5023 & & QUSQ-01G2-0MQ & 1010 & 16.9 & & & & & \\
\hline 5024 & & QUSQ-01G3-0MQ & 1010 & 16.9 & & & & & \\
\hline 5025 & & QUSQ-01G4-0MQ & 1010 & 16.9 & & & & & \\
\hline 5026 & & QUSQ-01G5-0MQ & 1010 & 16.9 & & & & & \\
\hline 5027 & & QUSQ-01G6-0MQ & 1010 & 16.9 & & & & & \\
\hline 5028 & & FMXT-BP $-2-230$ & 1005 & 15.8 & & & & & \\
\hline 5029 & & FMXT-BP $-1-230$ & 996 & 14.4 & & & & & \\
\hline 5030 & 1 & QASALESG1-000 & 971 & 14.4 & 0.0 & 1.45 & & & \\
\hline 5031 & & QUAS-01G2-0MQ & 970 & 14.4 & & & & & \\
\hline 5032 & 1 & QASALESG2-1GR & 993 & 21.0 & 75.0 & 15.83 & & & \\
\hline
\end{tabular}




\begin{tabular}{|c|c|c|c|c|c|c|c|c|c|}
\hline \multirow{2}{*}{ BAR } & \multirow{2}{*}{$\mathbf{T}$} & \multirow{2}{*}{ NOME DA BARRA } & \multirow{2}{*}{$\begin{array}{c}\text { TENSAO } \\
\text { P.U }\end{array}$} & \multirow{2}{*}{$\begin{array}{l}\text { ANGULO } \\
\text { RAD }\end{array}$} & \multicolumn{2}{|c|}{ " INJEÇÃO DE POTENCIA } & \multicolumn{2}{|c|}{ CARGA } & \multirow{2}{*}{$\begin{array}{l}\text { SHUNT } \\
\text { MVAR }\end{array}$} \\
\hline & & & & & MW & MVAR & MW & MVAR & \\
\hline 5033 & & QUAS-01G4-0MQ & 978 & 15.8 & & & & & \\
\hline 5050 & & CL.GONZAG-500 & 1069 & 17.7 & & & & & \\
\hline 5051 & 1 & QLGONZAG1-3GR & 1019 & 21.5 & 510.0 & -158.00 & & & \\
\hline 5052 & & QULG-01G2-0MQ & 1037 & 17.7 & & & & & \\
\hline 5053 & & QULG-01G3-0MQ & 1037 & 17.7 & & & & & \\
\hline 5054 & 1 & QLGONZAG2-2GR & 1019 & 21.5 & 340.0 & -105.00 & & & \\
\hline 5055 & & QULG-01G5-0MQ & 1037 & 17.7 & & & & & \\
\hline 5056 & & QULG-01G6-0MQ & 1037 & 17.7 & & & & & \\
\hline 5060 & & CXINGO----500 & 1060 & 15.7 & & & & & \\
\hline 5061 & 1 & QXINGO----3GR & 989 & 22.7 & 1500.0 & -448.00 & & & \\
\hline 5062 & & QUXG-01G2-0MQ & 1010 & 15.7 & & & & & \\
\hline 5063 & & QUXG-01G3-0MQ & 1010 & 15.7 & & & & & \\
\hline 5064 & & QUXG-01G4-0MQ & 1010 & 15.7 & & & & & \\
\hline 5065 & & QUXG-01G5-0MQ & 1010 & 15.7 & & & & & \\
\hline 5066 & & QUXG-01G6-0MQ & 1010 & 15.7 & & & & & \\
\hline 5100 & & CANGELIM--500 & 1064 & 8.1 & & & & & \\
\hline 5101 & & FANGELIM--230 & 1028 & 5.2 & & & & & \\
\hline 5102 & & TANGELIM--000 & 1040 & 0.7 & & & & & \\
\hline 5103 & & IANGELIM--069 & 1041 & 0.8 & & & 124.7 & 32.82 & \\
\hline 5104 & & MANGELIM--013 & 1040 & 0.7 & & & & & \\
\hline 5106 & & MAGL-TIP. -013 & 1029 & -0.6 & & & 3.83 & 1.855 & \\
\hline 5110 & & FSALGEMA--230 & 1001 & 1.1 & & & & & \\
\hline 5111 & & FR. LARGO--230 & 1021 & 3.1 & & & & & \\
\hline 5113 & & IR. LARGO--069 & 1028 & 0.4 & & & 76 & 27.6 & 85.2 \\
\hline 5114 & & MR. LARGO--013 & 1028 & 0.4 & & & & & \\
\hline 5115 & & MSGM----A-013 & 998 & -5.9 & & & 56 & 21.68 & \\
\hline 5116 & & MSGM-----B-013 & 998 & -5.9 & & & 56 & 21.68 & \\
\hline 5117 & & MSGM----C-013 & 998 & -4.6 & & & 56 & 21.68 & \\
\hline 5118 & & MSGM---A1-013 & 1038 & -5.9 & & & & & 5.1 \\
\hline 5119 & & MSGM---B1-013 & 1038 & -5.9 & & & & & 5.1 \\
\hline 5120 & & MSGM---C1-013 & 1045 & -4.6 & & & & & 20 \\
\hline 5121 & & FTACAIMBO-230 & 1020 & 1.3 & & & & & \\
\hline 5123 & & ITACAIMBO-069 & 1012 & -2.8 & & & 114.1 & 28.09 & \\
\hline 5125 & & MTACAIMBO-013 & 1038 & -2.8 & & & & & \\
\hline 5131 & & FPIRAPAMA-230 & 1019 & -2.4 & & & 9.9 & 1.481 & \\
\hline 5133 & & IP IRAPAMA-069 & 1003 & -7.7 & & & 214.7 & 38.87 & 20.4 \\
\hline 5140 & & CRECIFEII-500 & 1065 & 1.7 & & & & & \\
\hline 5141 & & FRCD $-B P-1-230$ & 1025 & -0.9 & & & & & \\
\hline 5142 & & FRCD $-B P-2-230$ & 1025 & -0.7 & & & & & \\
\hline 5144 & & QRCD $-C S-1-000$ & 1004 & -0.9 & & & & & \\
\hline 5145 & 1 & QRCD-SIE--1CS & 1025 & -0.9 & 0.0 & 65.94 & & & \\
\hline 5146 & & QRCD $-C S-2-000$ & 1004 & -0.9 & & & & & \\
\hline 5147 & 1 & QRCD-ALS--1CS & 1025 & -0.9 & 0.0 & 65.94 & & & \\
\hline 5150 & & FTERMOPE--230 & 1020 & -2.4 & & & & & \\
\hline 5151 & 1 & QTERMOPEG-000 & 1026 & -2.4 & 0.0 & 35.93 & & & \\
\hline 5152 & & FBONGI----230 & 1019 & -1.6 & & & 6.3 & 1.5 & \\
\hline 5153 & & QGERTERMO-OMQ & 1020 & -2.4 & & & & & \\
\hline 5154 & 1 & QTERMOPEV-000 & 1015 & -2.4 & 0.0 & -10.50 & & & \\
\hline 5156 & & IBONGI----069 & 1000 & -6.1 & & & 230.9 & 48.09 & 40.8 \\
\hline 5157 & & MBGI-RLT6-013 & 1019 & -4.0 & & & & & \\
\hline
\end{tabular}




\begin{tabular}{|c|c|c|c|c|c|c|c|c|c|}
\hline \multirow{2}{*}{ BAR } & \multirow{2}{*}{$\mathbf{T}$} & \multirow{2}{*}{ NOME DA BARRA } & \multirow{2}{*}{$\begin{array}{c}\text { TENSAO } \\
\text { P.U }\end{array}$} & \multirow{2}{*}{$\begin{array}{l}\text { ANGULO } \\
\text { RAD }\end{array}$} & \multicolumn{2}{|c|}{ INJEÇÃO DE POTENCIA } & \multicolumn{2}{|c|}{ CARGA } & \multirow{2}{*}{$\begin{array}{l}\text { SHUNT } \\
\text { MVAR }\end{array}$} \\
\hline & & & & & MW & MVAR & MW & MVAR & \\
\hline 5158 & & MBONGI-T6-013 & 1000 & -5.5 & & & 17.36 & 11.76 & \\
\hline 5159 & & MBGI-RLT7-013 & 972 & -5.8 & & & & & \\
\hline 5160 & & MBGI-T7K1-013 & 953 & -8.5 & & & 27.16 & 19.31 & \\
\hline 5161 & & MBONGI-T9-013 & 1015 & -6.1 & & & & & \\
\hline 5163 & & MBONGI-T8-013 & 1001 & -7.2 & & & 3 & 0.987 & \\
\hline 5171 & & MBONGI-G1-013 & 994 & -1.6 & & & & & \\
\hline 5172 & & MBONGI-G2-013 & 994 & -1.6 & & & & & \\
\hline 5175 & & MBONGI-G4-013 & 994 & -1.6 & & & & & \\
\hline 5181 & & FP.FERRO--230 & 1016 & -3.2 & & & & & \\
\hline 5183 & & IP.FERRO--069 & 1000 & -8.3 & & & 145 & 35.7 & \\
\hline 5191 & & FMIRUEIRA-230 & 1011 & -3.5 & & & & & \\
\hline 5193 & & IMIRUEIRA-0 69 & 1014 & -8.5 & & & 262.7 & 84.48 & 40.8 \\
\hline 5194 & & MMIRUEIR2-013 & 1014 & -8.5 & & & & & \\
\hline 5195 & & MMIRUEIRA-013 & 1014 & -8.5 & & & & & \\
\hline 5196 & & MMIRUEIR3-013 & 1014 & -8.5 & & & & & \\
\hline 5197 & & MMIRUEIRA-013 & 1014 & -8.5 & & & & & \\
\hline 5201 & & FGOIANINH-230 & 1000 & -5.8 & & & & & \\
\hline 5203 & & IGOIANINH-069 & 1014 & -9.5 & & & 100.4 & 33.51 & 21.3 \\
\hline 5204 & & TGNN-RLT1-000 & 1019 & -9.5 & & & & & \\
\hline 5205 & 1 & QGNN--T1--1CS & 1030 & -9.5 & 0.0 & 4.21 & & & \\
\hline 5206 & & MGNN--T2--013 & 1014 & -9.5 & & & & & \\
\hline 5211 & & FMUSSURE--230 & 982 & -8.3 & & & & & \\
\hline 5213 & & IMUSSURE--069 & 1028 & -13.0 & & & 266.1 & 87.5 & 42.6 \\
\hline 5214 & & MMUSSURE2-013 & 1028 & -13.0 & & & & & \\
\hline 5215 & & MMUSSURE1-013 & 1028 & -13.0 & & & & & \\
\hline 5222 & & FC.GRANDE -230 & 1023 & -6.5 & & & & & -10 \\
\hline 5223 & & ICATOLE-D-069 & 1041 & -11.0 & & & & & \\
\hline 5224 & & ICATOLE---069 & 1041 & -11.0 & & & & & \\
\hline 5225 & & MCATOLE---013 & 1041 & -11.0 & & & & & \\
\hline 5226 & & ICGD------069 & 1041 & -11.0 & & & 158.7 & 52.1 & \\
\hline 5227 & & ICGU-------069 & 1041 & -11.0 & & & & & \\
\hline 5228 & & IB. -VISTA-069 & 1041 & -11.0 & & & & & \\
\hline 5229 & & MB.VISTA--013 & 1041 & -11.0 & & & & & \\
\hline 5230 & & MCGD-------013 & 1021 & -14.0 & & & 22.5 & 7.4 & \\
\hline 5231 & & MCGD $-2----013$ & 1036 & -7.5 & & & & & \\
\hline 5232 & 1 & MCGD-1----013 & 1040 & -7.6 & 0.0 & -2.68 & & & \\
\hline 5233 & & MCGU-------013 & 1041 & -11.0 & & & & & \\
\hline 5234 & & MB.VISTA2-013 & 1041 & -11.0 & & & & & \\
\hline 5235 & & GC.GRANDE-138 & 1048 & -8.4 & & & & & \\
\hline 5236 & & TCGD $---2--000$ & 1036 & -7.5 & & & & & \\
\hline 5237 & & TCGD ----1--000 & 1046 & -7.6 & & & & & \\
\hline 5238 & & MCGD-RL-1-013 & 1044 & -7.6 & & & & & \\
\hline 5239 & & $\mathrm{CE} \quad \mathrm{CGD}$ & 1023 & -6.5 & & & & & \\
\hline 5241 & & FNATAL-II-230 & 1031 & -13.0 & & & & & \\
\hline 5243 & 1 & INATAL-II-069 & 1014 & -18.0 & 0.0 & 25.42 & 302.2 & 45.61 & 42.6 \\
\hline 5252 & & GS.CRUZ ---138 & 1041 & -10.0 & & & & & \\
\hline 5253 & & IS.CRUZ ---069 & 1011 & -13.0 & & & 18.84 & 1.017 & \\
\hline 5254 & & FPARAISO--230 & 1033 & -11.0 & & & & & \\
\hline 5255 & & GPARAISO--138 & 999 & -13.0 & & & & & \\
\hline 5256 & & MSTD-TIP. -013 & 974 & -17.0 & & & 4.686 & 2.708 & \\
\hline
\end{tabular}




\begin{tabular}{|c|c|c|c|c|c|c|c|c|c|}
\hline \multirow{2}{*}{ BAR } & \multirow{2}{*}{$\mathbf{T}$} & \multirow{2}{*}{ NOME DA BARRA } & \multirow{2}{*}{$\begin{array}{c}\text { TENSAO } \\
\text { P.U }\end{array}$} & \multirow{2}{*}{$\begin{array}{c}\text { ANGULO } \\
\text { RAD }\end{array}$} & \multicolumn{2}{|c|}{ INJEÇÃO DE POTENCIA } & \multicolumn{2}{|c|}{ CARGA } & \multirow{2}{*}{$\begin{array}{l}\text { SHUNT } \\
\text { MVAR }\end{array}$} \\
\hline & & & & & MW & MVAR & MW & MVAR & \\
\hline 5262 & & GC.NOVOS--138 & 980 & -16.0 & & & & & \\
\hline 5263 & & IC.NOVOS--069 & 1012 & -24.0 & & & 28.28 & 9.498 & \\
\hline 5265 & & MC.NOVOS--013 & 1048 & -22.0 & & & & & 7.2 \\
\hline 5266 & & MCRD-TIP. -013 & 1038 & -24.0 & & & & & \\
\hline 5268 & & TCRD-------000 & 1048 & -22.0 & & & & & \\
\hline 5281 & & FRIBEIRAO-230 & 1016 & -0.7 & & & & & \\
\hline 5283 & & IRIBEIRAO-069 & 1000 & -3.9 & & & 89.18 & 16.15 & \\
\hline 5291 & & FPENEDO---230 & 981 & -2.3 & & & & & \\
\hline 5293 & & IPENEDO---069 & 998 & -5.2 & & & 81.06 & 19.71 & \\
\hline 5300 & & CMESSIAS- -500 & 1053 & 5.2 & & & & & \\
\hline 5301 & & FMESSIAS- -230 & 1024 & 3.7 & & & & & \\
\hline 5311 & & FMACEIO---230 & 1014 & 2.9 & & & & & \\
\hline 5313 & & IMACEIO---069 & 999 & -2.2 & & & 209.8 & 76.2 & \\
\hline 5331 & & FVARZEA---230 & 1022 & -1.2 & & & & & \\
\hline 5333 & & IVARZEA---069 & 1000 & -6.1 & & & 135 & 28.12 & \\
\hline 5401 & & FB.NOME ---230 & 1023 & 11.0 & & & & & \\
\hline 5402 & & GB. NOME---138 & 997 & 9.8 & & & 45.87 & 5.456 & \\
\hline 5403 & & IB. NOME---069 & 1040 & 6.1 & & & 50.89 & 18.13 & \\
\hline 5406 & & MBNO-TIP. -013 & 1060 & 4.7 & & & 4.4 & 1.103 & \\
\hline 5408 & & CMILAGRES -500 & 1077 & 12.4 & & & & & -100 \\
\hline 5409 & & MMLG--T3--013 & 1026 & 7.1 & & & & & \\
\hline 5410 & & $\mathrm{QCE} \quad \mathrm{MLG}$ & 1013 & 10.3 & & & & & -9.6 \\
\hline 5411 & & FMILAGRES-230 & 1027 & 10.3 & & & & & \\
\hline 5412 & & MMLG-RLT3-013 & 1026 & 7.1 & & & & & \\
\hline 5413 & & IMILAGRES-069 & 1026 & 7.2 & & & 79.6 & 11.34 & \\
\hline 5414 & & MMLG-RLT4-013 & 1026 & 7.1 & & & & & \\
\hline 5415 & & MMLG--T4--013 & 1026 & 7.1 & & & & & \\
\hline 5416 & & MMLG-TIP. -013 & 997 & 5.6 & & & 7.3 & 3.997 & \\
\hline 5417 & & MMILAGRES-013 & 1011 & 5.7 & & & & & \\
\hline 5418 & & TMLG--T3--000 & 1026 & 7.1 & & & & & \\
\hline 5419 & & TMLG--T4--000 & 1026 & 7.1 & & & & & \\
\hline 5421 & & FBANABUIU-230 & 1031 & 4.7 & & & & & \\
\hline 5422 & & MLIBRA----013 & 1030 & 4.6 & & & 0.3 & 0.099 & \\
\hline 5423 & & IBANABUIU-069 & 1027 & -0.5 & & & 50.5 & 0 & \\
\hline 5424 & & MBNB--RS--013 & 1018 & -1.1 & & & & & \\
\hline 5426 & & MBNB-TIP. -013 & 999 & -1.1 & & & 0.8 & 0.654 & \\
\hline 5428 & & CQUIXADA 500 & 1095 & 11.4 & & & & & \\
\hline 5431 & & FRUSSAS ---230 & 1015 & -2.9 & & & & & \\
\hline 5433 & & IRUSSAS---069 & 1013 & -5.4 & & & 43.6 & 14.33 & \\
\hline 5441 & & FMOSSORO--230 & 1018 & -6.3 & & & & & \\
\hline 5443 & 1 & IMOSSORO--069 & 1014 & -9.8 & 0.0 & 10.98 & 98.1 & 14.38 & \\
\hline 5445 & & MMOSSORO1-013 & 984 & -9.8 & & & & & \\
\hline 5446 & & MMOSSORO2-013 & 984 & -9.8 & & & & & \\
\hline 5450 & & QCE FTZ & 990 & 8.6 & & & & & -34.3 \\
\hline 5451 & & CFTZ-II---500 & 1079 & 11.0 & & & & & \\
\hline 5452 & & FFORTALEZ-230 & 1014 & 8.6 & & & & & 50.5 \\
\hline 5453 & & IFORTALEZ-069 & 1028 & 3.8 & & & 276.3 & 90.79 & 81.4 \\
\hline 5454 & & MFTZ-RLT3-013 & 1028 & 3.8 & & & & & \\
\hline 5455 & & MFTZ-1-T3-013 & 1028 & 3.8 & & & & & \\
\hline 5456 & & MFTZ-RLT4-013 & 1028 & 3.8 & & & & & \\
\hline
\end{tabular}




\begin{tabular}{|c|c|c|c|c|c|c|c|c|c|}
\hline \multirow{2}{*}{ BAR } & \multirow{2}{*}{$\mathbf{T}$} & \multirow{2}{*}{ NOME DA BARRA } & \multirow{2}{*}{$\begin{array}{c}\text { TENSAO } \\
\text { P.U }\end{array}$} & \multirow{2}{*}{$\begin{array}{l}\text { ANGULO } \\
\text { RAD }\end{array}$} & \multicolumn{2}{|c|}{ " INJEÇÃO DE POTENCIA } & \multicolumn{2}{|c|}{ CARGA } & \multirow{2}{*}{$\begin{array}{l}\text { SHUNT } \\
\text { MVAR }\end{array}$} \\
\hline & & & & & MW & MVAR & MW & MVAR & \\
\hline 5457 & & MFTZ-2-T4-013 & 1028 & 3.8 & & & & & \\
\hline 5458 & & FFTZ-II---230 & 1014 & 8.6 & & & & & \\
\hline 5461 & & FACU-II---230 & 1027 & -10.0 & & & & & \\
\hline 5463 & & IACU-II---069 & 1013 & -12.0 & & & 23.33 & -3.64 & \\
\hline 5464 & & MACU--T5--013 & 1013 & -12.0 & & & & & \\
\hline 5465 & & MACU--T4--013 & 1013 & -12.0 & & & & & \\
\hline 5468 & & GACU-II---138 & 1026 & -14.0 & & & 56.11 & 2.511 & \\
\hline 5471 & & FD.GOUVEI-230 & 1015 & 8.3 & & & & & 50.5 \\
\hline 5473 & & ID.GOUVEI-069 & 1028 & 3.9 & & & 255.4 & 83.92 & 97.2 \\
\hline 5474 & & GS.MATOS--138 & 979 & -16.0 & & & & & \\
\hline 5475 & & IS.MATOS--069 & 999 & -24.0 & & & 4.926 & -1.63 & \\
\hline 5476 & & MS.MATOS--013 & 986 & -21.0 & & & 1.637 & 0.651 & \\
\hline 5477 & & SMD-ABERT138 & 1028 & -14.0 & & & & & \\
\hline 5478 & & TS.MATOS--000 & 986 & -21.0 & & & & & \\
\hline 5480 & & CSOBRALIII500 & 1071 & 18.8 & & & & & \\
\hline 5481 & & FSOBRALII-230 & 1021 & 17.2 & & & 8.9 & 3.791 & \\
\hline 5482 & & TSBD--T1--000 & 1022 & 12.3 & & & & & \\
\hline 5483 & & ISOBRALII-069 & 1015 & 14.0 & & & 135.7 & 19.34 & 50 \\
\hline 5484 & & TSBD $--\mathrm{T} 2--000$ & 1022 & 12.3 & & & & & \\
\hline 5485 & & MSBD--T1--013 & 1022 & 12.3 & & & & & \\
\hline 5487 & & MSBD--T2--013 & 1022 & 12.3 & & & & & \\
\hline 5488 & & FSOBRALIII230 & 1021 & 17.7 & & & & & \\
\hline 5491 & & FPIRIP IRI -230 & 1011 & 21.2 & & & & & \\
\hline 5492 & & GPIRIP IRI -138 & 1002 & 18.9 & & & 36.83 & 15.78 & \\
\hline 5493 & & IPIRIP IRI -069 & 1045 & 18.9 & & & 23.15 & 7.442 & \\
\hline 5494 & & MPRI-RL-T1013 & 1049 & 18.8 & & & & & \\
\hline 5495 & & MPRI--T2--013 & 1045 & 18.7 & & & & & \\
\hline 5496 & & MPRI-------013 & 1026 & 17.3 & & & 7.063 & 4.5 & \\
\hline 5497 & & MPRI--T1--013 & 1064 & 18.8 & & & & & 4.2 \\
\hline 5498 & & TPRI $--\mathrm{T} 2--000$ & 1045 & 18.7 & & & & & \\
\hline 5499 & & TPRI--T1--000 & 1044 & 18.8 & & & & & \\
\hline 5500 & & CTERES-II-500 & 1053 & 34.9 & & & & & \\
\hline 5501 & & FTERESINA-230 & 1033 & 30.5 & & & & & 50.5 \\
\hline 5502 & & FTERES-II-230 & 1043 & 32.2 & & & & & \\
\hline 5503 & & ITERES INA-069 & 1047 & 25.9 & & & 206 & 108.5 & 42.6 \\
\hline 5504 & & TTSA--T1--000 & 1012 & 26.6 & & & & & \\
\hline 5505 & & MTSA--T1--013 & 1003 & 24.8 & & & 21.91 & 12.9 & 7.2 \\
\hline 5506 & & MTSA--T2--013 & 1004 & 26.6 & & & 14.61 & 8.602 & 10.8 \\
\hline 5507 & & TTSA--T2--000 & 1001 & 27.8 & & & & & \\
\hline 5508 & & MTSA----R-013 & 999 & 30.5 & & & & & \\
\hline 5509 & 1 & QTERESINA-1CS & 1040 & 32.2 & 0.0 & -4.09 & & & \\
\hline 5510 & & CB.ESPER. -500 & 1065 & 33.0 & & & & & -100 \\
\hline 5511 & & FB.ESPER. -230 & 1020 & 33.8 & & & & & \\
\hline 5512 & & TUBE--T5--000 & 1035 & 30.8 & & & & & \\
\hline 5513 & & IB.ESPER--069 & 1037 & 30.9 & & & 49.21 & 19.91 & \\
\hline 5514 & & TUBE--T6--000 & 1036 & 30.7 & & & & & \\
\hline 5515 & & MUBE--T5--013 & 1035 & 30.8 & & & & & \\
\hline 5516 & & MUBE--T6--013 & 1033 & 30.4 & & & 0.77 & 0.301 & \\
\hline 5517 & & MUBE------013 & 1036 & 30.7 & & & & & \\
\hline 5518 & & TUBE--T8--000 & 1037 & 30.8 & & & & & \\
\hline
\end{tabular}




\begin{tabular}{|c|c|c|c|c|c|c|c|c|c|}
\hline \multirow{2}{*}{ BAR } & \multirow{2}{*}{$\mathbf{T}$} & \multirow{2}{*}{ NOME DA BARRA } & \multirow{2}{*}{$\begin{array}{c}\text { TENSAO } \\
\text { P.U }\end{array}$} & \multirow{2}{*}{$\begin{array}{l}\text { ANGULO } \\
\text { RAD }\end{array}$} & \multicolumn{2}{|c|}{ INJEÇÃO DE POTENCIA } & \multicolumn{2}{|c|}{ CARGA } & \multirow{2}{*}{$\begin{array}{l}\text { SHUNT } \\
\text { MVAR }\end{array}$} \\
\hline & & & & & MW & MVAR & MW & MVAR & \\
\hline 5519 & & MUBE--T8--013 & 1037 & 30.8 & & & & & \\
\hline 5520 & 1 & QBOAESP-1-2GR & 1025 & 38.9 & 98.0 & 10.03 & & & \\
\hline 5521 & & QUBE-01G2-0MQ & 1020 & 33.8 & & & & & \\
\hline 5522 & 1 & QBOAESP-2-1GR & 1025 & 40.0 & 59.0 & 6.01 & & & \\
\hline 5523 & 1 & QBOAESP-2-000 & 1025 & 33.8 & 0.0 & 3.02 & & & \\
\hline 5524 & & FC.NETO-P-TAP & 1034 & 30.6 & & & & & \\
\hline 5525 & & FC.NETO---230 & 1034 & 29.7 & & & & & \\
\hline 5526 & & IC.NETO---069 & 1006 & 27.2 & & & 20.53 & 2.926 & \\
\hline 5528 & & SCHIN-MA 230 & 1032 & 30.9 & & & & & \\
\hline 5531 & & FPERITORO-230 & 1005 & 33.1 & & & 4 & 1.315 & \\
\hline 5533 & & IPERITORO-069 & 1061 & 29.8 & & & 49.42 & 19.72 & \\
\hline 5535 & & MPERITORO-013 & 1059 & 29.4 & & & 1.263 & 0.504 & \\
\hline 5538 & & TPERITORO-000 & 1059 & 29.5 & & & & & \\
\hline 5541 & & FMIRANDA--230 & 1009 & 32.7 & & & & & \\
\hline 5542 & & GMIRANDA--138 & 1043 & 29.8 & & & 62.62 & 25.94 & \\
\hline 5543 & & IMIRANDA--069 & 1072 & 31.5 & & & 32.59 & 8.14 & \\
\hline 5544 & & MIRANDA13-2 & 1071 & 31.4 & & & & & \\
\hline 5545 & & MMIRANDA-1013 & 1071 & 31.3 & & & 3.08 & 0.769 & \\
\hline 5546 & & MMIRANDA-2013 & 985 & 29.6 & & & & & \\
\hline 5547 & & TMIRANDA-2000 & 1071 & 31.4 & & & & & \\
\hline 5548 & & TMIRANDA-1000 & 1071 & 31.4 & & & & & \\
\hline 5549 & & TMIRANDA--000 & 985 & 29.6 & & & & & \\
\hline 5550 & & CS.LUISII -500 & 1047 & 38.2 & & & & & -136 \\
\hline 5551 & & FS.LUISII-230 & 1059 & 37.5 & & & 836.5 & 297.4 & 281.6 \\
\hline 5556 & 1 & QSAOLUIZ--000 & 990 & 37.5 & 0.0 & -24.90 & & & \\
\hline 5557 & & QUTS-01G2-0MQ & 1033 & 37.5 & & & & & \\
\hline 5558 & 1 & QS.LUISII-1CE & 1020 & 37.5 & 0.0 & -266.00 & & & \\
\hline 5561 & & FS.LUIS-I-230 & 1049 & 36.9 & & & & & \\
\hline 5562 & & MS.LUIS-I-013 & 1071 & 33.6 & & & & & \\
\hline 5563 & & IS.LUIS-I-069 & 1071 & 33.6 & & & 158.1 & 92.18 & \\
\hline 5565 & & MS.LUIS-I-013 & 1037 & 36.9 & & & & & \\
\hline 5568 & & TS.LUIS-I-000 & 1037 & 36.9 & & & & & \\
\hline 5570 & & CS.J.PIAUI500 & 1061 & 29.7 & & & & & \\
\hline 5571 & & FS.J.PIAUI 230 & 1010 & 28.6 & & & & & \\
\hline 5572 & & CBCSSJIUSB500 & 1055 & 32.7 & & & & & \\
\hline 5573 & & IS.J.PIAUI069 & 1023 & 25.4 & & & 26.69 & 2.544 & \\
\hline 5574 & & CBCSBEASJI 500 & 1072 & 26.1 & & & & & \\
\hline 5576 & & CBCSBEASJI 500 & 1052 & 36.6 & & & & & \\
\hline 5578 & & CBCSSJIUSB500 & 1058 & 24.1 & & & & & \\
\hline 5580 & & CP.DUTRA --500 & 1062 & 41.6 & & & & & \\
\hline 5581 & & FP.DUTRA--230 & 988 & 39.7 & & & & & \\
\hline 5582 & & QPDD-CS12-000 & 966 & 39.7 & & & & & \\
\hline 5583 & & IP.DUTRA--069 & 1035 & 33.8 & & & 24.57 & 10.89 & \\
\hline 5584 & & MP. DUTRA-2013 & 1051 & 35.8 & & & & & \\
\hline 5585 & & MP.DUTRA--013 & 1012 & 40.0 & & & & & \\
\hline 5586 & 1 & QPDUTRA---2CS & 960 & 39.7 & 0.0 & -17.30 & & & \\
\hline 5588 & & TPDD-ATR--000 & 1012 & 40.0 & & & & & \\
\hline 5589 & & TP.DUTRA --000 & 1051 & 35.8 & & & & & \\
\hline 5590 & & CIMPERATR-500 & 1071 & 48.6 & & & & & -272 \\
\hline 5591 & & F IMPERATR-230 & 1036 & 47.8 & & & & & \\
\hline
\end{tabular}




\begin{tabular}{|c|c|c|c|c|c|c|c|c|c|}
\hline \multirow{2}{*}{ BAR } & \multirow{2}{*}{$\mathbf{T}$} & \multirow{2}{*}{ NOME DA BARRA } & \multirow{2}{*}{$\begin{array}{c}\text { TENSAO } \\
\text { P.U }\end{array}$} & \multirow{2}{*}{$\begin{array}{l}\text { ANGULO } \\
\text { RAD }\end{array}$} & \multicolumn{2}{|c|}{ INJEÇÃO DE POTENCIA } & \multicolumn{2}{|c|}{ CARGA } & \multirow{2}{*}{$\begin{array}{c}\text { SHUNT } \\
\text { MVAR }\end{array}$} \\
\hline & & & & & MW & MVAR & MW & MVAR & \\
\hline 5593 & & IIMPERATR-069 & 1033 & 45.0 & & & 83.07 & 43.85 & \\
\hline 5596 & 1 & QIMPERATR-3CS & 1020 & 47.8 & 0.0 & 25.11 & & & \\
\hline 5601 & & FP.FRANCO-230 & 1027 & 44.8 & & & & & \\
\hline 5602 & & GP.FRANCO-138 & 1019 & 43.6 & & & 31 & -3.3 & \\
\hline 5603 & & IP.FRANCO-069 & 1033 & 42.9 & & & 19.96 & 9.777 & \\
\hline 5605 & & MP.FRANCO-013 & 1029 & 43.5 & & & & & \\
\hline 5608 & & TP.FRANCO-000 & 1029 & 43.5 & & & & & \\
\hline 5621 & & FCOREMAS--230 & 958 & 3.7 & & & & & \\
\hline 5623 & & ICOREMAS-I069 & 1040 & 0.2 & & & 103.7 & 34.1 & \\
\hline 5624 & & MCOREMAS--013 & 1040 & 0.2 & & & & & \\
\hline 5631 & & FICO-------230 & 1030 & 6.6 & & & & & \\
\hline 5633 & & IICO------069 & 1012 & 2.9 & & & 52.1 & 7.257 & \\
\hline 5641 & & FPICI 230 & 1003 & 7.8 & & & & & \\
\hline 5643 & & IPICI 69 & 999 & 0.9 & & & 193.2 & 63.49 & \\
\hline 5651 & & FCAUIPE---230 & 1019 & 9.6 & & & & & \\
\hline 5652 & & FUTE_FORT.230 & 1019 & 9.7 & & & & & \\
\hline 5653 & & ICAUIPE---069 & 999 & 6.4 & & & 43.7 & 0 & \\
\hline 5654 & 1 & QTERMFTZG-1GR & 1000 & 14.6 & 100.0 & 11.00 & & & \\
\hline 5655 & 1 & QTERMFTZV-000 & 995 & 9.7 & 0.0 & 0.80 & & & \\
\hline 5656 & & QUTE_FORTAMQ3 & 994 & 9.7 & & & & & \\
\hline 5660 & 1 & QTERMOCEG-000 & 1017 & 9.6 & 0.0 & -3.24 & & & \\
\hline 5661 & & QUTE_CEARAMQ2 & 1019 & 9.6 & & & & & \\
\hline 5662 & & QUTE_CEARAMQ3 & 1019 & 9.6 & & & & & \\
\hline 5663 & & QUTE_CEARAMQ 4 & 1019 & 9.6 & & & & & \\
\hline 5664 & & QUTE_CEARAMQ5 & 1019 & 9.6 & & & & & \\
\hline 5667 & & QUCE-MQ12-000 & 1019 & 9.6 & & & & & \\
\hline 5668 & & QUCE-MQ34-000 & 1019 & 9.6 & & & & & \\
\hline 5671 & & FPICOS----230 & 994 & 25.5 & & & & & \\
\hline 5673 & & IPICOS----069 & 995 & 20.3 & & & 33.88 & 12.4 & \\
\hline 5701 & & FC.DANTAS-230 & 1023 & 10.2 & & & & & \\
\hline 5703 & & IC.DANTAS-069 & 1012 & 3.2 & & & 20.52 & 1.627 & \\
\hline 5704 & & MC.DANTAS-013 & 1012 & 3.2 & & & & & \\
\hline 5711 & & FITABAIANA230 & 1014 & 8.4 & & & & & \\
\hline 5713 & & IITABAIANA0 69 & 1027 & 4.3 & & & 92.04 & 5.295 & \\
\hline 5715 & & MITB--T1--013 & 1027 & 4.1 & & & & & \\
\hline 5716 & & MITB-TIP. -013 & 1010 & 1.6 & & & 14.35 & 4.712 & \\
\hline 5717 & & MITB--T2--013 & 1027 & 4.0 & & & & & \\
\hline 5718 & & TITB--T1--000 & 1027 & 4.1 & & & & & \\
\hline 5719 & & TITB--T2--000 & 1027 & 4.0 & & & & & \\
\hline 5720 & & CJARDIM---500 & 1074 & 10.3 & & & & & \\
\hline 5721 & & F JARD IM---230 & 1018 & 8.4 & & & & & \\
\hline 5722 & & FFAFEN----230 & 1017 & 8.3 & & & 24.7 & 9 & \\
\hline 5723 & & IJARDIM---069 & 1028 & 2.3 & & & 251.5 & 15.93 & 61.9 \\
\hline 5724 & & FCIMESA---230 & 1018 & 8.4 & & & 16.46 & 5.976 & \\
\hline 5730 & & FDER. OLD-1230 & 1027 & 8.0 & & & & & \\
\hline 5731 & & $\mathrm{FSCH}------230$ & 1023 & 5.7 & & & & & \\
\hline 5735 & & MOLD-------013 & 1014 & 6.4 & & & 5.23 & 2.286 & \\
\hline 5736 & & $\mathrm{MSCH}------013$ & 1020 & 4.6 & & & 3 & 0.5 & \\
\hline 5740 & & COLINDINA-500 & 1071 & 10.9 & & & & & \\
\hline 5750 & & CCAMACARI -500 & 1059 & 6.8 & & & & & \\
\hline
\end{tabular}




\begin{tabular}{|c|c|c|c|c|c|c|c|c|c|}
\hline \multirow{2}{*}{ BAR } & \multirow{2}{*}{$\mathbf{T}$} & \multirow{2}{*}{ NOME DA BARRA } & \multirow{2}{*}{$\begin{array}{c}\text { TENSAO } \\
\text { P.U }\end{array}$} & \multirow{2}{*}{$\begin{array}{l}\text { ANGULO } \\
\text { RAD }\end{array}$} & \multicolumn{2}{|c|}{ " INJEÇÃO DE POTENCIA } & \multicolumn{2}{|c|}{ CARGA } & \multirow{2}{*}{$\begin{array}{c}\text { SHUNT } \\
\text { MVAR }\end{array}$} \\
\hline & & & & & MW & MVAR & MW & MVAR & \\
\hline 5751 & & $\mathrm{FCMD}-\mathrm{BP}-1-230$ & 1018 & 5.0 & & & 86 & 35.99 & \\
\hline 5753 & & FCOPENE---230 & 1016 & 4.8 & & & 130 & 42.77 & \\
\hline 5754 & & $\mathrm{FCQR}------230$ & 1016 & 4.8 & & & 42 & 13.82 & \\
\hline 5757 & & ICAMACARI-069 & 998 & 3.2 & & & 48.48 & 1.434 & \\
\hline 5770 & 1 & QCAMACARI-1GR & 1020 & 10.5 & 70.0 & 5.07 & & & \\
\hline 5771 & 1 & QCAMACARI - 000 & 994 & 5.0 & 0.0 & 0.69 & & & \\
\hline 5778 & 1 & QCAMACARI-2CS & 1010 & 5.0 & 0.0 & 109.20 & & & \\
\hline 5782 & & FCATU-----230 & 1020 & 5.1 & & & 3 & 0.987 & \\
\hline 5786 & & ICATU-----069 & 998 & -2.0 & & & 98.4 & 16.34 & \\
\hline 5788 & & TCATU-T1--000 & 1007 & -0.2 & & & & & \\
\hline 5789 & & TCATU-T2--000 & 1006 & 0.8 & & & & & \\
\hline 5790 & & TCATU-T3--000 & 998 & -2.3 & & & & & \\
\hline 5791 & & MCTU-RL-T1013 & 1007 & -0.2 & & & & & \\
\hline 5792 & & MCTU-RL-T2013 & 1006 & 0.8 & & & & & \\
\hline 5793 & & MCATU-T1--013 & 1019 & -2.4 & & & 14.52 & 2.416 & 7.2 \\
\hline 5794 & & MCATU-T2--013 & 1016 & 0.8 & & & & & 3.6 \\
\hline 5795 & & MCATU-T3--013 & 998 & -2.3 & & & & & \\
\hline 5802 & & FCOTEGIPE-230 & 1007 & 3.8 & & & 18 & 3.632 & \\
\hline 5803 & & ICOTEGIPE-069 & 1028 & 0.1 & & & 28.88 & 5.095 & \\
\hline 5804 & & ID.P ITUACU230 & 1001 & 2.5 & & & & & \\
\hline 5806 & & COTEGIPE-069 & 999 & -4.0 & & & 115.5 & 20.38 & \\
\hline 5807 & & TCTG--T2--000 & 1027 & 0.0 & & & & & \\
\hline 5808 & & TCTG--T4--000 & 997 & -4.5 & & & & & \\
\hline 5809 & & MCTG-RL-T2013 & 1027 & 0.0 & & & & & \\
\hline 5810 & & QCTG-T2-130CS & 1027 & 0.0 & & & & & \\
\hline 5812 & & MCOTEG.T4-013 & 997 & -4.5 & & & & & \\
\hline 5817 & & L.FREITAS069 & 999 & -3.7 & & & & & \\
\hline 5821 & & FTERMOBAH-230 & 1003 & 4.9 & & & & & \\
\hline 5822 & & F JACARAC --230 & 1007 & 4.4 & & & 57 & 4.3 & \\
\hline 5824 & & FDOW-------230 & 1004 & 4.2 & & & 125 & 47.76 & \\
\hline 5826 & & IJACARAC. -069 & 999 & 2.0 & & & 63.5 & 1.712 & 27.1 \\
\hline 5827 & 1 & QT. BAH-G1-1GR & 1020 & 9.7 & 187.4 & -68.40 & & & \\
\hline 5828 & 1 & $\mathrm{QT} . \mathrm{BAH}-\mathrm{G} 2-000$ & 1056 & 4.9 & 0.0 & -0.56 & & & \\
\hline 5830 & & MJCR-------013 & 999 & 2.0 & & & & & \\
\hline 5831 & & MJCR------013 & 999 & 2.0 & & & & & \\
\hline 5842 & & FPITUACU--230 & 1001 & 2.5 & & & & & \\
\hline 5843 & & IPITUACU--069 & 999 & -3.4 & & & 309 & 96.74 & 21.2 \\
\hline 5846 & & MPTU--B2--013 & 999 & -3.4 & & & & & \\
\hline 5847 & & MPTU--B3--013 & 999 & -3.4 & & & & & \\
\hline 5848 & & TPTU--T4--000 & 997 & -3.9 & & & & & \\
\hline 5849 & & MP TU--T4--013 & 997 & -3.9 & & & & & \\
\hline 5852 & & FMATATU---230 & 1000 & 2.0 & & & & & \\
\hline 5856 & & IMATATU---069 & 999 & -3.5 & & & 225.5 & 18.53 & 27.1 \\
\hline 5863 & 1 & XMATATU-T4011 & 1020 & -6.2 & 0.0 & 2.16 & 24.33 & 2.005 & \\
\hline 5864 & & XMATATU-T5011 & 1004 & -5.7 & & & 22.45 & 1.851 & \\
\hline 5865 & 1 & XMATATU-T3011 & 1020 & -3.5 & 0.0 & 6.96 & & & \\
\hline 5871 & & FTOMBA----230 & 997 & 2.6 & & & & & \\
\hline 5872 & & FEMBASA---230 & 1011 & 4.6 & & & 0.65 & 0.277 & \\
\hline 5873 & & ITOMBA----069 & 999 & -1.5 & & & 170.4 & 31.51 & \\
\hline 5875 & & MTOMBA----013 & 999 & -1.5 & & & & & \\
\hline
\end{tabular}




\begin{tabular}{|c|c|c|c|c|c|c|c|c|c|}
\hline \multirow{2}{*}{ BAR } & \multirow{2}{*}{$\mathbf{T}$} & \multirow{2}{*}{ NOME DA BARRA } & \multirow{2}{*}{$\begin{array}{c}\text { TENSAO } \\
\text { P.U }\end{array}$} & \multirow{2}{*}{$\begin{array}{c}\text { ANGULO } \\
\text { RAD }\end{array}$} & \multicolumn{2}{|c|}{ INJEÇÃO DE POTENCIA } & \multicolumn{2}{|c|}{ CARGA } & \multirow{2}{*}{$\begin{array}{l}\text { SHUNT } \\
\text { MVAR }\end{array}$} \\
\hline & & & & & MW & MVAR & MW & MVAR & \\
\hline 5881 & & FG.MANGAB. 230 & 1016 & 5.3 & & & & & \\
\hline 5883 & & IG.MANGAB.069 & 1014 & 2.2 & & & 44.56 & 15.42 & \\
\hline 5886 & & MGVM--T1--013 & 1014 & 2.2 & & & & & \\
\hline 5887 & & MGVM-RL-T1013 & 1014 & 2.2 & & & & & \\
\hline 5891 & & FSA. JESUS-230 & 1016 & 4.9 & & & & & \\
\hline 5893 & & ISA. JESUS-069 & 1014 & -0.4 & & & 75.05 & 13.22 & \\
\hline 5902 & & FFUNIL----230 & 1019 & 4.4 & & & & & \\
\hline 5904 & & GFUNIL----138 & 1035 & 0.4 & & & 226.2 & -0.12 & \\
\hline 5905 & & CE FUNIL & 1018 & 4.4 & & & & & -0.9 \\
\hline 5910 & & MFUNIL-T5-013 & 1039 & 1.3 & & & & & \\
\hline 5911 & & MFUNIL-TR-013 & 1033 & -0.7 & & & 5.61 & 0.594 & \\
\hline 5915 & & XFUNIL----115 & 1039 & 1.4 & & & & & \\
\hline 5918 & & TFUNIL-T5-000 & 1039 & 1.3 & & & & & \\
\hline 5920 & 1 & QUFL-01G1-1MQ & 1000 & 2.9 & 4.0 & 0.90 & & & \\
\hline 5921 & 1 & QUFL-01G2-1MQ & 1000 & 2.8 & 4.0 & 0.90 & & & \\
\hline 5922 & 1 & QUFL-01G3-1MQ & 1000 & 2.8 & 4.0 & 0.90 & & & \\
\hline 5941 & & FBRUMADO--230 & 1030 & -2.8 & & & & & \\
\hline 5944 & & IBRUMADO--069 & 1028 & -4.5 & & & 49.19 & 5.235 & \\
\hline 5961 & & FITBNINHA-230 & 1017 & 6.6 & & & & & \\
\hline 5963 & & IITBNINHA-069 & 1012 & 4.4 & & & 22.2 & 10.85 & \\
\hline 5965 & & MITBNINHA-013 & 1012 & 4.4 & & & & & \\
\hline 5970 & & FITAPEBI --230 & 998 & 16.2 & & & & & \\
\hline 5972 & & FEUNAPOLIS 230 & 988 & 14.1 & & & & & \\
\hline 5974 & & GEUNAPOLIS138 & 1027 & 12.0 & & & 137.7 & -8.39 & \\
\hline 5975 & 1 & QITAPEBI--3GR & 983 & 22.3 & 381.0 & -32.80 & 5970 & & \\
\hline 5976 & & QITAPEBI--OMQ & 998 & 16.2 & & & & & \\
\hline 5977 & & QITAPEBI--OMQ & 998 & 16.2 & & & & & \\
\hline 5978 & & TENP--T2--000 & 1028 & 11.5 & & & & & \\
\hline 5979 & & MEUNAPOLIS 013 & 1028 & 11.5 & & & & & \\
\hline 6200 & & GUSD--G1--138 & 967 & 14.4 & & & & & \\
\hline 6201 & & GUSD--G2--138 & 965 & 16.1 & & & & & \\
\hline 6202 & & GP.AFONSO-138 & 969 & 14.4 & & & & & \\
\hline 6203 & & IABAIXAD. -069 & 1025 & 10.9 & & & 67.57 & 17.77 & \\
\hline 6250 & & GZEBU-----138 & 964 & 16.0 & & & & & \\
\hline 6253 & & IZEBU-RS--069 & 1034 & 11.2 & & & 3.78 & -4.9 & \\
\hline 6294 & 1 & QSOBRADIN-4GR & 1000 & 31.5 & 550.0 & -108.00 & 6300 & & \\
\hline 6295 & 1 & QSOBRADIN-000 & 1000 & 27.1 & 0.0 & -32.20 & & & \\
\hline 6296 & & QUSB-01G3-0MQ & 1018 & 27.1 & & & & & \\
\hline 6297 & & QUSB-01G4-0MQ & 1018 & 27.1 & & & & & \\
\hline 6298 & & QUSB-01G5-0MQ & 1018 & 27.1 & & & & & \\
\hline 6299 & & QUSB-01G6-0MQ & 1018 & 27.1 & & & & & \\
\hline 6300 & & CSOBRAD. --500 & 1044 & 27.1 & & & & & \\
\hline 6301 & & FSOBRAD. --230 & 991 & 25.0 & & & & & \\
\hline 6311 & & F JUAZEIRO-230 & 993 & 22.4 & & & & & \\
\hline 6313 & & IJZB-2----069 & 989 & 19.3 & & & 84.44 & -0.21 & \\
\hline 6321 & & F JAGUARARI 230 & 999 & 19.4 & & & 11.3 & 3.053 & \\
\hline 6331 & & FSBF-------230 & 1001 & 17.1 & & & & & \\
\hline 6333 & & IS.BONF IM-0 69 & 992 & 13.9 & & & 62.26 & 7.738 & \\
\hline 6339 & & MIRECE-T3-013 & 1009 & 8.2 & & & & & \\
\hline 6340 & & QIRECE-T3-000 & 1009 & 8.2 & & & & & \\
\hline
\end{tabular}




\begin{tabular}{|c|c|c|c|c|c|c|c|c|c|}
\hline \multirow{2}{*}{ BAR } & \multirow{2}{*}{$\mathbf{T}$} & \multirow{2}{*}{ NOME DA BARRA } & \multirow{2}{*}{$\begin{array}{c}\text { TENSAO } \\
\text { P.U }\end{array}$} & \multirow{2}{*}{$\begin{array}{l}\text { ANGULO } \\
\text { RAD }\end{array}$} & \multicolumn{2}{|c|}{ INJEÇÃO DE POTENCIA } & \multicolumn{2}{|c|}{ CARGA } & \multirow{2}{*}{$\begin{array}{c}\text { SHUNT } \\
\text { MVAR }\end{array}$} \\
\hline & & & & & MW & MVAR & MW & MVAR & \\
\hline 6341 & & FIRECE----230 & 1010 & 10.3 & & & & & \\
\hline 6342 & & GIRECE----138 & 1005 & 8.1 & & & 35.4 & 1.445 & \\
\hline 6343 & & IIRECE----069 & 1020 & 6.5 & & & 45.49 & 2.241 & \\
\hline 6344 & & QIRECE-T2-000 & 1009 & 8.2 & & & & & \\
\hline 6345 & & MIRECE----013 & 1005 & 6.5 & & & & & -10 \\
\hline 6346 & & MIRECE-T2-013 & 1009 & 8.2 & & & & & \\
\hline 6347 & 1 & QIRECE----1CS & 1025 & 10.3 & 0.0 & -3.58 & & & \\
\hline 6348 & & QBJ. LAPAIIICE & 1079 & 15.8 & & & & & 41.7 \\
\hline 6349 & & CBJLAPAII-500 & 1054 & 15.8 & & & & & \\
\hline 6350 & 1 & QBJLAPA $---1 C S$ & 1030 & 14.5 & 0.0 & -7.62 & & & \\
\hline 6351 & & FB.J.LAPA-230 & 1016 & 14.5 & & & & & -10 \\
\hline 6352 & & TBJS-04T3-000 & 1016 & 8.0 & & & & & \\
\hline 6353 & & IB.J.LAPA-069 & 1016 & 8.4 & 6.0 & 0.00 & 78.04 & -12.9 & \\
\hline 6354 & & TBJS $-04 \mathrm{~T} 2-000$ & 1031 & 11.1 & & & & & \\
\hline 6355 & & MB. J. LAPA-013 & 1016 & 8.0 & & & & & \\
\hline 6356 & & MBJS--T2--013 & 1028 & 11.1 & & & & & -10 \\
\hline 6358 & & TBJS $-04 \mathrm{~T} 1-000$ & 1037 & 14.5 & & & & & \\
\hline 6359 & & CIBICOARA-500 & 1027 & 11.8 & & & & & -100 \\
\hline 6361 & & FBARREIRAS2 30 & 991 & 4.1 & & & & & \\
\hline 6363 & & IBARREIRAS 069 & 1016 & 1.2 & 9.8 & 0.00 & 50.69 & -2.85 & \\
\hline 6365 & & GBARREIRAS 138 & 1007 & 1.7 & & & 38.69 & -2.18 & \\
\hline 6368 & & FSAPEACU--230 & 1020 & 6.1 & & & & & \\
\hline 6369 & & CSAPEACU--500 & 1039 & 7.2 & & & & & \\
\hline 6400 & & CMARABA ---500 & 1043 & 59.7 & & & & & \\
\hline 6401 & & FMARABA ---230 & 1022 & 54.3 & & & 79.69 & -1.5 & \\
\hline 6402 & & TMAR-AUX--000 & 1018 & 52.2 & & & & & \\
\hline 6403 & & IMARABA ---069 & 1018 & 52.2 & & & 20.9 & 1.9 & \\
\hline 6404 & & MMAR-AUX--013 & 1018 & 52.2 & & & & & \\
\hline 6405 & 1 & QMARABA $---1 C S$ & 1025 & 54.3 & 0.0 & 85.60 & & & \\
\hline 6406 & & MMARABA ---013 & 1018 & 53.1 & & & & & \\
\hline 6407 & & FSE-09----230 & 896 & 37.4 & & & 11.73 & 4.05 & \\
\hline 6408 & & TMAR-ATR--000 & 1044 & 53.1 & & & & & \\
\hline 6409 & 1 & FCVRD-----230 & 879 & 33.6 & 0.0 & 44.08 & 182 & 58.73 & \\
\hline 6410 & & CTUCURUI--500 & 1032 & 71.3 & & & & & \\
\hline 6411 & & MGA1-TUC--013 & 998 & 70.7 & & & & & \\
\hline 6412 & 1 & MGA2-TUC--013 & 1045 & 73.4 & 20.0 & 20.61 & & & \\
\hline 6413 & & ITUCURUI--069 & 1023 & 70.7 & & & & & \\
\hline 6414 & & MTUC. OBRAS 013 & 966 & 69.7 & & & 5.906 & 2.86 & \\
\hline 6415 & & MTUCURUI--013 & 1044 & 70.7 & & & & & \\
\hline 6416 & & FTUC-ATR--230 & 938 & 69.9 & & & 59 & 14.53 & \\
\hline 6417 & & MTUCURUI--013 & 974 & 70.7 & & & & & \\
\hline 6418 & & TTUC-ATR--000 & 1044 & 70.7 & & & & & \\
\hline 6419 & 1 & QTUCURUI1-5GR & 983 & 78.2 & 1700.0 & 109.90 & 6410 & & \\
\hline 6420 & 1 & QTUCURUI2-3GR & 986 & 78.2 & 1020.0 & 91.58 & 6410 & & \\
\hline 6421 & 1 & QTUCURUI2-000 & 986 & 71.3 & 0.0 & 19.80 & 6410 & & \\
\hline 6422 & 1 & QTUCURUI3-4GR & 984 & 78.2 & 1360.0 & 99.31 & 6410 & & \\
\hline 6423 & 1 & QTUCURUI3-000 & 1023 & 67.9 & 0.0 & 163.00 & & & \\
\hline 6424 & 1 & QTUCURUI5-2GR & 933 & 78.1 & 680.0 & -78.70 & 6430 & & \\
\hline 6425 & 2 & QTUCURUI6-5GR & 894 & 73.6 & 913.6 & -659.00 & 6430 & & \\
\hline 6428 & & QTUCURUI2-OMQ & 968 & 67.9 & & & & & \\
\hline
\end{tabular}




\begin{tabular}{|c|c|c|c|c|c|c|c|c|c|}
\hline \multirow{2}{*}{ BAR } & \multirow{2}{*}{$\mathbf{T}$} & \multirow{2}{*}{ NOME DA BARRA } & \multirow{2}{*}{$\begin{array}{c}\text { TENSAO } \\
\text { P.U }\end{array}$} & \multirow{2}{*}{$\begin{array}{l}\text { ANGULO } \\
\text { RAD }\end{array}$} & \multicolumn{2}{|c|}{ INJEÇÃO DE POTENCIA } & \multicolumn{2}{|c|}{ CARGA } & \multirow{2}{*}{$\begin{array}{l}\text { SHUNT } \\
\text { MVAR }\end{array}$} \\
\hline & & & & & MW & MVAR & MW & MVAR & \\
\hline 6430 & & CTUCURUI2-500 & 1017 & 67.9 & & & & & \\
\hline 6444 & & CRIO EGUAS & 1045 & 24.8 & & & & & -100 \\
\hline 6451 & & MCAMETA---013 & 947 & 64.2 & & & 3.216 & 1.708 & \\
\hline 6452 & & KTUC.VILA-034 & 1007 & 68.4 & & & 9.994 & 2.85 & \\
\hline 6453 & & ITUC.VILA-069 & 1016 & 70.1 & & & & & \\
\hline 6454 & & MTUC.ATR--013 & 989 & 65.5 & & & 8.982 & 2.562 & \\
\hline 6455 & & MTUC.VILA-013 & 955 & 69.5 & & & & & \\
\hline 6456 & & MTUC.VILA-013 & 1006 & 68.2 & & & & & \\
\hline 6457 & & ICAMETA---069 & 975 & 65.2 & & & 0.8 & 0 & \\
\hline 6458 & & TTUC-ATR-1000 & 955 & 69.5 & & & & & \\
\hline 6459 & & TTUC.VILA-000 & 1006 & 68.2 & & & & & \\
\hline 6460 & & CV. CONDE--500 & 969 & 55.1 & & & & & \\
\hline 6461 & & FV.CONDE--230 & 969 & 50.8 & & & 778 & 271.8 & 111 \\
\hline 6462 & & TV. CONDE-2000 & 963 & 47.6 & & & & & \\
\hline 6463 & & IV. CONDE--069 & 963 & 47.7 & & & 42.13 & 3.552 & \\
\hline 6464 & & MV.CONDE--013 & 963 & 47.6 & & & & & \\
\hline 6465 & 1 & QVCONDE---2CS & 970 & 50.8 & 0.0 & 150.10 & & & \\
\hline 6467 & & TV. CONDE-1000 & 963 & 47.6 & & & & & \\
\hline 6468 & & TV. CONDE-3000 & 963 & 47.6 & & & & & \\
\hline 6471 & & FGUAMA----230 & 950 & 46.5 & & & & & \\
\hline 6472 & & IGUAMA----069 & 952 & 42.4 & & & 141.3 & 37.07 & \\
\hline 6481 & & FUTINGA---230 & 948 & 45.3 & & & & & 111 \\
\hline 6482 & & IUT INGA---069 & 969 & 40.5 & & & 260 & 83.59 & \\
\hline 6491 & & FSTA.MARIA230 & 950 & 44.0 & & & & & \\
\hline 6492 & & GSTA.MARIA138 & 967 & 42.3 & & & 33.52 & -9.25 & \\
\hline 6493 & & ISTA.MARIA0 69 & 963 & 39.2 & & & 83.75 & 17.02 & \\
\hline 6494 & & TSTA.MARIA0 00 & 962 & 38.9 & & & & & \\
\hline 6495 & & MSTA.MARIA013 & 962 & 38.9 & & & & & \\
\hline 6497 & & TSTA.MARIA000 & 958 & 42.2 & & & & & \\
\hline 6498 & & MSTA.MARIA013 & 958 & 42.2 & & & & & \\
\hline 6507 & & $\mathrm{CMB}-\mathrm{C} 4-\mathrm{BCS} 500$ & 1058 & 56.4 & & & & & \\
\hline 6509 & & $\mathrm{CMB}-\mathrm{C} 3-\mathrm{BCS} 500$ & 1048 & 56.4 & & & & & \\
\hline 6510 & & $\mathrm{CMB}-\mathrm{C} 1-\mathrm{BCS} 500$ & 1051 & 54.9 & & & & & \\
\hline 6511 & & $\mathrm{CMB}-\mathrm{C} 2-\mathrm{BCS} 500$ & 1050 & 54.9 & & & & & \\
\hline 6512 & & $\mathrm{CPD}-\mathrm{C} 1-\mathrm{BCS} 500$ & 1042 & 37.4 & & & & & \\
\hline 6513 & & CIZ-C1-BCS500 & 1034 & 52.9 & & & & & \\
\hline 6514 & & $\mathrm{CPD}-\mathrm{C} 2-\mathrm{BCS} 500$ & 1040 & 37.3 & & & & & \\
\hline 6515 & & $\mathrm{CIZ}-\mathrm{C} 2-\mathrm{BCS} 500$ & 1037 & 53.0 & & & & & \\
\hline 6517 & & $\mathrm{CPD}-\mathrm{C} 3-\mathrm{BCS} 500$ & 1079 & 35.4 & & & & & \\
\hline 6521 & & FALTAMIRA-230 & 991 & 65.3 & & & & & \\
\hline 6523 & & IALTAMIRA-069 & 944 & 63.8 & & & 13.31 & 0.439 & \\
\hline 6525 & & MALTAMIRA-013 & 990 & 63.7 & & & & & \\
\hline 6528 & & TALTAMIRA 1000 & 990 & 63.7 & & & & & \\
\hline 6531 & & FTRANSAM. -230 & 971 & 64.0 & & & & & \\
\hline 6534 & & KTRANSAM. -034 & 935 & 63.0 & & & 3.707 & 1.28 & \\
\hline 6541 & & FRUROP. ----230 & 943 & 63.3 & & & & & -30 \\
\hline 6542 & & GRUROP. $-1-138$ & 935 & 63.0 & 30.0 & 0.00 & 35.28 & 3.528 & \\
\hline 6543 & & MRUROP. $-1-013$ & 938 & 62.9 & & & 0.889 & 0.675 & \\
\hline 6544 & & GRUROP. $-2-138$ & 930 & 62.7 & & & 12.62 & -9.85 & \\
\hline 6545 & & MRUROP. $-2-013$ & 951 & 62.6 & & & & & \\
\hline
\end{tabular}




\begin{tabular}{|c|c|c|c|c|c|c|c|c|c|}
\hline \multirow{2}{*}{ BAR } & \multirow{2}{*}{$\mathbf{T}$} & \multirow{2}{*}{ NOME DA BARRA } & \multirow{2}{*}{$\begin{array}{c}\text { TENSAO } \\
\text { P.U }\end{array}$} & \multirow{2}{*}{$\begin{array}{l}\text { ANGULO } \\
\text { RAD }\end{array}$} & \multicolumn{2}{|c|}{ INJEÇÃO DE POTENCIA } & \multicolumn{2}{|c|}{ CARGA } & \multirow{2}{*}{$\begin{array}{l}\text { SHUNT } \\
\text { MVAR }\end{array}$} \\
\hline & & & & & MW & MVAR & MW & MVAR & \\
\hline 6548 & & TRUROP. $-1-000$ & 939 & 62.9 & & & & & \\
\hline 6549 & & TRUROP. $-2-000$ & 951 & 62.6 & & & & & \\
\hline 6561 & & FMB-CELPA-230 & 1023 & 54.3 & & & & & \\
\hline 6562 & & GMB-CELPA-138 & 1004 & 54.3 & & & & & \\
\hline 6564 & & QMB-CELPA-000 & 1023 & 54.3 & & & & & \\
\hline 6565 & & MMB-CELPA-013 & 1004 & 54.3 & & & & & \\
\hline 6700 & & CACAILAND . 500 & 1063 & 50.9 & & & & & -180 \\
\hline 6701 & & $\mathrm{CAC}-\mathrm{MB}-\mathrm{BCS} 500$ & 1073 & 47.4 & & & & & \\
\hline 6702 & & $\mathrm{CAC}-\mathrm{PD}-\mathrm{BCS} 500$ & 1045 & 57.5 & & & & & \\
\hline 6703 & & $\mathrm{CAC}-\mathrm{MB}-\mathrm{BCS} 500$ & 1073 & 47.4 & & & & & \\
\hline 7100 & & CGURUP I ---500 & 1064 & 37.7 & & & & & \\
\hline 7101 & & CGUR-SMA--500 & 1044 & 42.8 & & & & & \\
\hline 7102 & & CGUR-MIR--500 & 1092 & 32.9 & & & & & \\
\hline 7103 & & CGUR-SMA2-500 & 1044 & 42.5 & & & & & \\
\hline 7104 & & CGUR-MIR2-500 & 1091 & 33.1 & & & & & \\
\hline 7200 & & CMIRACEM--500 & 1059 & 42.0 & & & & & -136 \\
\hline 7201 & & CMIR-GUR--500 & 1034 & 47.2 & & & & & \\
\hline 7202 & & GMIRACEMA-138 & 1014 & 39.4 & 41.0 & 0.00 & 113.8 & -7.4 & \\
\hline 7203 & & CMIR-GUR2-500 & 1033 & 47.0 & & & & & \\
\hline 7204 & & CLAJEADO--500 & 1059 & 43.9 & & & & & \\
\hline 7205 & & MMIRACEMA-013 & 1063 & 39.3 & & & & & \\
\hline 7206 & 1 & QLAJEADO--5GR & 1000 & 57.0 & 900.0 & 166.70 & & & \\
\hline 7207 & & FLAJEADO--230 & 1010 & 50.4 & & & & & \\
\hline 7208 & & QMIRACEMA-000 & 1063 & 39.3 & & & & & \\
\hline 7236 & & CSMA-GUR--500 & 1087 & 28.5 & & & & & \\
\hline 7237 & & CSMA-GUR2-500 & 1086 & 28.7 & & & & & \\
\hline 7300 & & CCOLINAS- -500 & 1060 & 45.0 & & & & & -136 \\
\hline 7301 & & CCOL-MIR--500 & 1030 & 48.1 & & & & & \\
\hline 7302 & & CCOL-IPZ--500 & 1087 & 42.1 & & & & & \\
\hline 7303 & & CCOL-MIR2-500 & 1029 & 48.1 & & & & & \\
\hline 7304 & & CCOL-IPZ2-500 & 1086 & 42.2 & & & & & \\
\hline 7591 & & CIPZ-COL --500 & 1019 & 53.9 & & & & & \\
\hline 7592 & & CIPZ-COL--500 & 1049 & 50.7 & & & & & \\
\hline 7593 & & CIPZ-COL2-500 & 1018 & 53.7 & & & & & \\
\hline 7594 & & CIPZ-COL2-500 & 1048 & 50.6 & & & & & \\
\hline
\end{tabular}

\section{Parâmetros de Linhas de Transmissão e Transformadores de Potencia}

\begin{tabular}{|c|c|c|c|c|c|c|c|c|c|}
\hline \multirow{2}{*}{$\mathrm{DE}$} & \multirow{2}{*}{ PARA } & \multirow{2}{*}{ C } & \multirow{2}{*}{ RESIS \% } & \multirow{2}{*}{ REAT \% } & \multirow{2}{*}{ SUCEP \% } & \multicolumn{3}{|c|}{ POSIÇÃO DE TAPE } & \multirow{2}{*}{$\begin{array}{c}\text { POT. } \\
\text { NOMINAL }\end{array}$} \\
\hline & & & & & & TAPNOM & TAPMIN & TAPMAX & \\
\hline 235 & 36 & 1 & & 0.83567 & & 1.05 & & & \\
\hline 235 & 6444 & 1 & 0.188 & 2.736 & 389.72 & & & & 2249 \\
\hline 235 & 7236 & 1 & & -0.637 & & & & & \\
\hline 235 & 7237 & 1 & & -0.637 & & & & & \\
\hline 5001 & 5022 & 1 & & 0.5342 & & 1.025 & & & 2250 \\
\hline 5001 & 5023 & 1 & & 2.6711 & & 1.06 & & & 450 \\
\hline 5001 & 5024 & 1 & & 2.6711 & & 1.06 & & & 450 \\
\hline 5001 & 5025 & 1 & & 2.6711 & & 1.06 & & & 450 \\
\hline 5001 & 5026 & 1 & & 2.6711 & & 1.06 & & & 450 \\
\hline 5001 & 5027 & 1 & & 2.6711 & & 1.06 & & & 450 \\
\hline
\end{tabular}




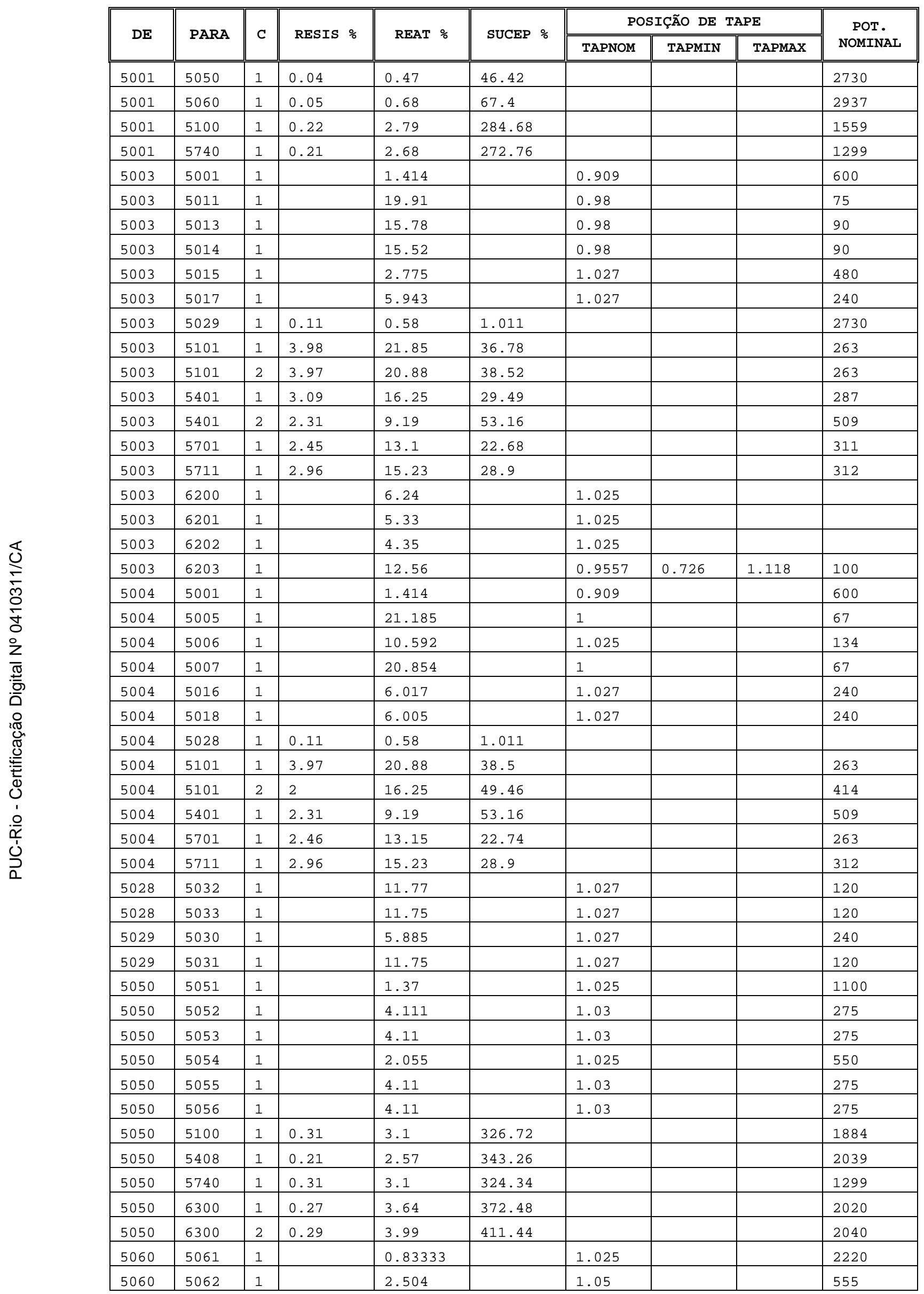




\begin{tabular}{|c|c|c|c|c|c|c|c|c|c|}
\hline \multirow{2}{*}{$\mathrm{DE}$} & \multirow{2}{*}{ PARA } & \multirow{2}{*}{ C } & \multirow{2}{*}{ RESIS \% } & \multirow{2}{*}{ REAT \% } & \multirow{2}{*}{ SUCEP \% } & \multicolumn{3}{|c|}{ POSIÇÃO DE TAPE } & \multirow{2}{*}{$\begin{array}{c}\text { POT. } \\
\text { NOMINAL }\end{array}$} \\
\hline & & & & & & TAPNOM & TAPMIN & TAPMAX & \\
\hline 5060 & 5063 & 1 & & 2.574 & & 1.05 & & & 555 \\
\hline 5060 & 5064 & 1 & & 2.549 & & 1.05 & & & 555 \\
\hline 5060 & 5065 & 1 & & 2.585 & & 1.05 & & & 555 \\
\hline 5060 & 5066 & 1 & & 2.512 & & 1.05 & & & 555 \\
\hline 5060 & 5100 & 1 & 0.206 & 2.525 & 261.95 & & & & 2039 \\
\hline 5060 & 5300 & 1 & 0.21 & 2.78 & 279.86 & & & & 2733 \\
\hline 5060 & 5720 & 1 & 0.15 & 2.03 & 204.54 & & & & 2733 \\
\hline 5100 & 5140 & 1 & 0.22 & 2.13 & 220.7 & & & & 1559 \\
\hline 5100 & 5140 & 2 & 0.17 & 2.15 & 218.68 & & & & 1559 \\
\hline 5101 & 5100 & 1 & & 1.777 & & 0.9654 & 0.867 & 1.038 & 600 \\
\hline 5101 & 5100 & 2 & & 1.777 & & 0.9654 & 0.867 & 1.038 & 600 \\
\hline 5101 & 5102 & 1 & & 13.56 & & 0.962 & 0.728 & 1.117 & 100 \\
\hline 5101 & 5103 & 1 & & 13 & & 0.9671 & 0.85 & 1.117 & 100 \\
\hline 5101 & 5121 & 1 & 1.14 & 5.97 & 10.64 & & & & 319 \\
\hline 5101 & 5121 & 2 & 1.15 & 6.14 & 10.64 & & & & 314 \\
\hline 5101 & 5121 & 3 & 1.19 & 6.11 & 11.42 & & & & 314 \\
\hline 5101 & 5141 & 1 & 3.09 & 16.15 & 29.48 & & & & 263 \\
\hline 5101 & 5142 & 1 & 3.1 & 16.14 & 29.6 & & & & 263 \\
\hline 5101 & 5281 & 1 & 2.1 & 11.44 & 18.96 & & & & 196 \\
\hline 5101 & 5301 & 1 & 1.44 & 7.35 & 13.74 & & & & 272 \\
\hline 5101 & 5301 & 2 & 1.44 & 7.35 & 13.74 & & & & 272 \\
\hline 5101 & 5301 & 3 & 1.46 & 7.7 & 13.42 & & & & 312 \\
\hline 5102 & 5103 & 1 & & -0.51 & & 1 & & & 100 \\
\hline 5102 & 5104 & 1 & & 27 & & 1 & & & 30 \\
\hline 5103 & 5106 & 1 & & 135 & & 1 & & & \\
\hline 5103 & 5106 & 2 & & 143 & & 1 & & & \\
\hline 5110 & 5111 & 1 & 0.42 & 2.26 & 3.86 & & & & 311 \\
\hline 5110 & 5115 & 1 & & 22.652 & & 0.9599 & 0.696 & 1.043 & \\
\hline 5110 & 5116 & 1 & & 22.652 & & 0.9599 & 0.696 & 1.043 & \\
\hline 5110 & 5117 & 1 & & 17.857 & & 0.9966 & 0.696 & 1.043 & \\
\hline 5111 & 5113 & 1 & & 12.75 & & 1.031 & 0.785 & 1.118 & 100 \\
\hline 5111 & 5113 & 2 & & 12.73 & & 1.031 & 0.785 & 1.118 & 100 \\
\hline 5111 & 5291 & 1 & 2.29 & 11.9 & 21.62 & & & & 311 \\
\hline 5111 & 5301 & 1 & 0.21 & 1.12 & 1.94 & & & & 312 \\
\hline 5111 & 5301 & 2 & 0.21 & 1.09 & 2.02 & & & & 258 \\
\hline 5111 & 5301 & 3 & 0.21 & 1.09 & 2.02 & & & & 258 \\
\hline 5113 & 5114 & 1 & & 8.491 & & 1 & & & 2 \\
\hline 5115 & 5118 & 1 & & 75 & & 1 & & & \\
\hline 5116 & 5119 & 1 & & 75 & & 1 & & & \\
\hline 5117 & 5120 & 1 & & 22.475 & & 1 & & & \\
\hline 5121 & 5123 & 1 & & 13.5 & & 0.9871 & 0.824 & 1.118 & 100 \\
\hline 5121 & 5123 & 2 & & 12.87 & & 0.9871 & 0.824 & 1.118 & 100 \\
\hline 5121 & 5222 & 1 & 2.26 & 11.85 & 21.3 & & & & 314 \\
\hline 5121 & 5222 & 2 & 2.25 & 12.04 & 20.8 & & & & 232 \\
\hline 5123 & 5125 & 1 & & 419 & & 0.975 & & & 1 \\
\hline 5131 & 5133 & 1 & & 12.71 & & 1.003 & 0.804 & 1.118 & 100 \\
\hline 5131 & 5133 & 2 & & 13.43 & & 1.003 & 0.804 & 1.118 & 100 \\
\hline 5131 & 5133 & 3 & & 12.89 & & 1.003 & 0.804 & 1.118 & 100 \\
\hline 5131 & 5141 & 1 & 0.53 & 2.69 & 5 & & & & 408 \\
\hline 5131 & 5142 & 1 & 0.53 & 2.69 & 5 & & & & 408 \\
\hline
\end{tabular}




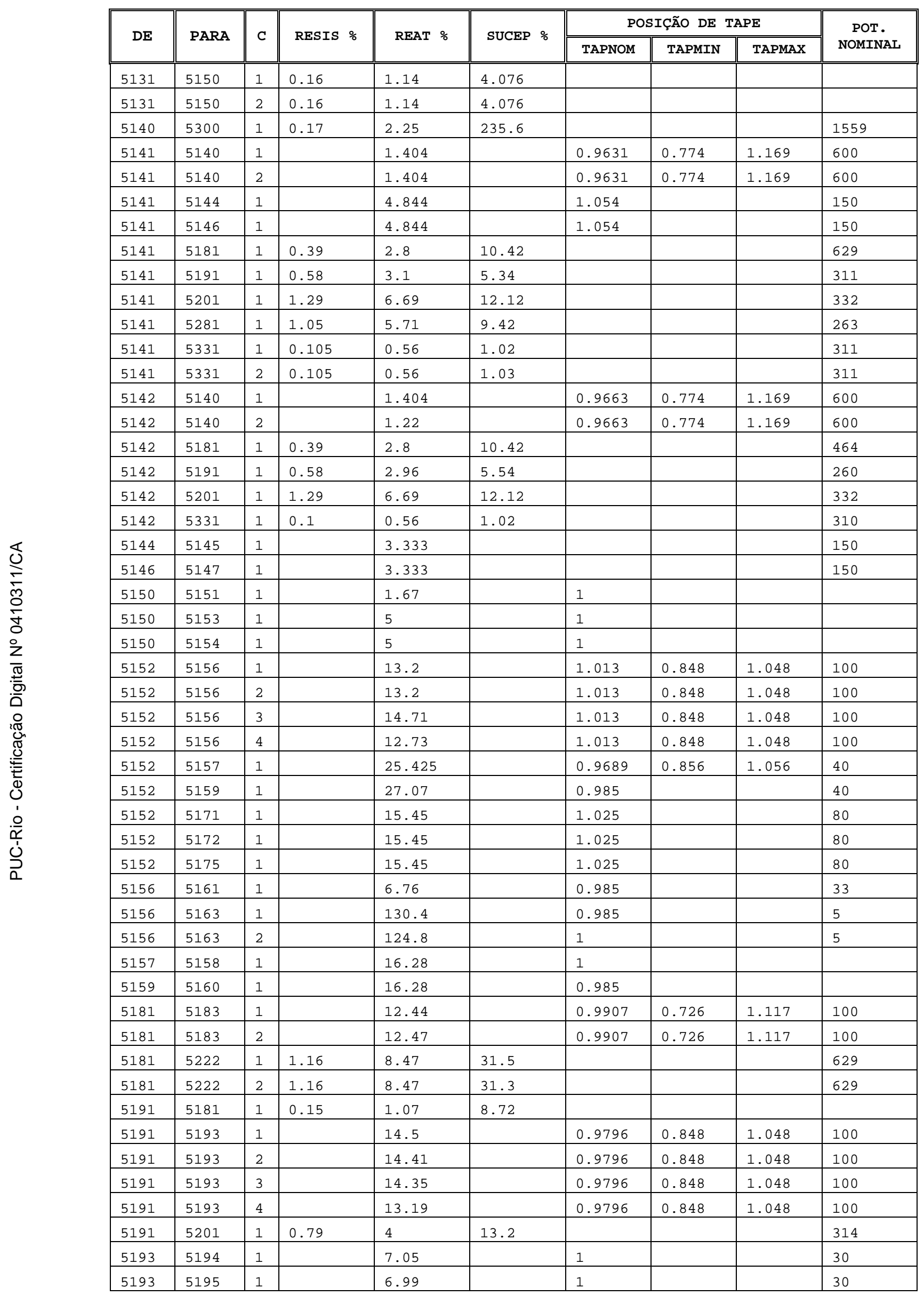




\begin{tabular}{|c|c|c|c|c|c|c|c|c|c|}
\hline \multirow{2}{*}{$\mathrm{DE}$} & \multirow{2}{*}{ PARA } & \multirow{2}{*}{$\mathrm{C}$} & \multirow{2}{*}{ RESIS \% } & \multirow{2}{*}{ REAT \% } & \multirow{2}{*}{ SUCEP \% } & \multicolumn{3}{|c|}{ POSIÇÃO DE TAPE } & \multirow{2}{*}{$\begin{array}{c}\text { POT. } \\
\text { NOMINAL }\end{array}$} \\
\hline & & & & & & TAPNOM & TAPMIN & TAPMAX & \\
\hline 5193 & 5196 & 1 & & 7.3 & & 1 & & & 30 \\
\hline 5193 & 5197 & 1 & & 7.53 & & 1 & & & 30 \\
\hline 5201 & 5203 & 1 & & 13.15 & & 0.9803 & 0.848 & 1.098 & 100 \\
\hline 5201 & 5203 & 2 & & 13.3 & & 0.9803 & 0.848 & 1.098 & 100 \\
\hline 5201 & 5211 & 1 & 0.95 & 4.95 & 8.74 & & & & 314 \\
\hline 5201 & 5211 & 2 & 0.95 & 4.95 & 8.74 & & & & 314 \\
\hline 5201 & 5211 & 3 & 0.925 & 4.858 & 8.922 & & & & 260 \\
\hline 5201 & 5222 & 1 & 1.81 & 9.69 & 16.8 & & & & 263 \\
\hline 5203 & 5204 & 1 & & 14.08 & & 1 & & & \\
\hline 5203 & 5206 & 1 & & 14.1 & & 1 & & & \\
\hline 5204 & 5205 & 1 & & 26.25 & & 1 & & & \\
\hline 5211 & 5213 & 1 & & 13.19 & & 0.94 & 0.726 & 1.118 & 100 \\
\hline 5211 & 5213 & 2 & & 12.976 & & 0.94 & 0.726 & 1.118 & 100 \\
\hline 5211 & 5213 & 3 & & 13.03 & & 0.94 & 0.726 & 1.118 & 100 \\
\hline 5211 & 5213 & 4 & & 12.53 & & 0.94 & 0.726 & 1.117 & 100 \\
\hline 5213 & 5214 & 1 & & 14.01 & & 1 & & & 30 \\
\hline 5213 & 5215 & 1 & & 8.424 & & 1 & & & \\
\hline 5222 & 5101 & 1 & 1.795 & 12.507 & 45.62 & & & & 200 \\
\hline 5222 & 5226 & 1 & & 13.3 & & 0.9563 & 0.85 & 1.037 & 100 \\
\hline 5222 & 5226 & 2 & & 14.34 & & 0.9563 & 0.85 & 1.037 & 100 \\
\hline 5222 & 5226 & 3 & & 12.63 & & 0.9563 & 0.726 & 1.117 & 100 \\
\hline 5222 & 5236 & 1 & & 14.883 & & 1 & & & 55 \\
\hline 5222 & 5237 & 1 & & 16.47 & & 0.975 & & & 55 \\
\hline 5222 & 5239 & 1 & & 6.8925 & & 1 & & & \\
\hline 5222 & 5241 & 1 & 3.86 & 19.94 & 38.02 & & & & 311 \\
\hline 5222 & 5241 & 2 & 1.65 & 11.03 & 55.54 & & & & \\
\hline 5222 & 5241 & 3 & 1.65 & 11.03 & 55.54 & & & & \\
\hline 5222 & 5254 & 1 & 2.11 & 10.88 & 20.74 & & & & 314 \\
\hline 5223 & 5224 & 1 & 0.21 & 0.95 & 0.016 & & & & \\
\hline 5223 & 5226 & 1 & 1.705 & 5.476 & 0.088 & & & & \\
\hline 5223 & 5227 & 1 & 1.385 & 4.444 & 0.072 & & & & \\
\hline 5224 & 5225 & 1 & & 80.5 & & 1 & & & \\
\hline 5226 & 5228 & 1 & 1.63 & 6.4 & 0.12 & & & & \\
\hline 5226 & 5230 & 1 & & 82.9 & & 1 & & & 10 \\
\hline 5226 & 5230 & 2 & & 82 & & 1 & & & 10 \\
\hline 5226 & 5230 & 3 & & 65.9 & & 1 & & & 10 \\
\hline 5227 & 5228 & 1 & 2.21 & 8.68 & 0.18 & & & & \\
\hline 5227 & 5233 & 1 & & 125.2 & & 1 & & & \\
\hline 5227 & 5233 & 2 & & 131.2 & & 1 & & & \\
\hline 5227 & 5233 & 3 & & 135.4 & & 1 & & & \\
\hline 5227 & 5233 & 4 & & 84 & & 1 & & & \\
\hline 5227 & 5233 & 5 & & 82.5 & & 1 & & & \\
\hline 5228 & 5229 & 1 & & 82.9 & & 1 & & & \\
\hline 5228 & 5229 & 2 & & 82.9 & & 1 & & & \\
\hline 5228 & 5234 & 1 & & 134 & & 1 & & & \\
\hline 5232 & 5238 & 1 & & 16.28 & & 1 & & & \\
\hline 5235 & 5252 & 1 & 9.5 & 29.63 & 7.7 & & & & 68 \\
\hline 5235 & 5252 & 2 & 9.5 & 29.63 & 7.7 & & & & 68 \\
\hline 5236 & 5231 & 1 & & 7.183 & & 1 & & & 22 \\
\hline 5236 & 5235 & 1 & & 14.147 & & 1 & & & 50 \\
\hline
\end{tabular}




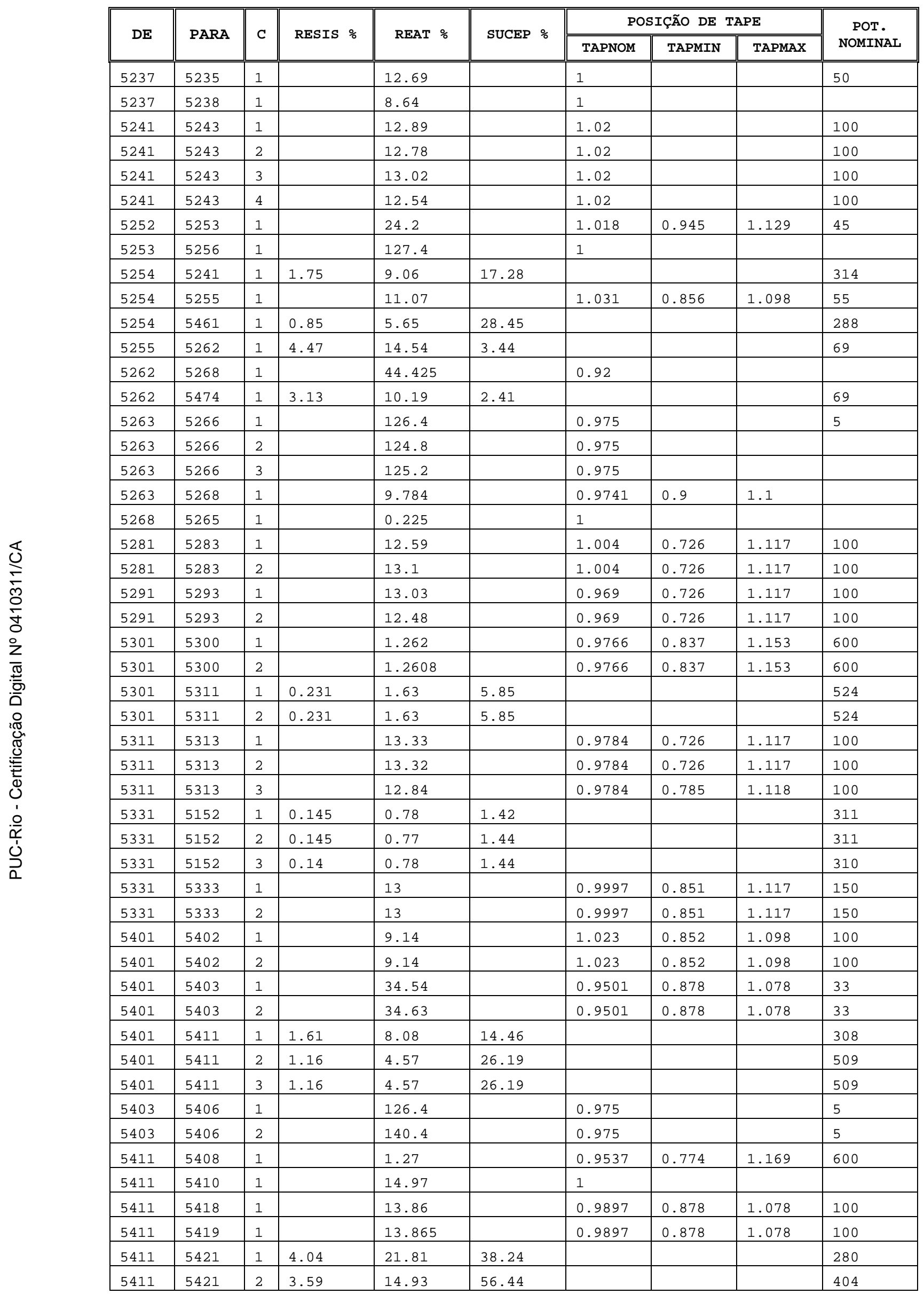




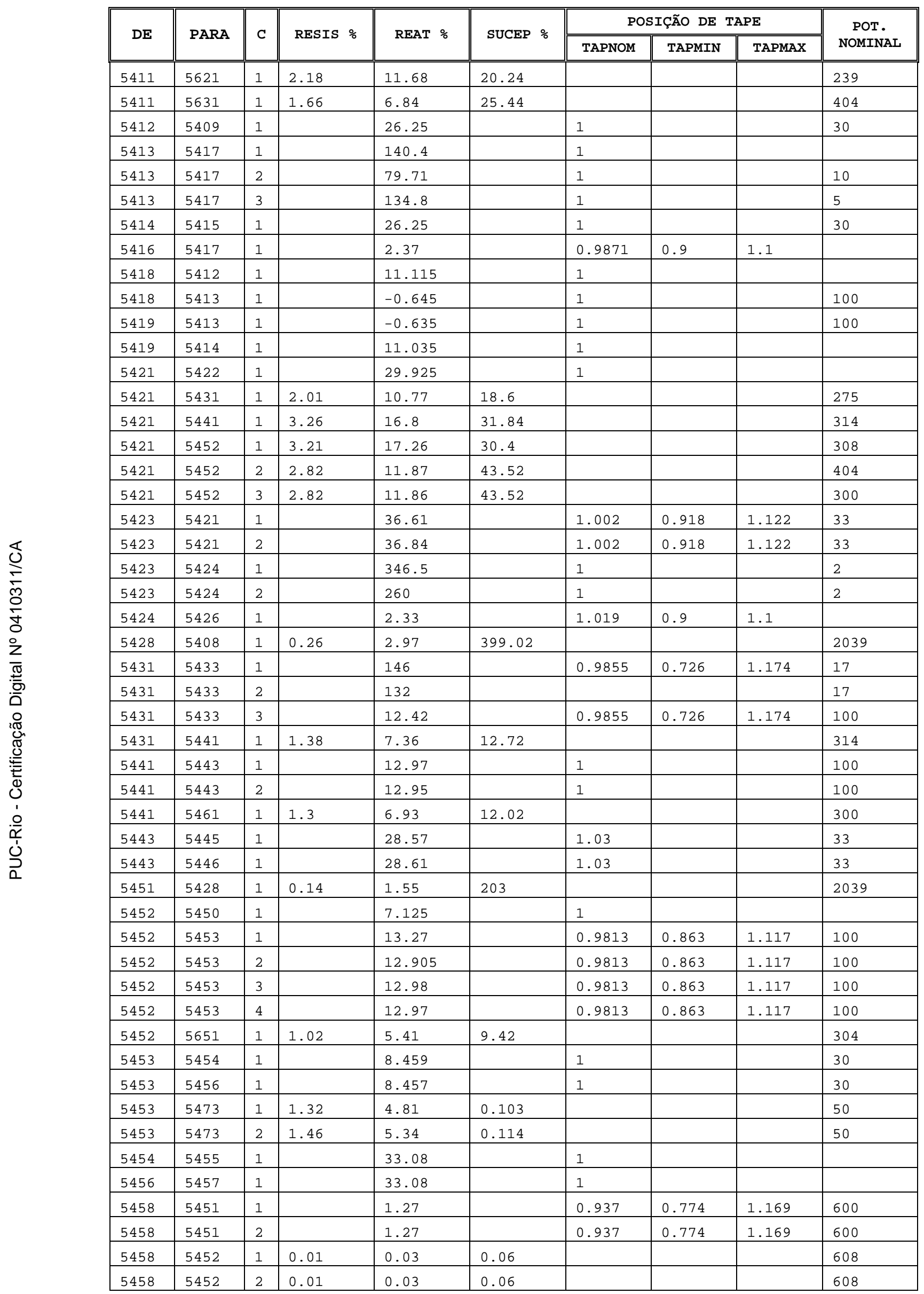




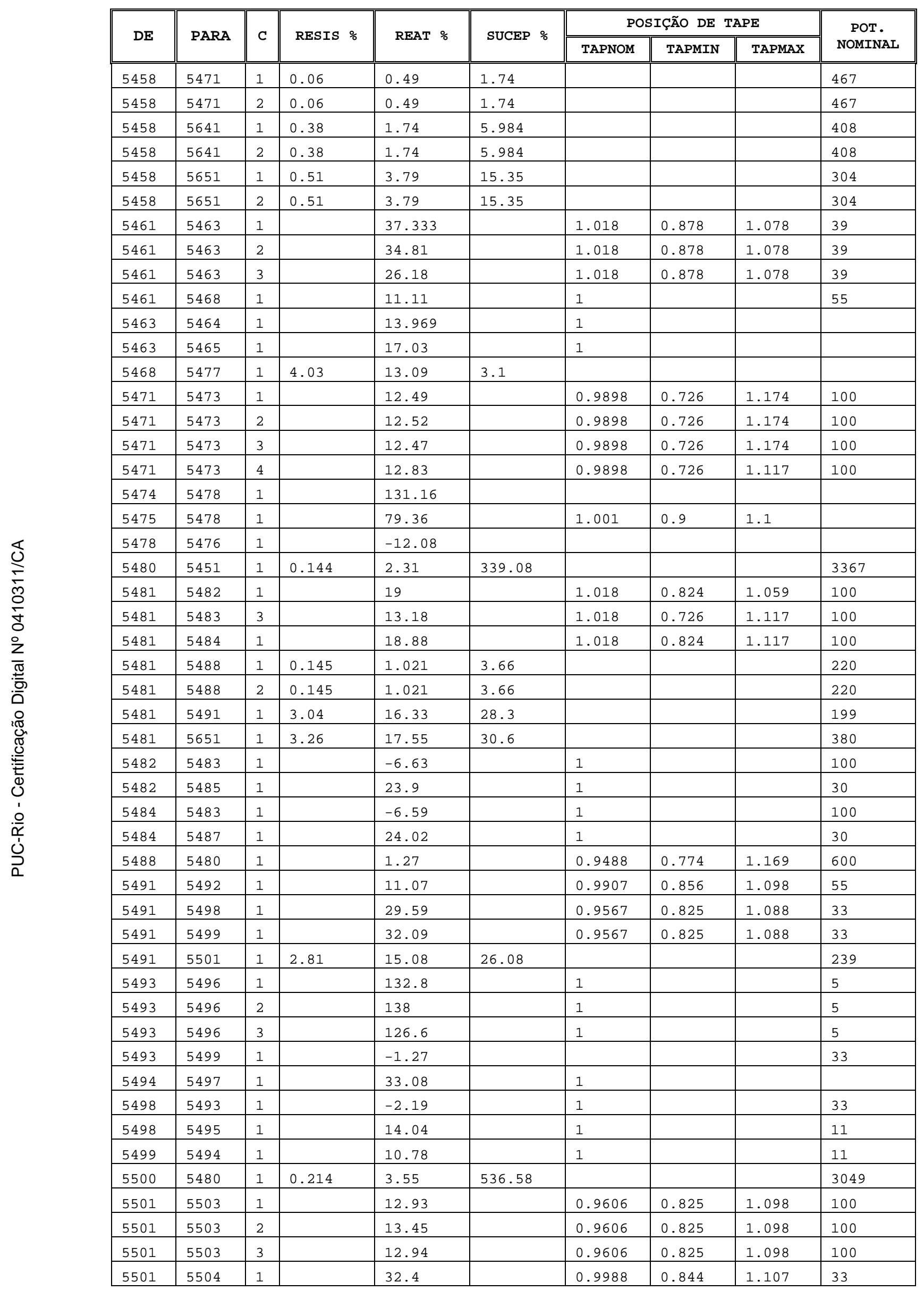




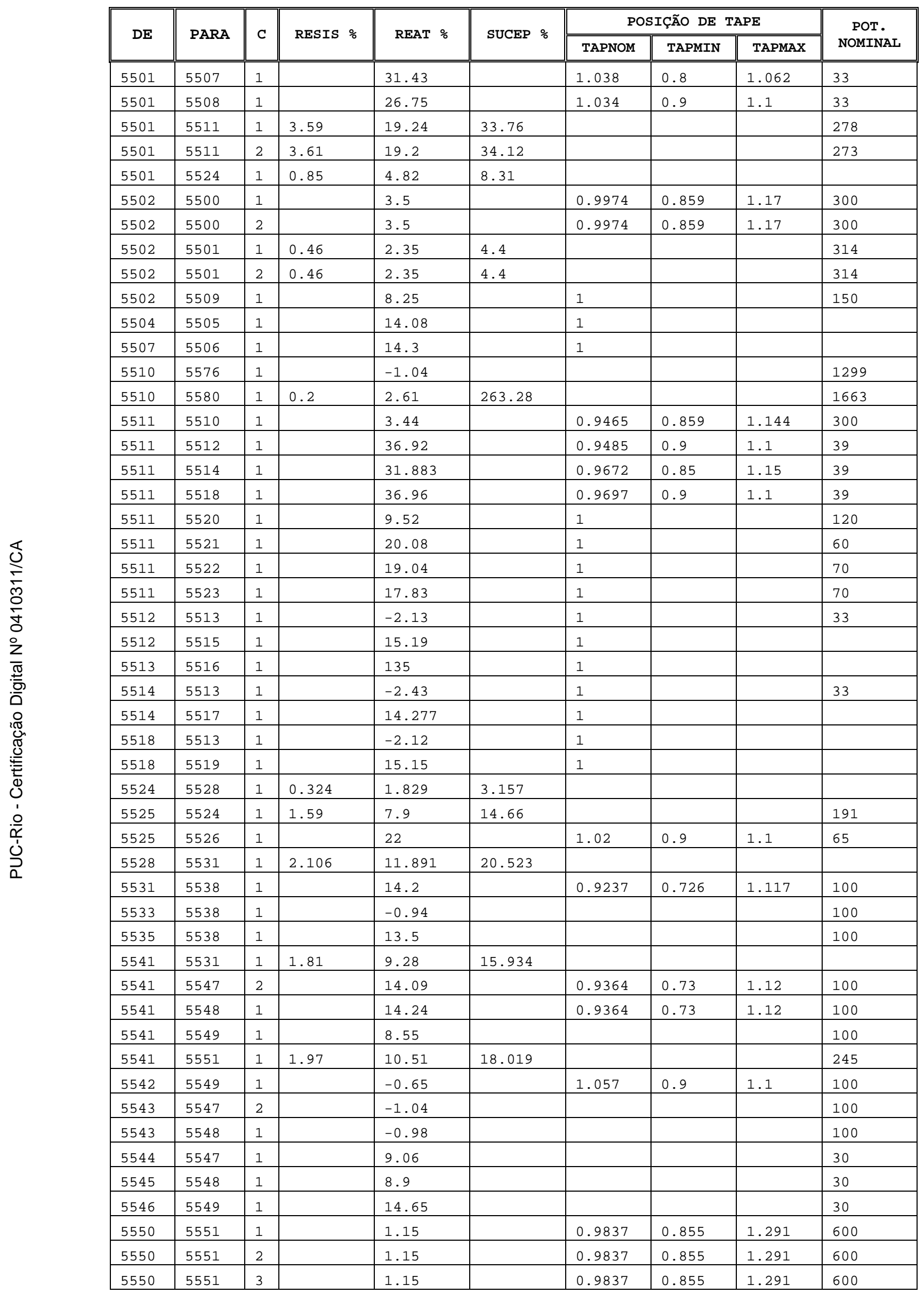




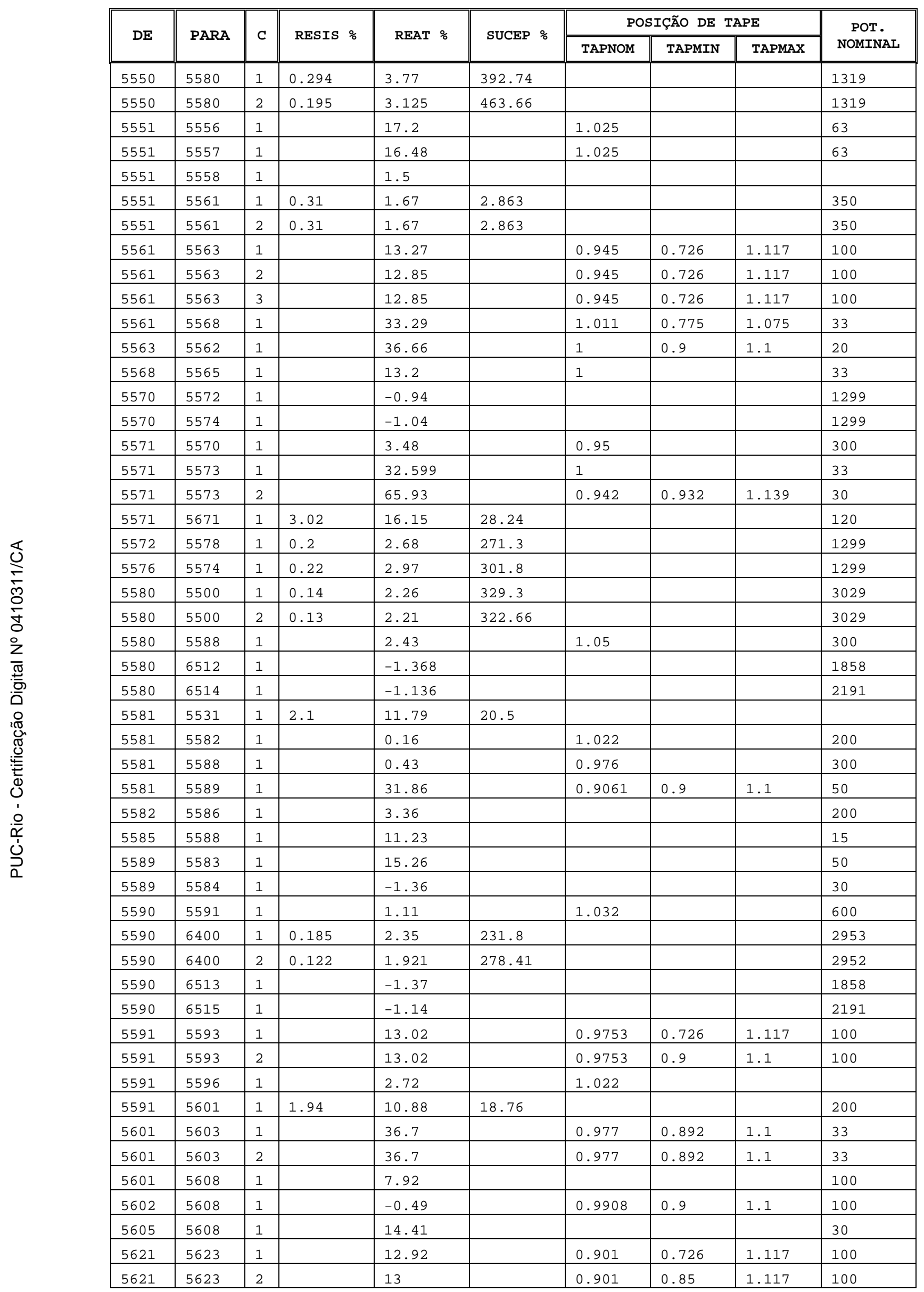




\begin{tabular}{|c|c|c|c|c|c|c|c|c|c|}
\hline \multirow{2}{*}{$\mathrm{DE}$} & \multirow{2}{*}{ PARA } & \multirow{2}{*}{$\mathrm{C}$} & \multirow{2}{*}{ RESIS \% } & \multirow{2}{*}{ REAT \% } & \multirow{2}{*}{ SUCEP \% } & \multicolumn{3}{|c|}{ POSIÇÃO DE TAPE } & \multirow{2}{*}{$\begin{array}{c}\text { POT. } \\
\text { NOMINAL }\end{array}$} \\
\hline & & & & & & TAPNOM & TAPMIN & TAPMAX & \\
\hline 5623 & 5624 & 1 & & 28.59 & & & & & 30 \\
\hline 5631 & 5421 & 1 & 2 & 8.24 & 30.72 & & & & 404 \\
\hline 5631 & 5633 & 1 & & 12.8 & & 1.006 & 0.726 & 1.117 & 100 \\
\hline 5641 & 5643 & 1 & & 13 & & 0.9572 & 0.863 & 1.117 & 100 \\
\hline 5641 & 5643 & 2 & & 13 & & 0.9572 & 0.863 & 1.117 & 100 \\
\hline 5651 & 5653 & 1 & & 13 & & 1.018 & 0.85 & 1.117 & 100 \\
\hline 5651 & 5667 & 1 & & 0.42 & & 1 & & & 300 \\
\hline 5651 & 5668 & 1 & & 0.84 & & 1 & & & 150 \\
\hline 5652 & 5651 & 1 & 0.014 & 0.157 & 0.342 & & & & 438 \\
\hline 5652 & 5651 & 2 & 0.014 & 0.157 & 0.342 & & & & 438 \\
\hline 5652 & 5654 & 1 & & 8.571 & & 1.025 & & & \\
\hline 5652 & 5655 & 1 & & 9 & & 1.025 & & & \\
\hline 5652 & 5656 & 1 & & 9 & & 1.025 & & & \\
\hline 5664 & 5651 & 1 & & 7 & & 1 & & & \\
\hline 5667 & 5660 & 1 & & 5.975 & & & & & 300 \\
\hline 5667 & 5661 & 1 & & 23.82 & & & & & 75 \\
\hline 5668 & 5662 & 1 & & 23.98 & & & & & 75 \\
\hline 5668 & 5663 & 1 & & 23.82 & & & & & 75 \\
\hline 5671 & 5673 & 1 & & 64.97 & & 0.96 & & & 33 \\
\hline 5673 & 5671 & 2 & & 44.37 & & 1.038 & & & 33 \\
\hline 5701 & 5730 & 1 & 1.44 & 7.65 & 13.18 & & & & 273 \\
\hline 5701 & 5731 & 1 & 3.15 & 16.86 & 29.3 & & & & 263 \\
\hline 5703 & 5701 & 1 & & 122.6 & & 1.007 & 0.9 & 1.1 & 17 \\
\hline 5703 & 5701 & 2 & & 122.6 & & 1.007 & 0.9 & 1.1 & 17 \\
\hline 5703 & 5704 & 1 & & 16.706 & & 1 & & & \\
\hline 5711 & 5718 & 1 & & 15.095 & & 0.9775 & 0.9 & 1.1 & 100 \\
\hline 5711 & 5719 & 1 & & 15.29 & & 0.9775 & 0.9 & 1.1 & 100 \\
\hline 5711 & 5721 & 1 & 0.79 & 4.04 & 7.58 & & & & 311 \\
\hline 5711 & 5721 & 2 & 0.79 & 4.04 & 7.58 & & & & 311 \\
\hline 5711 & 5961 & 1 & 1.42 & 7.71 & 12.74 & & & & 262 \\
\hline 5713 & 5716 & 1 & & 136.6 & & 1 & & & 5 \\
\hline 5713 & 5716 & 2 & & 134 & & 1 & & & 5 \\
\hline 5713 & 5716 & 3 & & 136 & & 1 & & & 5 \\
\hline 5713 & 5716 & 4 & & 136 & & 1 & & & 5 \\
\hline 5718 & 5713 & 1 & & -0.605 & & 1 & & & 100 \\
\hline 5718 & 5715 & 1 & & 6.305 & & 1 & & & \\
\hline 5719 & 5713 & 1 & & -0.78 & & 1 & & & 100 \\
\hline 5719 & 5717 & 1 & & 6.44 & & 1 & & & \\
\hline 5720 & 5750 & 1 & 0.23 & 3.15 & 321.92 & & & & 2733 \\
\hline 5721 & 5720 & 1 & & 1.27 & & 0.9487 & 0.774 & 1.169 & 600 \\
\hline 5721 & 5722 & 1 & 0.22 & 1.22 & 2.12 & & & & 314 \\
\hline 5721 & 5723 & 1 & & 13.95 & & 1.006 & 0.824 & 1.118 & 100 \\
\hline 5721 & 5723 & 2 & & 12.992 & & 1.006 & 0.824 & 1.118 & 100 \\
\hline 5721 & 5723 & 3 & & 12.81 & & 1.006 & 0.824 & 1.118 & 100 \\
\hline 5721 & 5724 & 1 & 0.14 & 0.74 & 1.26 & & & & \\
\hline 5730 & 5735 & 1 & & 55 & & 1 & & & 40 \\
\hline 5730 & 5782 & 1 & 2.23 & 11.94 & 20.62 & & & & 273 \\
\hline 5731 & 5736 & 1 & & 64 & & 1 & & & \\
\hline 5731 & 5782 & 1 & 0.5 & 2.65 & 4.58 & & & & 263 \\
\hline 5740 & 5750 & 1 & 0.2 & 1.88 & 195 & & & & 1299 \\
\hline
\end{tabular}




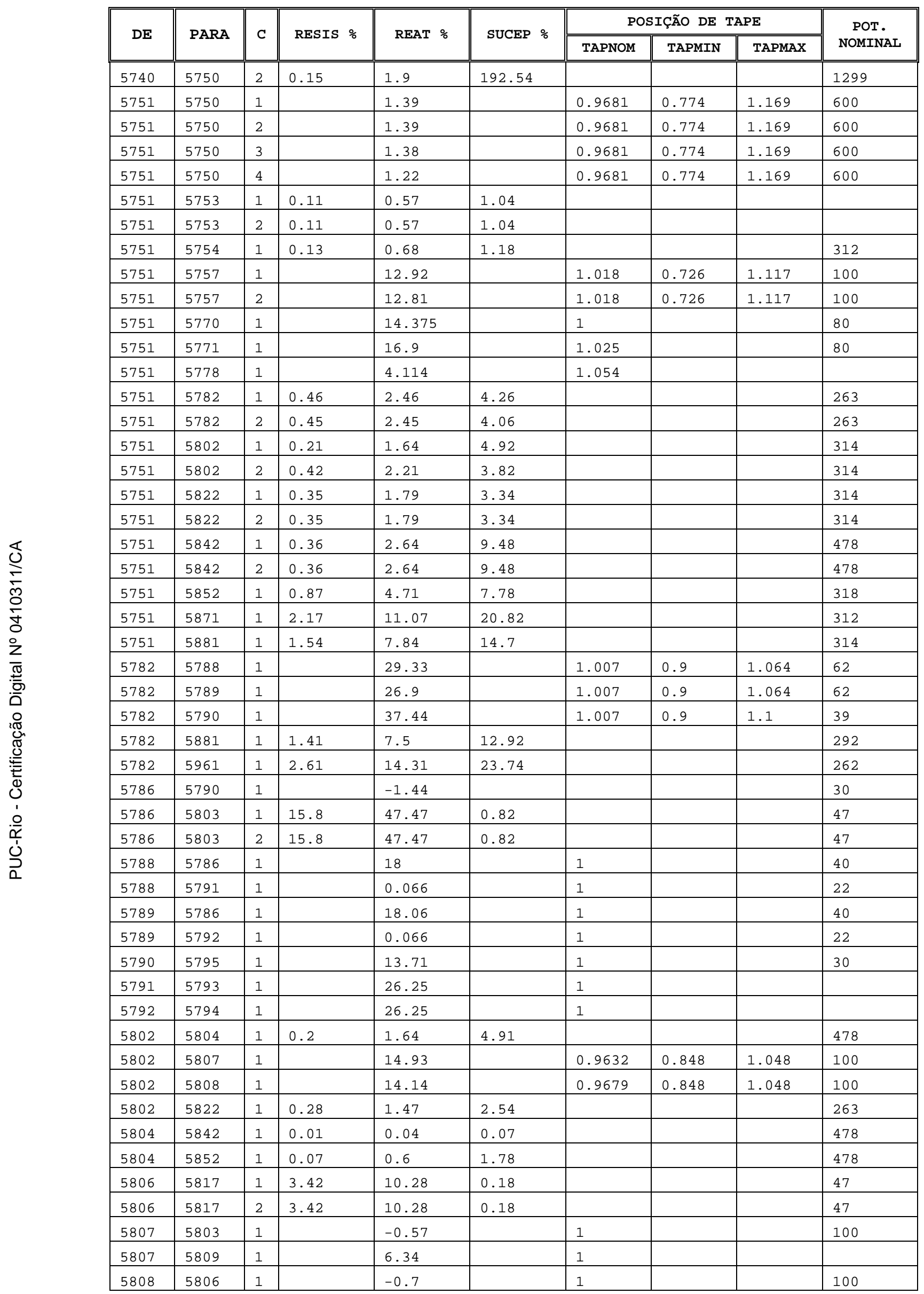




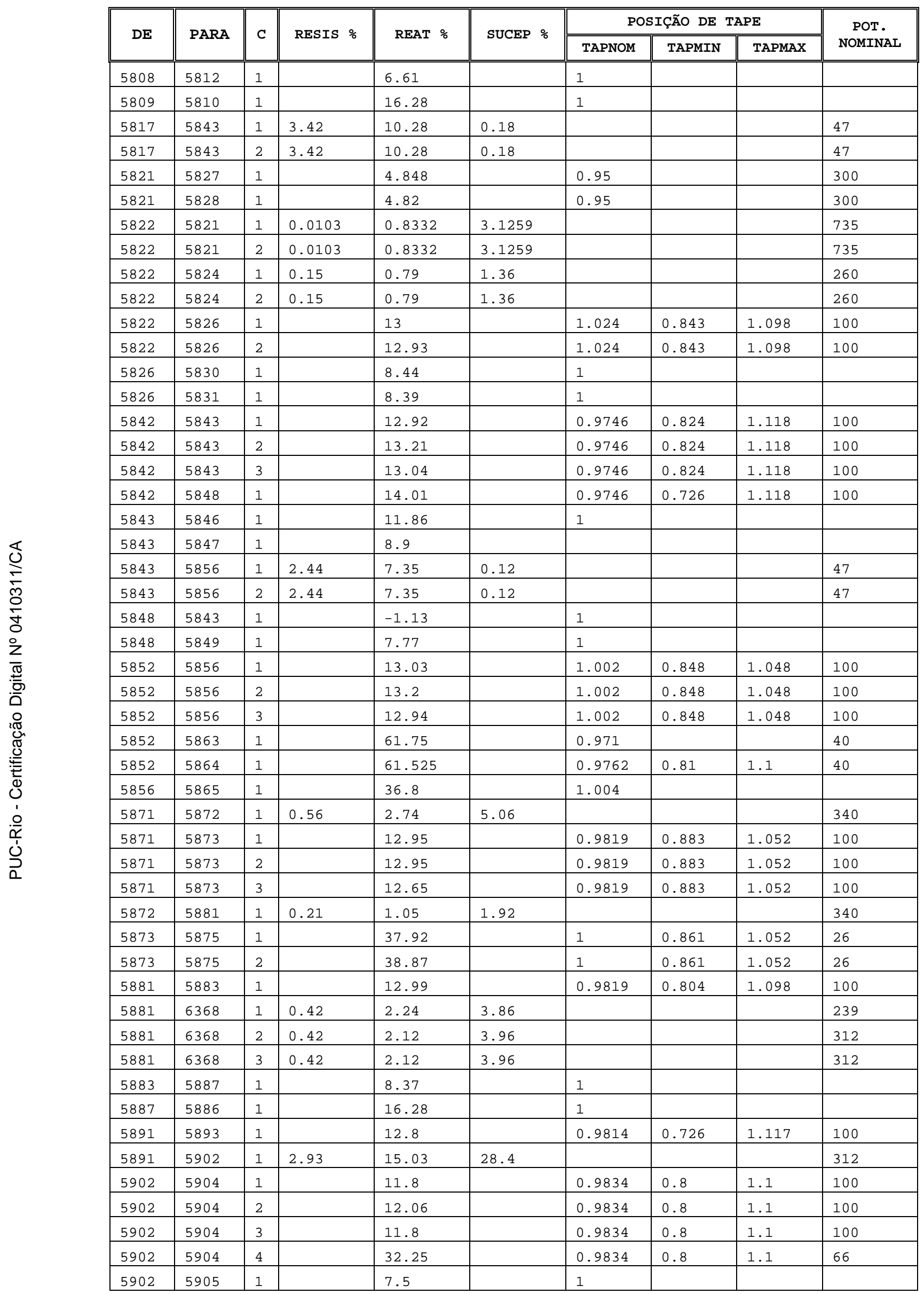




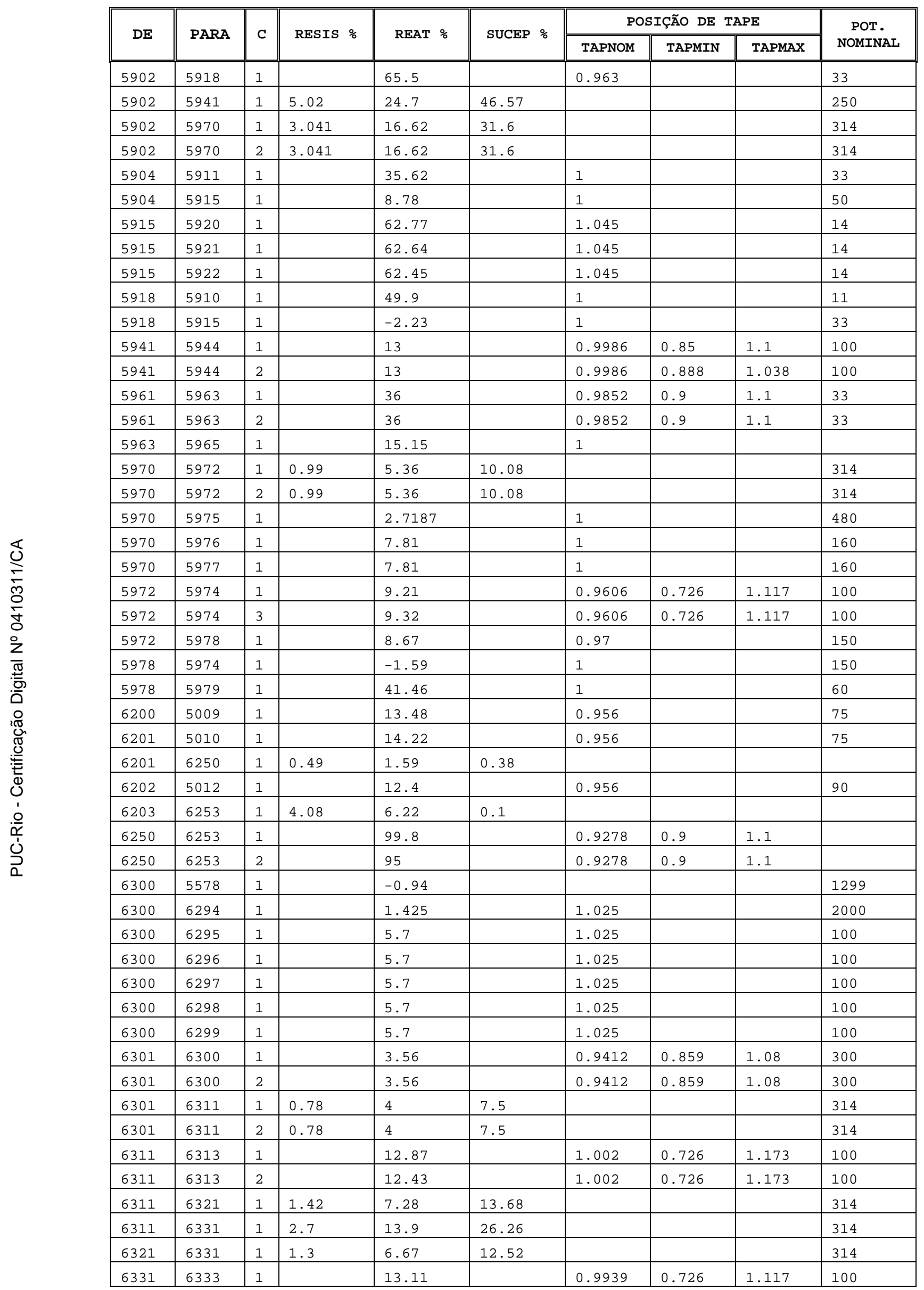




\begin{tabular}{|c|c|c|c|c|c|c|c|c|c|}
\hline \multirow{2}{*}{$\mathrm{DE}$} & \multirow{2}{*}{ PARA } & \multirow{2}{*}{$\mathrm{C}$} & \multirow{2}{*}{ RESIS \% } & \multirow{2}{*}{ REAT $\%$} & \multirow{2}{*}{ SUCEP $\%$} & \multicolumn{3}{|c|}{ POSIÇÃO DE TAPE } & \multirow{2}{*}{$\begin{array}{c}\text { POT. } \\
\text { NOMINAL }\end{array}$} \\
\hline & & & & & & TAPNOM & TAPMIN & TAPMAX & \\
\hline 6333 & 6331 & 2 & & 59.5 & & 0.9843 & 0.918 & 1.12 & 33 \\
\hline 6333 & 6331 & 3 & & 59.54 & & 0.9843 & 0.918 & 1.12 & 33 \\
\hline 6331 & 6341 & 1 & 3.85 & 20.82 & 36.42 & & & & 314 \\
\hline 6339 & 6340 & 1 & & 2.45 & & & & & 22 \\
\hline 6341 & 6340 & 1 & & 31.2 & & 0.975 & & & 40 \\
\hline 6341 & 6342 & 1 & & 11.09 & & 1.002 & 0.85 & 1.1 & 55 \\
\hline 6341 & 6343 & 1 & & 32.28 & & 0.9978 & 0.825 & 1.1 & 39 \\
\hline 6341 & 6344 & 1 & & 31.2 & & 0.975 & & & 40 \\
\hline 6341 & 6351 & 1 & 5.06 & 27.48 & 49.1 & & & & 239 \\
\hline 6343 & 6340 & 1 & & 25.05 & & 1.032 & & & 33 \\
\hline 6343 & 6344 & 1 & & 25.05 & & 1.032 & & & 33 \\
\hline 6343 & 6345 & 1 & & 15.15 & & 1 & & & \\
\hline 6344 & 6346 & 1 & & 2.45 & & & & & 22 \\
\hline 6347 & 6341 & 1 & & 26.75 & & 1.025 & & & \\
\hline 6348 & 6349 & 1 & & 5.6 & & & & & \\
\hline 6349 & 6359 & 1 & 0.17 & 2.463 & 350.9 & & & & 2249 \\
\hline 6350 & 6351 & 1 & & 15.25 & & 1.025 & & & \\
\hline 6351 & 6349 & 1 & & 2.702 & & 0.9625 & 0.792 & 1.195 & 300 \\
\hline 6351 & 6349 & 2 & & 2.702 & & 0.9625 & 0.792 & 1.195 & 300 \\
\hline 6351 & 6352 & 1 & & 35.33 & & 1 & & & 39 \\
\hline 6351 & 6354 & 1 & & 30.98 & & 0.975 & & & 40 \\
\hline 6351 & 6358 & 1 & & 0.01 & & 0.98 & & & 33 \\
\hline 6351 & 6361 & 1 & 4.25 & 22.18 & 40.68 & & & & 120 \\
\hline 6352 & 6353 & 1 & & -2.26 & & 1 & & & 39 \\
\hline 6352 & 6355 & 1 & & 14.23 & & 1 & & & \\
\hline 6353 & 6354 & 1 & & 25.02 & & 0.968 & & & 40 \\
\hline 6353 & 6358 & 1 & & 61.44 & & 0.968 & & & 33 \\
\hline 6354 & 6356 & 1 & & 2.47 & & 1 & & & 22 \\
\hline 6359 & 6369 & 1 & 0.193 & 2.802 & 399.03 & & & & 2249 \\
\hline 6361 & 6363 & 1 & & 12.81 & & 0.9783 & 0.726 & 1.117 & 100 \\
\hline 6361 & 6365 & 1 & & 11.09 & & 0.9863 & 0.85 & 1.1 & 100 \\
\hline 6368 & 5891 & 1 & 0.54 & 2.73 & 5.1 & & & & 239 \\
\hline 6368 & 5902 & 1 & 3.53 & 19.02 & 33.1 & & & & 312 \\
\hline 6368 & 5902 & 2 & 3.51 & 18.07 & 34.28 & & & & 312 \\
\hline 6368 & 6369 & 1 & & 1.351 & & 0.9796 & 0.792 & 1.195 & 600 \\
\hline 6368 & 6369 & 2 & & 1.351 & & 0.9796 & 0.792 & 1.195 & 600 \\
\hline 6400 & 6408 & 1 & & 4.07 & & 1 & & & 300 \\
\hline 6400 & 6510 & 1 & & -0.876 & & & & & 2191 \\
\hline 6400 & 6511 & 1 & & -0.712 & & & & & 2191 \\
\hline 6400 & 6701 & 1 & 0.17 & 2.63 & 387.1 & & & & 2191 \\
\hline 6401 & 6402 & 1 & & 37.12 & & 1 & & & 33 \\
\hline 6401 & 6402 & 2 & & 37.12 & & 1 & & & 33 \\
\hline 6401 & 6405 & 1 & & 6.18 & & 1.05 & & & 160 \\
\hline 6401 & 6407 & 1 & 2.554 & 13.82 & 25.86 & & & & \\
\hline 6401 & 6408 & 1 & & -0.77 & & 0.98 & & & 300 \\
\hline 6401 & 6561 & 1 & 0.525 & 2.572 & 4.856 & & & & \\
\hline 6402 & 6403 & 1 & & -0.76 & & & & & 33 \\
\hline 6402 & 6403 & 2 & & -0.76 & & & & & 33 \\
\hline 6402 & 6404 & 1 & & 9.85 & & & & & 6 \\
\hline 6402 & 6404 & 2 & & 9.85 & & & & & 6 \\
\hline
\end{tabular}




\begin{tabular}{|c|c|c|c|c|c|c|c|c|c|}
\hline \multirow{2}{*}{$\mathrm{DE}$} & \multirow{2}{*}{ PARA } & \multirow{2}{*}{ C } & \multirow{2}{*}{ RESIS \% } & \multirow{2}{*}{ REAT \% } & \multirow{2}{*}{ SUCEP \% } & \multicolumn{3}{|c|}{ POSIÇÃO DE TAPE } & \multirow{2}{*}{$\begin{array}{c}\text { POT. } \\
\text { NOMINAL }\end{array}$} \\
\hline & & & & & & TAPNOM & TAPMIN & TAPMAX & \\
\hline 6406 & 6408 & 1 & & 5.93 & & 0.975 & & & 160 \\
\hline 6407 & 6409 & 1 & 0.541 & 2.92 & 5.47 & & & & \\
\hline 6410 & 6418 & 1 & & 11.92 & & 1 & & & 100 \\
\hline 6410 & 6419 & 1 & & 0.688 & & 1.05 & & & 2025 \\
\hline 6410 & 6420 & 1 & & 1.1467 & & 1.05 & & & 1215 \\
\hline 6410 & 6421 & 1 & & 1.725 & & 1.05 & & & 405 \\
\hline 6410 & 6422 & 1 & & 0.86 & & 1.05 & & & 1620 \\
\hline 6410 & 6430 & 1 & & 0.8 & & & & & 1040 \\
\hline 6410 & 6458 & 1 & & 2.88 & & 1.1 & & & 450 \\
\hline 6410 & 6460 & 2 & 0.21 & 3.4 & 507.5 & & & & 1539 \\
\hline 6410 & 6510 & 1 & 0.225 & 2.872 & 284.81 & & & & 2191 \\
\hline 6410 & 6511 & 1 & 0.148 & 2.344 & 342.06 & & & & 2191 \\
\hline 6413 & 6411 & 1 & & 24.35 & & 1.025 & & & \\
\hline 6413 & 6412 & 1 & & 24.35 & & 1.025 & & & \\
\hline 6413 & 6414 & 1 & & 28.2 & & 1.05 & 0.85 & 1.05 & \\
\hline 6413 & 6417 & 1 & & 28.2 & & 1.05 & 0.85 & 1.05 & \\
\hline 6413 & 6453 & 1 & 1.999 & 4.837 & 0.092 & & & & \\
\hline 6416 & 6521 & 1 & 2.38 & 18.08 & 94.669 & & & & 290 \\
\hline 6418 & 6413 & 1 & & -0.11 & & 1.02 & & & 100 \\
\hline 6418 & 6415 & 1 & & 5.38 & & 1 & & & 34 \\
\hline 6430 & 6423 & 1 & & 3.44 & & 1.05 & & & 405 \\
\hline 6430 & 6424 & 1 & & 2.355 & & 1.05 & & & 810 \\
\hline 6430 & 6425 & 1 & & 0.942 & & 1.05 & & & 810 \\
\hline 6430 & 6428 & 1 & & 4.94 & & 1.05 & & & 405 \\
\hline 6430 & 6460 & 1 & 0.321 & 4.161 & 422.6 & & & & 1539 \\
\hline 6430 & 6507 & 1 & 0.15 & 2.3 & 335.5 & & & & 2191 \\
\hline 6430 & 6509 & 1 & 0.15 & 2.3 & 335.5 & & & & 2191 \\
\hline 6444 & 6349 & 1 & 0.24 & 3.488 & 496.85 & & & & 2249 \\
\hline 6451 & 6457 & 1 & & 106.67 & & 0.9812 & 0.9 & 1.1 & \\
\hline 6451 & 6457 & 2 & & 106.67 & & 0.9812 & 0.9 & 1.1 & \\
\hline 6453 & 6454 & 1 & & 90.13 & & 1 & & & \\
\hline 6453 & 6457 & 1 & 85.9 & 213.03 & 3.586 & & & & 20 \\
\hline 6453 & 6459 & 1 & & 34 & & 1 & & & \\
\hline 6455 & 6458 & 1 & & 3.889 & & & & & 94 \\
\hline 6456 & 6459 & 1 & & 40.34 & & & & & \\
\hline 6458 & 6416 & 1 & & -0.56 & & 1.015 & 0.9 & 1.1 & 450 \\
\hline 6459 & 6452 & 1 & & -3.67 & & 1 & & & \\
\hline 6461 & 6460 & 1 & & 1.54 & & 1.006 & & & 750 \\
\hline 6461 & 6460 & 2 & & 1.54 & & 1.006 & & & 750 \\
\hline 6461 & 6460 & 3 & & 1.54 & & 1.006 & & & 750 \\
\hline 6461 & 6462 & 1 & & 37.12 & & 1 & & & 33 \\
\hline 6461 & 6465 & 1 & & 3.05 & & 1.05 & & & 320 \\
\hline 6461 & 6467 & 1 & & 37.12 & & 1 & & & 33 \\
\hline 6461 & 6468 & 1 & & 37.12 & & 1 & & & 33 \\
\hline 6461 & 6471 & 1 & 0.475 & 3.33 & 12.12 & & & & 613 \\
\hline 6461 & 6471 & 2 & 0.475 & 3.33 & 12.12 & & & & 613 \\
\hline 6461 & 6491 & 1 & 1.852 & 11.578 & 47.31 & & & & \\
\hline 6462 & 6463 & 1 & & -0.77 & & & & & 33 \\
\hline 6462 & 6464 & 1 & & 9.85 & & & & & 6 \\
\hline 6463 & 6467 & 1 & & -0.77 & & & & & 33 \\
\hline
\end{tabular}




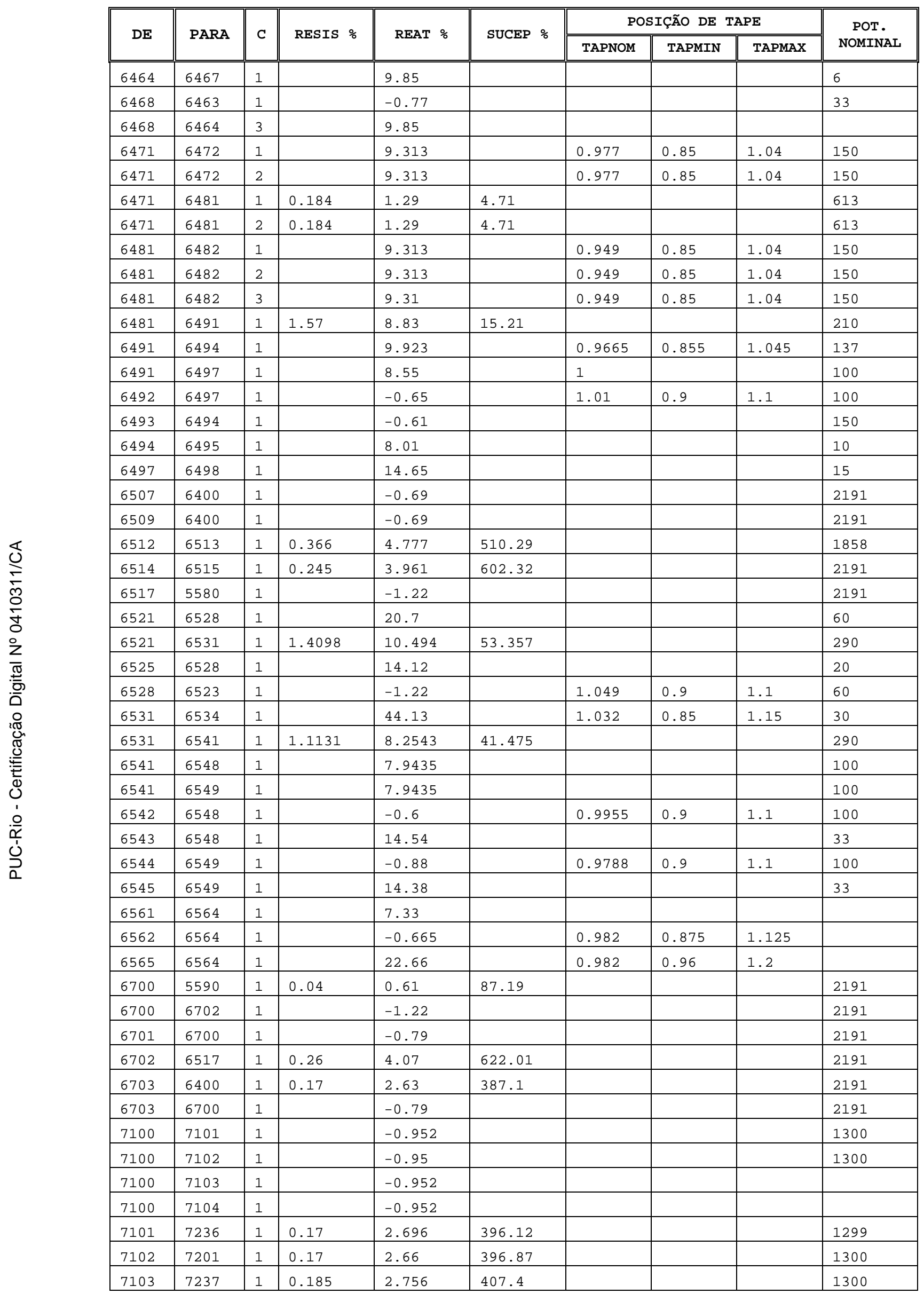




\begin{tabular}{|c|c|c|c|c|c|c|c|c|c|}
\hline \multirow{2}{*}{ DE } & \multirow{2}{*}{ PARA } & \multirow{2}{*}{ C } & \multirow{2}{*}{ RESIS \% } & \multirow{2}{*}{ REAT \% } & \multirow{2}{*}{ SUCEP \% } & \multicolumn{3}{|c|}{ POSIÇÃO DE TAPE } & \multirow{2}{*}{$\begin{array}{c}\text { POT. } \\
\text { NOMINAL }\end{array}$} \\
\hline & & & & & & TAPNOM & TAPMIN & TAPMAX & \\
\hline 7104 & 7203 & 1 & 0.183 & 2.681 & 403.5 & & & & 1300 \\
\hline 7200 & 7201 & 1 & & -0.95 & & & & & 1300 \\
\hline 7200 & 7203 & 1 & & -0.952 & & & & & \\
\hline 7200 & 7208 & 1 & & 7.42 & & & & & 180 \\
\hline 7200 & 7301 & 1 & 0.12 & 1.843 & 265.83 & & & & 1299 \\
\hline 7200 & 7303 & 1 & 0.126 & 1.851 & 270.44 & & & & 1429 \\
\hline 7202 & 7208 & 1 & & -0.445 & & 0.9541 & 0.916 & 1.178 & 180 \\
\hline 7204 & 7200 & 1 & 0.023 & 0.396 & 38.695 & & & & 1000 \\
\hline 7204 & 7207 & 1 & & 1.284 & & 1.05 & & & 960 \\
\hline 7205 & 7208 & 1 & & 4.61 & & 1 & & & \\
\hline 7207 & 7206 & 1 & & 1.264 & & 1.025 & & & 900 \\
\hline 7300 & 7301 & 1 & & -0.952 & & & & & 1429 \\
\hline 7300 & 7302 & 1 & & -0.95 & & & & & 1429 \\
\hline 7300 & 7303 & 1 & & -0.952 & & & & & \\
\hline 7300 & 7304 & 1 & & -0.952 & & & & & \\
\hline 7302 & 7591 & 1 & 0.22 & 3.53 & 529.69 & & & & 1429 \\
\hline 7304 & 7593 & 1 & 0.236 & 3.562 & 539.69 & & & & 1429 \\
\hline 7591 & 7592 & 1 & & -0.95 & & & & & 1429 \\
\hline 7592 & 5590 & 1 & & -0.637 & & & & & \\
\hline 7593 & 7594 & 2 & & -0.952 & & & & & \\
\hline 7594 & 5590 & 1 & & -0.637 & & & & & \\
\hline
\end{tabular}

\section{D.3.2 Modelos CDU associado ás máquinas de geração do Sistema N-NE Brasileiro}

\begin{tabular}{|c|c|c|c|c|c|c|c|c|c|c|c|c|}
\hline No) & $\mathrm{O} \mathrm{Mq}$ & (P) & (Q) & Un & (Mg) & (Mt) & $\mathrm{u}$ & (Mv) & $\mathrm{u}$ & (Me) & $\mathrm{u}$ & BARRA DE GERAÇÃO \\
\hline 36 & 10 & 100 & 100 & 3 & 124 & 117 & u & 157 & & 187 & $\mathrm{u}$ & S.MESA---3GR \\
\hline 5010 & 10 & 100 & 100 & 1 & 1201 & 1203 & u & 1243 & $\mathrm{u}$ & & & $\mathrm{PAFO}-2 \mathrm{G} 2-1 \mathrm{GR}$ \\
\hline 5016 & 10 & 100 & 100 & 1 & 1203 & 1210 & $\mathrm{u}$ & 1250 & $\mathrm{u}$ & & & $\mathrm{PAFO}-3 \mathrm{G} 2-1 \mathrm{GR}$ \\
\hline 5022 & 10 & 100 & 100 & 5 & 1204 & 1211 & $\mathrm{u}$ & & & 1271 & $\mathrm{u}$ & $\mathrm{PAFO}-4 \mathrm{G} 1-5 \mathrm{GR}$ \\
\hline 5032 & 10 & 100 & 100 & 1 & 1205 & 1215 & $\mathrm{u}$ & 1255 & $\mathrm{u}$ & & & ASALESG2-1GR \\
\hline 5051 & 10 & 100 & 100 & 3 & 1206 & 1217 & $\mathrm{u}$ & 1257 & u & 1272 & $\mathrm{u}$ & LGONZAG1-3GR \\
\hline 5054 & 10 & 100 & 100 & 2 & 1207 & 1219 & $\mathrm{u}$ & 1259 & $\mathrm{u}$ & 1273 & $\mathrm{u}$ & LGONZAG2-2GR \\
\hline 5061 & 10 & 100 & 100 & 3 & 1208 & 1221 & $\mathrm{u}$ & & & 1274 & $\mathrm{u}$ & XINGO----3GR \\
\hline 5145 & 10 & 100 & 100 & 1 & 1212 & 1231 & $\mathrm{u}$ & & & & & RCD - SIE $--1 C S$ \\
\hline 5147 & 10 & 100 & 100 & 1 & 1213 & 1232 & $\mathrm{u}$ & & & & & RCD $-A L S--1 C S$ \\
\hline 5509 & 10 & 100 & 100 & 1 & 1218 & 1233 & $\mathrm{u}$ & & & & & TERESINA-1CS \\
\hline 5520 & 10 & 100 & 100 & 2 & 1210 & 1226 & $\mathrm{u}$ & 1266 & $\mathrm{u}$ & & & BOAESP-1-2GR \\
\hline 5522 & 10 & 100 & 100 & 1 & 1211 & 1228 & $\mathrm{u}$ & 1268 & $\mathrm{u}$ & 1277 & $\mathrm{u}$ & BOAESP $-2-1 \mathrm{GR}$ \\
\hline 5586 & 10 & 100 & 100 & 2 & 1308 & 1308 & u & & & & & PDUTRA ---2 CS \\
\hline 5596 & 10 & 100 & 100 & 3 & 1310 & 1310 & $\mathrm{u}$ & & & & & IMPERATR-3CS \\
\hline 5654 & 10 & 100 & 100 & 1 & 2900 & & & & & & & TERMFTZG-1GR \\
\hline 5770 & 10 & 100 & 100 & 1 & 1214 & & & & & & & CAMACARI-1GR \\
\hline
\end{tabular}




\begin{tabular}{|c|c|c|c|c|c|c|c|c|c|c|c|c|}
\hline 5778 & 10 & 100 & 100 & 2 & 1217 & 1234 & $\mathrm{u}$ & & & & & CAMACARI-2CS \\
\hline No) & $0 \mathrm{Mq}$ & (P) & (Q) & Un & (Mg) & (Mt) & $\mathrm{u}$ & (Mv) & $\mathrm{u}$ & (Me) & $\mathbf{u}$ & BARRA DE GERAÇÃO \\
\hline 5827 & 10 & 100 & 100 & 1 & 2300 & & & & & & & T. BAH-G1-1GR \\
\hline 5975 & 10 & 100 & 100 & 3 & 2100 & 2100 & $\mathrm{u}$ & 157 & & 2170 & $\mathrm{u}$ & ITAPEBI $--3 \mathrm{GR}$ \\
\hline 6294 & 10 & 100 & 100 & 4 & 1209 & & & & & & & SOBRADIN-4GR \\
\hline 6347 & 10 & 100 & 100 & 1 & 1216 & 1237 & $\mathrm{u}$ & & & & & IRECE $----1 \mathrm{CS}$ \\
\hline 6350 & 10 & 100 & 100 & 1 & 1215 & 1238 & $\mathrm{u}$ & & & & & BJLAPA $---1 C S$ \\
\hline 6405 & 10 & 100 & 100 & 1 & 1306 & 1307 & $\mathrm{u}$ & & & & & MARABA $---1 C S$ \\
\hline 6419 & 10 & 100 & 100 & 5 & 1300 & 1300 & $\mathrm{u}$ & 1340 & $\mathrm{u}$ & 1370 & $\mathrm{u}$ & TUCURUI1-5GR \\
\hline 6420 & 10 & 100 & 100 & 3 & 1301 & 1301 & $\mathrm{u}$ & 1341 & $\mathrm{u}$ & 1371 & $\mathrm{u}$ & TUCURUI2-3GR \\
\hline 6422 & 10 & 100 & 100 & 4 & 1303 & 1302 & $\mathrm{u}$ & 1342 & $\mathrm{u}$ & 1372 & $\mathrm{u}$ & TUCURUI3-4GR \\
\hline 6424 & 10 & 100 & 100 & 2 & 1304 & 1311 & $\mathrm{u}$ & 1343 & $\mathrm{u}$ & 1374 & $\mathrm{u}$ & TUCURUI5-2GR \\
\hline 6425 & 10 & 100 & 100 & 5 & 98 & & & & & & & TUCURUI $6-5 \mathrm{GR}$ \\
\hline 6465 & 10 & 100 & 100 & 2 & 1307 & 1306 & $\mathrm{u}$ & & & & & VCONDE $---2 \mathrm{CS}$ \\
\hline 7206 & 10 & 100 & 100 & 5 & 1500 & 1500 & $\mathrm{u}$ & 1540 & $\mathrm{u}$ & & & LAJEADO--5GR \\
\hline
\end{tabular}

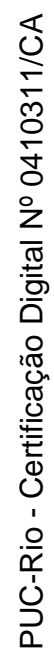

